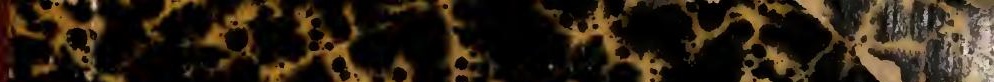

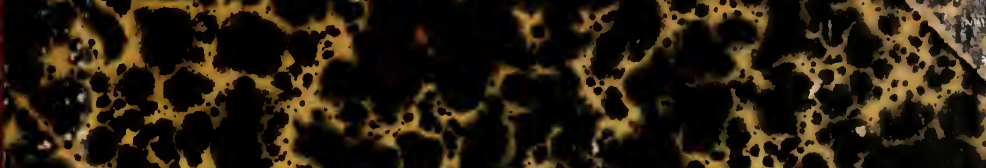

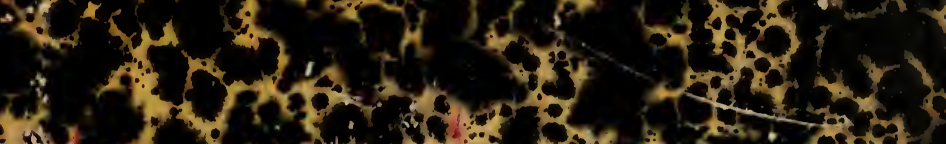

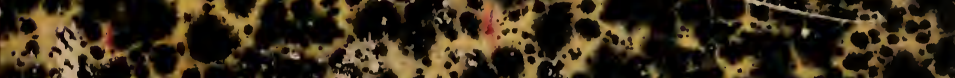

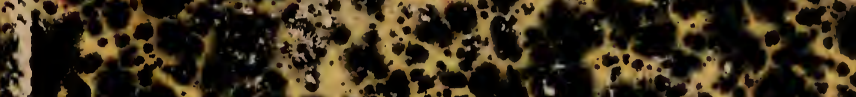

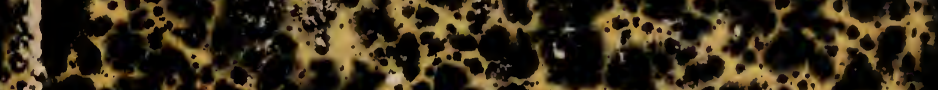

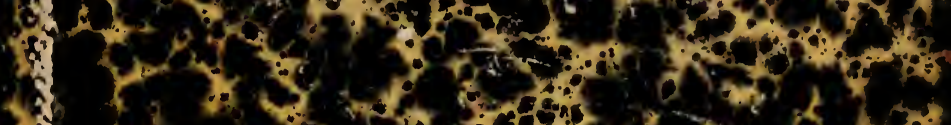
1.

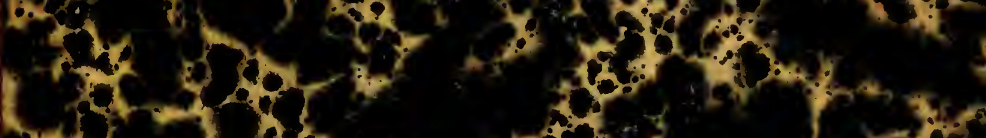

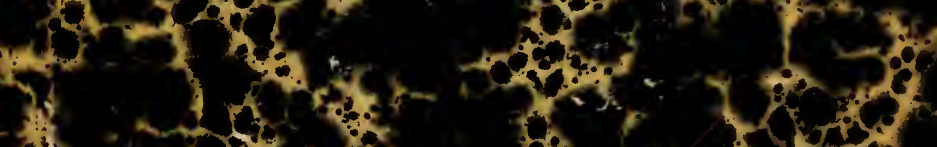

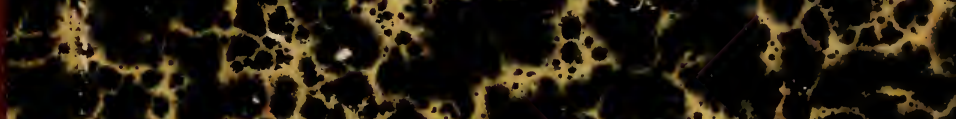
(x)

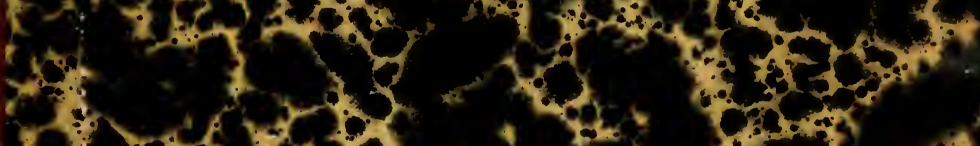
T.1. T.

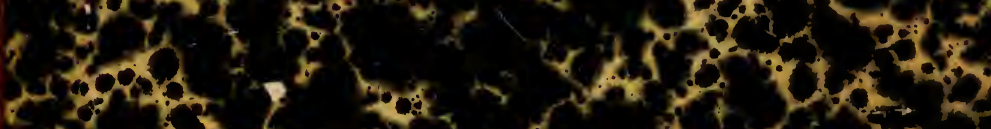

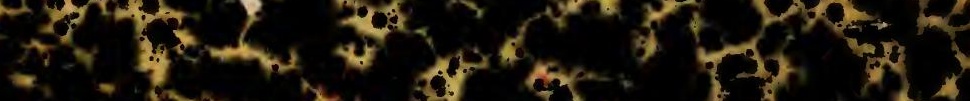
$+22^{2}+x^{2}+3$ $6+x^{3}+36$

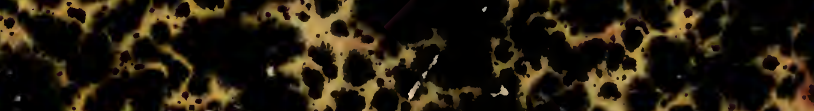

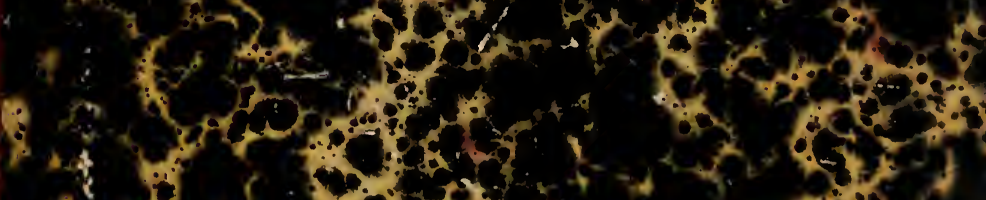

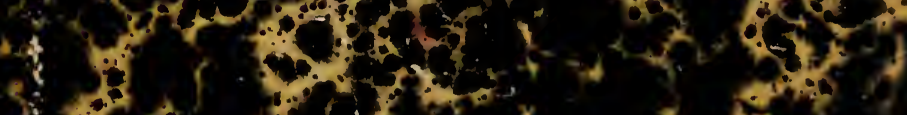

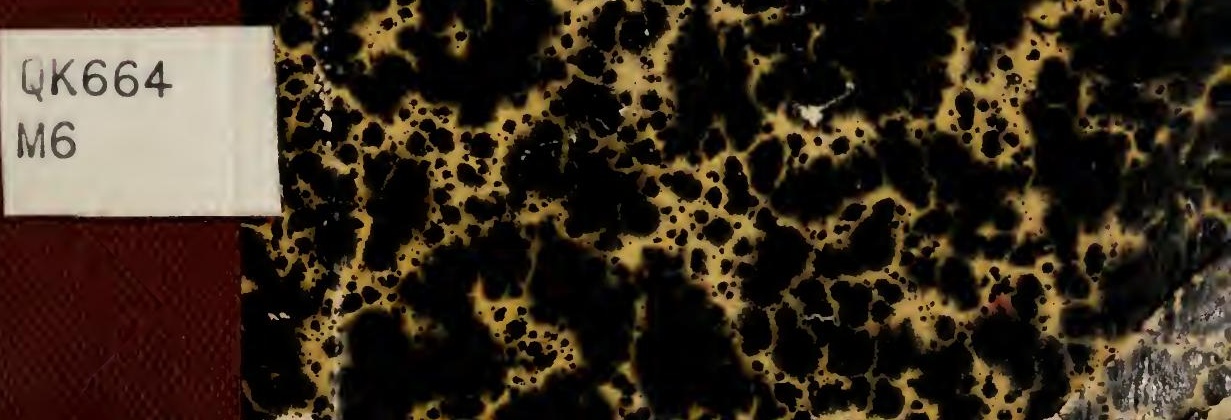







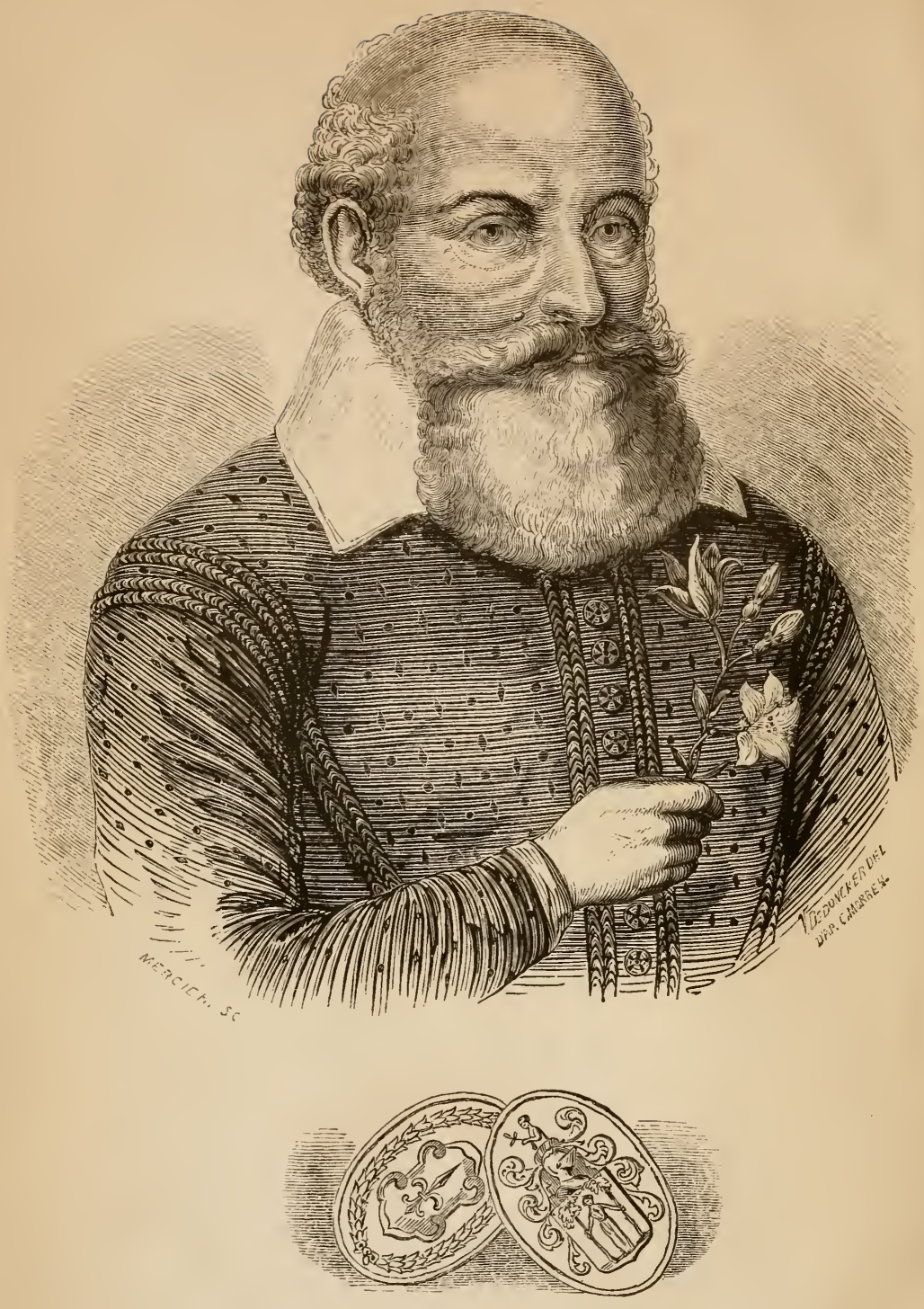

\section{IIATTHIAS DE L'OBEL}

$1538+1616$. 


\title{
IOB B
}

()U

\section{RECUELIL D'oBSERTITIOIS DE BORANIQQUE}

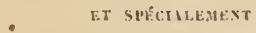

bQ TERTTOLGIS VÉGÉfaLi,

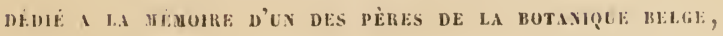

IMATHIAS DE L'OBEL,

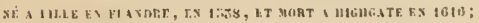

par

\section{CH. MORREN,}

Ductenr elt sciences, en philosophie naturelle ct en medceine,

l'rolesseur ordinaire de bolanique et d'agriculture à l'universitè de l.iege, Directeur du jarlin holanique; Chevalier des Ordres le Liopold,

de l'Etoile Politire de sitede et خorwége, de l'ordre royal de Dancbrog, de la

Couronite de Wurtemberg, de la Couronne de chine, ete.; Membre titulaite de

l'aeademic royale des scicnces, des lettres et des beaux-arts de lielgigue, Ifembre th couscil supiricus d'agrieulture du royaune, Menibre honosaire de l'académic royale de oublin; Correspondant de's acalemies tes sciences de lireslau, Florence, Madrid, Naples, Padou.

limme, Turin; de l'aeadémie royale d'agricutture du royaune de Sirdaigne et de l'juon!; des socititis royales d'agrieullure, de botanique, des sciences naturclles ou midicales

de Barcelone, Berlin, Bruxelles, Caen, Clermond-Ferriend, Dijon, de la Dienthe, d'Edimbourg, de Gand, de Groningue, de Ilal'c, IIcidelherg, lecipzig, Màcon, Malines, Marbourg, Paris, lialislonne, liostot, Rolterdam, kouen, Silesie, Strashourg, Stochholm. Lirecht, des Pays-l'is, Valeuce, rte.

Ouvrage orne de quatorze planches el d'un portrait de De L'Obel.

\section{BRUXELLES.}

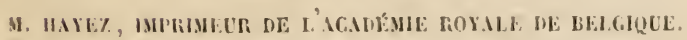

\section{$183 \mathrm{i}$}



La publication par l'Académie royale des sciences, lettres et beaux-arts de Belgique, des notices adopiées par elle pour son bulletin des séances, permet aux auteurs de réunir par volumes les tirages à part de leurs communications. J'ai dit dans mon avant-propos de la Fuchsia, publiće en 1850 , comment le volume portant ce nom, renfermait mes dissertations de 1845 i 1849. Le présent volume contient mes opuscules académiques présentés, en 18500 et $185 \%$, au premier corps savant de Belgique. J'ai placé, selon ma coutume, ce petit ouvrage sous le patronage de la mémoire de Mathias de L'Obel, une de nos gloires nationales, et ce souvenir m'a permis de joindre au titre un portrait. auparavant très-rare, de l'illustre botaniste flamand.

La plupart des notices contenues dans ce volume sont relatives à la science des aberrations ou monstruosités végétales. Je me suis cru autorisé en partic à placer ces sortes de phénomènes sous les auspices de L'Obel à cause de plusieurs circon- 
stances. Le botaniste lillois s'est fait peindre, tenant à la main un lis blanc à cinq parties au périanthe, ce qui est une monstruosité de réduction. Est-ce à dessein ou involontairement? je l'ignore, quoique je penche, je l'avoue vers la dernière idée, mais le fait n'en subsiste pas moins. Puis, les lobéliacées dédiées à notre ancien compatriote, sont des types irréguliers dérivés des campanulacées, au point qu'autrefois, et même dans les écrits de deCandolle, on réunissait les uns et les autres dans une même famille. Enfin, les lobéliacées elles-mêmes m'ont fourni le sujet d'une notice sur un genre de monstruosités très-rare et très-curieux pour la philosophie de la science tératologique. Je crois ces arguments suffisants pour légitimer le titre que j’ai donné à ce présent volume.

Liége, 50 décembre 1831.

Chr. Morrex. 


\section{TABLE DES MATIËRES}

1. P'rologue à la mémoire de Mathias de L'Obel . . . . . . . I

2. Le globe, le temps et la vie ou discours sur les phénomènes périodiques auxquels la plyysiologie de la terre est soumise . . . I 1

3. Memorandum sur la vanille, son histoire et sa culture (1 ${ }^{\text {re }}$ partic, 1 planche) . . . . . . . . . . . . . . 29

4. Sur la speiranthie des Cypripèdes, nouveau genre de monstruosités. 55

5. Étude d'une pétalification successive dans les Saxifrages (1 planche). Ğ

6. Notice sur la structure morphologique de la fleur des Lopéziées et sur une adénopétalie observée dans cette tribu (1 planclıe). .

7. Notice sur la disparition des organes sexuels (cénanthic) et sur le développement de nombreux rameaux ananthes (mischomanic) dans le Bellevalia comosa et sa variété monstrosa (2 planches)

8 . Les virescences distinctes des phyllomorphies et cas particulier l'une virescence du Chèrrefeuille (4 planche) . . . . . .

9. Note sur un procédé qui fait produire à certaines races de pommes de terre, quatre récoltes lans l'annéc. . . . . . . . .

10. Coryphyllic d'un Gesneria, genre de monstruosité où la feuille termine l'axe végétal (1 planche) . . . . . . . . . 10 -

11. Notice sur le spiralisme tératologique des tiges (1 planclie). . . 111

12. De l'atrophie en général et démonstration par l'étude de l'organisation même, de ce fait que les pollens de certains monstres sont impuissants (1 planche). . . . . . . . . . . .

15. D'une pélorisation siģmoïde des Calcéolaires, noureau genre de nonstruosité, d'une synanthie bicalcéifère et endostaminale, et enfin, d'une synanthie unicalcëifère et exostaninale de ces mêmes plantes (1 planche). . . . . . . . . . . . . 


\section{( VIII )}

14. Solẻnaidie ou métamorphose des organes sexuels en tubes creux et stériles (1 planehe). . . . . . . . . . . . . . . 149

15. De l'influence de l'éclipse du soleil du 28 juillet 1851, sur les plantes. . . . . . . . . . . . . . 157

16. Recherches sur un nouveau genre de monstruosités végétales modifiant l'axe de certaines fleurs et appelé gymnaxonie, ou dénudation de cet organe (1 planche).

17. Notice sur les anomalies de déplacement et analyse de monstres nouveaux compliqués de métaphéric, de dédoublement et de disjonction (1 planche). . . . . . . . . . . . . . 177

18. Rapport sur un mémoire concernant la topographie, la géologie, l'économie rurale et la fertilité des poldels . . . . . . . 191 


\section{QUELQUES}

\section{IFUC \\ JBTÉES}

sur la tombe d'Un des píres de la botanique belge,

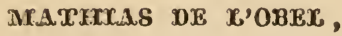

AE A LILLE EN PLANDHE, ES 4538 , ET MORT A HIGHGATE, EN 1016.

$\Rightarrow 0$ 
(Extrait du tome XIX, no 6, des Bulletins de l'Académie royale de Belgique.) 


\section{QLELQUES FLEURS DE LOBELIA}

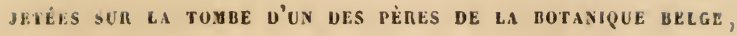

MATIIIAS DE L'OBEL.

Il y a de nos jours deux espèces de Flamands : les Flamands de France et les Flamands de Belgique. Louis XIV, quoiqu'il les nommât des magots, ne fut pas fâché toutefois d'incorporer à son royaume (1668) quelques bonnes villes de celte antique Flandre, et de faire désormais des habitants de ces provinces des magots français. Jusqu'au temps de cette violente séparation, imposée par la conquète à des pays possédant la même langue, la même foi, les mêmes mœurs et la même origine, il nous sera permis de regarder comme véritablement flamand ce peuple uni par les liens les plus naturels. C'est à ce titre que l'histoire des sciences a le droit incontestable de regarder comme flamand et, par conséquent, comme belge, l'illustre naturaliste à la mémoire duquel nous consacrons ces pages. D’ailleurs, la France doit s'étonner d'autant moins de voir passer cet homme célèbre dans le panthéon belge, et même de le trouver cité souvent comme une grande illustration de la science anglaise, que, flamand par sa naissance et par sa famille, on ne l'a vu lié à la patrie qui le revendique d'ordinaire, que par son éducation et quelques voyages. Sa vie, il la consacra à la Belgique, à la Hollande, à l'Angleterre; ses écrits, il les publia en latin et en flamand, tantôt à Anvers, tantôt à Londres; ses re- 
lations furent entièrement belges et, à deux époques de sa carrière, anglaises; dans aucune de ses ouvres on ne le saisit portant ses affections vers la France, mais toujours vers le pays qu'il regardait lui-même comme sa patrie, vers la Belgique, dont il estimait la botanique et l'horticulture les premières de l'Europe, et dont il admirait tant les jardins qu'il consacra à leur étude constante et ses forces, et son savoir et une grande partie de sa fortune. L'ensemble de toute celte vie, si belle, si noble et si utilement remplie, ne peut laisser aucun douteà l'esprit sur la nationalité qu'il revendiquerait encore lui-même, si sa tombe pouvait retentir des vœux de son cœur.

Curtius Sprengel, dans son IIistoria rei herbariae (1), a bien soin de ne pas mettre cette nationalité en doute. Dodonaei civis, dit-il, Mathias Lobelius, Insulis Belgii 1558 natus. En effet, Mathias de L'Obel et non Lobel, comme l'écrivent à tort le plus grand nombre des auteurs (2), naquit en 1558 , peut-être en 1559 , à Lille, d'une famille belge d'origine et qui l'est restée par la suite et de nos jours encore oì elle a compté et compte de nobles défenseurs dans l'armée. Son père était un homme de loi; mais, comme Mathias

(1) Tome 1, page 598.

(2) Son portrait, gravé par Dellarame, porte le nom orthographié tel qu'il doit l'être. Les Anglais, comme Loudon (Arboretum britannicum), l'écrivent correctement. Si cette particularité avait été connue de Linné, il est probable que nous aurions écrit Obelia au lieu de Lobelia, et Obéliacées en lieu et place de Lobéliacées. Les Don Quichotte de la nomenclature, qui prétendent pouvoir un jour rendre le langage de la science rationnel, raisonnable, vrai et euphonique, toutes choses plus aisées à souhaiter qu'à réaliser, trouveront dans ce nom de L'Obel une nouvelle matière à proposer des changements. Il est vrai que l'usage, despotique comme la mode, se rira comme elle de la raison. 
l'apprend lui-mème, un invincible attrait le portait comme malgré lui vers l'étude des fleurs, et cela des l’âge le plus temlre. A seize ans, il était déjà botaniste. Les travaux quili publia plus tard avec Pena, prouveni que ce furent les plantes indigènes de sa patrie qu’il étudia d’abord et profondément, de manière à en bien distinguer les espèces. L'utilité de ces comnaissances devait de toute nécessité le mence à la carrière médicale, el pour prendre ses degrés, il partit pour Montpellier, ou florissait alors le fameux naturaliste Rondelet. Ce dernier, qui avait été nommé en  gnait souvent le carlinal de Tournon, et fit avec lui plusieurs voyagés en Italie et dans les Pays-Bas. Il avait étudié avec ferveur les ètres naturels de notre pays, et quand de L'Obel vint s'asseoir sur les bancs de son auditoire, une intimité véritable s'établit bientôt entre le maître et l'élève, à cause de la communauté de leurs recherclıes. Rabelais estimait comme un sage, Rondelet, dont il avait fait son rondibilis, et il le fait parler avec une haute raison : il était, en effet, regardé comme un des hommes éminents de ce savant XVI $I^{\mathrm{e}}$ siècle. De L'Obel se pénétra de cet esprit : il fut toute sa vie un homme de science profonde, d'imperturbable gravité et de mœurs antiques. Son portrait que nous avons joint à cette notice indique bien l'union de ces qualités austères.

Le ciel du Midi l'avait sans doute inspiré, et les plantes si belles et si nombreuses de ces heureuses contrées exerçaient trop d'empire sur sa passion innée, pour que le jeune Belge ne s'empressât d'en faire une ample moisson. II parcourut done, comme on herborisait alors, à pied et à petites journées, les Pyrénées, la Suisse, le Tyrol, les M/pes et l'Allemagne. A Narbonne, il connul Pena, naturaliste non 


\section{( vj}

moins ardent que lui et sur le compte duquel nous devons nous arrêter quelques instants. La Biographie universelle représente Pierre Pena comme une victime de de L'Obel, et celui-ci n'aurait rien moins à se reprocher que l'ingratitude, et peut-être même quelques escroqueries scientifiques. Cette double accusation est, croyons-nous, deux fois et radicalement mal fondée. On raconte que de L'Obel rencontra fortuitement Pena dans le Midi ; que ce dernier recueillit un grand nombre de plantes qu'il communiqua au botaniste de Lille; que ces plantes parurent dans les Adversaria, imprimés pour la première fois à Londres de 15070 à 1579 , avec 268 gravures; enfin, que les contemporains de Pena le citaient comme un collaborateur de de L'Obel, tandis que Mathias se borne à mettre une fois son nom avec le sien en tête de ces Adversaria. Toutes ces assertions sont dénuées de preuves. Si Pena eût été un homme si extraordinaire par sa science et sa renommée, il est peu probable qu'on eût ignoré et le lieu et l'année de sa naissance, aussi bien que celle de sa mort : les uns en font un Narbonnais, parce qu'il habitait Narbonne; les autres (Plumier) le disent d'Aix. Pena n'a d'ailleurs rien écrit de lui-même. Nous avons lu page par page tous les Adversaria, et nous n'avons aucun doute que le texte entier ne soit de la rédaction unique de de L'Obel : c'est son style, sa manière, ses pensées habituelles, ses citations, son érudition familière; partout il cite la Belgique, sa patrie, les amis de son pays, l'Angleterre, les connaissances qu'il y a faites, les dons qu'il en a reçus, et chaque fois qu'il entame l'histoire d'une plante du Midi, il en parle ou comme d'une espèce qu'il y a vue par lui-même ou comme d'une sorte sur laquelle des auteurs connus avaient déjà fourni des renseignements. Dans ce livre, il fait l'efietet d'avoir profité 


\section{( vij )}

simplement des plantes et pas de toutes, loin s'en faut, de Pierre Pena, mais nullement d'avoir écrit une ouvre en commun avec ce dernier. Des exemples abondent pour prouver que c'est dans la simple communication de quelques espèces que consiste tout le secours du botaniste de Narbonne. A l'histoire du froment, de L'Obel parle du commerce des grains d'Anvers; il dit comment l'Espagne déversait à cette époque sur notre pays des masses de blés durs que les moulins indigènes ne savaient pas moudre; il donne le blé de mars comme une production toute et essentiellement flamande; il explique la fabrication de la bière par le seigle et par l'orge, sépare l'orge d'hiver sous le nom de soucrion, et fait de toutes les céréales une histoire tellement précise et tellement flamande, qu'il ne peut y a voir l'ombre du doute que jamais Narbonnais aurait pu devenir belge à ce point. Quand on traite ainsi de a byère de a zythe $\triangleright$ et de a curme " c'est qu'on est plein de son sujet, et un français du Midi succomberait à cette tâche-là.

A propos des Asphodèles, de L'Obel cite ses amis Guillaume Driesch et Pierre Coudenberg, ces deux célèbres cultivateurs de plantes exotiques dans nos provinces; mais aucun détail analogue nulle part ne se trouve fourni par Pena sur des amis de sa localité, ce qui conduit à croire que de L'Obel seul a pu écrire et penser ce livre. Quand, à propos de l'Erythronium, de L'Obel cite sa floraison au mois d'avril à Lyon, dans le jardin de Donrez (Lillois de naissance comme de L'Obel lui-même), qui cherchait cette espèce dans le Jura, il parle de cette particularité comme d'une chose qu'il a vue lui-même. En figurant le chou-marin pour la première fois, de L'Obel rapporte que depuis longtemps Turner, célèbre botaniste anglais de l'époque, lui en avait donné des graines que le botaniste de Lille avait 


\section{( viij )}

semées en Belgique : nulle part on ne parle de faits semblibles qui auraient été posésà Narbonne. En citant la chicorée, il fait connaître de quelle manière les Brabançons la cultivaient déjà de ce temps comme légume d'hiver, en étiolant les plantes dans la terre. Au chapitre du Stramonium peregrinum, il dit qu'il n'a vu fleurir cette espèce que dans les jardins de Padoue et de Belgique; fait qui prouve qu'il faisait les observations par lui-même et cun voyageant, et jamais il n'en cite de semblables faites par Pena. Il raconte comment l'amour d'avoir, l'hiver, des plantes pourvues de couleurs vives, alors que les serres n'étaient pas encore inventées, ou du moins répandues, portait les Belges à cultiver jusqu'aux grands froids, volupialis causâ, la brillante Alkekenge. Le Paris quadrifolia quil avait vu dans les forêts de son pays, en France, en Suisse, près de Bâle, devint l'objet de ses expériences sur les chiens vivants faites en commun avec un de ses amis intimes, le Suisse Bathone; Pena n'y intervint en rien. Si cependant il en avait fait de semblables avec le médecin Pena, le soin qu'il prenait de citer religieusement les autres lui aurait-il laissé taire le nom de son collaborateur aux $A d$ versaria? Cela n'est pas probable, et tout porte à croire que celui-ci se borna à lui communiquer simplement des espèces dont sa plume exercée traçait l'histoire. En décrivant la rhubarbe, qui fut, comme on le sait, introduite en Europe par l'empereur Charles-Quint lui-même, de L'Obel relate, avec ponctualité, comment, sous le nom de rhuharbe du pape, on en répandit, en 1561 , une nouvelle espèce en Italie, comment il la vit employer dans les hôpitaux à Florence, à Venise et, en 1564, en Bohême; il y trouve une nouvelle occasion de citer son compatriote de Lille, Valerandus Donrez, valde ingeniosus. Sa plume 


\section{( ix )}

ne souffrait donc pas de prodigner l'éloge, et de choisir des adjectifs que le poëte Goëthe trouvait quand ils s'adressaient à lui, e jolis et agréables. „ Partout, il rappelle les herborisations qu'il a faites dans les lieux les plus divers, et il ne néglige pas les plus chétifs détails, témoin le Pyrola qu'il a eu tant de plaisir à trouver à Berchem, près d'Anvers, l'mula helenium qu'il vit tleurir dans les forêts épaisses des environs d'Orléans, le Cypripedium calceolus qu'il admira en Suisse et aux abords d'Inspruck, le Gentiana minor de Micon, etc. Les Adversaria abondent en preuves de ce genre. Tant de conscience ne peut laisser soupçonner que s'il avait dû à Pena des détails analogues, il ne se serait pas fait faute de les honorer d'une citation particulière. En associant le nom du botaniste de Narbonne à la totalité de son œuvre, il lui a certes donné une part très-large dans la gloire que la postérité a vonée, en toute justice, à cette œuvre, et loin de tourner à blâme ce procédé plein de délicatesse, les biographes eussent mieux fait de chercher dans la lecture même de ces pages anciennes le vrai sentiment qui animait notre illustre botaniste.

Sprengel n'hésite pas à déclarer que pour lui, qui avait comparé entre elles les œuvres des contemporaius de de L'Olıel, ce dernier était un homme remarquable par ses voyages, ses lectures, son esprit, le commerce qu'il entretenait avec les savants de son temps, et surtout par son immense connaissance des plantes. Il le place immédiatement en valeur après Gesmer et de L'Escluse, honneur de premier mérite. L'affaire de Pena, si mal interprétée par les biographes universels, se réduil pour l'historien de la botanique à la simple publication de ses notes, par son ami de L'Olsel, qui avait reçu son assentiment à ce sujet. C'est là, en ellet, la vraie manière d'envisager cette conpération. 
Pulteney peuse que, puisque les Adversaria ont paru à Londres, en 1570, avec une dédicace à la reine Élisabeth, de L'Obel s'était déjà rendu, avant cette époque, en Angleterre. Ce qu'il dit du don des graines du Crambe maritima par Turner, et les nombreuses observations qu'il avait faites sur la flore britannique, autorisent à croire que réellement, à cette époque, l'Angleterre l'avait reçu et avait obtenu de lui une large part dans ses affections.

Dans sa lettre à la reine Élisabeth qui précède l'édition des Adversaria faite à Londres, de L'Obel explique clairement le motif de son séjour en Angleterre : il fuyait les guerres civiles de sa patrie. Le père de famille, dit-il dans cette lettre, n'ira pas établir son ménage sur une mer sans cesse tourmentée par la tempête, et puisque Pindare ne chante pas au milieu des soldats, il ne voit pas pourquoi lui, l'homme des jardins et des fleurs, doit voir la terre arrosée de sang humain. L'Angleterre offrant son antique hospitalité aux indigents, aux pauvres, aux vilains, aux inconnus comme aux nobles et aux riches, il a cru, dans l'intérêt de ses études, de son repos et de ses goùts, devoir user de cette éminente qualité nationale. D'ailleurs, il n'a pas voulu vivre sur le sol britannique sans l'enrichir du fruit de ses recherches. Il dit à la reine que son ouvrage prouvera combien déjà il avait étudié les espèces indigènes et de combien d'espèces utiles et remarquables, introduites par ses soins, il avait doté les jardins. Il cite, à ce sujet, ses relations avec Turner, Robert Huick, Richard Master, tous médecins de la couronne, puis un grand nombre d'illustres Anglais avec lesquels il entretenait un commerce littéraire et scientifique. Ce sont ces détails qui ont amené les historiens anglais à réclamer plus tard de L’Obel comme une de leurs illustrations nationales. Il est curienx 


\section{$(x j)$}

pour les botanistes de lire, dans cette lettre, comment de L'Obel puise dans la flore d'Angleterre des images et des idées qui devaient nécessairement plaire à la souveraine: Votre patrie, dit-il à Élisabeth, produit une toute petite herbe, appelée la rosée du soleil, mais le soleil lui-même voit sa splendeur éclipsée par la beauté de cette merveille. Et comme, pour empêcher la fille de Henri VIII, dont le caractère âpre sympathisait très-peu avec le monde si doux des fleurs, de sourire à cette image bucolique, l'adroit de L'Obel a soin d'ajouter que, sans une herbe aux botanistes connue, son aïenl Édouard, près de rendre le dernier soupir, n’anrait pas conservé le souffle d'une vie qui se prolongea encore plusieurs années à la plus grande gloire de sa maison.

Dans cette première édition, dont les planches diffèrent totalement des figures publiées après, il parle des anatifes, des polypiers et de l'arbor Christi ledifolia, chapitres qui ne se trouvent plus dans l'édition de Plantin de 1586; mais à la fin des Stirpium observationes de cette année, les polypiers figurent de nouveau, ainsi que les anatifes qu'il dit avoir été reçus à Lille par un négociant de ses amis, André de Fourmestranx, et au sujet desquels il rappelle la singulière croyance du temps, à savoir que ces cirrhipèdes se transformaient en canards! Le canard moderne, dont un membre de l'Académie de Bruxelles, l'original et fantasque Cornelissen, s'est attribué l'invention, se trouve déjà en germe très-viable dans les doctes écrits du botaniste royal de Jacques ${ }^{\text {er }}$.

De L'Obel revint dans sa patrie quand il la vit plus tranquille. En 1575 , n'étant encore âgé que de 57 ans (il n'en avait que 52 quand il publia ses immortels Adversaria), il obtint à Bruxelles, en faveur de Plantin et pour le terme de dix ans, le brevet d'imprimer son Stirpium on Plan- 


\section{( $x i j$ )}

tarum historia, enrichi de 1486 ligures nouvelles qui avaient déjà servi aux publications de Dodoëns, de L'Escluse et de Mathiole. Il y joint son traité sur les succédanés, De Succedaneis, imitatione Rondeletii, qu'il déclare avoir puisé presque entièrement dans les leçons de son ancien professeur et ami, déclaration de délicatesse dont beaucoup d'élèves sont fort peu soucieux de notre temps, où, comme on l'a vu, on blâme si légèrement nos modèles et nos maîtres. Ce traité des succélanés est très-remarquable, et il y règne des principes de matière médicale qui passeraient pour neufs, si on venait à les reproduire. La similitude des propriétés y repose sur la similitude des corps : des racines y remplacent des racines, des herbes se prennent les unes au lieu des autres, les résines se substituent à des résines, et ainsi de suite. Les odeurs, les saveurs, les âges, les états, les propriétés visibles et même les propriétés occultes doivent être analogues pour que les substitutions puissent s'établir avec utilité. La pharmacopée range les médicaments dans des casier's où les succédanés se suivent d'après un ordre d'identité ou de similitude. Tout ce classement est fort ingénieux. Pour la publication de cet ouvrage, le pléban et chanoine de NotreDame d'Anvers, Sébastien Baer, lui délivre le certificat qu'il n'y a rien dans cet ouvrage et dans le Plantarum historia qui puisse blesser la foi de l'Église romaine et les droits de l'État, et que, par conséquent, les imprimeurs peuvent répandre cet ouvrage au plus grand profit de tous. Cette soumission à l'Église catholique est donc une preuve que de L'Obel résista au protestantisme, ce qui lui donne encore le caractère d'un écrivain véritablement belge. Cette observation ne sera pas perdue pour un autre trait de sa vie. 


\section{( xiij )}

Au Stirpium adversaria nova, de L'Obel a ajouté, en 1576 , le Fruticum sub/ruticum cremionum et arborum adversuria conciscque recensiones, dans lequel il fait connaître des médicaments nouveaux ou des végétaux singuliers, entre autres les Sarracenia, qu'on appelait alors le Thuris limpidifolium, le caroubier, le jujubier, le laurier-tin, le chène-liége, l'arbre de Julée, le platane, l'érable et d'autres espèces intéressantes. Il y joint un appendix de plantes nouvelles qui lui étaient restées inconnues, et un formulaire de remèdes écrit par Rondelet.

Pendant l'impression de ses œuvres, de L'Obel se fixa comme médecin à Auvers : il eut ainsi le moyen d'en surveiller les corrections. Il ne paraît pas qu'il ait quitté la métropole du commerce belge, dont il cite souvent les pré-

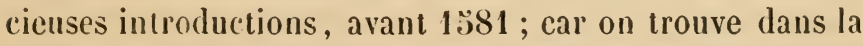
traduction llamande de son Histoire des plantes qu'il y signa, le $1^{\text {er }}$ mai de cette année, la dédicace de son livre au prince d'Orange. Il avait alors 45 ans; mais quelque temps après, attiré, sans doute, en Hollande par la famille du prince, il alla séjourner à Delft, où il se livra aussi à la pratique de la médecine.

La dédicace du Kruydboek de 1581, donne d'ailleurs plusieurs motifs de son amitié pour les Hollandais. II y fait connaitre avec une vive reconnaissance que, grâce à l'activité et à la réputation des savants de cette nation, il a reçu un grand nombre de plantes des Indes, de Constantinople, d'Italie, d'Allemagne et d'Espagne. Il s'y loue d'une façon toute spéciale de la largesse de Charles de L'Escluse, qui, à cette époque, occupait les fonctions d'intendant du jardin botanique de Vienne, mais se trouvait, en 1:50, en Angleterre. Ces deux hommes étaient sans doute faits pour s'estimer. Dans cette mème dédicace, de 


\section{( xiv)}

L'Obel prend plaisir à citer quelques noms belges, chers à l'histoire de l'horticulture et de la botanique, dont nous le verrons bientôt peindre à grands traits le prodigieux développement dans nos provinces. Il mentionme les de Renoultre, de Brancion, Vanderdilft, morts à cette époque, et comme contemporains ayant le culte des fleurs en honneur, Philippe de Marnix de St-Aldegonde, Charles de Houchin, seigneur de Longastre, Jean Boisot, Mathias Laurin, trésorier des états, Cornelis Druynen, également trésorier, maitre Guillaume Martini et Jean de Ioboken, greffier de la ville d'Anvers, les gentilshommes Jacques Duym et Jaspar Roclofs, enfin Jean Mouton de Tournai et Jacques Durin. C'est à eux, dit-il, que la Belgique est redevable de l'introduction des plantes utiles d'Italie, d'Allemagne, d'Angleterre, du Languedoc et de la Provence, et il les signale à la reconnaissance de la postérité.

La première partie du Kruydboek, formée de 994 pages in-folio, et la seconde qui en comprend $\mathbf{3 1 2}$, sont suivies du Traité des succédanés, 15 pages, en tout 1521 pages sans les tables. Les figures sont plus nombreuses que dans les Adversaria, et avaient servi, entre les mains de Plantin, aux éditions de Fuchs, Dodoëns, de L'Escluse et de Mathiole. L'auteur y a joint à la fin un petit traité des champignons, et les arbres, cette fois, se trouvent non plus séparés comme dans les Adversaria, mais forment un chapitre seulement dans le traité général. Le Kruydboek eut sans doute, dans les provinces flamandes et hollandaises, une vogue très-grande, puisqu'il est plus rare de le trouver aujourd'hui entier et bien conservé, que les Adversaria, dont la langue a permis cependant la diffusion dans toute l'Europe.

De L’Obel avait dédié, pendant son séjour à Anvers, son 
Stirpium historia aux gouverneurs, magistrats et généraux de la Gaule Belginue. M. Louis Debacker, dans son ouvrage sur Les Flamands de France, éludes sur leur langue, leur littérature el leurs monuments, publié récemment(18:92), croit que la rareté des monuments littéraires de quelque valeur antérieurs au XVe siècle, ne doit être attribuée qu'à l'état de guerre où se trouvaient ces provinces. « Comment l'ouvrier de la pensée, dit-il, l'écrivain, aurait-il pu se livrer à ses méditations au milieu de ces cris d'alarme, de tout ce bruit des batailles, à la vue de ces lueurs sinistres que projetaient les villes incendiées? Pour se produire, ajoute l'auteur, les lettres et les arts ont besoin de paix et de liberté : les armes effraient leur muse. ¿Déjà, un de nos critiques, à la fois sagace et bienveillant, M. Édouard Fétis, a fait remarquer avec grande raison que cette observation de M. Louis Debacker n'est pas applicable au culte des arts, qui certes prirent une élévation considérable sous la puissante et guerroyante maison de Bourgogne. Comme il est facile de se l'expliquer par la nature même des monuments de ces siècles agités, le contre-poids des armes était le culte, et une phase toute religieuse se pose ici dans la série des progrès de l'art. La biographie de de L'Obel atteste encore le même fait. Pendant ce XVI siècle, si sanglant et si abîmé, les savants s'occupaient, dans une sérénité parfaite, de l'étude des fleurs, les êtres les plus pacifiques et les plus placides de la création; et cependant à voir comment de L'Obel sent les événements de son époque, on reste convaincu que ce calme ne procède ni de l'insensibilité, ni de l'indifférence. Les botanistes aiment toujours leur patric par un sentiment dont eux seuls peuvent apprécier le prix et la chaleur : ils adorent les fleurs; les premières qu'ils ont pu admirer se sont écloses près de leur ber- 


\section{( $x v j)$.}

cean, et l'on nait avec l'amour des lleurs comme on nait peintre, poëte on penseur. Ces impressions premières ne s'effacent jamais, et quand le botaniste songe ${ }^{\text {sa }}$ son pays, il en voit dans son esprit l'attachante image, entourée de l'auréole de ses fleurs nationales. Au souvenir du lieu natal et des premières affections, la nature elle-même vient joindre celui de ses plus gracieuses merveilles: comment alors ne pas aimer deux fois le pays de sa naissance et de ses premières amours!

" Je ne puis pas assez déplorer, disait de L'Obel, aux gouverneurs, magistrats et généraux de son pays, les calamités de notre commune patrie, déchirée misérablement par une odieuse guerre civile; nos villes voient tomber leurs remparts et l'incendie les consume; l'eau, le fer et la famine tuent des milliers de nos compatriotes; nos champs sont dévastés, nos villages pillés, nos laboureurs exterminés. Ces provinces, livrées naguère au culte charmant des Muses, qui semblaient avoir quitté la Grèce pour chercher au milieu de nous un moderne Hélicon, nos provinces n'entendent plus les chants des poëtes, ni les discours des sages : le clairon des combats retentit seul dans les airs; quel est l'homme de mansuétude et de piété, qui contemplera sans une suprême douleur des dissensions si malheureuses, et des dommages si irréparables! Et cependant, tout ce pays si noble et si antique, cette Gaule Belgique, connue depuis longtemps sous le nom de Flandre ou de Germanie inférieure, est le plus vaste et le plus célèbre bazar de toute l'Europe, où l'on porte en abondance par terre et par mer, tout ce que les différentes contrées du globe offrent de curieux et de remarquable, où l'on voit accumulés les trésors de l'Europe, de l'Asie et de l'Afrique. Ce pays est fécond en hommes 


\section{( xvij )}

brillants par leur esprit, et livrés avee succès à l'étude des arts ef-des sciences. Et quoique cette région septentrionale soît soumise à un cicl rigoureux, et devienne par conséquent moins propre ì nourrir une infinitéde plantes, tant sévissent les froids et les longs hivers, tant sont fortes les tempêtes et fréquentes les variations des temps; cependant telle est l'habileté de ce peuple, telle est sa constance et l'opportunité de ses soins dans l'art de protéger les plantes contre l'inclémence des saisons, qu'il est impossible de trouver un végétal, quelque délicat qu'il soit, qu'on ne parvienne à élever et à faire prospérer par l'assiduité et l'infatigable travail de ces hommes instruits et illustres qui n'épargnent, pour arriver à cette fin, ni dépenses, ni peines. C'est par cette raison que je ne fais aucune difficulté de mettre les Belges au premier rang dans l'art de la botanique (in excolenda re herbaria). Vous trouverez dans ce seul pays plus d'espèces et de variétés de plantes, d'arbustes et d'arbres que dans la Grèce antique, la spacieuse Espagne, toute l'Allemagne, l'Angleterre, la France, dans l'Italie, si bien cultivée, ou dans tel royaume et telle province adjacents. Aussi cette floréale Belgique compte-elle en nombre de zélés amateurs de l'art des jardins; et pour moi, je ne cite que ceux qui me sont connus : ils brillent non-seulement par la culture des fleurs, mais aussi par la culture des lettres. Tels sont Charles de Croy, prince de Chimay, Pierre de Bossu, seigneur de Jeumont, Charles de Bossu, vicomte de Bruxelles, feu le très-révérend seigneur Gérard d'Oignies, évêque de Tournay, Jean de Brancion, Charles de Houchin, scigneur de Longastre, Jean Dilft, Jean Boisot, Jacques Utenhoven, Philippe Deurnagle, seigneur de Vroyland, Jean de Limoges, surnommé Nonnius, Charles 


\section{( xviij )}

de L'Escluse, intendant du jardin de l'empereur Maximilien d'Autriche, le premier de tous les écrivains dans la science des plantes, et les professeurs royaux de l'antique et noble université de Louvain, Pierre de Breughel, Corneille Gemma et Jean Viringus, lesquels se sont livrés à cette étude avec un louable succès. Ces botanistes ont fait venir à grands frais de Constantinople, de la Grèce, d'Espagne, d'Italie, de différentes parties de l'Asie et de l'Afrique, et même du Nouveau Monde, récemment découvert, des végétaux nombreux formant l'ornement de nos jardins. Moi même, j'en avais expédié d'Italie, de la Provence et du Languedoc, mais presque tous ont péri dans le sac de Lyon. „ Ce passage des Adversaria est un magnifique éloge de l'horticulture ancienne de la Belgique, qui, depuis cinq siècles au moins, n’a pas failli dans cet amour raisonné et profondément senti des merveilles de la création. Aussi ces paroles, ou du moins une partie de ce passage, arrangées avec plus ou moins de complaisance, selon les temps, les gouvernements et les vues politiques on autres des écrivains, ont-elles été souvent reproduites ou rappelées : témoin les discours de Van Iulthem, la préface des Annales des sciences physiques, rédigées par Bory de $\mathrm{S}^{\mathrm{t}}$-Vincent, Van Mons et Drapier, les écrits de Voisin, etc. Nous nous sommes fait un devoir, nous, de donner ce passage de de L'Obel tel qu'il est, sans restriction ni variante, et nous ne pouvons, en effet, ne pas faire remarquer ici avec un sentiment pénible, qu'on ne comprend pas, dans cette citation des gloires du pays à l'endroit de la botanique, l'omission du nom de Dodoëns, dont le botaniste lillois connaissait si bien les œuvres, qu’à propos des espèces, il en fait usage un grand nombre de fois, et que là il le désigne religieusement. Dans l'édition anglaise des Adver- 


\section{( xix )}

saria, on trouve une préface adressće aux professeurs de Montpellier, oì l'auteur déclare que son but n'est pas de suivre dans l'histoire d'ıne flore nationale le a très-docte et très-candide Dodonæus. „II n'avait done rien qui dût l'empêcher de rendre à l'illustre botaniste de Malines la justice qu'il avait si bien méritée.

Après son séjour en Hollande, nous retrouvons de L'Obel une seconde fois en Angleterre, où il accomplit la dernière partie de sa carrière. Pulteney, dans ses Esquisses historiques et biographiques des progrès de la botanique en Angleterre (t. I, p. 100), sans déterminer à quelle éporpue précise le botaniste de Lille alla se fixer au delà du détroit, croit pouvoir toutefois conclure qu'il était dans la capitale de la Grande-Bretagne en 15070. Sans doute, il y était alors, mais pas à demeure; de 1575 , au moins, à 1381 ( 6 ans), nous le trouvons médecin à Anvers, et, plus tard, à Delft. Ce qui paraît certain, c'est que de L'Obel s'était fixé définitivement en Angleterre avant 1592. On a vu comment, en Belgique, ses connaissances en botanique le meltaient en relation avec de nobles et influents personnages : ce fait se reproduit partout, dans tous les pays et à propos de la plupart des botanistes illustres. De L'Obel, arrivé en Angleterre, y fut fêté par de puissants seigneurs : il y connut lord Zouch, qui, envoyé en ambassade auprès de la cour de Danemark, en 1592, pria de L'Obel de l'accompagner. Les écrits anglais sur les introductions des plantes mentionnent, à cet égard, qu'il saisit cette nouvelle occasion pour ramener avec lui des espèces de ce pays, des raretés exotiques, inconnues auparavant dans les Iles Britanniques, et pour établir avec les savants danois d'utiles correspondances. $\Lambda$ son retour, il devint surintendant d'un jardiu botanique, fondé 


\section{( $\mathbf{x}$ )}

par lord Zouch, à Hackney. Cette sorte de fonction était ambitionnée alors par plusieurs botanistes célèbres, et le fait se conçoit sans peine : nos temps actuels ont remplacé sur le continent les grands seigneurs, par des gouvernements, qui sont loin souvent, et très-loin, d'avoir la libéralité éclairée de ces premiers et généreux protecteurs des sciences. Nous voyons à cette même époque Gérard de Nantwich, en Cheshire, né en 15030 , devenu médecin, recevoir la protection de lord Burleigh, qui possédait un jardin botanique au Strand, à Londres. Gérard exploitait lui-même un jardin de plantes médicinales, à Holborn. Gérard et de L'Obel se connurent et s'estimèrent : notre botaniste flamand mentionne $\mathbf{1 1 0 0}$ sortes de plantes qu'il a vues chez son ami, à Holborn; et quand Gérard publia, en 1596, le catalogue de ses plantes cultivées, de L'Obel y inséra une lettre toute en faveur de son collègue. Il eut aussi des relations suivies avec Gray, riche pharmacien de Londres, et il le cite à propos de plusieurs plantes remarquables.

Le fils de Marie Stuart, Jacques $I^{\text {er }}$, monta sur le trône d'Écosse, en 1̋87. On sait que ce roi s'occupa de botanique, et que parmi les livres célèbres se trouve son fameux traité contre l'usage du tabac: Misocapnos sive de abusu tobacci, lusus regius, qu'il publia, en 1604, un an après être monté sur le trône d'Angleterre. L'amiral sir Walter Raleich fut, comme on le sait, le premier Anglais qui fuma dans son pays : il rapporta de Virginie l'usage des pipes, et l'on raconte que son domestique voyant de la fumée sortir de la bouche el du nez de son maître, s'imagina qu'il avait pris feu à l'intérieur et lui jeta un pot d'eau à la tête pour éteindre cette combustion. De L'Escluse rapporte comment le tabac fit fureur en Angleterre, surtout à 


\section{$(\mathbf{x x j})$}

la cour. Jacques $I^{\text {er }}$ ne le souffrait pas, et dans son Misocapnos, il regarde comme un soin qui ne déroge pas à la dignité de la couronne, d'écrire lui-même contre cel abus. " Sil vous reste quelque pudeur, ô mes concitoyens! จ s'écrie-t-il, " laissez-là cette chose insensée : elle naquit - de l'ignominie; elle fut nourrie par l'erreur et propagée - par la folie. Cette fumée provoque la colère du Ciel; elle ๖ altère la santé du corps; elle ruine le ménage; elle dé„ grade la nation; elle vieillit la demeure; elle empeste la • cité; elle est odieuse à voir, dégoûtante à sentir; elle " alourdit le cerveau et gangrène les poumons, et, il ne • laut pas hésiter à le dire, la fumée du tabac, c'est la " fumée de l'enfer. »A ce portrait, peu flatteur, précurseur des lois qui mitigeaient ou proserivaient l'usage du tabac, les jésuites répondirent par une brillante apologie de l'importation de Christophe Colomb. En 1604, l'année mème où parut la première édition du Counterblast to tobacco, texte anglais du Misocapnos, Jacques $\mathbf{l}^{\text {er }}$ bannit du royaume les prêtres catholiques. En 1603 éclata la fameuse conspiration des poudres, et les deux jésuites, Garnet et Oldcorn, furent pendus. Lambert, Gilles, Vincent et Thomas Morren, tous quatre prêtres, et quoique parents d'un membre de la haute chambre et de l'ambassadeur du roi lui-même, Bavon Morren, furent massacrés, martyrs de la foi catholique, avec les nombreuses victimes de la réaction. Lambert Morren, provincial des jésuites d'Angleterre, dut fuir (1); et, en 1606, éclatèrent les divisions

(1) Ces détails sont puisés dans les papiers originaux de ma famille, que j'ai hérités de mon père, et que j’ai complétés plus tard en Angleterre, et surtout en Écosse. 


\section{( $\mathbf{x} x \mathrm{ij}$ )}

entre le roi et le parlement. De L'Obel qui, peu d'annces auparavant, avait déploré, comme nous l'avons vu, en termes si énergiques, les malheurs politiques et religieux de sa patrie, était allé se précipiter dans un gouffre nouveau. C'est dans ces circonstances critiques que lui, catholique et belge, fut choisi par le roi comme botaniste royal, titre que n'eurent point ses contemporains nationaux, et gni n'excita de leur part ni plainte, ni récrimination : ce silence est un hommage éloquent à sa gloire, puisqu'il ratifie la justice que sa réputation lui avait acquise.

A partir de cette époque et depuis cette nomination, de L'Obel, âgé alors de 68 ans, se repose. Pulteney pense qu’ayant marié sa fille à Jacques Coel, qui demeurait à Highgate, près de Londres, Mathias de L'Obel alla vivre avec son gendre. Il y mit la dernière main à un manuscrit sur les plantes alors inédites, et à leur propos, il mentionne souvent son jardin de Highgate. Ce manuscrit fut publié en 1655, trente-neuf ans après la mort de son auteur, par Guillaume Ilow, sous le titre de : Stirpium illustrationes, plurimas elaborantes ineditas plantas, Joannis Parkinsonii rapsodiis sparsim gravalae. London, 16005 , in- $4^{\circ}$.

En 1616, le 5 mars, mourut Mathias de L'Obel, âgé de soixante-dix-huit ans, ayant accompli une vie d'agitation et de labeurs, pleine d'études et de méditations qui eussent exigé du calme et qui furent accomplies cependant au milieu des malheurs de la guerre et des dissensions civiles et religieuses, exemple mémorable de l'indépendance que peut acquérir l'esprit et de la hauteur où peut se placer l'intelligence au-dessus des intérêts matériels de la vie commune.

Pulteney finit la vie de L'Obel en parlant de son portrait : il le dit très-rare, et l'historien de la botanique 


\section{( xxiij )}

anglaise ne l'avait vu qu'une senle fois dans la collection de gravures de M. Gulston. Nous avons été plus heureux. Parlant un jour de la rareté de ce portrait, qu'on ne trouve pas, en effet, en tête des œuvres du botaniste de Lille, au respectable et savant M. Treviranus, professeur de botanique à Bonn, il se trouva que ce portrait avait été conservé dans la famille de madlame Treviranus, une des descendantes du célèbre Rivinus. Notre honorable collègue de Bonin nous a confié ce portrait que nous avons dessiné avec tout le soin dont nous sommes capable, et nous venons de le faire graver sur bois pour en orner la présente publication. Désormais, ce portrait permettra de représenter de L'Obel, comme il était, avec sa large tête, son front ample et pur, ses yeux d'observateur doux et perçants à la fois, sa barbe grave et digne, coupée carrément, comme l'était le caractère de cet homme antique de mœurs et de langage. Il y a loin de ce portrait au buste qu'on voit à Gand, au Jardin botanique, buste donné naguère par Van Hulthem et fait de fantaisie. Sur l'original, dessiné el gravé par François Dellarame, on lit en tête du portrait : Praesentem monstrat quaelibet herba Deum ; autour de la tête celte inscription : Matheas de L'Obel, medicus et bolanographus Insulensis anno reparatae salutis 1615 actatis 76 . Cette date prouve d'ahord que le portrait a été fait un an avant la mort de de L'Obel, et ensuite que sa naissance devrait être rapportée à 1559 et non à 1558 , comme le disent tous ses biographes. L'erreur étant possible des deux còtés, nous avons suivi la date généralement adoptée.

De L'Obel fit placer sur son portrait, d'un côté, les armoiries de sa famille, une fleur de lis d'argent sur champ d'azur, et de l'autre un écusson que nous prenons 


\section{( xxiv)}

volontiers pour des armes parlantes : c'est un jardinier plantant deux arbres. Sous le portrait se lisent les épigraphes Candore et Spe, mots placés sous un chérubin, et plus loin :

\section{Melius a limpidissimis fontium scaturiginibus Haurire quam turbidos confectari rivulos.}

JuL.

Ce qui indique clairement que, dans les eaux troubles de son époque, de L'Obel ne pêcha ni sa fortune ni son existence, mais qu'il fit l'une et entretint l'autre des œuvres de sa haute intelligence. Il n'était ni le savant flatteur des pouvoirs, ni l'intrigant politique faisant de son savoir un marchepied, et sa réputation dérivait de source pure, la science placée au-dessus de la puissance des hommes et à Dieu seul soumise : Deus scientiarum dominus est.

Je ne sache pas que le mérite principal de de L'Obel comme botaniste ait jamais été mieux précisé que par $\mathrm{Cu}$ vier. Son jugement, quoique de même nature que celui de Sprengel, embrasse les choses de plus haut et dans une appréciation philosophique; cette hauteur même est une qualité. «On aperçoit dans les ouvrages de de L'Obel, dit Cuvier, le sentiment des familles naturelles; plusieurs même y sont assez bien distribuées : ainsi les gramens, les orchis, les palmiers, les mousses y sont déjà séparés et caractérisés à peu près comme ils le furent plus tard dans les ouvrages modernes. Les labiées, les personnées, les ombellifères y sont aussi rapprochées les unes des autres, mais beaucoup d'autres plantes sont encore pêle-mêle. Toutefois, le désordre y est beaucoup moindre que dans les ouvrages antérieurs, et l'on y voit clairement un certain progrès. Il est surtout remarquable que chaque section 
soit précédée d'un tableau synoptique des divisions des plantes. Ces divisions, quoique encore mal faites, pourraient conduire à la détermination des espèces et des genres. Entin, c'est dans de L'Obel qu'on trouve pour la première fois la distinction tranchée des plantes monocotylédones et des plantes dicotylédones. Cette séparation est aujourd'hui fondamentale en botanique et y tient le même rang qu'en zoologie la division des animaux en vertébrés et en non vertébrés. 》

Ce jugement est un magnitique éloge, et la bouche qui le prononça est certes compétente. La Belgique peut donc s'enorgueillir de posséder dans son panthéon national le précurseur de Jussieu, et proclamer que c'est en flamand qu'ont été jetés les premiers fondements de la méthod, naturelle. Les sciences de la nature sont des sciences toutes françaises, nos voisins du Midi ne cessent de nous le dire eux-mêmes dans chacune de leurs œuvres historiques : nous ne voyons aucun obstacle à cette prétention, du moment que, documents à la main, on veut y reconnaître un mélange de ce vieux sang de belge qui enfanta dans sa chaleur native ces gracieux contours de Van Dyck et ces brûlantes couleurs de Rubens. Si l'histoire des arts ne peut ensevelir dans l'oubli les phases glorieuses de notre école, l'histoire des sciences ne peut pas plus, sans cesser d'être juste, méconnaître l'influence et la gloire de nos artistes de la pensée. 



\section{LE GLOBE, LE TEMPS ET LA VIE,}

OU DISCOURS SUR LES PILÉNOMÈNES PÉRIODIQUES AIJXQUELS LA

PHYSIOLOGIE DE LA TERRE EST SOUMISE;

PAIR

Chjarles Alorren,

Sembre de l'Aeadémie royale de Belgique.

Flores appuruerunt in terra nostra, tempus putationis advenit: co. turluris audita est in terra nostra; ficus protulil grossos suos: cineae forentes dederun odorem suum. Surge, anima mea, speciosu neu el veni.

Lcs fleurs ont apparu sur notre terre, le temps de la taille est arrive: la voix de la tourterelle s'est fait entendre; le figuier a poussé ses fruits; les vignes en dicur ont répandu leur parfum. Lève-toi, mon amie, leve-toi, ma bien-aimce, je suis venu.

(Saloxox, Cantique des Cantiques, chapitre 11, verset 12.)

\section{Messieurs,}

Mes honorables confrères de la classe des sciences ont désiré que je prisse la parole dans cette circonstance solennelle. Je pourrais leur dire avec plus de raisons que n'en avait Buffon, en parlant à l'Académie française : "Je n'ai, Messieurs, à vous offrir que votre propre bien. » En effet, si, de l'assentiment de la Compagnic, j’ai à vous retracer quelques idées sur le magnifique spectacle que nous présente la nature dans la manifestation des phénomènes soumis à la périodicité, je ne fais que prendre sur moi de dérouler à vos yeux une suite de longs et patients travaux, dus en grande partie à l'infatigable activité, à la consciencieuse précision, aux lumières aussi variées que fécondes de plusieurs de nos collègues. Ma position, devant vous, a le droit de réclamer d'autant plus votre bienveillance que le restaurateur des idées des grands maîtres de la 
science, le rénovateur d'un vaste système d'observations importantes, partage, en ce moment, la présidence de notre assemblée. Il eût bien mieux que moi embrassé ce vaste cadre, et fait jaillir de la comparaison de ses travaux avec ceux de ses prédécesseurs des pensées originales, ingénieuses et surtout utiles; il eût fécondé ce sujet au profit de l'intérêt public, de la gloire de sa patrie et de la renommée de l'époque. Ce système, il l'avait conçu depuis longtemps : qui mieux que lui eût pu nous en offrir un rapide exposé? S'il a voulu me voir remplir ici une partie de sa mission, c'est qu'il a désiré attirer sur un de ses amis et de ses anciens élèves, une part de la considération dont ses travaux sont entourés chez nous et à l'étranger, et m'associer ainsi à la propagation d'un ordre d'idées qui font l'objet de sa constante sollicitude.

Mon anxiété redouble quand je vois ici des interprètes si instruits de la science des Buffon et des Cuvier, interprètes qui eussent pu, avec un succès auquel il m'est défendu d'aspirer, vous présenter la fidèle et éloquente peinture des harmonies qui lient entre eux, à des temps déterminés, ces innombrables êtres animés donnant à la nature sa vie et sa puissance; quand j'entrevois à mes côtés ces continuateurs du savoir des Linné et des De Candolle qui pourraient, dans un style digne des merveilles de la création, vous développer le tableau si coloré des végétations fleuries, prodiguant dans clıque saison à notre globe ses ornements et sa pompe. Chacun de mes honorables confrères est venu apporter à l'édifice que la classe des sciences élève aux connaissances exactes, depuis près de quinze ans, des matériaux savamment élaborés; chacun eût pu vous lire, sur ses méditations et ses veilles, des aperçus du plus saisissant intérêt, et je dois regretter, pour vous comme pour moi, de ne pouvoir, en cette circonstance, applaudir 
ì des paroles qui, mieux que les miennes, eussent retracé, avec vérité, cette phase du spectacle de l'univers.

La terre parcourt dans l'espace sa route silencieuse et tracée par les lois de l'attraction. Son orbite est régulière, sans doute depuis l'origine des temps; elle force notre globe à revenir précisément à la même place où il se trouvait à l'heure correspondante dans son cycle précédent. Ainsi, tout est réglé divinement, et dans la rotation du globe sur lui-ıême et dans sa trajectoire autour du soleil. La fixité de la mécanique céleste ne frappe plus l'attention de nos populations adverses aux sciences, les penseurs seuls se préoccupent de ces admirables et providentielles combinaisons, et le monde marche bien aux yeux de tant de gens, parce que l'almanach le dit ainsi. Dans le peuple, on ne va pas, on ne pense pas plus loin.

Mais, pendant que s'accomplit ainsi la marche annuelle de la terre autour du soleil, les saisons se suivent, pour l'astronome, avec une régularité et une constance semblables à celles du mouvement qui les fait naître, pour le commun des hommes, avec une irrégularité et une inconstance qui font l'objet de quotidiennes préoccupations. On interroge la couleur du crépuscule, on s'inquiète de quelques nuages qui sillonnent les airs, on s'adresse à la fumée de l'âtre, aux galeries des fourmis, aux chants du coq pour savoir si, le lendemain, le temps sera celui de la veille, si l'hiver doit être rigoureux, l'été chand ou froid, le printemps sec ou humide. Que d'absurdités écrites, mille fois imprimées, mille fois combattues par l'expérience et la raison et sans cesse reproduites, parce que rien n'intéresse plus les petites ou les grandes actions de notre vie que ces variations de l'état de l'atmosphère où elles se passent. Qui ne se rappelle le soleil d'Austerlitz et les nuages qui paralysaient Manuel dans ses foudroyants dis- 


\section{(4)}

cours? Il y aurait un livre curieux à écrire de l'influence du plus ou moins de vapeur dans l'air sur les événements politiques, sociaux et littéraires.

Ainsi, l'homme est en présence, d'un côté, de changements immuables, fixes et réglés par un imperturbable retour; de l'autre, de changements imprévus (on le croil du moins), instables (ils apparaissent tels), échappant, diraiton, à cet instinct anxieux de notre espèce qui tend à tout catégoriser, limiter et prévoir. Or, tandis que les saisons reviennent, il se passe sur notre globe une série de phénomènes dont l'apparition est connue, qu'on a, de ci et de là, examinés isolément, mais dont les lois de retour ont échappé jusqu’à présent aux sciences si rigoureuses de l'observation. Non-seulement, l'Académie s'est occupée de la recherche de ces lois, mais elle a pris à tâche de faire découvrir encore celles de la coordination, de la dépendance et de la corrélation de ces différents phénomènes. C'est à la conquête de toutes ces inconnues qu'elle marche résolument, et nous avons l'espoir fondé de la voir atteindre à son but.

L'histoire du développement et des progrès des seiences nous prouve que, dans les pays de deuxième ou troisième ordre, privés de grandes et riches capitales qui seules peuvent offrir les ressources si dispendieuses d'une haute et profonde instruction, les travaux scientifiques se bornent à des découvertes partielles, à des avancements restreints, laboricusement et patiemment conquis. Ce sont des monographies, des spécialités, des additions, des corrections d'idées ou de faits. Trop souvent encore, chez les peuples resserrés dans un territoire de peu d'étendue, mais caractérisés par un grand amour national, l'activité littéraire ou scientifique ne s'occupe guère que de ce qui est cher à cette nation. Son sol, son histoire, sa littérature, ses arts, 


\section{(}

son industrie, son commerce, son agriculture, son climal, sa faune, sa flore, voilà la circonscription où s'agitent les débats et se poursuivent les recherches. Je ne blâme pas cette tendance, car elle est digne de respect; je ne fais que la signaler, et à ce signalement vous avez tous reconnu notre Belgique, dont l'histoire, en ce qui regarde les sciences, les lettres et les arts, vous est si bien connue. Mais lorsque la Belgique fut admise dans la grande famille européenne, que ses lois, la sagesse de ses peuples et du Roi qui les gouverne, eurent donné à ce pays le rang qu'il méritait d'occuper dans l'estime de l'Europe, le reflet de cette grandeur se fit entrevoir aussi dans le progrès de ses travaux scientifiques. On a pu le pressentir : quand il s'agissait de découvrir des lois inaperçues jusqu’à cette heure, lois qui s'appliquaient au globe terrestre tout entier; quand il fallut embrasser une étude véritablement cosmique dans toute son étendue, l'Académie royale des sciences secoua les langes qui la tenaient trop serrée sur le sein de sa mère, elle leva la tête en fille émancipée et fit un appel à toutes les nations de l'Europe, de l'Amérique et même de l'Asie. Sa voix fut entendue et de toutes les parties du monde civilisé partirent des accents de sympathie et de confraternité qui permirent, enfin, à la vieille institution de Marie-Thérèse d'étendre ses travaux, non plus sur un petit coin de terre, trop souvent morcelé, mais sur le globe terrestre tout entier.

Qu'on promène dans les capitales de l'Europe les chefsd'œuvre de notre peinture et de notre sculpture, nous y applandissons; que nos artistes aillent de leur talent charmer les sens des populations les plus délicates et les plus impressionnables de notre époque, notre fierté nationale s'en enorgueillit; mais qu'il nous soit permis de le dire aussi, à ceux surtout qui ne rendent pas justice aux sa- 


\section{(6)}

vants leurs compatriotes, la renommée scientifique de la Belgique ne s'arrête pas aux boulevards de Bruxelles, ni à la ligne de nos douanes; clle aussi a su faire estimer, respecter et aimer dans l'Europe entière les travaux que nos frères ont fournis au monde de la pensée, à l'égal de ceux que d'autres Belges ont produits dans le monde des arts. Nous devons en grande partie ces honorables succès à la vaste association qui s'est fondée pour observer les phénomènes de la nature, ramenés annuellement devant nos regards par la périodicité des saisons, association immense dont l'Académie de Bruxelles a donné l'initiative et est devenue le centre. Il y aurait une faiblesse coupable à vous cacher ce résultat, car s'il récompense les labeurs de nos confrères, il devient honorable pour toute la famille belge.

Vous parler des phénomènes périodiques, c'est donc encore entretenir chez vous cet amour de la patrie dont, depuis deux ans surtout, nous sommes si heureux de pouvoir donner des preuves. C'est appeler, par cela seul, une attention toute spéciale de votre part vers cet ordre de recherches.

Observer les phénomènes périodiques, c'est s'attacher à connaître à quel jour, à quelle heure tout ce qui a vie sur cette terre, éelôt à l'existence, comment et quand grandissent et se développent les êtres, comment, pourquoi et quand ils s'épanouissent dans tous leurs organes, à quel moment et par quelle influence le feu de l'amour s'empare d'eux et de leur postérité naissante, d'après quelles règles se fait leur succession et quelle est l'heure fatale de leur dépérissement, de leur mort, de leur disparition. Là, ne s'arrête pas encore ce champ déjà si vaste de recherches, car il faut découvrir, après avoir traduit tous ces faits en lois et axiomes, par quels rapports ces phénomènes se lient entre eux. La nature est pleine d'harmonies. Aree 
l'apparition d'un être coincide la venue d'un autre : l'arrivée de l'hirondelle est annoncée par les jeunes thyrses des lilas; les lucioles, ces lanternes volantes dont Pline nous a déja retracé l'histoire, viennent étinceler dans les airs quand le faucheur doit dépouiller la prairie de son foin; mille rapprochements de ce genre doivent pouvoir se déduire de l'étude comparative de ces faits, et de cette manière d'envisager cet ensemble, découlent une foule de déductions dont le commerce, pour la question des denrées alimentaires, le négoce, dans ses spéculations, l'agriculture et le jardinage, dans leurs importants travaux, l'hygiène publique ou la médecine, dans leurs impérieuses observations, doivent immanquablement savoir tirer des avantages nombreux. Après tous ces faits, ces comparaisons et ces déductions, il faut encore rechercher de quelle manière ces naissances, ces migrations, ces développements, ces reproductions et ces dépérissements de tous les êtres organisés coincident avec les phénomènes du climat, avec ces états d'une atmosphère si variable, avec ces agents impondérables, tels que la chaleur, la lumière, l'électricité, qui exercent sur toutes les existences une si mystérieuse et si énergique influence. Ici, le monde animé est mis ell rapport avec le monde inanimé, et c'est précisément dans la connaissance de l'action de l'un sur l'autre que j'aurai à signaler à votre attention une des plus belles découvertes que les travaux sur les phénomènes périodiques, entrepris par l'Académie, permettent d'inscrire dans notre histoire nationale des sciences.

De ces différentes manières d'envisager le problème découlent une série de lois naturelles qui se rattachent, par des rapports intimes, à ce qu'on est en droit d'appeler la physiologie du globe. C'est en réalité une science particulière, ayant pour but de connaitre la manifestation de la vie 
réglée par le temps, c'est la phénologie (1). La géologie abandonne le globe du moment qu'elle en a étudié la formation et l'état actuel, alors il tombe dans le domaine de la météorologie, qui examine comment les météores de toute espèce se comportent dans cette fine pellicule d'air qu'on appelle l'atmosphère; la botanique s'empare de la végétation de la surface de la terre, la zoologie étudie les races animales qui peuplent les airs, le sol et les eaux, l'anthropologie prend pour sujet l'homme, ce dernier terme de la création; une science générale, la physiologie, domine ces connaissances de l'homme, des animaux et des plantes : cette science est celle de la vie. Mais on le voit à l'instant, une lacune existe dans ces connaissances, c'est la science des rapports de la vie avec le globe lui-même, c'est la connaissance de ces rapports soumis à l'action des temps dont ils sont inséparables. Ainsi, trois éléments sont en relation constante : le globe, la vie et le temps. La science nouvelle, dont il s'agit, mérite donc un nom particulier; le nom de phénologie, exprimant la science des phénomènes qui se manifestent successivement sur la surface du globe,

(1) Фaivs $\mu x ı$, apparaitre, se manifester : phénologie, la science des phénomènes qui apparaissent successivement sur le globe. Considérée dans son ensemble, cette branche de connaissances humaines embrasse les êtres des deux règnes. Du moment que le temps devient l'élément selon lequel les phénomènes se coordonnent, sans en dépendre essentiellement, la phénologie se

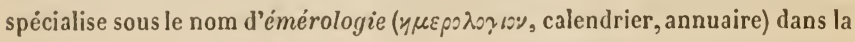
science des annuaires ou calendriers en tant que nalurels. Les rapports des calendriers de la nature avec les calendriers civils, religieux et technologiques n'en doivent pas moins être étudiés, afin de donner aux premiers toute leur utilité. Quand la phénologgie s'occupe de tracer sur les globes des lignes et les zones des floraisons, des migrations d'animaux, clle donne lieu à l'odologie (odò, chemin, direction que ces phénomènes parcourent). Cette partie se rat- 
rend bien cette idée. Ce n'est ni de la géologie, ni de la physiologie, ni de la chronologie, c'est un nouveau point de vue, une nouvelle direction désignée à l'activité de l'esprit.

Lorsque je dis que cet ordre de connaissances est nouveau, je prends l'état des choses comme le font l'ensemble des travaux actuels et la manière d'y procéder. Nais il est bien rare qu'une idée quelconque ne repose en germe dans les temps antérieurs. L'histoire de l'intelligence humaine dévoile presque toujours que les sciences se développent comme l'homme lui-même : elles ont leur état embryonnaire, leur enfance, leur virilité et leur âge mûr. L'astrologie précéda l'astronomie, les systèmes cosmogoniques pullulèrent avant que la géologie ne naquit, l'alchimie, cette science du faux et de l'absurde, prépara l'enfantement de la chimie, cette science qui convertit un creuset en une corne d'abondance.

Les mêmes précédents s'appliquent à la branche de connaissances humaines dont nous parlons. On peut même, remontant très-haut dans l'histoire, y retrouver des idées analogues à celles qui nous occupent en ce moment (1).

tache de près à la géographie hotanique ou zoologique. Enfin, la phénologie s'occupe encore de la connaissance des courbes de la végétation considérée dans ses différentes phases ou des propriétés physiologiques, comme les couleurs, les odeurs, etc., courbes représentatives des flores, des faunes, etc. J'examinerai bientôt cette partie dans ses applications à la Belģique.

(1) J'ai retracé cette marche listorique avec quelques détails depuis janvier 1848 jusqu'en décembre 1849, dans chaque livraison des Annales de la Société royale d'agriculture et de botanigue de Gand. Cependant le eadre et la spécialité de cet ouvrage ne permettent pas l'y poursuivre cette étude dans toute son étendue. Je l'ai appliquée là principalement à l'horticulture ct à l'agriculture. M. Quctelet m'a fortement engagé à revenir sur cet exposé 
La symbolique des Grees cachait sous le culte des idoles l'étude de la nature. Creutzer, Hug, Damm, Dierbach ont prouvé que, dans le pranthéisme mythologique, la vie était représentée par Jupiter, les circonstances météorologiques de l'atmosphère par Junon, l'influence du vent sur les fleurs par le mariage de Zéphyre et de Flore, la température terrestre par Cybèle et Pluton, l'hygroscopicité et la reproduction par Vénus et ses Nymphes, les éclosions des fleurs par Thallo, les saisons par ses sœurs, les Heures, la lumière vivifiante par Apollon, l'obscurité, sans laquelle il n'y aurait pas de végétation possible, par Diane. Le Déméter des Grecs ou la Cérès des Romains, représentait la maturation des fruits et le retour de ce phénomène en automne. Les graines sortent des fruits : Cérès eut pour fille Proserpine. La chaleur de la terre féconde les graines et les fait germer. Pluton, la chaleur du globe, enlève Proserpine, la graine du fruit: Proserpine devient la déesse de la germination des graines. Partout le mythe, bien entrevu, bien étudié, nous retrace que les anciens avaient mûrement réfléchi sur le retour et la constance des phénomènes périodiques : ils voyaient des dieux où nous voyons du calorique, de la lumière, de la vapeur, etc. La grande différence entre eux et nous, c'est que les savants de cette époque voilaient la vérité et que nous, nous la proclamons à la face de tous.

Dans les temps homériques, nous voyons Hippocrate et Hésiode s'occuper du retour des phénomènes vitaux de la

historique et à y joindre toutes les preures. Je pense aussi que la phénologie en tirerait de très-utiles inductions. Au premier moment, je ne dirai pas de loisir, ce mol n’a plus de réalité pour moi, mais de répit, je donnerai suite au désir de M. Quetelet. 
nature. Qu'Hésiode soit né avant ou après Homère, notre sujet s'en inquiète peu, mais il s'intéresse particulièrement à trouver dans l'ouvrage d'Hésiode, les Travaux el les Journécs, les preuves irréfragables que les opérations agricoles étaient déjà réglées par la périodicité des actions naturelles. On tiouve dans Hésiode des corrélations entre les phénomènes aussi bien établies qu'on pourrait les indiquer aujourd'hui.

Dans l'école péripatéticienne, Théophraste annote si exactement les dates des floraisons d'un grand nombre de plantes, qu'un savant du XVIII ${ }^{e}$ siècle, Stillingfleet, est parvenu, par les données du philosophe grec, à rédiger un calendrier de Flore pour le climat d'Athènes et l'époque l'Aristote. Il s'est trouvé, par suite de ces travaux de Théophraste, qu'on peut savoir exactement si deux mille ans après l'existence de ce naturaliste, le climat de la Grèce a changé et si la végétation a éprouvé quelque mutation. Deux mille ans ne sont rien dans les époques de la nature, mais deux mille ans sont beaucoup dans l'histoire de l'humanité.

Pline et Virgile n'ont pu rester insensibles devant la singularité des phénomènes périodiques. Virgile a posé le principe général : stat sua quemque Dies. Salomon, avant le poëte latin s'écriait : Omnia tempus habent et suis spatiis transeunt universa sub cœlo : toutes choses ont leur temps et tout passe sous le ciel après le terme qui lui a été prescrit. (Eccl., ch. 5). Cette pensée gisait dans tous les esprits, mais Virgile en tire de lumineuses inductions pour réglementer le travail des champs. Pline, dans sa bonne foi de compilateur, s'intéresse surtout aux migrations des oiseaux. On ne savait pas alors où se rendaient ces habitants de l'air dans leurs mystéricux voyages. L'almosphère, le ciel, 
comme on le désigne, a passé chez tous les peuples pour le séjour des divinités, des bienheureux : on a nommé les étoiles du nom des héros immortalisés. Les oiseaux semblaient donc naturellement habiter l'Olympe et recevoir les confidences des dieux. De là, l'aigle de Jupiter, les augures tirés du vol des oiseaux, et, par conséquent, une grande attention fixée sur les époques de leurs migrations, Le sommeil périodique des plantes, la feuillaison, la floraison, la maturation des fruits, le semis des graines, toutes ces questions du plus haut intérêt occupent tour à tour le naturaliste rumain.

Dans le $V^{e}$ siècle, nous voyons l'agronome Palladius décrire toute l'agriculture de son temps en la divisant d'après les douze mois de l'année. Ainsi, quatorze siècles, avant Mathieu De Dombasle, l'annuaire du cultivateur reposait déjà sur la périodicité des phénomènes naturels.

" Je viens de trouver un trésor pour la climatologie, écrivait le membre de l'Institut de France, M. Dureau de la Malle, à l'Académie des sciences de Bruxelles (le 13 décembre 1848). C'est un calendrier rural, médical, astronomique, composé en 861 pour le deuxième calife de Cordoue, Nakem-Ilostanser-Bellam, par l'évêque Aril, fils de Zéab...... Ce traité, plein de faits, d'observations curieuses sur les phénomènes périodiques annuels de la végétation, sur les migrations des oiseaux, des poissons, pour l'Espagne et le territoire de Cordone, est un registre précieux de l'état des sciences pliysiques et mathématiques chez les Arabes et les chrétiens espagnols, soumis à leurs vainqueurs au $I X^{\circ}$ siècle. Il est presque aussi détaillé que le registre d'observations faites par Vassali-Eandi et Bonelli, de 1809 à 1812, et dont je ne connais qu'un seul exemplaire a Paris, qui sort de la bibliothèque de Georges Cuvier. » 
Les sagas, ces livres historiques des peuples du Nord, abondent en remarques précieuses pour la climatologie, l'agriculture et les sciences d'observation : la périodicité règle leurs recherches. Voyez le bracelet d'Ingebory : les faits relatifs aux plantes, aux oiseaux, aux poissons, aux travaux du jardinage et des champs, ne viennent pas seulement se placer dans l'ordre des temps, mais ils donnent à ces temps eux-mêmes leurs désignations et leurs usages. Aussi, on y trouve le mois des oufs, le mois du beurre, le mois des abeilles, le mois des poules. De même chaque semaine et chaque mois obtient aussi sa représentation et son travail : telles sont la semaine des haies, la semaine des branches, la semaine des houes, celles des navets, de la fécondation des épis de blés, de la formation des glands, etc. La poésie des peuples soumis à Saga, la déesse de l'histoire, emprunte à ces données des sciences naturelles du gìobe, des épisodes où la grâce est à la hauteur de la vérité.

"Que voulez-vous que sache un moine? ignorantia in monacho saltem excusanda, "s'écriait l'historien de la botanique, Curtius Sprengel, quand il examinait le Monastica res herbaria. N'en déplaise à Curtius Sprengel et à ceux qui ont aveuglément suivi sa doctrine et ses livres, il y avait des moines fort savants. Les cloîtres s'établissaient dans des lieux sauvages quỉl fallait livrer à la culture. La paix du monastère, les travaux réguliers et prescrits, une vie où chaque minute appelle une œuvre ordonnée, devaient naturellement amener l'esprit de ces religieux vers l'ordre dont la nature elle-même donne l'exemple. La pauvreté de ces institutions faisait apporter sur les autels les lleurs des champs et des jardins comme des hommages dignes de Celui qui les avait fait éclore. Le pa- 
ganisme s'était écroulé; chaque jour de l'année se plaçait sous l'invocation d'un martyr, d'un confesseur de la foi, d'un législateur que l'Église élevait au rang des saints. La mémoire de ces noms illustres revenait aussi fixément que l'éclosion des fleurs, et e'est de cette époque que datent ces calendriers, où chaque saint trouve une fleur qui porte son nom. Ces légendes comportent donc le retour des phénomènes périodiques de la végétation, parmi leurs sources essentielles et, du langage des fleurs, tel qu'on nous le donne aujourd'hui dans toute sa fadeur, à la poésie touchante de ces calendriers du moyen âge, la distance est grande.

La poésie trouve, en effet, à puiser à pleines mains dans la succession non interrompue de ces êtres vivants sur la surface du globe. Au XVII ${ }^{\text {e }}$ siècle, le poëte Jacques Cats s'empare de cet ordre d'idées, et dans ses chants sur la vie champêtre, l'imagination la plus riante et la plus fertile se plaît à trouver les plus ingénieux rapports entre les opérations de la nature et les travaux de l'art rural.

Arrive enfin l'époque linnéenne. Il était impossible que Linné, avec sa verve, son imagination abondante, sa pensée pleine d'érudition et son style aussi pur qu'énergique, laissât dans l'oubli \& les joies de l'année; » car c'est ainsi qu'il nomme et définit d'un trait les phénomènes périodiques de la végétation. Linné va droit au but. Pline avait dit qu'une plante dormait; Linné en examine des centaines, et il inventele sommeil des plantes. On savait avant lui que certaines fleurs s'ouvraient à certaines heures du jour, le professeur d'Upsal crée une horloge de Flore. Flore était son Égérie, sa fée, son Elvire, il fallait bien lui donner, au jour de l'an, son annuaire. Linné n'avait que faire des noms de saints, auxquels il ne croyait pas, 


\section{(10)}

ni des travaux agricoles auxquels il ne se livrait guère, mais il était enthousiaste des fleurs, il compose donc pour sa Flore bien-aimée le calendrier qui porte son nom, admirable conception que nous ne faisons encore aujourd'hui qu’augmenter et suivre. L'astronome a catalogué sesétoiles, disait l'illustre savant de Suède, et de leur coïncidence sur nos têtes avec le soleil, il fait les mois. Les fleurs sont les étoiles de la terre, le botaniste les inventorie aussi, elles aussi s'ouvrent à la surface du globe dans un ordre constant. Pourquoi ne serviraient-elles donc pas à nous indiquer le temps et sa mesure. Cette idée est aussi gracieuse que vraie.

Linné ne voulut pas des noms des mois dédiés à des dieux de l'Olympe, alors que les dieux en sont déchus. Il divise les mois en ceux de la gelée, du dégel, de la germination, de la feuillaison, de la floraison, des fruits, de la moisson, etc. Il prend l'année pour un homme, janvier en est l'œuf, février l'embryon, mars l'enfance, avril la puberté, mai l'adolescence, juin la jeunesse, juillet la virilité, août l'âge mûr, septembre l'âge de retour, octobre la vieillesse, novembre la décrépitude et décembre la mort. Il donne à chaque mois sa couleur, comme s'il avait contemplé à distance le globe ceint de sa large bande de végétation, et qu'il l'avait vu se diaprer de teintes différentes à mesure qu'il se rapproche ou s'éloigne du soleil. Chaque travail d'agriculture est indiqué, à son temps voulu, par une fleur qui s'ouvre à son époque fixe ou par un grand phénomène de la vie du globe qui frappe les regards; de sorte que l’idée de Linné conduirait, comme celle de Charlemagne, à construire dans chaque village, autour de la maison communale, par exemple, un jardin indicateur des travaux des champs, non plus d'après des usages arbitraires 
et souvent funestes dans leur résultat, mais d'après les lois même d'une nature qui ne se trompe jamais. Ce grand naturaliste formula la dernière expression de son système, en 1730 , il y a précisément un siècle.

L'exemple de Linné ne pouvait rester stérile. BenjaminStillingfleet, naturaliste, poëte et musicien anglais, publia, dès 1762, un calendrier de Flore qu'il venait de composer pour l'Angleterre : il eut le bon esprit d'observer surtout les plantes indigènes et spontanées, et il tira de ces recherches les déductions les plus utiles pour l'économie rurale, l'agriculture et l'art du forestier.

De 1727 à 1806 vécut un des savants les plus originaux que puisse citer l'histoire, Michel Adanson. Il était contemporain de Buffon et il imagina de réformer la langue française tout entière en l'écrivant comme on la prononce. Il vivait en même temps que Linné et Jussieu, et pour narguer les classifications, il en composa soixantecinq. Il connut Réaumur, le modèle des observateurs consciencieux de la nature, et, se passant des recherches directes pour faire avancer la science, il empila soixante et quinze mille figures d'histoire naturelle, de physique, de choses relatives aux sciences morales et intellectuelles, sur lesquelles il écrivit des idées dans cent vingt volumes qui, heureusement pour nous, n'ont pas paru. Adanson eut donc de grandes imperfections, et cependant Cuvier le plaça avec raison parmi les hommes de génie. La nature, dans ses manifestations de la vie, le préoccupa aussi. Ce fut lui qui ramena le premier les phénomènes périodiques à la météorologie et tâcha d'expliquer la raison intime pour laquelle les plantes portent feuille, fleur ou fruit à des époques moyennes fixes. Il regarda la chaleur comme l'agent principal de la végétation, et pour exprimer le ca- 


\section{(17)}

lorique nécessaire à chaque plante pour se feuiller, fleurir ou fructifier, il additionnait, à partir du $\mathbf{1}^{\text {er }}$ janvier, les degrés de chaleur moyenne de chaque jour, sous l'influence desquels la plante s'était trouvée. Adanson, qui aimait tant à critiquer ses émules, fut tellement aveuglé sur le compte de sa propre théorie, qu'il oublia la chose la plus simple du monde, à savoir qu'il n'existe un $\mathbf{1}^{\text {er }}$ janvier que dans l'almanach et pour les amateurs d'étrennes, mais que, dans la nature, le $\mathbf{4}^{\mathrm{er}}$ janvier et les étrennes seraient difficiles à trouver. De tous les sens de l'homme, disait un satirique, le plus rare à trouver est le bon sens. Adanson nous en fournit une preuve, quoiqu'il fùt un savant remarquable.

En France, Réaumur et le père Cotte s'occupèrent aussi d'annoter les phénomènes périodiques de la végétation et de les mettre en regard avec la température. En Bohême, Haenlie et Jirasek, en 1787, appliquent ces études à la floraison des plantes spontanées. La Palestine et l'Égypte sont elles-mêmes soumises à des observations analogues par Buhle, Walch et Nordmeyer, tandis qu'un contemporain de Linné, le pasteur Bjerkander, écrivait, en 1777, le thermomètre de Flore et, en $\mathbf{1 7 8 2}$, l'hygromètre de Flore indiquant les degrés de chaleur et d'humidité nécessaires pour que des plantes désignées pussent croître, prospérer et fleurir.

Il eùt été extraordinaire que, dans cette suite de travaux entrepris sur la physiologie du globe terrestre, on n'eût prêté quelque part à une exagération irréalisable. Un des hommes les plus savants du commencement de notre siècle y donna lieu. Je veux parler du chevalier de Lamarck. Après avoir servi honorablement dans l'armée, devenu à la suite de glorieuses campagnes, lieutenant des grenadiers, Lamarck fut pris d'une longue et pénible maladie. 
La pénurie de sa fortune le força de se loger sous le toit d'un hôtel. Une lucarne s'ouvrait au-dessus de son lit de douleur. Ses yeux rencontrèrent sans cesse le ciel, ses nuages, ses astres. Lamarck devint météorologue, mais naturaliste avant tout; il fit servir l'étude des météores à la connaissance de la vie des plantes et des animaux; il crut, dans l'abstraction de ses pensées, que l'état météorologique de l'atmosphère était soumis aux lois d'un retour constant; il proposa, à l'exemple de Linné, de Stillingfleet et d'Adanson, un vaste système d'observations simultanées, et il croyait pouvoir arriver, par des données nombreuses, à savoir prédire le temps. Il ne se doutait pas, dans sa bonne foi, que

Prédire à chaque jour la pluie et le beau temps, C'est faire le prophète et se moquer des gens.

Lamarck tit de bonnes observations, il échoua complétement dans ses prédictions, et, désigné pour devenir le précepteur du fils de Buffon, élu membre de l'Institut, il consacra le reste de ses jours à des travaux sérieux qui ont rendu son nom impérissable.

Pendant que les savants préparaient ainsi le fondement de la physiologie du globe, des passions politiques minaient peu à peu les bases de la société. L'édifice social s'écroula. La révolution de 1792 songea à dresser ses échafauds et à faire couler des fleuves de sang. L'autel du Christ fut abattu. On divinisait la raison dans la personne d'un être abject. Les saints furent abolis et le jour du Seigneur remplacé par un décadi. Gilbert Romme, représentant du peuple et rapporteur de la loi du calendrier républicain à la Convention, se fit aider, dans son œuvre impie, d'un savant et d'un littérateur. L'astronome de Lalande, 
qui mangeait des araignées et demandait au pape sil croyait en Dieu, un ancien acteur du théâtre de Bruxelles, bon poëte au fond, Fabre d'Eglantine, ne trouvèrent rien de plus aisé que d'emprunter, sans mot dire, à l'œuvre savante de Linné, un calendrier qui a tout l'air d'être fondé sur l'observation des phénomènes de la nature, mais qui, au fond, n'est qu'une parodie dénaturée de la conception suédoise. Pêle-mêle, au hasard, on plaça les pierres, les plantes, les animaux, les instruments agricoles dans une série quelconque, et ce calendrier, image du désordre, de la bouffonnerie et de l'athéisme, fut imposé aux populations de la République française et des peuples conquis. On ne sait ce qui frappe le plus d'étonnement et de surprise dans cette ouvre, ou du ridicule ou du non-sens. Si l'empire, si la haute raison de Napoléon n'était venue mettre ordre à tant de scandale, nous nous trouverions placés sous de singuliers patronages; ne serions-nous pas étonnés de voir, par exemple, le nom de notre honorable ami et confrère, de celui qui a pris à cœur de revenir aux études sérieuses du calendrier de la nature, placé sous l'invocation du thym de nos gazons brouté avec tant de plaisir par nos races ovines (1)? Moi qui ai l'honneur de vous parler, au lieu de me trouver sous la protection de l'illustre archerêque de Milan, j'aurais pour patron l'endive et pour veille de ma fête le fécond topinambour, dont, par une singulière fatalité, je n’ai cessé de préconiser la culture à l'usage du bétail (2). La science, quand de maladroites

(1) M. Adolplse Quetelet; sa fête patronale tombe le 16 juin, correspondant au 28 prairial, jour consacré au thym.

(2) La fête de saint Charles Borromée arrive le 4 novembre, correspondant all 14 lirumaire, jour de l'endive. La veille cst consacrée au topinambour. 


\section{(20)}

mains s'en emparent, prête à plus d'un abus, et dans l'histoire des phénomènes périodiques, les temps dont je parle ici, sont dignes, tout au plus, de commisération et de pitié. Vous voudrez bien me permettre de ne pas m'y arrêter plus longtemps.

On comprendra facilement comment cette abjecte inspiration dut être reçue en Belgique. A cette époque, nous nous glorifions de trouver un magistrat de la ville de Bruxelles, un bourgmestre, Vanderstegen de Putte, qui seul lutta, et par des armes aussi courageuses que savantes, contre l'œuvre de la Convention. En 1794, ce naturaliste honorable de notre pays publia un calendrier moral dans lequel les saints, les hommes célèbres, les plantes, les animaux, les minéraux et les arts trouvèrent tous leur jour de commémoration, et par un trait piquant, qu'il est permis, sans doute, de signaler, le spirituel magistrat de Bruxelles conserva les décades républicaines, uniquement pour l'almanach des bêtes. Ailleurs, le dimanche était remis à sa place.

Depuis cette époque et successivement, le naturaliste suédois Rosen, l'ancien élève de Linné qui vint apporter en Belgique les doctrines de son maître, $M^{\text {1le }}$ Victorine de Chastenay, dont Châteaubriand vante l'esprit et la grâce dans ses Mémoires d'outre-tombe, le botaniste Philibert, les naturalistes belges Pollart de Canivris et Jean Kickix, Emmanuel Gilibert de Lyon, Madame Lortet en France, le docteur Thomas Forster, habitant Bruges en ce moment, Bigelow, dans les États de New-York, les régents actuels de l'Université des États-Unis, le baron D'HombreFirmas, à Nismes, Charles Kreutzer, à Vienne, etc., ont successivement publié un grand nombre de recherches, qui toutes tendent à ce but de nous faire connaitre d'unc 
manière définitive dans quelle progression marche la nature, quand elle revêt le globe des feuilles de ses forêts, des fleurs de sa flore, et qu'elle anime sa surface des innombrables légions de ses animaux.

Nous voguons à pleine voile dans un océan de faits : il faut des pilotes pour éclairer la route, des phares pour nous faire aborder au port, et je puis le dire avec bonheur, parce que vos cœurs de Belges partageront ma joie, ce port, c'est Bruxelles. Après cette pérégrination à travers les siècles et les peuples, nous sommes revenus chez nous.

Ce que Linné, Stillingfleet, Adanson et Lamarck proposèrent et ne surent accomplir, à savoir la fondation d'une vaste association embrassant sur des points nombreux et très-diversifiés du globe terrestre des observations simultanées, suivies et bien exécutées sur les phénomènes météorologiques, botaniques et zoologiques, la classe des sciences de l'Académie royale de Belgique a osé le proposer et l'a conduit à bien, grâce à l'infatigable activité, au zèle et aux lumières de son secrétaire général et perpétuel. Deux voies lui restaient ouvertes, ou d'observer par lui-même, pendant une série d'années, des êtres nombreux et toujours les mêmes, ou de comparer entre elles des observations transmises par des tiers et venant de lieux multipliés. Il a parcouru ces deux voies avec un égal succès. Le système d'Adanson est tombé! La fleuraison ne se fait pas d'après la somme des températures qui ont agi sur les plantes à partir de leur réveil, après le sommeil hivernal, mais d'après la somme des carrés de ces températures. La chaleur agit donc à la manière des forces vives, et une loi vitale semble participer ici à la nature des forces mécaniques. Il y a, dans ce premier pas, une source de 


\section{( 22$)$}

fécondes découvertes pour l'avenir. Mais quels qu'en soient les résultats, elle restera comme un des faits qui honorent la science belge.

Humboldt traça sur le globe les lignes d'égales températures moyennes et le partagea ainsi en zones isothermiques, dont l'étude est indispensable à ceux qui s'occupent sérieusement de la naturalisation des plantes, objet de si grave importance depuis qu'un lléau, tombé soudainement sur l'Europe, nous est venu prouver que, pas plus que nos aieux, nous ne sommes à l'abri de la disette et de la famine. D’autres météorologues ont tracé également sur le globe des lignes passant par tous les lieux d'égal hiver moyen, ce sont les lignes isochimènes. La botanique est venue prouver que les arbres et les plantes vivaces se distribuent sur la terre dans leur culture selon ces lignes. Enfin, on dessina sur le globe des lignes passant par tous les lieux d'un été moyen égal, ce sont les lignes isothères. Il se trouve que ces lignes indiquent précisément la culture possible des plantes annuelles. Depuis longtemps la géographie des plantes possède des cartes et des mappemondes où sont indiquées les zones occupées sur le globe par les grandes cultures agricoles. Je n'ai pas besoin de faire ressortir ici les conséquences importantes de ces études pour le commerce, la navigation, l'économie forestière, l'agriculture et l'horticulture. Ces applications sautent aux yeux. La science est donc venue formuler en lois fixes ce qui d'abord n'était l'objet que de longs et pénibles tâtonnements, de recherches dirigées au hasard, de voyages à l'aventure. Les travaux de la classe des sciences de l'Académie de Belgique ont fait tracer sur le globe des lignes et des zones non moins importantes et complétement inconnues avant ces recherches. Ce sont les lignes et les zones 


\section{MENORANDUM}

\section{SUR LA VANILLE,}

SON IISTURRE ET SA CULTURE;

PAR

II. CIIARLES MORREN,

Meinbre de l'. Icademic royale de Relgुitue 



\section{MEMORANDUN}

SUR LA VANILLE, SON HiSTOIRE ET SA CULTURE.

(PREMİ̀RE PARTIE.)

- Lorsqu'en 1840, la Belgique venait d'accomplir la $10^{\mathrm{e}}$ année de son indépendance, l'Académie royale des sciences et des belles-lettres décida qu'elle publierait, par l'organe de son secrétaire perpétuel, un rapport décennal sur les travaux auxquels elle s'était livrée pendant cette période. Qu'il me soit perınis de reproduire ici un passage de ce rapport, dont je ne récuse que la partie laudative. a Nous n'avous pu donner que l'indication de quelques-uns des nombreux mémoires que M. Yorren a insérés dans nos recueils; nous ne devons cependant pas passer sous si- 
lence la belle alpplieation de la lécondation des orchidées a la production de la ranille qui, si elle parvient à s'opérer avec lacilité sur une échelle un peu grande, formera une véritable conquète que la science aura faite au prolit de la socićté (1). „ Le vœu de la Compagnie était donc de voir établir la culture du vanillier dans des proportions comparables à celle qui ont fait de l'ananas, renu en Europe, un fruit meilleur que celui du lieu natal. Lorsqu'en 1857, j'eus réussi à produire dans l'ancienne serre, actuellement abattue, du Jardin Botanique de Liége, des fruits de vanille dignes en tout point de rivaliser avec ceux du Mexique, l'idée d'étendre ces essais et d'établir des plantations commercialement productives m’arriva aussi, et je proposai même, dès cette époque, au Gouvernement, un système pour parvenir à ce résultat, la loi sur l'enseignement supérieur interdisant aux professeurs d'exercer une autre profession, à moins d'unc autorisation spéciale du Gouvernement (art. 12). Ce système ne fut pas adopté, el la production de la vanille, dans nos serres d'Europe, resta à l'état de curiosité et de chose intéressante. Cette production, faite seulement sur quelques fruits, se répéta à Gand, à Paris, à Londres, à Hambourg, à Padoue, mais toujours dans des proportions qui, certes, ne pouvaient porter la moindre atteinte au commerce mexicain. Le gouvernement des Pays-Bas fit même acheter, en 1840, un grand nombre de pieds de vanillier disponibles en Belgique; ils furent embarqués à Amsterdam et soumis aux soins d'un horticulteur, nommé Pierot, yui reçut la mission d'établir des

(1) Lictport decennal des tracaux de l'Académie royale de b'ruxelles, depuis 18.50 ; par N. A Quctelel: Bullet. de l'Acad., 1840, tom. VII. 20" partic, p. 315. 


\section{(51)}

cultures réglées de vanillier à Java. Pierot mourut peu de temps après son arrivée aux Indes, et je n’ai pas appris que les plantations y eussent prospéré, encore moins produit un résultat important, comme elles pouvaient en avoir. Devant ces faits et d'autres, on comprend que je tenais à cœur de répondre aux vœux de l'Académie, la première institution savante de mon pays; et vers l'époque où je pouvais prévoir qu'un de mes fils füt capable de me remplacer dans la direction qu'il convenait de donner à une culture établie sur une grande échelle, une vaste vanillière fut annexée à la demeure de la famille. L'expérience a déjà démontré actuellement que la culture en grand de la vanille est possible en Europe; des produits obtenus à Liége sont partis pour le Mexique lui-même et revenus en Europe, pour faire pièce à de ridicules préjugés; ils ont été estimés par des négociants de premier ordre, comme des produits mexicains de qualité supérieure. Le vou de l'Académie s'accomplira annuellement, et le succès de l'entreprise, je l'espère du moins, marchera selon de justes et rationnelles prévisions.

A l'exposition agricole et horticole ouverte par les soins du gouvernement belge, en 1818 , le public a pu voir $1^{\circ}$ la grappe de fruits, qui a été représentée depuis dans les Annales de la Société d'horticulture de Gand, grappe montrant la disposition des fruits, le nombre moven des gousses, leur forme, leur direction, leurs grandeurs diverses, $2^{\circ}$ des gousses parfaitement mùres, séchées, givrées, préparées pour les besoins du commerce, $5^{\circ}$ d'autres gousses mùres et non préparées, $4^{\circ}$ des gousses mûres, fraiches et molles, quelques-unes à moitié mûres, offrant la moitié brune, l'autre verte, quelques autres commençant leur maturité à l'extrémité libre, et enfin $3^{\circ}$ des gousses entièrement verles el yui faisaient dire à des visiteurs incrédules 
que c'étaient là, sans doute, des haricots verts embaumés, par fraude, de quelques gonttes d'essence de vanille. Toutes ces choses avee une branche de feuilles et des gousses ouvertes, pour montrer les graines noires et si nombreuses de la plante, se trouvaient sons un bocal de verre, et si une partie de la presse a condamné ce mode d'exposition qui, disait-on, empêchait les visiteurs de se pâmer au délicieux parfum du premier de nos aromates, je dois déclarer ici, que ce mode a été adopté, parce que, lorsqué les gousses de vanille fraiche sont à mûrir dans un enJroit un peu chaud, l'odeur devient tellement forte, tellement pénétrante, que jai connu beauconp de personnes qui ne pouvaient la supporter. Chez quelques-unes se déclaraient des céphalalgies et des soulèvements de cœur. Je n'eusse pas voulu occasionner ces inconvénients même à mes critiques, et ce par respect pour la propreté dı lieu où l'exposition ouvrait ses portes à unc foule compacte, avide d'instruction. Ce hocal vanillifêre obtenait, en effet, les honneurs de la popularité, et ce fut un des objets sur lequel se fixait une constante attention. Le jury écarta toutefois la dame exposante ( $\mathbb{M}^{\mathrm{me}}$ Horren) comme une personne interposée entre un objet exposé et un membre du jury. Cette mesure, qui ne fut pas appliquée à d'autres cas analognes, adoptée sur la proposition de M. Royer, de Namur, u'est pas, à mon avis, ni fort juste, ni fort encourageante pour les expositions à venir, et mieux vaudrait adopter le mode suivi aux expositions de la Société royale d'agriculture et de botanique de Gand, et ailleurs, oì te sentiment seul de la délicatesse fait que les membres dı jury qui ont senlement l'apparence d'un intérêt quelconque, se récusent et se retirent, mais ne sont pas privés d'une récompense légitime. Quni quil en soit, la troisième section du jury ayant l'horticulture dans ses attri- 


\section{( 35$)$}

butions, exprima, dans son rapport, le jugement que si la vanille de Liége avait pu entrer en lice pour le $2 y^{e}$ concours, comprenant des fruits de serre antres que les ananas, elle eût obtenu le premier prix ou la médaille de vermeil. Ce fut par erreur que, daus l'arrêté royal du 16 décembre 1848, fixant la distribution des distinctions méritées à l'occasion de l'exposition des prodnits de l'agriculture et de l'horticulture de l'année 18 's, H'me Marie Morren figure comme ayant mérité la médaille d'argent pour la vanille exposée. M. le Ministre de l'intérieur reconnut luimême cette erreur, le diplôme ofliciel en porte la rectification, et la vanille a réellement obtenu les honneurs de la première médaille de ce concours. Dans l'intérêt de la vérité, ces rectifications étaient nécessaires.

Bien que j’aie publić dans les journaux scientifiques, et notamment dans les Comptes rendus de l'Institut de France, les Bulletins de l'Académie royale de Bruxelles, les Annales de la Société royale d'horticulture de Paris, les Annals of natural history de Londres, le Report sur le congrès scientifique de Newcastle, de 1859, les Atti du congrès scientifique de Florence, de 1811, et ailleurs, des détails nombreux sur l'histoire, l'introduction, la spéeification, la culture el la fructification de la vanille, bien qu'uu grand nombre de publications savantes, tant celles de Russie que celles mème de Mexique, aient tour a tour examiné ce qui a trait à celte plante intéressante, je ne connais pas un seul travail complet sur cette matière, et le sujet, anjourd'hui plus que jamais, mériterait d'être examiné de nouvean, surtont en présence des recherches publiées dernièrement par II. Gardner, qui a examiné la culture des vanilliers au Brésil et au Mexique. Toutefois, quil me soit permis de rappeler ici que l'écrit dans lequel il $\mathrm{y}$ a le plus de renseignements sur l'histoire 
naturelle de la vanille, est l'article intitulé : On the produclion of vanilla in Europa, que j'ai publié dans les $A n$ nals of natural history de Londres, vol. III, $\mathrm{n}^{\circ} 14$; mars 1859. Les nouvelles publications faites au sujet de cette plante, n’ont en rien modifié les assertions consignées dans cet écrit. Je vais récapituler ici les faits principanx relatifs it la vanille.

\section{\$1. Sur les especes de vanillier produisant des fruits} aromatiques ayant cours dans le commerce.

C'était une question naguère très-controversée de savoir si toutes les gousses de vanille ayant cours dans le commerce, provenaient d'une seule et même espèce de plantes. Ce n'en est plus une, anjourd'hui que le fait avéré de l'existence : $1^{\circ}$ de plusieurs especes distinctes du genre vanillier; $2^{n}$ de plusieurs variétés d'une même espèce; $5^{\circ}$ ct enfin, de plusieurs sortes commerciales de fruits de vanille provenaut d'une seule el même variété. La connaissance exacte de ces distinctions est loin d'être une chose aisée.

M. Desvaux, dans son mémoire intitulé : Quelques notions nouvelles sur les vanilles el la culture de l'espice commerçable (1), pense avoir résolu une partie de la question en prenant pour une vérité que Swartz a retiré du genre Epidendrum de Linné la véritable vanille sous le nom de Vanilla aromatica, et cet auteur pense ensuite que l'ouvrage dı père Plımier, publié en 16\%̈, doit être pris comme joint de départ pour débrouiller les confusions qui règnent au sujet de ce produit commercial.

Je pense que ni la séparation des vanilles, comme genre,

(1) Annales des sciences naturelles, J̈e série, août 1846, p. 117. 
par Swartz, ni les écrits de Plumier ne peuvent rien éclaircir dans cette question, qu'elle est encore aujourd'hui aussi obscure que jamais, que rien n'est moins prouré que l'existence d'un Vanilla aromalica comme souche d'une plante commerciale, et que les écrits de M. Blume sur les vanilles (Flora Javae), ceux de Schiede (Limnaea 1899) et ceux de M. Desvaux lui-même (Annales sc. nal., 18.16) sont plutôt destinés à rendre plus ardue encore aujourd'hui, la question de savoir à quelles espèces, variétés et sortes de firuits provenant d'une même plante, il faut faire remonter l'origine des vanilles qu'on rend tlans le commerce. Cette question ne peut être résolue que par un naturaliste instruit, examinant sur les lieux mêmes la production et ramenant les fruits différents de longueur, de grosseur, de forme, de couleur, de goût, de parfum et de valeur, d'abord anx insertions différentes que ces fruits ont sur une seule et même plante, ensuite aux variétés d'une espèce donnée et enfin aux espèces mêmes. Des diagnoses directes et de bonnes figures faites d’après le vivant, seraient ici nécessaires.

Un fait me semble cependant sans réplique : c'est que nos serres d'Europe produisent des fruits de vanille que. l'œil le plus exercé ne distingue pas des fruits de première qualité (primiera). Il est de fait que ces fruits supérieurs proviennent du Vanilla planifolia d'Andrew. Or, devant les faits observés par M. Schiede, il est bien à craindre que l'Epidendrum vanilla de Linné, devenu le Vamilla aromalica de Swartz, ne soit une pure création nominale on une espèce non commerçable. Je cherche en vain partout dans les jardins botaniques de l'Europe et che\% nos plus grands horticulteurs, depuis 14 ans, ce fameux Tanilla aromalica et je ne le vois nulle part. Quand on en trouve l'étiquette, on bien clle est annexíe à un véri- 
table Vanilla planifolia d'Andrew, on hien on l'a donnée à quelque branche chétive et malingre de cette même espèce, branche dont le: feuilles sont alors petites, plus pointues et diflérentes de forme de ceiles d'un pied sain et vigoureux.

Linné n’a jamais vu sur le vivant la plante qui produit la vanille et dont il avait fait son Epidendrum vanilla. II la décrivit laprès Plumier, ne lui assigna que les caractères si vag̣ıes d'ètre une plante rampante, d'avoir des fenilles ovales-oblongnes, nerveuses, sessiles et canlinaires et des cirhes en spirale (1). Le vanillier de l'Inde et celui de l'Amérique sont pour lui la même espèce : elle est paracite, deux choses parfaitement inexactes.

Plumier (ㅃ) n'a donné qu'une diagnose insignifiante: Vanilla flore viridi et albo, fructu nigricanle, en s'en rapportant à la description de (ieoffroy, que Swartz consulta principalement four séparer la vanille du genre Épidendrum.

La vanilie à fleur verte et blanche et à fruit noir de Plumier a été de nouveau figurée et décrite par Catesby, dans son Histoire naturolle de la Caroline (p. 7, tab. 7). On trouve la copie de celte planche dans la Collectio slirpium d'Élisabeth Blackwell (6e centurie, tab). ॐ9), et texte correspondant). Or, fuand on examine celte planche, on y reconnait évidemment lo Vanilla planifolia d'Andrew avec son seconal mode i’inflorescence, car j’ai, par expérience multipliće, consiaté que cette espèce de vanillier a deux inflorescences, celle en épi cour' et ramassé, rl celle en panicule làche. La plante dessinée dans Cateshy est du dernier mode. Si les feuilles paraissent nervées, on re-

(1) Linn., Spec , edit. Richter, 608.

(2) Plantarum americanarum fasciculi, edit. Burmanni; Amsted.. 1655, p. 25. 


\section{( 37$)$}

connaît là l'aspect d'une feuille du planifolia, telle qu'elle se trouve dans les herbiers. Comme M. Sehiede l'a déjà fait remarquer, depuis IIlorlus Kocoensis d'Aiton, les diagnoses de Robert Brown, à savoir que le Vanilla aromatica de Swartz aurait les feuilles nervées et le planifolia d'Audrew des feuilles simplement et obscurément striées, sont éternellement reproduites dans les ouvrages descriptifs, sans qu'on retrouve celte vanille à feuilles nervées ni en Europe dans les serres, ni en Amérique dans la nature. M. Schiede naguère, et M. Gardner dans ces dernières années, ont visité les districts vanillicoles et n'ont pàs trouvé un seul vanillier à leuilles nervées.

II. Kunth, dans son Synopsis plantarum acquinoctialium (1), conserve encore le Vanilla aromatica comme la plante produisant les vanilles du commerce et croissant sur les arbres et dans les crenx des rochers de l'A mérique méridionale, dans la région la plus chaude, mais ombragée, à la source des ruisseaux ét sous un ciel ombrageux, sur les rives du flenve de l'Orénoque, pris de Carrichana, aux catarartes de Maypur el d"Atur, à Javita et à Esmeralda; lans la Nouvelle-Anda!ousie, près du couvent de Caripa, à San Feruando, Bordones et Carupano; dans la province de Venezucla, entre Porio Cabello, Guayguaza, Aroa et Nueva Valencia; dans la Valle de Capaya et près du promontoire de Codiera; dans les andes de la Nouvelle-Grenade, de (Suito ei du Pérou, pris de Turbaco, d'Almaguer et de Popayan; sur le versant ocrilental dı mont Pichincha; dans les vallées de Loxo at pròs du lleuve des Amazones, entre Tomependa et darn de liracamoros; dans l'île de Cula, près d'Elmariel, et Bahia

(1) Tom. I, p. 5.59. 
IInnda. De même, dit M. Kúunth, d'après de IIumboldt, cette vanille crồt spontanément et se cultive sous le nom de Telxochill par les Iexicains, et de Baynilla par les Espagnols, dans les provinces mexicaines d'Oaxaca et de Vera-Cruz, près de Nesantla, Papantla, Nantla, Colipa et Tuntla, où, ćtant vivace, elle fleurit d'arril au mois d'aoùt.

Or, c'est précisément au centre de ce district vanillicole de Papantla et de Mesantla que Mi. Schiede a décrit les vanilliers qu'on y cultive ou qui croissent en liberté, et pas une n’a le caractire d'avoir des feuilles nervées, le seul yui puisse être de quelque valeur dans la diagnose de l'espice de Swartz, aveuglément adoptée par les naturalistes. Ces faits infirment singulièrement l'opinion de l'existence d'un Vanilla aromalica comme espèce botanique bien constatée.

Le Tanilla planifolia d'Andrew auquel on rapporte l'espèce qui donne en Europe des fruits comparables aux plus helles gousses du commerce, a moius d'obscurité dans sa détermination, mais il n'en est pas cependant tout à fait exempt. Le Repository d'Andrew étant un ourrage de haut prix, dont il n'existe pas, pensons-nous, un seul exemplaire en Belgique, je crois faire chose utile de publier iri ce qu’il rapporte de ce vanillier. Je l'ai consulté à Newcastle, dans la bibliothèque de la Société des sciences naturelles.

Andrew décrit ainsi la plante: Corolla pentapetala. Labellum basi subcucullatum, ecalcaratum. Anthera opercularis, decirna (1). Capsula siliquaeformis, carnosa.

(1) Ce caractère est inexact: la coiffe anthérienne n'est caduque que lorsqu'on la détache : l'e!li-même. elle ne lombe pas, ct l'anthere ne dure que ì is liemes. 


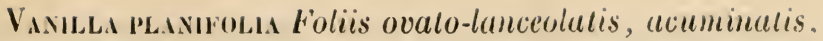
obliquis, obsolete striatis, nitidis; petalis sublanceolatis, incurvis, oblusis (1).

La ligure jointe est bonme, saul les glandes du labellum, qui sont mal représentées et domnent une idéc fausse de la nature.

Plumier, dit Andrew, a laissé des planches inćdites, dont l'une représente un Vanilla flore albo, fruch Ireviori corallino. Andrew a tort de croire que c'est la son espece, car d'abord son lanilla planifolia n'a pas la fleur blanche, mais verte, et puis le fruit n'est ni court, ni couleur de corail. Je crois ce dernier cas le résultat d'une erreur manifeste. L'histoire botanique de cette plante est curieuse, ajoute Andrew. Elle a été décrite par Plumier, en $170 . \overline{5}$. comme une troisième espèce de Vanilla, ainsi que nous nous en sommes assuré par une épreıve du dessin original déposée dans la collection de A.-B. Lambert, mais non renseignée par Limué ou aucun autre auteur. Dans le Paradisus Londinensis de Salisbury, on l'a prise pou' l'espèce primitive décrite par Plumier, dont Linné avait fait son Epidendrun vanilla, devenu le Vanilla aromalica de Swartz et de Willdenow, plante dont nous possédons trois ligures originales : celles de Catesby, dans son IIistoire de la Caroline (vol. III, tab. 7), de mademoiselle Merian el de Plumier, publiée par Burman. Toutes ces ligures sont différentes de notre Vanilla planifolia (2). Deux plantes ne peuvent différer davantage spécifiquement, et

(1) Repository, vol. VIII - 1. 558.

(2) Oui, sil’on admet lés feuilles à cótes, nou, si ces feuilles ue sont páas ainsi : tout le reste est le même. (Morren.) 
nous n'arons vu nulle part deux inflorescences plus différentes (1).

Le Vanilla planifolia, dit-il en terminant, est une plante d'ornement très-remarquable, mais elle est encore fort rare. E:le grimpe à plusieurs pieds de hauteur et s'attache an! moyen de vrilles sortant de l'aisselle de fenilles. Le plus heau pied d'Angleterre, et le seul qui ait tleuri, est celui de la collection de l'honorable Charles Greville, a Paddington, où nous avons fait notre dessin. Nous avons appris que cette espèce provient d'Amérique el a été introduite en Angleterre par le marquis de Blandford (devenu plus tard due de Marlborough).

Or, le doute existe, relativement à la valeur de cette espèce, depuis que M. Schiède a partagé les vanilliers cultivés ou venant spontanément à Papantla et Misantla, en quatre espèces, dont le Vanilla sativa et le Vanilla sylvestris sont, d'après lui, confondus dans le Vanilla planifolia d'Europe.

Voici d'abord les diagnoses de ces quatre espèces:

$1^{0}$ Vaxilla sativa Schiede, foliis oblongis succulentis, floralibus nuinimis fruclibus esulcatis (feuilles oblongues succulentes, les florales petites, fruits sans sillons).

Bayrilla mansa des Espagnols du Mexique.

Croît spontanément à Papantla, Misantla, Nantla et Colipa, et s'y cultive de même.

20 Vanilua sruvestris Schiede, foliis oblongis-lanceolatis suc-

(1) Cela s'explique, parce qu'en effet, sur les vieux pieds de Vanilla planifolia, nous observons deux inflorescences très-distinctes. l'une en épi serré et dense, l'autre en panicule longue et lâche. Je conçois qu'Andrew. n'ayant p.Is va ces deux consiructions sur une même plante, ait pu les prendre pour des diagnoses. (Morren.) 
culentis, floralibus nuinimis, fructibus bisulcatis ( feuilles oblongues-lancéolées succulentes, les florales très-petites, fruits ì deux sillons).

Baynilla cimurroua des Espagnols du Mexique.

Habite Papantla, Nantla et Colipa.

$5^{0}$ Vaxtula pompoxa Schiede, maxima, joliis oblongis, succulentis, subinde latissimis et basi subcordatis, foralibus minimis, finclibus bisulcutis (plante grande, feuilles oblongues, succulentes, plus tard très-larges et subcordiformes à la base, les florales petites, fruits ì deux sillons).

Buynilla pompona des Espagnols du Mexique.

La forme des feuilles est ordinairement semblable à celle de ces organes dans le Vanilla sativa. Le firuit est très-grand.

Habite Papantla et Colipa.

$4^{0}$ Vaxilu inomona Schiede, foliis ovatis vel ovalo-lanceolatis, membranaceis, floralibus maximis, fructibus bisulcalis inodoris ( feuilles ovales ou ovales-lancéolées, membraneuses, les florales très-grandes, fruits à deux sillons, inodores).

Baynilla de puerco des habitants de Misantla.

Espèce très-distincte.

Habite Misintla.

Schiede exprime le doute que ses Vanilla saliva et sylvestris sont confondus sous le nom de Vanilla planifolia, mais comme leur distinction est importante pour le commerce, il a cru devoir leur domner des noms spéciaux, bien qu'il n'ait pas vu le passage de l'une à l'autre. Le fàcheux, c'est qu'en présence de diagnoses si courtes et si peu caractéristiques, on ne puisse déterminer à laquelle de ces espèces appartient la plante qui, depuis 1857, a porté de magnitiques fruits dans nos serres. Seulement, en poursuivant les idées de II. Schiede, on pent se rapprocher un peu plus de la vérité sans pouvoir l'atteindre. Les fleurs de toutes ces espèces lui sont restées inconnues. 
Le Vanilla sativa est regardé à Papantla comme la meilleure espèce, mais on en mélange les fruits avec ceux du Vanilla sylvestris, qui sont aussi fort estimés. Le Vanilla pompona est riche en huile éthérée et répand un parfum délicieux, mais les fruits n'en sèchent pas lorsqu'ils sont mis en tas, et ne peuvent servir au commerce avec l'Europe, car ils restent toujours humides. Aussi n'en fait-on pas d'article de commerce. A plus forte raison, condamnet-on le Vanilla inodora. II. Schiede n'a pu s'assurer de ce 'qu'était un Vanilla de mono, dont on lui a parlé, et quant à ce qu'on appelle Baynilla mestiza, ce sont des fruits intermédiaires, pour la forme et la qualité, entre ceux des $V$. saliva et sylvestris. Papantla est la région qui produit le plus de vanilles, mais, dans une foule de localités, on mélange une masse de gousses de sylvestris avec celles de la sativa, de sorte qu'en Europe, ces fruits sont confondus (1).

Je ferai remarquer, $1^{\circ}$ qu’à partir de ces travaux écrits sur les lieux mêmes où la vanille se produit, il n'est plus question d'un vanillier à feuilles nervées ou costées;

qo Que notre vanille de l'Europe ne peut appartenir an 1. saliva, vu que les gousses ont ici deux sillons;

$5^{\circ}$ Que ce ne peut être le Vanilla inodora;

$4^{\circ}$ Mais qu'on ne saurait dire si notre vanille cultivée actuellement en Europe est ou le Vanilla sylvestris ou te Vanilla pompona de Schiede. Quand le vanillier est jeune, il ressemble davantage au Vanilla sylcestris; quand il a de

(1) Bolanische Berichte aus Mexico, mityetheilt von $D^{\text {r Schicde. }}$ Dritter Bericht; über die Gegendin von I'apantla, und .Misantla und iiber die Reize von Jalapa dorthin und zuruchl. (Écrit de Misantla, 20 mars 1820.) Linnaea, P1). 514-583, vol. IV , 1829. 
l'àge ou une bonne croissance, il devient une plante énorme; car lorsqu'on a abattu l'ancienne serre du jardin botanique de Liége, le vanillier qui avait porté fruit pour la première fois en Europe, en 1857, dut être enlevé, et l'on ne put y parvenir, tellement les branches avaient embrassé les colonnettes de fer qui soutenaient l'édifice. Cette plante mesurait plus de cinq cents pieds de longueur dans ses nombreux replis. Dans cet état de croissance, les feuilles deviennent larges, et, en sc repliant à leur base, y prennent la forme d'un cœur. Les caractères de Schiede sont done impropres à faire trancher la question de savoir si le vanillier d'Europe est le Vanilla pompona ou le sylvestris. Seulement il y a plus de probabilité que ce soit le dernier, puisque les fruits se conservent, qu'ils se sèchent parfaitement et se couvrent de givre comme la vanille du commerce, qualités que Schiede dénie à la pompona.

Je ferai remarquer encore qu'étant à Londres, en 1858, j'examinai les vanilles de l'herbier de M. Lindley. Le vanilla planifolia, marqué d'un point d'interrogation dans cet herbier, est bien décidément la plante dont Francis Bauer a dessiné les nombreux détails anatomiques dans le Genera and species of Orchideous Plants; c'est bien décidément l'espèce représentée par Andrew, dans le Reposilory, et enfin, c'est bien elle qui se cultive à Liége et ailleurs, et produit les excellents fruits, rivaux de ceux de Mexique. Voilà des faits sur lesquels il ne peut y avoir aucun doute.

D’après cela $1^{\circ}$ puisque les diagnoses de Schiede relatives aux Vanilla sativa, sylvestris et pompona, sont incomplètes et nécessitent un examen ultérieur;

$2^{\circ}$ Puisqu'il est certain que le Vanilla nommé planifolia par Andrew, est bien celui qui donne des fruits tellement 
analogues à ceux que le commerce regarde comme les plus beaux, les meilleurs et de première qualité;

$5^{\circ}$.Puisqu'il est non moins certain que le Vanilla planifolia d'Andrew n'est pas l'espèce à fruit petit et couleur de corail et à fleur blanche de Plumier;

$4^{\circ}$ Puisqu'enfin, le travail comparatif des sortes de vanilles fournies par le commerce et publié par M. Desvaux, en 1846, ni les écrits de M. Blume, ne peuvent en rien établir une corrélation exacte entre les produits commerciaux et les spécifications botaniques, il est aussi juste que convenable de conserver au vanillier cultivé généralement en Europe, le nom de Vanilla planifolia qui lui a été donné par Andrew, le premier auteur qui l'a fait connaître d'une manière certaine.

Je rappellerai ici que le Vanilla viridiflora décrit et figuré par M. Blume, dans le Bijdragen tot de flora van nederlandsch Indie, p. 422, n'est autre que le Vanilla planifolia d'Andrew, corrélation que l'auteur a reconnue lui-même dans la Rumphia, p. 196. Salisbury, dans le Paradisus Londinensis, l'appelait Myrobroma fragrans.

Peu de temps après que j'eus, en 1857 , obtenu des fruits mûrs et odorants de la vanille, je commençai à m'apercevoir que les relations et des botanistes et des médecins sur la spécification et l'histoire médicale du $\mathbf{V a}$ nilla aromatica de Swartz, ou l'Epidendrum vanilla de Linné, étaient essentiellement fautives; mais ces allégations étaient tellement ancrées dans les ouvrages classiques que j'eus beaucoup de peine à convaincre certains esprits. Cependant, je prie de remarquer que le seul fait d'attribuer au Vanilla planifolia les beaux fruits du commerce est d'une importance majeure pour les États qui peuvent se livrer à la culture de cette plante, comme les 


\section{(43)}

gouvernements du Brésil, du Mexique, le gouvernement des Pays-Bas pour ses colonies, celui d'Espagne pour l'île de Cuba et autres possessions, le Portugal, la France, etc. C'est donc un fait qui mérite d'être pris en très-sérieuse considération. IIeureusement que des botanistes distingués se sont rangés de mon avis, et c'est pour moi un vrai bonheur que de pouvoir citer ici, à l'appui de mes vues, l'opinion de II. le professeur Lindley. Évidemment, c'est ce savant qui a le micux aujourd'hui établi la monographic du genre Vanilla.

\section{§. Monographie du genre Vanilla.}

En 1853, dans son Key to structural physiological and systematic Botany, M. Lindley émet pour la première fois l'idée que les Vanilles et les Epistephium devaient former une famille particulière du règne végétal, à la suite des orchidées finissant elles-mêmes par les Cypripedium. La qualité charnue du fruit, l'absence des valves, la non-existence d'une membrane libre (spermophore des uns, testa des autres) autour des graines, le port et enfin les propriétés aromatiques des vanilles, étaient opposés aux fruits secs et valvés, aux graines entourées d'une membrane scarieuse et à l'absence de tout principe aromatique avec l'existence d'un port spécial clıez les vraies Orehidées. La famille des Vanillacées parut donc comme famille distincte dans le Natural system of Botany, de 1856 (p. 541). Elle fut conservée, en 1858, dans la Flora medica du même auteur (p. 579), à propos du Vanilla claviculata, seule espèce conservée comme médicinale, par M. Lindley, dans cet ouvrage. Cependant, dans le Genera and species: of Orchideous Plants, part. VI. Arethuseae, publić après le 
Genera de M. Endlicher, les Vanillacées ont disparu, et le genre Vanilla devient le deux cent-quarante-septième genre de la famille des Orchidées et rentre dans les Arélhusées.

M. Lindley, dans la description du genre, admet l'opinion que la testa des graines serait ici fortement adhérente à la graine, qu'elle est crustacée et fragile. Cela est vrai, mais je ne pense pas que cette testa doive être comparée au sac libre des autres Orchidées nommé Spermophore par Blume et autres. Je crois, après des analyses minutieuses de la vanille, que ce sac ou spermophore, comparable à une arille, est simplement converti en pulpe odorante dans les vanilles parfumées. C'est, au reste, un sujet qui mérite d'être examiné de nouveau.

Voici la monographie du genre Vanilla, telle qu'on peut l'établir actuellement. Elle tranche bien des doutes, et c'est, nous parait-il, la seule rationnelle en ce moment.

\section{ETIITLA.}

Vanilla. Plumier, Swartz, Nov. Act. Ups., 6, p. 66, t. 5, fig. 1.Endlicher gen., n 1614.

Myrobroma, Salisb. parad., 82.

Vaxilla. Schw. Perianthium apice tantum patens, cum ovario articulatum, saepius caliculatum. Sepala el petala subctequalia conformia, basi libera. Labellum cum columna connatum, integrum, concavum, medio barbatum. Columna elongata, aptera. Anthera terminalis, opercularis. Pollinia duo, biloba, granulosa. Fructus siliquiformis, carnosus, a lutere dehiscens, placentis 5-G seminiferis. Semina globosa, testa arcte adnata, crustacea, fragili.
Vaxille. Sehw. Périanthe ouvert seulement au sommet, articulé avec l'ovaire, le plus souvent caliculé. Sépales et pétales subégaux, conformes, libres à la base. Labellum conné avec la colonne, entier, coneave, barbu au milieu. Colonne allongée, aptère. Anthère terminale, operculaire. Deux pollinies bilobées granuleuses. Fruit siliquiforme, charnu, s'ourrant de côté, placentas au nombre de trois à six, séminifères. Graines globuleuses, testa fortement adné, crustacé, fragile.

Plantes grimpantes, habitant l'Amérique et l'Asie tropicales. Tiges cylin- 
driques. Feuilles articulées à la tige, charnues, subcordées à la base. Fleurs clıarnues. Fruit aromatique, cliez quelques espèces, par une huile essentielle et l'acide benzoïque (?) qui se cristallise en aiguilles, à leur extérieur.

\section{ESPÈCES.}

1. Vavilla anomatica. Swartz, in Act. Ups., 6, p. 66. - R. Brown, in Hort. Rew., V, 220.

V. Foliis ovato-oblongis acuminatıs sessilibus; perianthii campanulati, laciniis s undulatis acuminatis apice revolutis; labello acuminato basi cucullato, linea media nuda elevata (capsulis cylindraceis longissimis).
V. Feuilles ovales-oblongues, acumi-. nées sessiles; périanthe campanulé, divisions au nombre de cinq, ondulées, aiguës, révolulées au sommet; labellum acuminé, cucullé à la base, ligne médiane nue, élevée (capsules cylindriques trèlongues).

\section{SyNonymes.}

Vanilla flore viridi et albo, fructu nigricante. Plum., ic. 18j, t. 188. Epidendrum vanilla. Linn., Sp., pl. 1347.

IIabite l'Amérique méridionale, dans les bois subhumides des montagnes, d'après Swartz; au Brésil, près de Rio Janeiro, d'après Gardner, 632 ; dans la province de Minas Geraès, d'après Martius.

Observations. - M. Lindley fait remarquer que les seuls échantillons qu’il possède de cette plante proviennent du Brésil, et qu'ils s'accordent parfaitement avee la figure de Plumier, par qui l'espèce a été établie. Cependant M. Lindley trouve que les feuilles ne sont pas plus costées que dans aucune autre espèce. Ceci me confirme dans l'idée que cette apparence de côles est ou un défaut de dessin, ou le résultat du desséehement des feuilles. Il ne paraît pas, ajoute M. Lindley, qu'il y ait une seule espèce de vanille dans le Brésil qui entre dans le commerce. Une espèce est, dit-on, préparée au sucre, employée dans le pays et parfois enroyée à Lisbonne, mais on ne la sèche pas pour les besoins du commerce. Est-ce peut-être le Vanilla pompona de Schiede? Ce qui est certain, dit en terminant M. Lindley, e'est quil est à croire que le Vanilla aromatica n'a rien i faire avec les fruits du commeree. 
Depuis que ce passage a été publié, M. Gardner a fait paraitre son ouvrage sur le Brésil (1). Il y parle de la vanille du Brésil (2). Près d'une fazenda appelée Riacho d'Area, dans la contrée, entre Parnaguì et Saco de Tanque, M. Gardner trouva, au milieu des endroits maréeageux et fourrés, des pieds du Vanilla planifolia, portant rarement des fleurs et encore plus rarement des fruits. M. Gardner pense toutefois qu'il n'est pas encore clairement établi que ce soit cette espèce-là qui fournit les fruits du commerce; mais il n'en est pas moins vrai que voilà donc le Vanilla planifolia existant au Brésil. " Au Mexique, dit-il, on le cultive considérablement pour les fruits qu'il y porte abondamment. Tandis que les plants de cette espèce qui ont été introduits dans les Indes orientales et dans les serres d'Europe, bien qu'ils aient fourni des fleurs, n'ont donné que fort rarement des fruits. Le docteur Morren, de Liége, a été le premier qui ait étudiẻ attentivement l'histoire naturelle de cette plante et prouvé, par des expériences, que les fruits du vanillier peuvent être produits aussi facilement dans les serres qu'au Mexique. Il a découvert, par quelques particularités, dans les organes reproducteurs de cette plante, qu'il fallait, pour former le fruit, une fécondation artificielle. En 1856, une seule plante du Jardin Botanique de Liége produisit cinquante-quatre fleurs qui, fécondées artificiellement, donnèrent le même nombre de fruits, égaux à ceux importés du Mexique, et, en 1857, une nouvelle récolte d'environ cent gousses fut obtenue sur un autre pied par le même procédé. M. Morren attribue la fécondation de la plante au Mexique à l'action de quelque insecte qui fréquente les fleurs, et de là il conclut qu'en expatriant la plante, sans l'insecte, elle doit ailleurs rester sans produit. On

(1) Travels in the interior of Brazil, principalles through the northern provinces, and the gold and diamond districts, during the years 1836-1841, by George Gardner, surintenilant du Jardin Botanique royal de Ceylan. Londres, Reeres, 1848.

(2) Op. cit., p. 290-297. 
ne peut pas douter qu'elle ne soit aujourd hui aussi parfaitement indigène au Brésil qu'elle l'est au Mexique; mais il n'en est pas moins certain qu'au Brésil il y a très-rarement des fruits mûrs. Doit-on attribuer ceci à l'absence des moyens par lesquels la nature fait effectuer la fécondation au Mexique? Ceci est un sujet qui, commele professeur Morren l'a judicieusement fait observer, mérite une attention spéciale sous le point de vue commercial, depuis que l'expérience prouve que, dans tontes les contrées intertropicales, la vanille peut se cultiver et produire une grande abondance de fruits. "

Je signale ce passage à l'attention sérieuse des gouvernements qui sont établis dans les régions intertropicales.

2. Vanilla claviculata. Sivartz, in Schroder Journal, 1799, 2, fig. 1, f. ind. occ. 1515 .

V. Foliis lanceolatis acutis concavis, recurvatis rigidis; floribus aggregatis, sepalis carnosis, ovato-lanceolatis, obtusis, concavis, petalis ovato-lanceolatis, obtusis, postice carinatis, labelli limbo ovato dilatato, deflexo, undulato crispo ungue sulco hirsuto-ciliato exarato; ciliis ramentaceis multifidis; fructu oblongo insipido.
V. Fenilles lancéolées, aiguës, concaves, recourbées, roides; fleurs agrégées, sépales charnues, ovalo-lancéolées, obtuses, concaves, pétales ovato-lancéolés, obtus, postérieurement carinés, limbe du labellum ovale dilaté, défléchi, ondulé, crépu, parcouru à son onglet d'un sillon perdu el cilié, cils ramentacés multifides; fruit oblong insipide.

\section{Srnonymes.}

Epidendrum claviculatum. Swartz, Prodr., 120.

Cerei affinis, etc. Sloane, p. 160 , t. 224 , fig. 5-4.

Habite les Antilles, dans les forêts intérieures et les lieux montagneux calcaires et très-secs, selon Swartz.

Observations. - Les fleurs sont blanches. La plante est appelée, à la Jamaïque, Greenwiche par les nègres. On fait servir une décoction de la plante entière dans le traitement des maladies syphilitiques. Ce remède est estimé. A Saint-Domingue, le jus exprimé de la plante nommée Liane à blessure, est regardé 
comme vulnéraire. Le goût en est amer, mais l'odeur de cette Orchidée est très-puissante, selon Swartz (1).

J'ai observé, pendant une année, cette espèce de vanillier chez M. Jacob Makoi, à Liége. On eut toutes les peines du monde de la conserver en vie, le long d'un treillis, dans la serre à Orchidées. Elle périssait constamment du bas. J'en obtins quelques morceaux que je ne pus parvenir non plus à maintenir vivants dans une grande vanillière. Elle n'a point donné de fleurs et encore moins des fruits.

3. Vaxilla playifolia. Bot. repos., 2, 558; R. Brown, in IIort. Rew., v. 220 .

Bauer's illustr. Gonera, t. 10 et 11; Blume, Rumphia, 1, 197, t. 68; Morren, in Ann. of Nat. history, 5, 1. - Id., Bulletin de l'Acad. roy. des sciences, t. IV, n' 5, p. 225. - Id., Ann. de la Soc. roy. d'horticulture de Paris , t. 20, 1857, 351. - Il., Alti della terza reunione degli scienziati italiani, Flor., 1841, p. 491, etc.

v. Foliis oblongo-lanceolatis planis obsolete striatis, sepalis, petalisque oblongis erectis obtusiusculis, labelli lamina emarginata crenata crispa utrinque recurva medio lamellis brevibus transversis cuneatis dentatis retrorsum imbricatis cristata sub apice verrucosa, columna antice pilosa; fructu cylindraceo longissimo odoratissimo.
V. Feuilles oblongues-lancéolées, planes, obscurément striées; sépales et pétales oblongs droits et obtusiuscules, labellum ayant la lame émarginée erénelée, crépue, recourbée de chaque eôté, au milieu des lames courtes, transverses, cunéiformes, dentées, imbriquées en arrière en forme de crêtes, verruqueuse au-dessous du sommet, colonne antérieurement poilue; fruit cylindracé, trèslong et très-odorant.

\section{Synonymies.}

Myrobroma fragrans. Salesb., Parad., t. 82.

Vanilla viridiflora. Blume, Bydr., 422.

Habite les Indes occidentales, selon Aiton; apportée en Angleterre, de là en Belgique, d'où elle émiģra dans les Indes orientales. Cultivée en Europe.

\section{Observations. - "C'est l'espèce, dit M. Lindley, de laquelle}

(1) Flora medica de Lindley, p. 579. 


\section{( 51$)$}

le professeur Morren est parvenu à obtenir d'excellents fruits daus le Jardin Botanique de Leyde (1). Il est infiniment probable que c'est d'elle que proviennent la majeure partie des vanilles du commerce Le botaniste, bien informé, Schiede, regarde le $V$. sylvestris comme étant probablement une synonymie du $\boldsymbol{V}$. planifolia, mais il n'est pas suffisamment démontré que cette opinion soit exacte. (Voy. Morren, dans les Annals of natural history, vol. III, p. 1, pour un aperçu détaillé sur la culture, etc., de la vanille.) 》

M. Blume, dans la Rumphia, p. 198, déclare qu'il n'a pas vu de fruits de cette espèce à Java, et qu'il ne peut dire s'ils sont odorants ou non. Il admet encore que le Vanilla aromatica a des feuilles à côtes, ce qui est aujourd'hui controuvé. M. Blume n'est pas plus heureux dans ses allégations au sujet de ce qu’il dit relativement à la vanille quill a vue à Liége. Les fruits y ont, dit-il, la longueur d'un spithame, la grosseur d'un doigt d'enfant; ils sont subcylindriques, chiarnus, lisses, verts extérieurement, en dedans la matière solide est incolore; ils sont remplis de graines très-petites, d'un noir brun. Ces fruits coupés, ajoute-t-il, répandent de suite l'odeur propre à la vanille marchande, mais moins forte, à moins qu'elle n'augmente par le desséchement et le rejet de parties humides. Quand M. Blume visita les serres de Liége, il n'y vit que des fruits à l'état d'immaturité. Avec un peu de patience, il cût reconnu que ces fruits mûrs sont bruns à l'extérieur, que leur matière interne est brun noirâtre et que leur parfum ne le cède en rien à celui de la meilleure vanille du commerce. A Java, les fruits ne sont pas venus, par les mêmes raisons que M. Gardner a mieux expliquées pour le Brésil. Il est indubitable qu'une plantation bien dirigée produirait à Java d'abondantes récoltes. Je donnerai plus tard sur ce fait des détails précis.

(1) Par crreur typographique, lisez Liége an lieu de Leygle. 


\section{( 52 )}

4. Vanilla albida. Blume, Bydr., 422, c. analysi, Rumphia, 1, 197, 1. 67 .

V. Foliis petiolatis lanceolatis crassis, planis obsolete nervosis, spicis $\mathbf{3}-\mathbf{9}$ floris, labelli limbo ovato rolundato, antice et infauce disco barbato instructo, columna glalra; fructibus triquetris falcatis inodoris.
V. Fenilles pétiolées, lancéolées, épaisses, planes, obscurément nerveuses, épis de 5 à 9 fleurs, limbe du labelle ovale, arrondi, antérieurement et à la gorge pourvu d'un disque barbu, colonne glabre; fruits triquètes, en faux, inodores.

Habite les forêts vier ̧̧es humides et montagncuses de Java; près du fleuve Tjapus, aux environs des monts Salak, dans les contrées montagneuses de Parang, ctc. Presque toujours en fleur, selon Blume.

Observations. - Le fruit est long d'environ trois pouces, luisant, d'un pâle vert, avec des taches brunes. Les sépales et les pétales verdâtres. Le labellum est d'un blanc de lait.

5. Vamilla graviflora Lind., Orch. gen. et sp., 4055.

V. Foliis spica brevi multiflora, bracteis latis rotundatis striatis, sepalis petalisque elongatis rectis planis oblongis obtusiusculis basi angustatis, labelli vetusi apiculati crispi limbo basi lamellis brevibus transtersis cuncatis dentatis retrorsum imbricatis cristato sub apice glabro venis paulo elevatis, columna antice pilosa. v. Feuilles......e épi court multiflore, bractées larges arrondies, striées, sépales et pétales allongés, droits, planes, oblongs, obtusiuscules étroits à liı base, labellum rétus, apiculé crépu, limbe à la base des lamelles courtes transverses, cunéiformes, dentées, imbriquées en arrière, glabre sous le sommet, à veines un peu élerées, colonne antérieurement poilue.

Ilabite la Griyane française, selon Martin. M. Ward communiqua cette espèce à $\mathbf{M}$. Lindley.

Observations. - Quoique M. Lindley n'ait vu de cette plante qu'un épi de fleurs sèches, il ne pent y avoir aucun doute que ce ne soit une espèce distincte. Elle se rapproche du Vanilla planifolia; mais ses fleurs sont plus grandes, les sépales et les pétales plus étroits et plus longs. L'absence des tubercules au sommet du labellum suffirait pour la distinguer.

Néanmoins, M. Lindley ne peut déterminer si e'est une des espèces observies à Cayenne par Aublet. Cet auteur dit quil y a 


\section{( $5 \overline{3}$ )}

dans cette contrée trois espèces de vanillier. L'une s'accorde avec la figure de Plumier et paraît être le $V$. aromatica; la seconde (la pelite vanille) a les fruits seulement de 5 pouces de long sur un pouce et demi environ de diamètre et doit être une espèce différente. La troisième (ou grosse vanille) n'est pas décrite. Voyez l'aperçu de cet auteur sur la culture, ete., de la vanille, dans les Plantes de la Guiane française, vol. II, p. 77, appendice.

6. Vavilla bicolor. Lind., in Bot. regist., 183̈8, Misc., $\mathrm{n}^{\circ} 58$.

V. Foliis ovato-oblongis subsessilibus acutis striatis margine rubescentibus, sepalis lineari-lanceolatis acutis patentibus dorso rotundatis, petalis conformibus carinatis, labello membranacco scmilibero convoluto apiculato undulato, venis ramentaceis in medio dense stuposis, columna barbata, clinandrii auriculis crenulatis.

Habite Demerara, selon Schomburgk. M. Loddiges cultive cetle vanille.

Observations. - Elle est très-odorante. Les fleurs sont pâles et ont trois pouces de longueur; les sépales et pétales sont d'un rouge terne, et le labellum d'une couleur de crème.

7. Vanilla Palmaruar. Lind, Orch. gen. et sp., 4036.

V. Foliis ovatis subcordatis brevi-petiolatis succulentis, florilus geminis, sepalis et petalis angustis oblongis erectis plenis, labello membranaceo...... ovario calyculato.
V. Feuilles ovales-oblongues, subses. siles, aiguës, strićes, rouges au bord, sépales linćaires lancéolées aiguës planes, arrondics au dos, pélales conformes carinés, labellum membraneux, semilibre , convolulé, apiculé, ondulé, veines ramentacées au milieu, pressées, colonne barbue, clinandre à oreilles crénulćes.

V. Feuilles ovales-subcordées à pétioles courts succulents, flcurs géminées, sépales et pétules étroits, oblongs, droits, planes, labellum membraneux..... ovaire calyculć.

\section{SyNoNymes.}

Epidendrum Palmarum. Salzmann, Pl. exsicc. braz. Epidendrum vanilla. Flora fluminensis, c. ic.

Habite à Bahia, sur les tiges des palmiers. Salzmann.

Observations. - M. Lindley a vainement cherehé à reconnaître lit structure et la forme du labellum daus trois ćchantillons 


\section{(}

quïil a eus ì sa disposition. L'espèce dilfère de toutes les autres par ses feuilles ovales, subcordées, et son calycule, qui, s’il est présent dans quelques espèces, n'est jamais si grand.

8. Vivilia aphylla. Blume, Bydr., 422. Rumphia, 1, 198, t. 68.

V. Aphylla, pedunculis subtrifloris, labelli limbo undulato obtuso, medio barbato, anthera biloba; fructu cylindraceo (insipido?).
V. Aphylle, pédoncules subtriflores, labellum à limbe ondulé, obtus, barbu au milieu, anthère bilobée; fruit cylindrique (insipide?).

Habite les alluvions de Java, entrc les arbrisseaux et aux bords des forêts, dans l'île de Nusa Kambangan, dans les broussailles, près des rives, selon M. Blume, et dans la Péninsule indienne, selon Wight.

Observations. - Les échantillons procurés à M. Lindley par M. Wight s'accordent avec les figures et la description de M. Blume, seulement le nombre de fleurs était plutôt cinq que trois. Le limbe du labellum a paru aigu dans la seule fleur soumise à la dissection. Selon M. Blume, les fleurs sont vertes, avec le labellum violet; elles sont très-odorantes.

J'ai vu également chez M. Jacob Makoi une espèce de vanillier aphylle, mais qui n'a point fleuri. Sur les tiges, grosses comme le petit doigt, lisses, mates et vertes, il y avait de chaque còté un sillon longitudinal, et la tige était partagée par des articulations placées à 15 centimètres de distance, où ces sillons s'arrêtaient pour ne pas se correspondre sur les mérithalles voisins. Cette singulière plante fut placée dans la mousse et dans la serre à Orchidées. Elle y languit longtemps et finit par mourir sans avoir poussé de nouveaux jets.

A la suite de ces huit espèces, M. Lindley cite les diagnoses de Schiede, sans pouvoir les rapporter avec certitude à aucune de ces huit espèces, et fait remarquer que le Vanilla angustifolia de Willdenow, plante du Java et non du Japon, doit être entièrement éloigné de ce genre. 
ACADÉMIE ROYALE DE BEIGIQUE.

(Extrait du tome XVII, $n^{\circ} 3$, des Bulletins.)

\section{TÉRATOLOGIE VÉGÉTALE.}

SUR LA SPEIRANTHIE DES GYPRIPÈDES, NOUVEAU GENRE

DE MONSTRUOSITÉS;

PA R

II. CII, MIORREN,

Membre de l'Académie royale de Belgique.

Un pied de Cypripedium insigne m'a présenté un si remarquable assemblage de monstruosités de diverses espèces, que je n'ai pu m'empêcher d'en conserver le souvenir dans le musée de tératologie végétale que je forme actuellement à Liége. Les orchidées offrent rarement des constructions anormales, mais toutes celles qui ont été signalées, sont riches en inductions philosophiques. Celle dont je publie en ce moment la dissection n'est pas moins importante dans la théorie actuelle de la science des aberrations de la nature. 
On doit se rappeler d'abord la structure normale du genre des Cypripedium, le seul sous-ordre des orchidées caractérisé par l'existence de deux anthères latérales fertiles et par l'anthère du milieu, devenue pétalö̈de, et partant stérile. Le genre Cypripedium a, de plus, les folioles extéricures (calice) du périgone uninerves libres, posées sur le labellum, la foliole supérieure conforme à l'inférieure, mais à nervures souvent au nombre de cinq, les folioles internes (corolle) plus étroites, le labellum grand, enflé et calcéiforme, la colonne courte, penchée, trifide au sommet, les lobes latéraux anthérifères au-dessous, l'intermédiaire stérile, pétaloïde et dilaté, les anthères à loges séparées, presque bivalves, le pollen pulpeux granulacé, le style deltoïde, occupant la face de la colonne au-dessous des anthères, la capsule uniloculaire, à trois placentas pariétaux, et les graines nombreuses, scobiformes.

Voici la très-singulière structure que m'offrait le monstre le Cypripedium insigne auquel j’avais affaire :

Il existait deux folioles extérieures au périgone, mais au lieu de se tronver en haut et en bas, opposées au labellum, elles étaient placées latéralement l'une à gauche, l'autre à droite. (Voy. fig. $\mathbf{1}^{\mathrm{re}}$.)

La foliole supérieure dans le type, la plus large des deux, celle qui devait offrir cinq nervures principales et qui en montrait neuf au contraire, avait fait un quart de cercle de révolution sinistrorse et descendante (je me suppose être la fleur, ma gauche est, par conséquent, celle du monstre lui-même). Donc, cette foliole calicinale, de supérieure qu'elle aurait dû être, était effectivement latérale.

La foliole calicinale inférieure dans le type, celle qui se place au-dessous du labellum, avait fait un quart de cercle de révolution dextrorse et ascendante. Donc, elle 


\section{$(5 i)$}

se trouvait it droite vis-à-vis de sa voisine de gauche; mais, devenue plus étroite que celle du type, elle avait pris l'aspect, la grandeur, la forme, la coloration d'une foliole corolline du second verticille. (Voy. $f \mathrm{~g} . \mathrm{f}^{\mathrm{re}}$.)

La foliole corolline de droite, qui, dans le type, est latérale et horizontale et se place vis-à-vis de sa voisine de gauche sur la même ligne, avait subi un mouvement ascendant dextrorse, d'un quart de cercle, de manière it occuper la place de la foliole calicinale supérieure. Cette foliole corolline offrait tous les caractères de nervation, de grandeur, de coloration et de figure propres aux folioles corollines ordinaires.

Quant à la foliole corolline de gauche, elle était complétement atrophiée; il n'y en avait aucune trace.

Son insertion, c'est-à-dire la hauteur de l'origine du second verticille floral, était occupée par le labellum. Donc, puisque la foliole corolline droite occupait le sommet de la fleur, le bas devait être occupé à son tour par le labellum qui, cependant, se trouvait, dans cette position normale, faire le vis-ì-vis d'un pétale latéral.

La conséquence de cette étrange perturbation dans les insertions, était qu'en voyant cette fleur, on ne saisissait d'abord que la moitié de son intérêt : on prenait la foliole calicinale supérieure pour une foliole corolline gauche, la foliole calicinale inférieure pour une foliole corolline droite. La foliole corolline droite, on la prenait pour une foliole calicinale supérieure, et à voir le labellum dans sa place ordinaire, on ne s'apercevait pas de l'absence de la cinquième partie du périgone.

Le labellum lui-même offrait bien la forme en pantoulle, caractéristique du genre, mais au lieu de présenter une convexité arrondie au bout extérieur de l'organe, il 


\section{(}

montrait là un enfoncement comme un chapeau qui aurait reçu un coup de poing. (Voy. $f g .1^{\text {re }}$.) Cet enfoncement produisait une saillie dans l'intérieur de la cavité du labellum lequel était pourvu de ses rebords marginaux comme de contume. (Voy. fig. 2.)

La colonne montrait d'étranges changements.

D'abord la colonne, plus grêle que dans le type, offrait une division en deux corps, l'un staminal supérieur, l'autre pistillaire inféricur. Ce corps pistillaire (fig. 5, 4, $\$, 6$ ) était normalement placé; il était terminé par le stigmate en disque propre au genre. Ce gynize conduisait à un ovaire régulier. De tous les organes de la fleur monstrueuse, il n'y avait que l'élément pistillaire qui fût le plus régulièrement formé, développé et placé.

Mais le corps staminal, au contraire, était celui dont les aberrations étaient les plus étranges : l'anthère de droite était seule développée ( $f i g .5,4,5$ et 6 ), et elle l'était régulièrement $(f g .7)$ ayant ses valves anthériennes bien distinctes, ouvertes en coquille et le pollen abondant et dans de bonnes conditions de fertilité. Quant à l'anthère de gauche et au lobe central, si développé en disque papillifère dans la plante normale, on n'en voyait aucune trace dans cette fleur. Les trois étamines primitives étaient done réduites en une seule, celle de droite.

Enfin, et pour finir cette description, au bas de l'ovaire ( $/$ ig..$^{\mathrm{re}}$ ) on voyait, à l'articulation de la bractée, celle-ci, petite et foliiforme, sortir de la gaine et se libérer, en forme te lame, et la gaine elle-même être formée par une énorme leuille développée comme celles de la tige verte et forte, et poursuivant sa longueur au-dessus de la fleur ellemème.

Voilà l'ćtat des choses dans leur complet. Voyons si 
nous pouvons nous rendre compte de la nature intime de ce cas de tératologie et remonter, si possible, à sa cause.

La feuille qui remplace la bractée, alors que celle-ci existe et que les feuilles, dans les monocotylédones sont normalement et primitivement alternes, semble done bien ètre la feuille ayant la fleur à son aisselle, mais seulement supportée par un rameau, division de la lige. Done là, se trouve un exemple d'une organisation anormale très-commune et très-explicable.

L'ovaire est droit, sans torsion, dans des conditions ordinaires de développement, de même que tout l'appareil pistillaire. Donc, nous pourons nous figurer l'axe de la fleur comme normal. Mais c'est autour de cet ase que les forces d'aberration ont fait leur circonvolution et ont laissé les traces de leur puissance. D'abord, une force de torsion s'est emparée des deux éléments calicinaux et leur a fait subir un mouvement d'un quart de cercle en descension gauche. Puis une force de torsion a fait subir au second verticille floral un mouvement aussi d'un quart de cercle en ascension droite, et, dans cette torsion, un élément foliaire, un pétale a été anéanti, comme si les ćléments organiques, froissés par ce mouvement, s'étaient trouvés dans l'impossibilité de se développer, et partant de produire un appareil foliairc. Enfin, on peut facilement concevoir que cette torsion arrivée au bout de son axe et se rapprochant de plus en plus de l'appareil central, le pistil a fait avorter de même el l'étamine de gauche et le lobe central de la colonne.

L’idéalisation de cette cause nous représente done cette force d'aberration tératologique comme consistant dans une torsion spiraloïle marchant de droite à gauche, s'écartant d'abord de l'axe floral et entrainant ainsi, non la 
destruction, mais le déplacement des premiers verticilles de l'appareil floral, puis cette torsion se rapproche de l'axe contre lequel on dirait que ce mouvement en spirale froisse les organes et les anéantit. Cette image, tout abstraite qu'elle est, nous explique d'une manière parfaite celle suite singulière de phénomènes d'atrophie, d'hypertrophie, de déplacement et de torsion que nous a offerts cette singulière fleur de Cypripède. Je ne pense pas qu'il y ait une autre théorie possible pour nous rendre compte de cet ordre de faits, et si l'on réléchit aux causes qui doivent, de toute nécessité, agir dans la jhyllotaxie pour faire naitre les feuilles dans des positions exprimables par un système de fractions relatif à des spirales, on doit, ce me semble, être convaincu que ces spirales génératrices, déviées dans leurs propriétés pendant que l'organisme se forme, peurent et doivent même donner lieu à certaines expressions tératologiques. Ce Cypripède réalise ce fait. Je ne sais si l'on y a réfléchi antérieurement dans les annales de la tératologie.

Fig. 1.

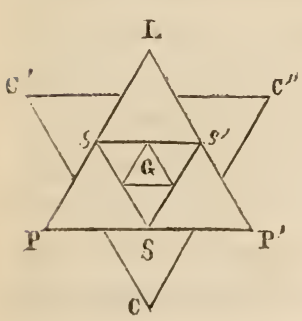

Fig. 2.

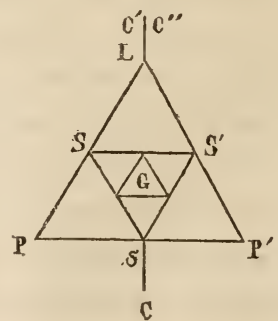

Fig. 3.

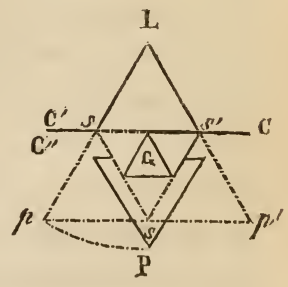

Soient $\mathrm{C} \mathrm{C}^{\prime} \mathrm{C}^{\prime \prime}$, fig. 1, angles du triangle équilatéral représentant le triple élément calicinal des orchidées, les trois sépales du calice, nous aurons par suite des lois d'alternance, en $\mathrm{P}, \mathrm{P}^{\prime}$ les pétales et en $\mathrm{L}$ le labellum, trois 


\section{(61)}

parties du second triangle de superposition ou la corolle; nous aurons de mème en Sss' les trois éléments du verticille staminal, mais ici S seul se développe pour constituer la seule anthère des vraies orchidées, $s s^{\prime}$ avortent ou mieux s'atrophient en staminodes, et enfin G est le pistil et l'ovaire avec ses trois placentas pariétaux représentés par les trois angles du triangle central.

De cette structure, il résultera : $1^{\circ}$ que le labellum (L) sera situé, vis-à-vis de l'intervalle, entre deux sépales $\left(\mathrm{C}^{\prime} \mathrm{C}^{\prime \prime}\right)$ et vis-à-vis de l'anthère $S ; 2^{\circ}$ que les placentas, alternes avec les sépales, seront opposés aux pétales et au labellum.

Dans les Cypripédiées, le fond de l'organisation reste le mème, avec un simple changement de plus ou de moins dans le développement de l'appareil mâle, et des modifications plus importantes dans le verticille extérieur de protection. En effet, soit fig. 2 le diagramme des Cypripédiées, G pistil, reste immuable avec les trois placentas, mais l'anthère $\mathrm{S}$ de la fig. 1 , s'atrophie et devient $s$; au contraire, $s, s^{\prime}$ de la fig. 1 deviennent des étamines fertiles $\mathrm{S} \mathrm{S}^{\prime}$. Le triangle corollin $\mathrm{L}, \mathrm{P}, \mathrm{P}^{\prime}$ reste le même, mais le triangle calicinal s'anéantit, $\mathrm{C}^{\prime} \mathrm{C}^{\prime \prime}$ ' se soudent vis-à-vis de $\mathrm{L}$ (labellum), et $\mathrm{C}$ seul reste en alternance de $\mathbf{P} \mathrm{P}^{\prime}$.

Il résulte de ces modifications : $1^{\circ}$ que le labellum est situé vis-à-vis d'un sépale du calice qui, bien que moins grand parfois que son homologue $\mathrm{C}^{\prime} \mathrm{C}^{\prime \prime}$, n'en est pas moins formé de deux éléments foliaires, comme le prouvent les deux nervures principales partant de lintervalle entre les pétales latéraux et le labellum; $2^{\circ}$ que le labellum est opposé à l'étamine atrophiée $s$, donc au disque pétaloïde et papillifère des Cypripédium; $5^{\circ}$ que le labellum est du côté des deux étamines fertiles; $4^{\circ}$ que la loi d'alternance des placentas avec les sépales est détruite, un seul sépale, 
C, fig. 2, étant alterne avec deux placentas, le troisième, alterne avec les étamines fertiles, étant opposé au sépale placé vis-ì-vis du labellum.

Done, si l'on compare les Cypripédiées aux orchidées, on voit que tout le jeu de variation a roulé sur le calice, dont l'alternance a changé par une rotation des éléments $\mathrm{C}^{\prime} \mathrm{C}^{\prime \prime}$ ver's $\mathrm{L}$, fig. 1 , et une soudure de ces éléments. Quant à la variation de l'élément staminal, tout se borne à l'atrophie d'un organe et à l'élévation aux fonctions des deux autres organes atrophiés dans le type des orchidées; mais dans l'alternance des éléments de ce verticille, rien ne change : il n'y a pas de rotation.

Dans la monstruosité par torsion, on voit évidemment, fig. 5 , que les relations des parties développées et atrophiées sont derenues les suivantes: $C^{\prime} C^{\prime \prime}$ (deux sépales du calice alternes au labellum dans les orchidées, opposés au labelIum dans les Cypripédiées) sont devenus de nouveau alternes au labellum L (développé) et au pétale $p$ (atrophié), mais la disjonction n'a pas eu lieu comme dans les orchidées, le type cypripédien s'est conservé, el $\mathrm{C}^{\prime \prime}$ a fait une révolution d'un demi-cercle, C' d'un quart de cercle. Quant à $\mathrm{C}$, alterne dans les deux groupes, les orchidées et les Cypripédiées, avec les pétales $\mathbf{P} \mathrm{P}^{\prime}$, ce sépale opposé à son homologue $\mathrm{C}^{\prime} \mathrm{C}^{\prime \prime}$, devient alterne avec le labellum $\mathrm{L}$ (développé) et $p^{\prime}$ pétale atrophié. Si l'on suppose que, dans un calice disépale, l'organisme forme un tout, on voit que la droite $\mathrm{C}^{\prime} \mathrm{C}^{\prime \prime}$ de la figure 2 a subi une simple rotation sur le milieu de la fleur, et de perpendiculaire est devenue horizontale.

Quant à la corolle, L labellum devient immuable, maisP, un des pétales, subit la rotation de $p$ en $\mathrm{P}$, et $p^{\prime}$ avorte. De là l'opposition du labellum $\mathrm{L}$ à ce seul pétale P développé. 


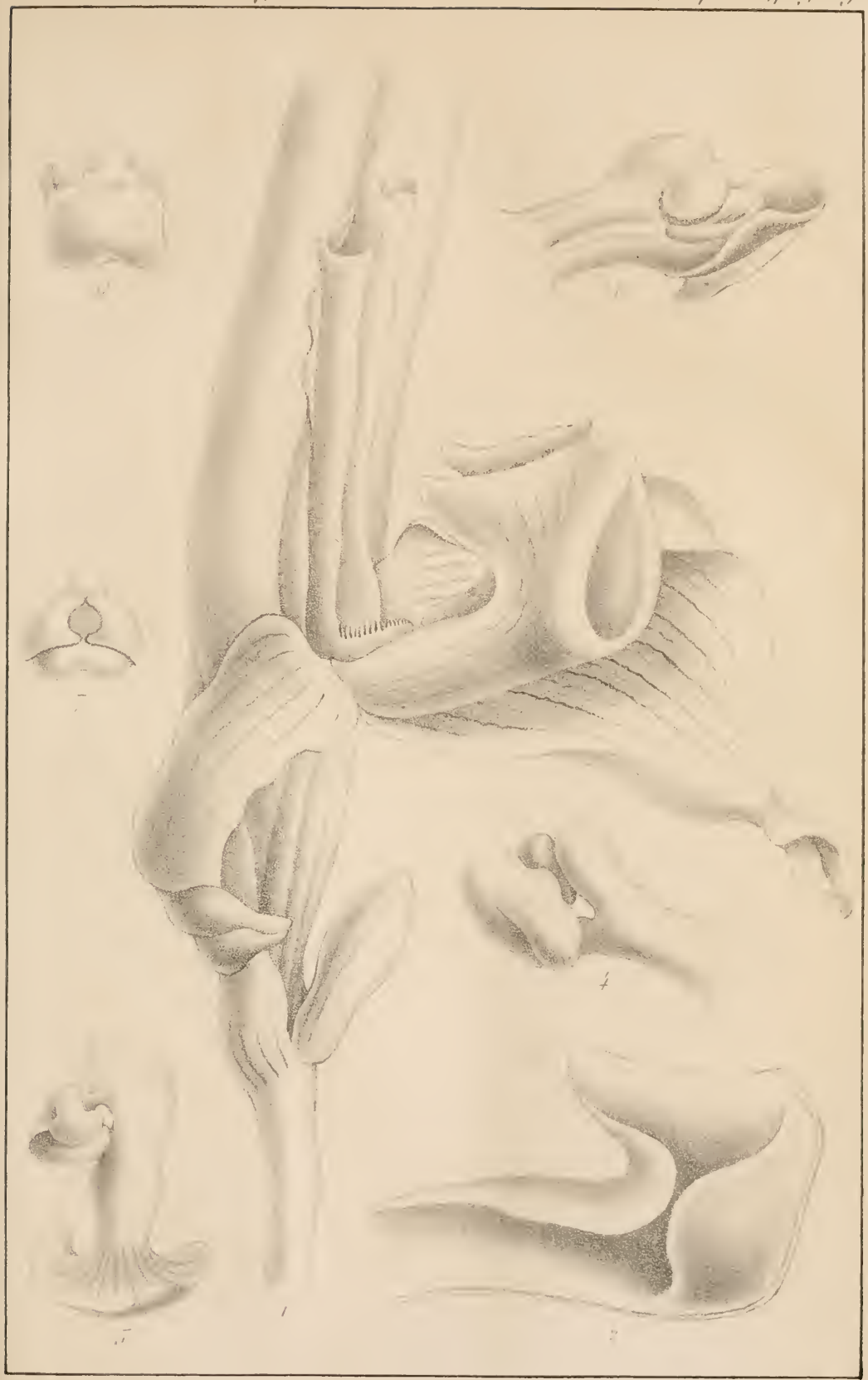

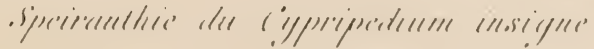



Dans le verticille staminal, tout le phénomène se borne, de même que dans la transformation des orchidées en Cypripédiées, à une simple atrophie, d'une part, et à une simple élévation aux fonctions, de l'autre; ainsi $\mathrm{S}^{\prime}$ reste étamine fertile, mais $s$ et $\mathrm{S}$ s'atrophient, quoique le triangle $s^{\prime} s^{\prime}$ conserve toutes ses relations d'alternance avec le triangle $G$, immuable dans tous ces changements.

Donc, il est évident que, dans cette monstruosité, la inême force de variation qui a fait des orchidées un type de Cypripédiées par un simple mouvement de rotation accompagné d'atrophie et d'hypertrophie, a continué d'agir. Il n'y a pas eu développement de forces nouvelles, mais continuation dans les effets d'une force donnée. On peut conclure de là que si les causes des changements morphologiques étaient connues, on serait conduit à savoir présumer quels sont les cas probables de la tératologie. La tératologie serait une déduction de la science des formes, au lieu d'être une énumération plus ou moins bien expliquée des monstruosités, regardées comme des aberrations ou des écarts de la nature.

Pour exprimer la construction singulière de ce Cypripedium sans périphrase, je propose de nommer ce genre de construction tératologique speiranthie, de orecpwoins, tors, torse, et ${ }_{\alpha}^{\prime} \theta_{0}$ s, fleur, fleur tordue.

\section{EXPLICATION DE LA PLANCHE.}

Fig. 1. Cypripedium insigne affecté de Fig. S. Colonne vue d'en haut. speiranthie.

2. Coupe longitudinale du labellum.

ㄱ. Colonne vue du côté droit.

*. Colonne vue du côté gauche.
6. Colonne vue de devant.

7. Anthère développée.

Les figures $3,4, j, 6$ et 7 sont rues in la loupe. 

ACA DEMHE ROYALE DE HELGIQUE.

(Extrait du tome XVII, $n^{\circ} ;$, des Bulletins.;

\section{TÉRATOLOGIE VÉGÉTALE.}

ITUDE DUNE PETALIGATION SHCCESSIVE DANS IRS SAXHRAGES;

par

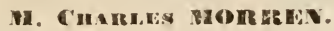

Membre de l'Aeademie royale de Belgique.

La transformation des étamines en pétales est, comme l'on sait, la plus commune des monstruosités. Cette pétalification, avec le dédoublement, constitue le fond et la raison de la plupart de nos fleurs doubles de jardins. On a tant de fois et si profondément examiné ce phénomène tératologique qu'on devrait croire à sa radicale stérilité en fait de déductions nouvelles, et cependant nous avons vainement cherché et dans la savante dissertation de M. Hugo Mohl, sur la métamorphose des anthères(1), et dans le traité de Goethe, la tératologie de M. Moquin-Tandon, la citation d'une pétalification très-remarquable dans l'ordre du développement successif qu'elle affecte. Ce cas s'est offert à moi dans la culture du Saxifraga decipiens, Ehrh.

Cette saxifrage, spontanée sur les rochers de l’Allemagne

(1) Flora, 1856, et la traduction on français, Ann. des sciences nat. Bot.; 1857, 1. VIII, p. 50. 
et de la Bohême, ne présente pas cette transformation dans le jardin botanique où nous la cultivons entre des pierres placées à demeure dans la terre. Là, la plante offre un grand développement en traçant tout à la fois sur le sol et les morceaux de roches. Mais la pétalification des étamines s'est montrée dès la première année de la culture forcée de cette espèce dans une terre tempérée, où le végétal avait reçu une bonne terre terreautée et beaucoup de soins; les rameaux s'allongèrent considérablement, les feuilles s'espacèrent, les tiges florales, se montrant dès février, devinrent grêles et longues, les fleurs plus grandes, moins serrées, se montrèrent peu à peu doubles, de sorte que sur un seul pied, on voit parfois se réaliser toutes les modifications qui s'emparent des étamines.

Nous commencerons par exposer ces transformations sans commentaires.

La fleur normale est dessinée figure $\mathbf{1}^{\mathrm{re}}$. Le calice, campaniforme, a ses cinq divisions ovales parfaitement indifférentes dans tous les états; la corolle est formée par cinq pétales obovés, alternes avec les divisions calicinales, offrant un onglet court et large. Remarquons que ces pétales ont ce système-ci de nervation (voyez fig. 6): une nervure médiane parcourt toute la longueur du pétale de l'onglet au sommet, et à l'endroit où le pétale s'élargit en lame, se détachent parallèlement aux bords marginaux, deux nervures latérales, de sorte que, prise dans son ensemble, celte nervation se compose de trois nervures à peu près parallèles, convergentes et presque de la même grosseur ou force. N'oublions pas ce fait.

La fleur normale est considérée dans la théorie d'Agardh, comme diplostémone; le premier rang d'éfamines se trouve ¿l'aisselle des sépales (ici soudées à l'ovaire par le disque); 
le second rang a ses organes à l'aisselle des pétales. L'étamine, quel que soit son rang, est formée d'un filet long, légèrement aplati, portant des poils glandulifères ( $\mathrm{fg} . \mathbf{7}$ ) jusqu'à la base de l'anthère, mais rares; l'anthère est large, ovale, le connectif très - développé et les loges de l'anthère séparées, réniformes, s'ouvrant longitudinalement. Le disque est élargi, plat, vert; on le voit baigné par dix gouttes de matière visqueuse, sécrétées devant chaque étamine, dont les deux rangs placés vers le pourtour extérieur du disque ne sont pas sensiblement sur deux lignes. Du centre du disque partent les deux styles obliquement tronqués par le stigmate. L'appareil pistillaire restant aussi indifférent que le calicinal dans l'acte de la métamorphose, nous ne parlerons guère ni de l'un ni de l'autre.

Voilà l'état des choses normal. Prenons maintenant une fleur où la pétalification ou la pétalomanie, comme le disait Decandolle, commence. (Voyez fig. 2.) Ici nous apercevons ce phénomène singulier qu'une étamine pétalifiée alterne avec une étamine normale, et bientôt on aperçoit que les seules étamines métamorphosées sont celles qui correspondent aux sépales; donc, la force modificatrice prend son initiative dans le premier rang de l'androcée ou les étamines qu'Agardh considérait comme les bourgeons calicinaux. Ce fait mérite une considération toute particulière.

Examinons de plus la forme de ces pétales provenus de la métamorphose des étamines. Nous y royons un onglet étroit, une lame proportionnellement plus large qu'aux pétales normaux $\left(f i g .6^{\text {bis }}\right.$, une forme plus rhomboïdale, deux petits plis vers le bord inférieur qui rappellent encore les loges de l'anthère, et sur tout l'organe se répète la nervation triplinerve des vrais pétales. Celte nervation rap- 
proche d'une manière évidente les pétales staminaux des pétales corollins, et ce qui achève de les mettre en rapport, c'est l'état entier de leurs bords.

Mais, nous prenons une fleur du Saxifraga decipiens qui offre une seconde modification dans l'ordre des progrès tératologiques (fig. $\mathbf{5})$. Ici, ce sont encore les seules étamines calicinales qui offrent la métamorphose, mais, au lieu d'avoir formé des lames pétaloïdes simples, elles ont formé des lames pétaloïdes trifides. En effet, devant chaque sépale se trouve un pétale (fig. 10) constitué par un onglet plat, n'offrant plus les poils glandulifères de l'étamine (fig. 7), mais des poils allongés, simples, et par une lame profondément trifide, le lobe du milieu plus large, plus grand, présentant la nervure médiane très-visible, et deux nervures latérales qui le sont moins dans les deux lobes latéraux. Évidemment, dans cette seconde phase de la métamorphose, il s'est déclaré dans le premier rang d'une androcée diptostémoniée un éloignement de la forme corolline; mais, pour peu qu'on examine la plante entière, on est étonné de trouver entre cette forme trifide de l'étamine pétalifiée et celle des feuilles une analogie frappante (fig. 12). La force tératologique a été poussée tout à coup de trois degrés plus bas; elle a sauté par-dessus la forme corolline, calicinale, bractéenne, pour arriver à la forme foliaire, comme si elle obéissait jusque-là au pouvoir des métamorphoses descendantes de Goethe. Ce fait est fort curieux, et nous ne voyons pas qu'il ait été signalé antérieurement.

Sur d'autres fleurs, nous retrouvons une phase encore plus avancée dans la transformation (fig. 4). Ici, les étamines calicinales pétalifiées sont restées avec leur forme trifide, mais les étamines corollines, jusque-là conservées 
dans leur fonction naturelle, se sont elles-mèmes pétalifiées. En premier lieu, elles prennent la forme de simples lames pétaliformes, entières, à trois nervures, absolument comme l'ont fail les étamines du premier rang. En second lieu, sur des fleurs arrivées au plus haut état de fleurs doubles dans ce genre, ces mêmes étamines du second rang ont acquis la forme trifide foliaire, comme on le voit fig. 5 . Alors, la fleur est réduite à la sexualité du pistil, et sa perfection horticole est accomplie. L'esthétique des horticulteurs la rangera alors dans l'ordre des fleurs les plus perfectionnées, et l'architecte, comme le dessinateur, pourront en effet y puiser des idées de rosace d'une grande élégance et cette fois fondées sur la nature.

Voilà les différentes phases que subissent ces métamorphoses qui s'accomplissent évidemment ici dans un ordre donné, d'après une marche progressive dont chaque station est réalisée par des états particuliers. Mais, pour tirer de ces comparaisons toutes les conséquences les plus utiles à la tératologie philosophique, nous devons faire remarquer les analogies qui existent entre les organes métamorphosés et les organes typiques, et démontrer comment les modifications s'établissent successivement.

Au bas de la tige du Saxifraga decipiens, on trouve des feuilles entières (fig. 11) plus grandes que les autres : ce sont les feuilles primordiales spatulées; elles offrent un pétiole long, aplati, continu avec le limbe, et sur ce limbe trois nervures, dont les deux latérales, parallèles au bord marginal sont convergentes.

La feuille caractéristique est d’abord trifide (fig. 12), chaque lobe ayant sa nervure médiane propre, et les poils commencent à abonder tant au-dessus qu'au-dessous. Puis, on apercoit des fenilles dont un des lobes latéraux se bi- 
furque (fig. 15), mais la bifurcation des deux lobes à la fois devient à la fin très-commune, et beaucoup de feuilles l'offrent comme dans les espèces voisines du genre Saxifrage (Saxifraga palmata, etc.). Nous n’avons jamais trouvé la trifurcation d'un lobe latéral comme Sturm l'a figurée dans sa Deutschlands Flora ( $\overline{7}^{\mathrm{e}} \mathrm{vol}$., X, 2), sur le Saxifraga palmata, pas plus que nous n'avons vu la bifurcation du lobe médian de la feuille palmée (à cinq lobes).

Or, il est intéressant de remarquer que, dans la pétalification des étamines, soit du premier, soit du second rang, l'irrégularité dans la formation des lobes peut avoir lieu comme dans la feuille. Ainsi, telles fleurs offrent des étamines métamorphosées en pétales, mais dont un seul lobe latéral s'est développé (fig. 9). Dans ce cas, la nervure latérale de l'autre côté est encore visible dans le lobe du milieu, preuve évidente que c'est la divarication des fibres qui amène cette formation de. lobes.

Un second fait que nous avons pu constater dans ces observations, c'est qu'ici, comme dans un grand nombre de cas, il est évident que c'est le connectif de l'anthère qui se pétalifie le premier. Le principe d'Engelmann se vérifie donc, à savoir que le pétale staminal est une anthère dilatée, bien que ce principe ne soit pas admis par tous les tératologistes (1). La fig. 8 représente une étamine en voie de se métamorphoser. Les poils sont encore glandulifères sur le lilet, mais l'un d'entre eux devient déjà simple sur l'anthère, les deux loges anthériennes existent encore, l'organe est toujours mâle, mais déjà le connectif, bien différent dans sa forme de ce qu'il est dans l'état normal (fig. 7), est

(1) Voy. Moquin-Tandon, Tératologic , p. 215. 
monstrueux; il devient le lobe médian du pétale staminal, donc les deux nervures latérales semblent bien représenter la cloison des loges anthériennes (trophopollen de Turpin).

Enfin une dernière considération doit frapper l'observateur. La métamorphose s'empare de l'organe mâle : il devient semblable aux pétales normaux. Puis, la force tératologique progressant toujours, l'étamine pétalifiée franchit dans ses modifications morphologiques, l'espace qui le sépare des organes intermédiaires, ct il revêt la forme des feuilles normales, mais il prend cette forme foliaire entre le premier degré qu'elle revêt, celle des feuilles primordiales dévolue aux pétales corollins normaux, et le dernier degré, celle des feuilles palmées à cinq divisions, la plus haute complication que le principe de la divarication des fibres peut imprimer à l'espèce. Dans la fleur double, il y a donc limite à la puissance modificatrice. L'étamine peut bien devenir pétale, ce pétale peut bien devenir feuille, quant à la forme, mais la feuille revêtira une forme plus avancée en organisation à laquelle le pétale foliifié ne pourra atteindre. L'art de la culture aura beau faire, il n'ira pas plus loin, et les modifications qu'il imprime aux êtres de la nature seront nettement tracées et fixées par elle-même.

Le lecteur aura remarqué que nous ne nous sommes guère appesanti sur l'ordre d'alternance et de successibilité dans la métamorphose dont il s'agit. D'abord, il est évident que si l'on admet que les modifications tératologiques sont des conséquences d'une force éminemment vitale dans sa nature, mais perturbatrice de l'ordre naturel qui assure à chaque espèce son existence fixe, immuable dans un temps donné, si l'on admet que ces changements sont le produit d'une force plutôt simplement morphologique que physiologique et de la nature des fonctions nécessaires 
ì la vie, on devra cependant recommaître que celte force et de forme et de perturbation, est réglée par la loi d'alternance, loi éminemment organologique e! régulière. La nature de la force tératologique est essentiellement destructive des fonctions : ce n'est pas l'organe qui est anéanti, c'est sa fonction qui est annulée, et cependant cette force qui produit les monstruosités ne peut échapper aux lois fonctionnelles. Ainsi l'on sait que, dans les fleurs diplostémones, la fécondation ne s'accomplit pas uniformément et indifféremment par les étamines des doubles verticilles. L'un rang agit, puis l'autre; dans le Saxifraga decipiens, cette fécondation coordonnée d'après le rang des mâles est aussi évidente que dans la Rue, et les étamines calicinales ont la priorité. La modification tératologique suit cette loi; si le rang calicinal est le premier à agir, il est aussi le premier à se déformer; puis vient le tour du rang corollin dans l'une et l'autre de ces actions. Cette corrélation est curieuse.

En résumé, on peut conclure de ces différentes recherches que :

10 Dans les fleurs diplostémones, du genre des Saxifrages, la pétalomanie ne s'établit pas sans ordre et confusément, mais elle suit la loi d'alternance organologi(yue. Par suite, le rang des étamines opposées aux sépales se métamorphose le premier : tantôt la modification s'arrête là, tantôt elle se poursuit et s'empare alors du rang des étamines opposées aux pétales;

$2^{\circ}$ La fleur semi-double se féconde donc par le rang corollin de l'androcée, le rang calicinal étant le premier à perdre sa fonction, et la fleur double, annulée dans ses fonctions reproductives, ne l'est que lorsque le rang supérieur a subi sa métamorphose tératologique; 
$5^{\circ}$ La première forme que subissent les étamines pétalitiées, les ramène à la morphologie de la corolle; la seconde les fait descendre par une métamorphose décursive, en sautant sur plusieurs formes intermédiaires, à la forme des feuilles caractéristiques, tandis que la forme pétaloïde normale ou celle des premières métamorphoses ramenait la morphologie des organes pétalificees à l'état des feuilles primordiales ;

$4^{\circ}$ Dans toutes ces modifications, la forme des organes modifiés est relative au système de nervation de la plante entière; toutes les combinaisons que permettent la divarication des fibres ou leur soudure, sont réalisables, entre certaines limites, par les organes métamorphosés, sans que le type vasculaire se perde;

$5^{\circ}$ Dans la pétalification des étamines de cette nature, évidemment l'organe modificateur est le connectif représentant de la nervure médiane de la feuille typique, et après lui viennent les nervures secondaires qui correspondent aux cloisons des loges anthériennes; de sorte qu'on peut en inférer que, dans l'étamine normale, les parois des loges correspondent aux portions du parenchyme de la feuille que bordent ces mêmes nervures secondaires, tandis que la séparation des loges de l'étamine normale correspond à l'interveine qui s'étend entre la nervure médiane et les nervures secondaires principales;

$6^{\circ}$ Donc, quand une fleur diplostémone se double, toutes les lois de l'alternance et de la similitude des parties daus un type donné d'organisation se conservent, quoique les fonctions pour l'exercice desquelles les organes sont créés soient abolies, et les aberrations des formes ne sont pas assez puissantes pour anéantir la nature intime et physiologique des appareils vitaux. 


\section{( 74 )}

\section{EXPLICATION DES FIGURES.}

Fig. 1. Fleur normale du Saxifraga decipiens, grandie d'un tiers.

ᄂ. Fleur pétalifiée dans le rang des étamines calicinales.

5. Fleur pétalifiée dans ce même ranğ les pétales staminales trifides.

4. Fleur pétalifiée pour les deux rangs, le calicinal affectant la forme foliaire, le second la forme pétaloïde.

3. Fleur pétalifiée dans les deux rangs de l'androcée. selon le typè foliaire.

6. Pétale normal.

6'. Pétale staminal de forme corolline.

7. Étamine normale, agrandie à la loupe.

8. Étamine se pétalifiant.

9. Pétale staminal à deux lobes, agrandi à la loupe.

10. Pétale staminal à trois lobes, agrandi à la loupe.

11. Feuille primordiale, grandeur naturelle.

12. Feuille trifide ordinaire.

13. Feuille quadrifide par la bifurcation d'un lobe latéral.

14. Feuille palmée.

C'es trois dernières figures, 12,15 et 14 , sont de grandeur naturelle. 

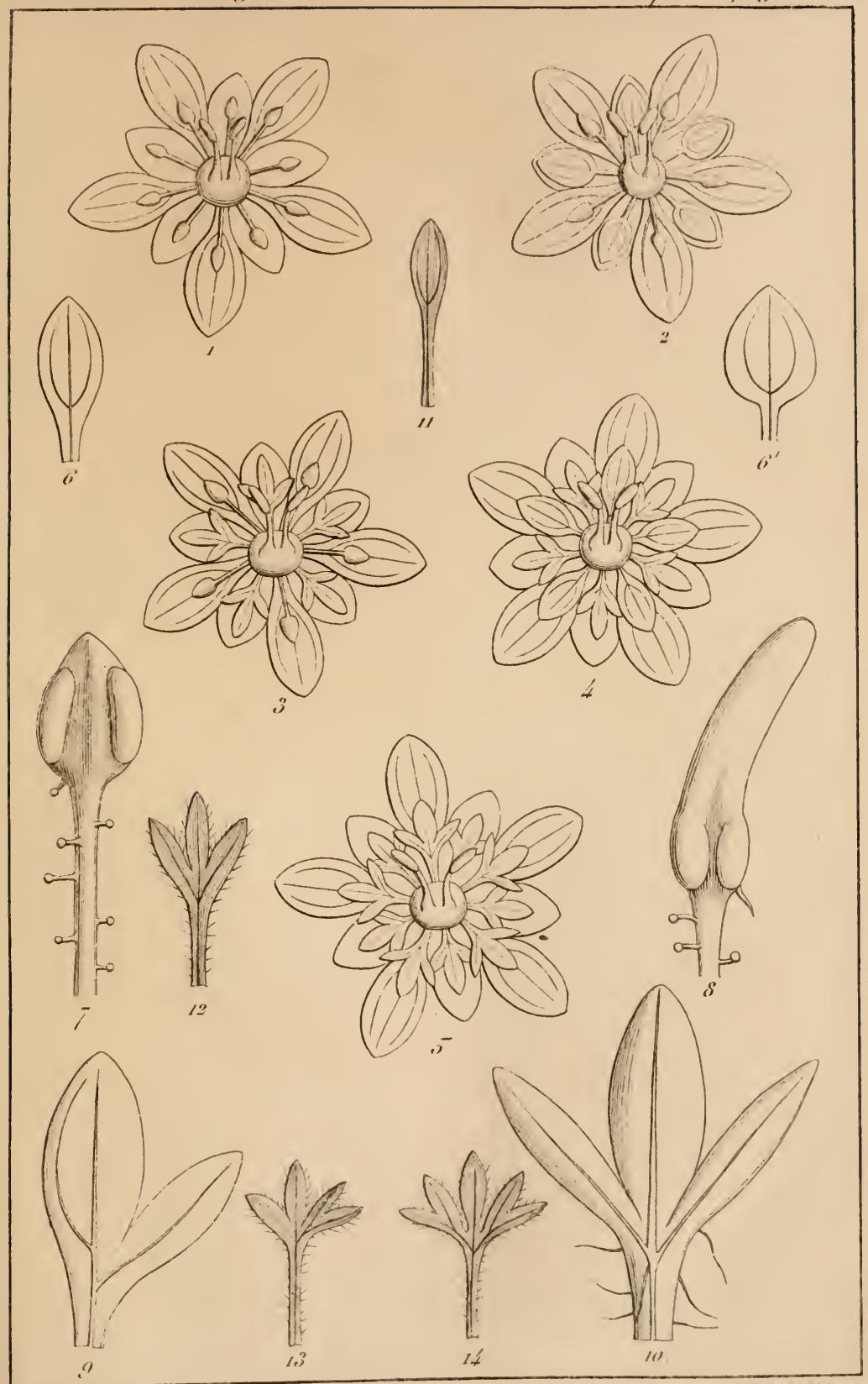

i25 $\mathbb{M}-\cos a d$ is

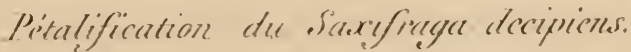





\section{ACADEMIE ROYALE DE BELGIQUE.}

(Extrait du tome XVII, $n^{\circ} 6$, des Bulletins.)

\section{NOTICE}

Sur la structure morphologique de la fleur des Lopéziées et sur une adénopélalie observée dans cette tribu;

par

At. (U). Allorren,

Membre de l'Académie royale de Belgique.

On ne peut nier que les OEnothérées (Onagrariées de Jussieu, Onagrariacées de Lindley, Onagrées de Spach) ne constituent en majorité une organisation symétrique dont le nombre normal est quatre ou ses multiples ou ses radicaux (deux), bien que le type dût être normalement cinq. Dans la tribu des Jussiévées, le type quinaire se rencontre encore, mais à partir des Épilobiées, l'agencement quaternaire l'emporte.

La tribu des Lopéziées est évidemment la plus singulière du groupe. Nous prenons pour exemple le genre Lopezia (Cav.) lui-même. Examinons d'abord comment les idées morphologiques se sont fait jour dans la description organographique de ce genre.

Tube du calice subglobuleux, soudé à l'ovaire, limbe supère, quadri-partite, divisions colorées, étroites, lancéo- 
lées, les trois postérieures (1) subsecondes, l'antérieure (2) éloignée des autres. Corolle à quatre pétales insérés au sommet du tube du calice, alternes avec ses divisions, longuement onguiculés, les deux postérieurs (5) à onglets longs, glanduleux à leur sommet (4), articulés avec la lame, qui est étroite et elliptique (ö), les pétales antérieurs (6) ayant leur onglet plan et la lame ovale ou suborbiculée et continue avec l'onglet. Deux étamines (7) insérées sur le même rang que les pétales opposées aux divisions antérieure et postérieures du calice, l'étamine antérieure (8) stérile, en lame pétaloïde à son extrémité, l'étamine opposée fertile et embrassant d'abord le style, puis s'en séparant avec élasticité; filet de l'étamine postérieure, subulée et aplatie, embrassant le style à la base, anthère intorse, biloculaire, ovale ou oblongue, loges parallèles, s'ouvrant longitudinalement. Ovaire infère, quadriloculaire. Ovules nombreux dans les loges, plurisérićes, pendants, anatropes, style filiforme, court (9), stigmate

(1) Ce mot est mal choisi : il exprime une idée fausse. Il n'y a pas deux rangs au calice mais un. Les divisions postérieures sont les supérieures dans la position horizontale de la fleur.

(2) En rẻalité, l'inférieure. Pétales.

(3) Encore une fois, les deux supérieurs.

(4) Plus clairement, glanduleux à la base de la lame des pétales.

(5) Cette articulation est importante à noter. Elle indique la nature mixte de cet organe glandulifère et pétalifère.

(6) Inférieurs.

(7) La loi seule de l'alternance permet ce langage. Ici la phytographie deviênt de la morphologic pure, car l'œil le plus complaisant ne pourrait voir lans un organe pétaloïle de forme, de fonction et d'insertion, une étamine.

(8) C'est-à-dire l'étamine inférieure.

(9) Pas plus court que l'étamine, de manière que, dans la copulation, l'anthère se place justement au-dessus du stigmate. 
capité (1); capsule globuleuse, quadriloculaire, loculicide, quadrivalves, colonne tétraptère, persistante, cloisonnée aux angles séminifères sur les faces. Graines petites, nombreuses, plurisériées. (Endlicher.)

M. Auguste de Saint-Hilaire a fait remarquer (2) avec beaucoup de justesse que c'est, grâce à la perspicacité d'Antoine-Laurent De Jussieu, que les Lopezia n'ont pas fait le type d'une famille nouvelle, la tendance des botanistes de premier ordre étant plutôt de diminuer le nombre de ces groupes que de les augmenter (5). N'oublions pas toutefois, qu'Adanson entrevit, le premier, que le Trapa, classé jusqu'alors parmi les monocotylédones, était voisin des onagraires où Ventenat le plaça définitivement entre les Circaea et les Ludwigia. Ce fut aussi Ventenat qui ramena les Lopezia à cette même famille, et fit voir les analogies considérables qui les rapprochent des Circaea. Antoine De Jussieu le reconnaît lui-même (4). Il ne fit donc que corroborer davantage les vues de Ventenat.

Antoine De Jussieu, parce que les Lopezias ont visiblement un calice quadrifide, conclut à l'existence forcée de quatre pétales. Naturellement, il devait regarder comme tels les deux pétales élargis en forme d'ailes (voy. fg. 1), et les deux pétales glandulifères étroits. Ce qu'il nomme le troisième pétale supérieur, et qui passerait, en effet, pour tel, si l'on s'en tenait aux formes et aux fonctions, est considéré par l'illustre botaniste français comme une éta-

(1) Fortement poilu, et visiblement bilobé.

(2) Morphologie végétale, 1). 655.

(5) Observations sur la famille des plantes onagraires, par A. L. Ius. sieu, Asv. nu Nus., t. 11I, 1), 515.

(4) Op. Iaurl., p. 517 
mine avortée, dit-il. Il ne donne comme motif que son insertion plus élevée (verticille androcéen), mais il ne parle ni de la correspondance vis-à-vis d'une division du calice, au lieu de venir se placer en alternance avec ces divisions, ni de la forme de l'organe. En comparant avec la nature les figures analytiques d'un Lopezia publiées par Antoine De Jussieu, on s'aperçoit aisément de leur infériorité relative aux analyses qu'on est en droit d'exiger maintenant. Toutefois, la nature staminale de cet organe paraissait claire à ces esprits dès ce moment. Dans sa description des figures, il n'est pas fait mention des glandes, dont la signification morphologique nous semble avoir été méconnue.

Puisque le Lopezia a un calice quadrifide, dit De Jussieu, il doit avoir quatre pétales. Autant vaudrait continuer la loi et dire: puisqu'il y a quatre divisions calicinales et quatre pétales, il doit y avoir quatre étamines. L'une loi est aussi certaine que l'autre. Or, une seule étamine n'est pas douteuse. La seconde est pour l'œil un pétale, et quant aux deux autres, on ne se donne pas la peine de les chercher.

D'abord, nous ferons remarquer que l'insertion seule ne détermine pas la nature staminale du cinquième pétale apparent. Cet organe est coudé à sa base (fig. 5). Jusqu'au coude, il est simple et représente bien un filet comparable au filet déjà dilaté de l'étamine fonctionnelle (fig. 6). Mais au-dessus, il se dilate, et quand on le déplie, on y trouve (fig. 4) deux lobes latéraux et un troisième plus petit, mais central. Il est bien difficile de résister à l'idée de voir dans les deux lobes latéraux les deux loges de l'anthère et dans le lobe mélian le connectif. Les lobes latéraux obéissent encore à la loi du repliement, et leur tendance est de 
laire une cavité close de tout l'organe. Les figures $1, \vec{j}$ et 7 montrent celte disposition d'une manière évidente.

Quand on ouvre avec soin un bouton du Lopezia hirsuta (Jacq.), qui est l'espèce que nous avons particulièrement étudiée, on voit que la fonction de cette étamine pétalifiée est de contenir, d'embrasser et d'envelopper complétement et le pistil et l'étamine fertile. Le style est embrassé à son tour par une partic du filet de l'étamine fertile. La fig. ¿ donne la clef de ce mécanisme. Le style (fg. 5) est articulé, dirait-on, au quart de sa longueur, vers le bas. En fait, il est simplement rétréci dans cette partie; puis il se dilate insensiblement. Or, dans sa partie la plus grosse, le filet de l'étamine fertile est rétréci également à sa base, au-dessus de son pied grossi (fig. 6) et dilaté, bientôt le style est contenu dans les replis de ce filet, de manière que l'anthère introrse vient se placer déjà dans le bouton au-dessus du stigmate bilobé et fortement poilu. Quand la fleur s'ouvre, les sexes sont conjoints et l'ćtamine se sépare brusquement du style en projetant le pollen, dont une bonne partie a certainement fécondé le stigmate dans le bouton. Ainsi, il en est ici comme des stylidiées où les sexes sont trop près l'un de l'autre et où la fécondation est favorisée par un éloignement, par un mouvement brusque qui projette le pollen et place le stigmate dans une atmosphère de matière prolifique. Aussi, quand la fleur des Lopezias est fécondée, que sa mission d'existence est finie, trouve-t-on l'étamine épuisće relerée, allant se cacher entre les deux pétales glandulifères et sous une division calicinale, ordinairement la supérieure. On dirait d'une pudeur instinctive qui place l'organe mâle sous la protection des enveloppes de la fleur, comme, dans les Juslicia, on voit les deux élamines qui ont accompli leur 
acte, se ployer en arrière et s'abriter derrière la lèvre supérieure de la corolle, où elles ne sont plus en vue d'une femelle qui peut se passer d'elles. Si on attribuait de l'instinct ou du sentiment aux plantes, on verrait dans cette phase de l'accouplement un fait très-analogue à celui que nous montrent un grand nombre d'animaux, où les sexes se fuient après avoir cherché par tant de moyens à se rapprocher.

Les deux pétales supérieurs ont chacun une glande nectarienne. Ces glandes existent au sommet de ce qu'on est convenu d'appeler l'onglet. Nous avons vu comment Endlicher envisage les pétales, ou plutôt les lames de ces pétales, par rapport à ces glandes. Il trouve, et il a raison, une articulation entre l'onglet et la lame. Cette articulation se produit au-dessus et en arrière de la glande. La fig. 2 exprime ces relations.

Or, ces deux glandes, avec leur pied ou support, nous paraissent bien des organes spéciaux auxquels les pétales se sont simplement annexés. Ils nous paraissent être les deux étamines dont on cherche vainement l'existence dans les Lopezias. Remarquons que la raison la plus forte invoquée pour saluer du nom d'étamine le cinquième prétendu pétale inférieur, a été non sa forme, nous l'avons dit plus haut, mais son opposition au sépale (division calicinale). Or, ici pour les deux glandes, la fig. 1 démontre que bien que ces glandes paraissent attachées aux pétales supérieurs, de fait, par la réunion des trois divisions calicinales vers le haut de la fleur, elles sont opposées aux deux divisions latérales, comme l'étamine l'est à celle du milieu. Voilà pour la position.

Quant au rang verticillaire qu'occupent les onglets prétendus, ils sont à la même hauteur que l'étamine fertile et 


\section{( 81 )}

l'étamine pétalifiée. De ce côté done, il n’y a pas d'obstacle à y voir les étamines.

Les exemples où les étamines deviennent des nectaires, sont trop nombreux et passés à l'état d'axiome pour devoir y insister. La nature du nectar est chimiquement, dans un grand nombre d'organismes, analogue au moins à celle du pollen, et ici les glandes sécrètent un nectar visqueux qui engage les insectes ailés à visiter la fleur des Lopezias, dont la figure rappelle si parfaitement celle d'un petit papillon.

Nous prenons donc ces deux nectaires pour les deux étamines modifiées, et nous admettons seulement que les deux pétales supérieurs se sont soudés à leur support pour se libérer par une articulation en dehors (insertion extérieure) sous forme d'une lame à bords parallèles. De cette manière, il y a dans les Lopezias restitution de tout le type quaternaire des Onagraires, quatre divisions au calice, quatre pétales, quatre étamines et un pistil.

Nous avions fait depuis longtemps ces réflexions au sujet de ce joli genre dont de charmantes espèces se cultivent aujourd'hui dans nos serres, lorsque nous avons trouvé une fleur monstrueuse dont l'explication génétique est possible dans ce système. Cette structure est dessinée fig. 7 . On y voit trois grands pétales élargis et un seul aminci. De même, il n'y a qu'une glande. La position de ce pétale rétréci le place à l'intervalle de deux divisions calicinales. La troisième division qui, dans l'état normal, occupe le haut, s'est déjetée vers le bas, de sorte que le calice offre la figure d'une croix de Saint-André et l'intervalle entre les deux bras du bas est visiblement occupé par le troisième pétale élargi. De mème, l'étamine pétalifiée est plus grande, 
plus pétaloide encore, et toute la fleur offre plus de volume que dans une fleur génuine.

Cette monstruosité par métamorphose est, comme d'ordinaire, compliquéc d'une torsion latérale qui a entrainé les parties de gauche à droite. La torsion explique pourquoi on doit voir le pétale normal de droite (je me suppose toujours l'axe de la fleur, comme on se suppose l'axe de la tige dans les dextrorses ou sinistrorses) dans le pétale du bas. Donc le pétale droit supérieur ne peut provenir que d'un nectaire modifié et dont la substance organique fait corps avec le pétale lui-même. C'est l'histoire des nectaires des aquiléges devenant pétales. Sans doute, il eût été plus élégant pour la théorie des Lopéziées de voir se transformer les nectaires en étamines que de voir un de ces organes se métamorphoser en pétale; mais on sait que la pétalomanie est bien plus commune que la staminomanie (métamorphose des pétales ou autres organes en étamines), les métamorphoses décursives l'emportant en nombre et en facilité pour la nature sur les ascensionnelles qui doivent donner aux organes protecteurs la haute mission de la reproduction de l'espèce.

Toutcfois, ce genre de monstruosité n'a pas, à notre connaissance, été signalé dans les Lopezias, dont une pélorification serait une bonne fortune pour les botanistes qui s'occupent des lois intimes de l'organisation.

M. Nloquin-Tandon, dans ses Éléments de tératologie, admet quatre sortes de métamorphoses en organes floraux, c'est-à-dire en sépales, pétales, étamines et pistils, mais le point de départ n'est pas indiqué. Ce ne sont pas toujours des feuilles qui se transforment ainsi. Il vaudrait micux, ce nous semble, mettre l'état final en rapport avec le point de départ, et traiter, par exemple, de la métamorphose 



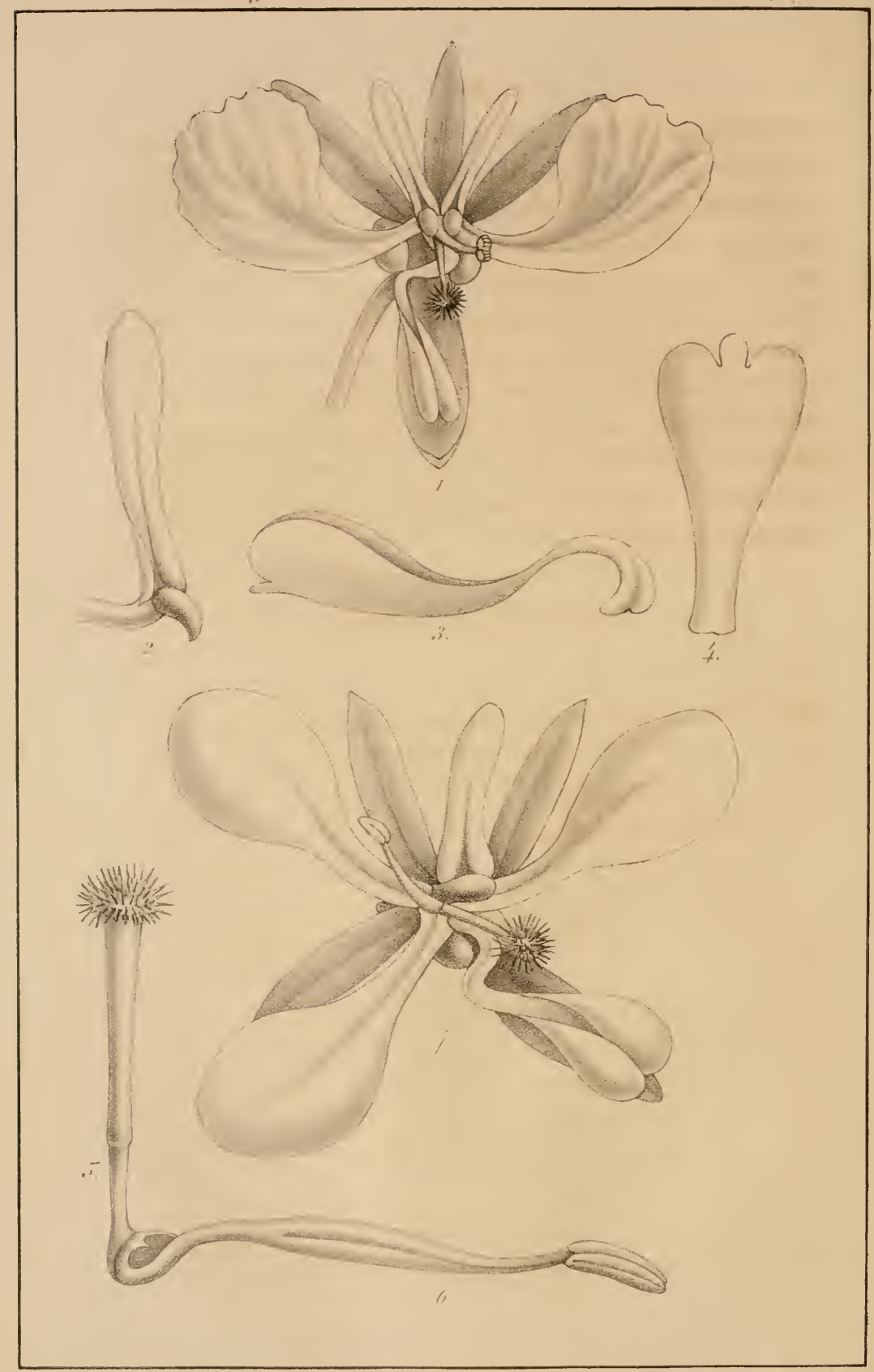

losperare hersules

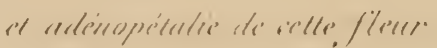




\section{( 85 )}

des sépales en pétales, des pétales en étamines, des étamines en pistils, etc. Dans ce mode d'envisager les choses, il faudrait une classe de faits où les nectaires seraient envisagés dans leurs métamorphoses en sépales (Tropaeolum), en pétales (Aquilegia, Lopezia), en étamines (Asclepias, Cobaea, etc.) Le genre de monstruosité que nous venons de décrire nous semble être un cas particulier de la transformation décursive des nectaires, considérés euxmêmes comme corps staminaux dans leur nature première, en pétales, et nous serions tenté de nommer ce groupe

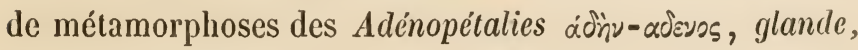

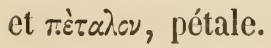

\section{EXPLICATION DES FIGURES.}

Fig. 1. Fleur ouverte du Lopezia hırsuta Jacq., agrandie à la loupe de six fois le diamètre conme les autres figures.

2. Nectaire et pétale supérieur.

5. Étamine pétalifiée.

4. Étamine pétalifiée déplicée.

5. Pistil attaché à

6. L'étamine fertile.

7. Fleur du même Lopezia adénopétaliée. 



\section{NOTICE}

Sur la disparition des organes sexuels (cénanthie) et sur le développement de nombreux rameaux ananthes (mischomanie) dans le Bellevalia comosa et sa variété moNSTROSA;

An. CU. Mlorren,

Membre de l'Académie royale de Belgique.

Le Bellevalia comosa (Mert et Koch), l'ancien Hyacinthus comosus de Linné, présente, dans son état habituel, le haut de l'épi ou ce que les taxonomistes appellent sa chevelure (coma) garni de fleur's d'un beau violet, mais que les uns regardent comme stériles (Bertoloni) et les autres comme neutres (Kunth). Au premier instant, on dirait ces deux adjectifs synonymes, mais en y réfléchissant bien, on doit reconnaître que des fleurs stériles sont celles qui ne produisent pas de fruits, ce qui n'implique pas qu'elles n'aient pas de sexes, et que des fleurs neutres sont celles qui n'ont 
pas de sexes du tout, et partant sont forcément stériles. Or, que sont-elles dans le Bellevalia comosa? Aucun taxonomiste ne le dit, et dans les documents de tératologie que nous possédons, il n’y a aucun fait à cet égard de publié. Mème le Traité général de tératologie de M. Mloquin-Tandon ne parle pas du Bellevalia comosa. On peut, en effet, regarder l'organisation des fleurs stériles de la chevelure comme des états non pas normaux, mais habituels de l'espèce, et partant ne pas les faire rentrer dans le cadre des monstruosités. Pour embrasser cette science de l'anormal dans toute son étendue, il sera plus rationnel d'y comprendre l'étude de la structure curieuse et hétéroclite à la fois de cette asphodelée de l'Europe australe.

Lorsqu'on analyse la fleur du Bellevalia comosa à l'état parfait, on lui voit un périanthe campanulé, anguleux, légèrement comprimé, à six angles, dont les deux plus saillants sont opposés. En se desséchant, alors que les fleurs ne sont pas fécondées, le périanthe affecte une forme subcylindrique. Au-dessus, le périanthe est ouvert par le repliement de dix dents qui indiquent les trois sépales et les trois pétales soudés ici en une seule enveloppe florale. Ces deux faits principaux sont dessinés pl. I, fig. 1 et $\mathbf{2}$.

Si l'on ouvre une fleur de cette forme, on y trouve, dit Kunth, six étamines insérées sur la gorge du périanthe, mais nous serions plus tenté de dire sur le tube de cet organe, vu que la gorge est clairement indiquée par un rétrécissement au-dessous des dents du limbe. De ces six étamines trois sont plus grandes et insérées plus haut, trois plus petites et insérées plus bas. Les trois étamines les plus grandes sont les premières à féconder le stigmate.

Nous ne savons comment Lapeyrouse a pu voir dans les filets de ces étamines une monadelphic, les filets étant 


\section{( 87 )}

distincts jusqu’à leur base. Ces filets sont linéaires, légèrement rétrécis vers le haut ou subulés. Les anthères sont biloculaires, introrses, elliptiques, oblongues, bilobées et fixées par le dos sur le filct. Ces anthères se réunissent devant l'ouverture du périanthe, de manière qu'en regardant la fleur d'en haut, on voit la cavité occupée par les organes sexucls. (Voy. pl. I, fig. 2.)

L'ovaire est libre, subsessile, triloculaire, deux ovules dans chaque loge; le style est droit, conique, allongé et le stigmate obtus, obscurément trigone. (Voy. pl. I, fig. 5.)

Il est à remarquer que sur cent fleurs, qu'on dirait entièrement et complétement fertiles, d'un épi de Bellevalia comosa, il n'y en a guère qu'une dizaine qui fournissent des capsules à graines fécondées. Beaucoup avortent. En examinant la cause de ce phénomène, nous l'avons trouvé dépendant d'un non-développement du stigmate. C'est l'organe femelle qui devient, dans cette plante, l'appareil le plus modifiable.

Vers le haut de l'épi, dans l'endroit où se montre la coloration bleue dans les pédicelles, l'axe de l'épi et les fleurs, on voit ces dernières présenter une autre forme; elles sont plus grêles, plus cylindriques, quoique encore anguleuses. Le rétrécissement de la gorge disparait (pl. I), fig. 4), les angles s'accroissent. Vues d'en haut, on s'aperçoit qu'elles restent fermées, le périanthe ne s'ouvre plus (pl. I, fig. ऽ, ) et l'on remarque trois tubercules blancliâtres au lieu des six divisions du périanthe ouvert.

Quand on ouvre une telle fleur qui reste toujours stérile, on s'aperçoit bientôt qu'elle n'est pas neutre. Elle est encore hermaphrodite, mais les sexes n'ont plus le pouvoir de la fécondation. Les étamines sont plus courtes, quoiyu'il y en ait encore trois un peu plus hautes que les trois 


\section{(88)}

autres. Les filets sont presque atrophiés, très-minces, trèspointus. Au contraire, les anthères sont plus grosses, mais bouffies, ne s'ouvrant plus, offrant au dedans un pollen humide, cellulaire, visqueux ou gluant. On dirait d'une hydropisie qui s'est emparée de ces organes mâles : c'est un véritable cas d'hydrocèle végétale. La couleur de ces anthères est le bleu-violet brunâtre foncé. (Voy. fig. 6, pl. 1).

Le pistil est tout changé. L'ovaire est globuleux, plus court que dans la fleur fertile. Le style est cylindrique et ne continue plus insensiblement l'ovaire. Ce style est aussi plus court et le stigmate est globuleux, à peine papillifère.

Si l'on prend une fleur de la chevelure placée plus vers le haut, plus petite et d'un bleu intense, on lui trouve une forme plus cylindrique, un aplatissement et des angles appréciables. Les lobes du périanthe sont encore visibles, mais ils ne se séparent plus, et la fleur reste complétement fermée (pl. I, fig. 7 et 8).

En dedans de ces fleurs, il y a encore des traces de trois étamines du rang supérieur et de trois étamines du rang inférieur, mais il n'y a plus de traces de filets; les anthères sont sessiles. Ces anthères se réduisent à de petits sachets doubles, de tissu cellulaire blanc, sans trace de pollen et d'une ténuité extrême. (Voy. pl. I, fig. 9.)

L'ovaire est un mamelon bleuâtre, déprimé et encore trilobé. Le style a disparu avec le stigmate, mais ils sont tous deux représentés par une petile boule placée sur l'ovaire, à l'emplacement du style. (Voy. pl. I, fig. 9.)

Enfin si l'on dissèque une fleur de la partie supérieure de la chevelure de l'épi, on ne trouve plus sur un long pédicelle bleu ou violet qu'un petit cylindre anguleux (pl. I, fig. 10 et 11), et si on ouvre ce périanthe, on ne 
voit plus de trace de sexes, mais seulement six stries qui correspondent à six fibres de vaisseaux. Le périanthe s'est vidé de ses sexes, d'où nous concluons qu'on ne peut mieux nommer ce phénomène que cénanthie, de «svos, vide, et ״.'Sos, fleur, fleur vide.

Ainsi, quant à la phytographie, il est à remarquer que, dans les premiers degrés de la métamorphose, la fleur devient stérile sans être neutre el que, dans les derniers degrés de la modification, de stérile elle devient réellement neutre, c'est-à-dire privée de tout sexe. Pour être donc exact, il faudrait dire que les fleurs de la chevelure sont stériles au-dessous, neutres au dessus.

La cénanthie s'établit, comme on l'a vu, graduellement, et plusieurs phases distinctes s'observent dans le phénomène, ainsi nous voyons que :

$1^{\circ}$ La fleur ne s'ouvre pas du moment que l'alrophie progressive s'empare de l'appareil sexuel; la non-déhiscence de la fleur entraîne l'annihilation de la fonction de fécondation, absolument, et beaucoup de faits le prouvent, comme si cette dernière était essentiellement liée à l'action de l'air sur le pollen;

2 Les étamines se modifient par l'abréviation de leurs tilets et l'hypertrophie de leurs anthères; ces derniers organes deviennent hydropiques par défaut d'évaporation, fonction qui, dans une fleur fermée, est gênée sinon empêchée; l'hydropisie entraîne la non-déhiscence de l'anthère et la modification du pollen, lequel est annulé dans ses fonctions; ultérieurement, le filet s'annihile complétement et l'anthère n'est plus qu'un petit sac cellulaire vide et blanc;

$5^{\circ}$ En même temps que cette modification a lieu daus l'appareil mâle, l'organe femelle s'écourte, le stigmate 
perd ses lobes, il se globifie, le style s'amoindrit pour disparaître, et l'ovaire passe de la forme triquètre à celle d'un ovoïde, puis d'un globe surbaissé; les ovules disparaissent comme le pollen;

$4^{\circ}$ Enfin quand, ultérieurement, l'atrophie marche de plus en plus, elle frappe complétement l'androcée et le gynécée, et la fleur, appareil nominal cette fois, est réduite à un sac périanthique vide d'organes et nul de fonctions.

Voilà dans quelle voie s'établit la cénanthie chez le Bellevalia comosa.

Il sera curieux de comparer les phases de ce phénomène avec celles que présenteront d'autres plantes chez lesquelles on retrouve son analogue.

Nous passons à l'étude du second ordre de faits que nous offre cette même espèce dans nos cultures. Chacun connaît cette plante étrange nommée naguère Hyacinthus monstrosus par Linné, puis Hyacinthus paniculatus par Lamarck, ou Muscari monstrosum ou paniculatum par Miller et d'autres auteurs qui, pour la plupart en ont fait une espèce, et une espèce qui, cette fois, ne montrait à personne, pas même à Linné qui les aimait tant, ces sexes sur lesquels on fondait cependant le genre auquel se réunissait cette plante agame.

Le riche panicule bleu ou violet de ce Bellevalia comosa monstrosa n'a pas cependant, que nous sachions, présenté le passage de ses étranges rameaux aux fleurs cénanthiées ou aux fleurs fertiles du type de l'espèce. Néanmoins, on ne conserve pas de doute que ce ne soit la même espèce, et la plupart des classificateurs qui, dans ces derniers temps, se sont occupés de la révision des espèces, ont réuni les deux formes en une seule, en déclarant 
monstruosité la plante paniculée et réduite à des ramuscules stériles.

L'épi a changé en panicule : l'axe s'est raccourci. Il est impossible de retrouver dans les rameaux pédicellés l'analogue des pédicelles des fleurs de l'épi du Bellevalia comosa, normalement formé. Il faut admettre une modification dans l'inflorescence tout entière, et les éléments organiques des fleurs se distribuent à un grand nombre de rameaux, qui deviennent très-compliqués sur des panicules de Bellevalia monstrosa, largement développés.

Nous dessinons un seul de ces rameaux (pl. II, fig. 1), puis la rosace terminale d'un des ramuscules (fig. 2), et enfin l'anatomie du sommet d'un de ces ramuscules avec celle de deux écailles bractéiformes, qu'on rencontre sur ces axes si singulièrement modifiés.

L'insertion de ces rameaux sur l'inflorescence sans fleurs, la coloration verte de leur base et la coloration bleu violet de leurs rosaces, leur texture délicate et la durée de leur existence, tous ces caractères y font reconnaitre évidemment des appareils pédonculaires. Chacun des ramuscules (fig. 1) naît à l'aisselle d'une écaille pétaloïde de texture et bractéenne d'insertion. Si l'on examine attentivement la composition d'une rosace, on trouve que son axe se termine par une prolongation conique toute couverte d'écailles bractéennes, semblables à celles qui se montrent à l'aisselle des ramuscules. Ceux-ci présentent sur leur étendue quelques rares écailles semblables, et à leur sommet une petite tête formée de la réunion, sur un court espace, de ces mêmes organes appendiculaires. Toute cette organisation est dessinée pl. II, fig. 9 .

Nous avons voulu savoir comment ces extrémités de ramuscules étaient anatomiquement composées. Elles of- 
frent au sommet un mamelon de tissu cellulaire recouvert de jeunes écailles également cellulaires au bout. Au mamelon central et aux écailles aboutissent, au centre, des fibres formées surtout de trachées déroulables et de vaisseaux séveux. Ces fibres sont entourées de tissu cellulaire, dans lequel on remarque quelques clestines remplies de raphides. Les écailles latérales sont constituées sur le même plan; la couleur bleue provient d'un fluide sans globules qui colore les cellules du tissu immédiatement situé au-dessous du derme. (Voyez pl. II, fig. 5.)

Cette organisation intérieure est celle des pétales; le sommet est structuré comme l'axe d'un bourgeon. Cependant ces rameaux, ces ramuscules, ces écailles et ces terminaisons gemmiformes n'ont rien qui puisse nous indiquer à quels organes de l'appareil floral il faudrait les ramener plus particulièrement. Le seul fait évident dans cette métamorphose, c'est la tendance manifeste de l'organisme à produire des prolongations et des agglomérations d'axes pédicellaires. On dirait, en effet, de tous pédicelles naissant de l'aisselle de bractéoles, mais ces pédicelles ne portent rien, sinon des bractéoles, et se terminent comme tous les axes végétaux. Voilà le fait le plus clair et le plus positif de cette métamorphose, qui doit évidemment constituer un genre dans la classilication de la tératologie. Nous proposons de le nommer mischomanie, $\mu$ í $\%$ s, pédicelle, pédoncule, el $\mu$ rĩa, manie), ou tendance à produire une exagération de pédoncules, en admettant toutefois que ce sont des pédoncules et des pédicelles ananthes.

L'explication donnée au phénomène par les horticulteurs est aussi fantasque qu'absurde. Nous lisons dans Miller que a les fleurs naissent dans cette espèce sur des pédoncules .... qui soutiennent chacun trois, quatre ou cinq fleurs, 


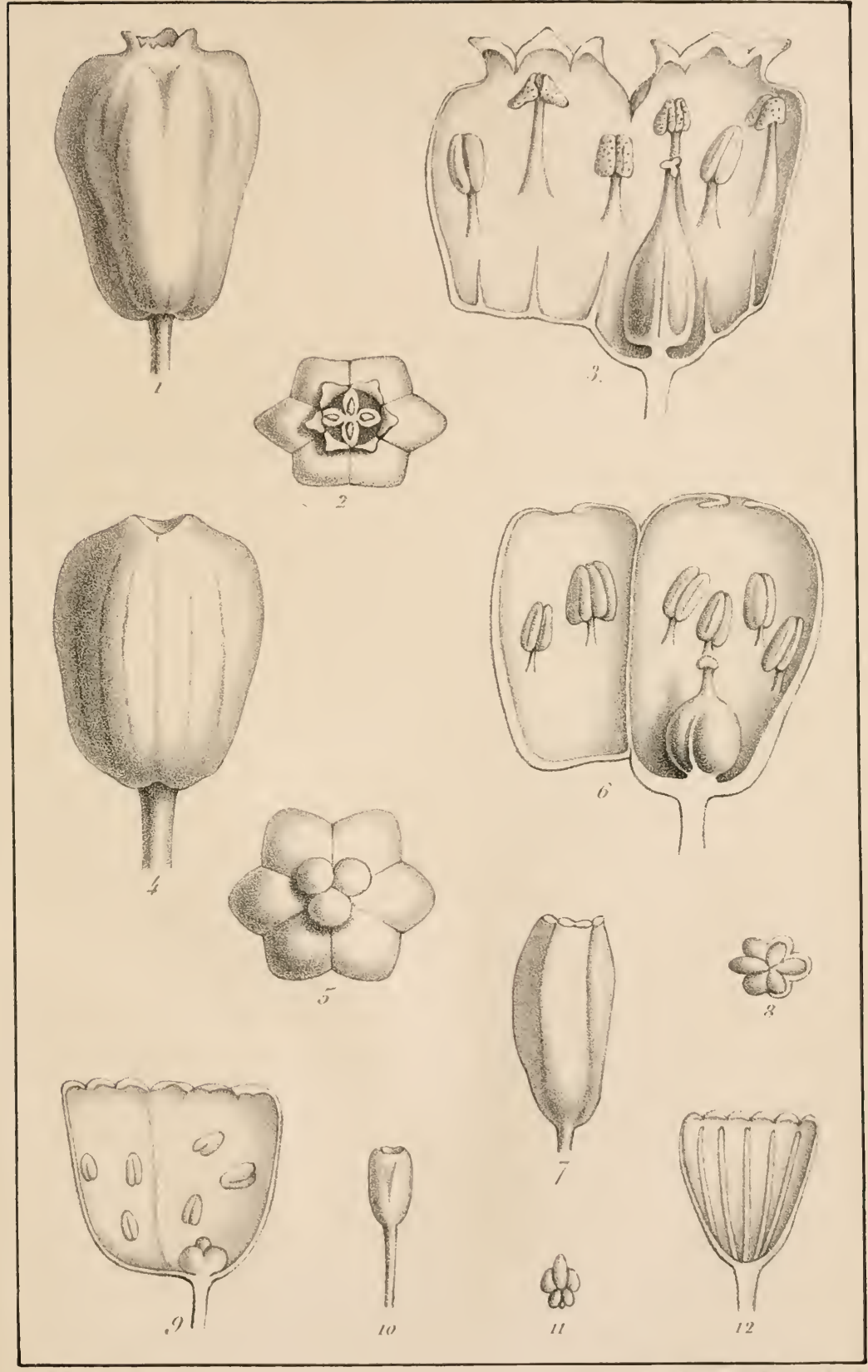

Cimunthier der bellemelen cemmesser 



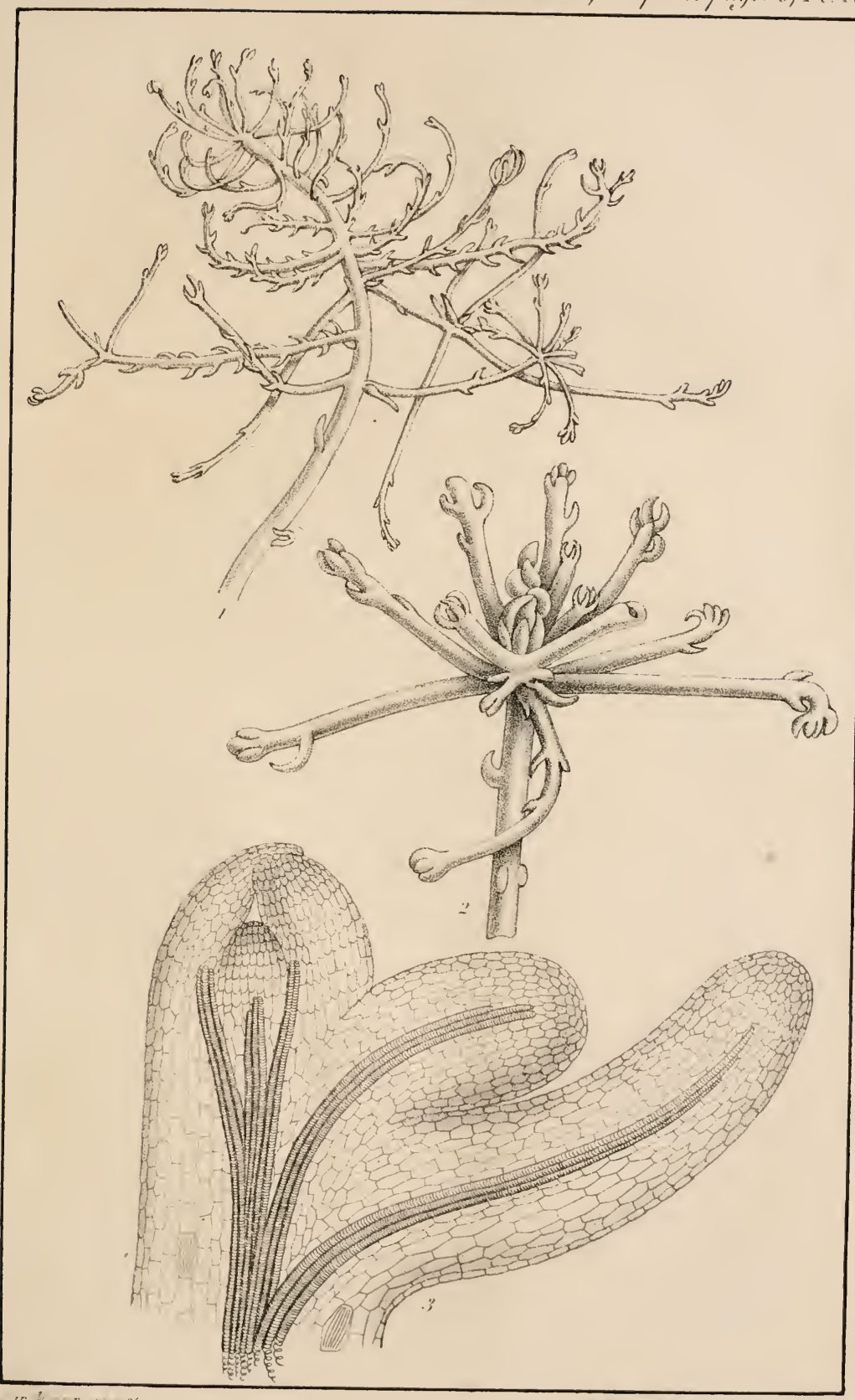

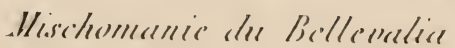





\section{(95)}

dont les corolles sont découpées en filaments minces comme des poils et sont d'un bleu pourprâtre; mais comme elles n'ont ni étamine, ni germe, elles ne produisent jamais de semences. 》

Rien, hors l'imagination gratuite, sans base et sans examen, n’indique la présence de plusieurs fleurs au sommet des pédoncules verts, et il y a plus de difficulté encore à retrouver dans les filaments la trace des corolles. On s'explique beaucoup mieux cette forme curieuse, en admettant comme une expression de la force tératologique, la tendance à produire des divarications continues des axes qui par leur nombre extrême, et leur prolongement en quelque sorte indéfini, font avorter les verticilles floraux. C'est une exagération de la prolification, telle qu'on la connaît dans les rosiers, le Sechium utile, les primevères, etc.

\section{EXPLICATION DES PLANCHES.}

Pl. I, fig. 1. Périanthe d'une fleur fertile du Bellevalia comosa, grandie 4 fois au diamètre comme les autres figures de cette planche.

2. Même périanthe vu d'en liaut.

5. Même fleur ouverte longitudinalement.

4. Périanthe entier commençant à devenir stérile.

5. Sommet fermé de la même fleur.

6. Même fleur ouverte en long.

7. Fleur tout à fait stérile.

8. Sommet dle cette fleur.

9. Même fleur ouverte.

10. Fleur tout à fait neutre.

11. Sommet de cette fleur.

12. Cette même fleur ouverte. 


\section{(94)}

Pl. II, fig. 1. Rameau d'un panicule du Bellevalia comosa var. monstrosa, grandeur naturelle.

2. Rosace terminale d'un ramuscule; cette figure augmentée à la loupe a 4 diamètres.

5. Sommet d'un ramuscule examiné au microscope. 


\section{TÉRATOLOGIE VÉGÉTALE.}

LES VIRESCENCES DISTINCTES DES PHYLLONORPHIES ET GAS Particulier d'UNE Virescence Dư ChèvrefeullLE;

par

Atr. (C). Allorren,

Membre de l'Aeademie rọale de Belgiquu.

Engelmann, au rapport de M. Moquin-Tandon, qui a admis la manière de voir du premier auteur, a nommé virescence, virenscentia, la métamorphose des organes appendiculaires, n'imporie leur nature, en fenilles. Tous les exemples cités dans les Éléments de tératologie végétale (p. 202-207) ont rapport, en effet, à des changements de bractées, de sépales, de pétales, d'étamines, de pistils et d'ovules en vraies feuilles.

Nous devons regretter que le nom de virescence ait été donné à une véritable métamorphose complète, tandis qu'au fond il n'indique que l'action de devenir vert. Quand un organe quelconque, depuis la stipule jusqu’à l'ovule, en passant par tous les ordres d'organes appendiculaires. 
devient feuille, il s'opère en lui une série de changements qui atteignent toutes les parties à la fois organiques et histologiques, c'est-ì-dire appareils et tissus. C'est là bien plus qu'une virescence. Ainsi, nous prenons pour exemple une étamine devenant feuille, comme nous l'avons vu dans l'Anemone sylvatica. Le filet devient le pétiole, le connectif se change en lobe central et les anthères en lobes latéraux: voilà pour les appareils; pour les tissus, le pollen disparait ou plutôt les cellules ne servent de gangue qu'à des grains chlorophyllaires, le tissu inenchymateux ne se développe plus, et l'endothèque se convertit en mésophylle, tandis que l'exothèque de l'anthère devient un derme supérieur; les trachées, qui formaient une seule ligne dans le filet pour mourir en pointes coniques au-dessous de l'anthère, se prolongent, augmentent en nombre et divariquent en système fixe de nervation. Ces métamorphoses sont radicales; elles ne se bornent pas, à la surface, à une simple viriditéqui reparaitt ou qui s'étend, mais elles vont, si nous pouvons le dire, au cœur de l'organisation; elles affectent l'essence de la vie. On conviendra qu'il y a là bien plus qu'une virescence, et si les mots sont destinés à représenter les idées, ce mot, ici, n'est pas heureusement choisi : l'idée qu'il entraîne est fausse.

La métamorphose des organes appendiculaires, que l'insertion sur l'axe végétal détermine dans leur nature, en vraies feuilles, se désignerait mieux par le terme de phyllomorphie, qui exprimeà la fois le changement et la nature de l'organe. C'est ainsi que dans les plantains, il y a souvent une phyllomorphie de bractées, dans les roses une phyllomorphie de sépales et ainsi du reste. Dans une science aussi neuve et aussi imparfaite encore que la tératologie végétale, il est important de ne pas fausser la nomencla- 
ture et de la rendre aussi exacte, aussi claire que possible.

Ce qui nous a étonné, c'est de ne pas trouver dans la partie consacrée à l'étude des prétendues virescences ou de ce que nous appelons des phyllomorphies, la relation d'une véritable virescence, e'est-à-dire d'une réduction à l'état vert et foliacé et non à l'état de feuille d'un organe qui, dans l'ordre normal, n'est pas destiné à être vert ni foliacé. Cette absence de cas précis nous expliquait pourquoi le mot de virescence avait pu être adopté par M. Moquin-Taudon, puisqu'il ne semblait pouvoir s'appliquer à rien de plus exact. Mais la virescence, en tant que changement d'un organe non foliacé de sa nature génuine en organe vert et foliacé, existe, et dès lors nous serions fort tenté de réserver ce mot à la chose qu'il exprime si bien. On nous reprochera d'apporter dans la science tératologique une confusion ou une synonymie de plus, et nous n'aurons aucune envic de nous laver de ce reproche; car il nous semble qu'en disant virescence, pour la modification à l'état vert et foliacé, et phyllomorphie pour la métamorphose en feuille, chacun nous comprendra par l'énoncé même du fait, tandis que, dans la nomenclature établie, il y aura toujours ambiguité en nommant virescence une métamorphose en feuille, alors qu'il existe réellement dans la nature un phénomène de simple viridité qui se manifeste dans un organisme normalement coloré.

Ce phénomène est très-ordinaire dans le chèvrefeuille de nos bois, Lonicera periclymenium L. Nous l'observous toutes les années dans les fleurs de nos haies et de nos charmilles. Au lieu de trouver au sommet du rameau deux bractées et un pelit capitule de fleurs parfaites où les bractéoles sont naviculaires et opposées (fig. 1), un calice à cinq lobes s'ouvrant en étoile après la chute de la co- 
rolle, une corolle en deux lèvres, dont la supérieure a normalement quatre lobes et l'inférieure un seul lobe, cinq étamines et un pistil, comme nous le rappelons par la figure 1, nous voyons au contraire le rameau non plus terminé par un capitule, mais par un thyrse irrégulier (voy. fig. 2). Aux aisselles des bractées naissent des axes floraux. Ces axes floraux se pressent au sommet en grande quantité. Nais aucune de ces fleurs n'est colorée en jaune nankin, aucune n'offre de système glandulaire et poilu (fig. 1); mais chacune est verte, quoique la corolle soit visiblement formée et distincte du calice; les étamines se raccourcissent, les anthères deviennent hydropiques et ne s'ouvrent plus, et dans l'immense majorité des fleurs, ces étamines sont réduites en simples lames jaunâtres, le pistil est annulé et au centre de la fleur, là où l'ovaire devrait exister, il n'y a plus qu'un axe vert et solide, sans cavité ni ovule.

Voilà dans quel état général se trouve cette monstruosité. Nous allons ajouter quelques détails qui la feront mieux connaître encore.

D'abord remarquons que le nombre d'appareils qui réellement constituent au fond des fleurs, est infiniment plus considérable sur une inflorescence anormale que sur un capitule régulier. Les mérithalles sont rapprochés; il y a polyanthic prononcée. Avec cette augmentation tératologique d'appareils floraux, se manifeste une série de changements dans tout l'appareil floral en particulier, sans qu'aucun de ces changements puisse cependant se définir une métamorphose en feuille. Le seul fait qui soit bien distinct, est une modification des organes à la consistance loliacée, la viridité y comprise :

$1^{\circ}$ Cet état n’affecte pas le calice qui, si la baie se dévelop- 
pait, serait toujours une aréole dont les dents ou les lobes couronneraient le sommet du fruit. Les figures $\overline{5}$, 4, : et 6 expriment bien cette permanence du calice.

Il faut conclure de là que l'organe le plus foliacé natırellement de la fleur est précisément celui qui éprouve le moins la foliification, et, de tous les appareils, celui qui se prêterait le mieux à la métamorphose que nous appelons phyllomorphie, est justement celui qui ne l'accomplit pas. Cet antagonisme éloigne encore, par un caractère extrêmement curieux, la monstruosité que nous décrivons iei de celles désignées par Engelmann sous le nom de virescences.

$2^{\circ}$ La corolle conserve encore évidemment sa forme bilabiée, elle est toujours corolle, en tant que second verticille floral. Toujours elle offre un tube et deux lèvres, dont l'une est large et l'autre étroite, dont l'une présente quatre lobes plus ou moins distincts, plus ou moins divisés, et l'autre un seul lobe. Cette structure saute aux yeux par les figures 5,4 et 5 . Mais le seul changement qu'on aperçoive à cette corolle, est une diminution de volume, une plus grande irrégularité, une tendance à se crisper, à rouler ses bords, une viridité parfaite, une consistance foliacée, mais sans qu'il y ait un système de nervation foliaire, une absence de toute sécrétion, de toute odeur.

Ainsi l'élément floral le plus antagoniste de la feuille, la corolle délicate, colorée, odorante, fugace, s'est convertie, nous ne dirons pas en feuille, mais en une corolle solide, verte, inodore et permanente, de sorte que c'est là, en effet, une virescence dans le sens le plus énergique de l'expression.

$\overline{5}^{\circ}$ L'androcée est, sur quelques fleurs, visible comme forméc d'étamines; ces étamines sont encore composées d'anthères, mais les filets disparaissent, de façon que ces 
organes sont inclus au lieu d'être exsertes. Les anthères sont plus longues que normalement, plus grosses, comme il arrive aux organes mâles malades, hypertrophiés par excès d'humidité. Les anthères, en effet, ne s'ouvrent pas absolument comme dans le cas de cénanthie que nous avons constaté sur le Bellevalia comosa.

Ailleurs, l'androcée se montre entre les lèvres de la corolle verdie comme formée de lames plus ou moins nombreuses, planes et d'un jaune verdâtre (voy. fig. 4). Ordinairement on voit une de ses lames se détacher du côté de la lèvre unilobée de la corolle verdie. Si l'on dissèque avec soin (voy. $f g .5$ ), on s'aperçoit que l'androcée forme une seconde corolle réunie en tube en bas et se divisant en lanières plus ou moins nombreuses, mais qui rappellent encore, dans leur ensemble, les lèvres polylobes et monolobes des corolles. C'est ce qui est visible dans la fig. 5 , qui représente une de ces fleurs ouvertes pour montrer l'androcée disséquée.

On ne peut pas dire, certes, que les lames qu'on sait être staminales, soient des feuilles; on ne peut non plus y voir des pétales, bien qu'il fallût moins d'imagination pour celte spécification que pour la première; mais on voit ici des étamines laminifiées et accompagnées, dans ce changement, par le phénomène de la virescence.

$4^{\circ}$ Hors de là, il y a atrophie complète. Plus de style, plus d'ovaire, plus d'ovules, plus de cavité, mais, dans le calice, on trouve une simple masse de tissu cellulaire compacte, et au centre un axe ligneux qui va en divariquant ses fibres dans toutes les parties de cette fleur viridifiée.

Nous pensons que ces détails confirment pleinement les inductions que nous avons exposées en tête de celte notice, et qu'il existe donc une virescence des organes flo- 


\section{(101)}

raux bien distincte des métamorphoses en feuilles que nous nommons phyllomorphies.

\section{EXPLICATION DES FIGURES.}

1. Fleur du Lonicera periclymerium, de grandeur naturelle.

2. Sommet d'un ramean à inflorescences virescentes, grandeur naturelle.

3. Fleur viridifiée à étamines encor'e anthériferes, frrandeur naturelle.

4. Fleur viridifiée à étamines laminifiées.

5 . Une fleur semblable ouverte.

6. Bas d'une fleur de ce genre coupée en dcux. Les figures 4,5 et 6 sout augmentées du double à la loupe. 



\section{ERATOLOGIE VEGETALE.}

1.9nymith e d'un Gesneria, genre de monstruosité où la leuille termine l'axe végétal;

$$
\text { P.AR }
$$

\section{Cin. HORREN,}

Membre de l'Académie royale de Belgique.

()ue les feuilles soient des parties appendiculaires de Ixe ascendant, il n'y aurait aucun moyen d'ébranler cette base fondamentale de toute la philosophie botanique, et par suite, il faut bien admettre que l'extrémité organique d'une plante est toujours la fin même de cet axe, quelle que soit sa forme, et non l'annexe de cet axe. Quand les morphologistes ont expliqué les vraies causes des insertions oppositifoliées, ils ont dû voir par les yeux de l'esprit une usurpation organique, la métamorphose de l'axe en vrille, en épine, ete., et le développenent hypertrophique du rameau provenant du bourgeon axillaire de la feuille. La structure de la vigne, celle du Phytolacca, etc., n'ont pas reçu d'autres interprétations.

Cependant, dans les folioles des feuilles composées, on 
a été enclin à voir plutôt des feuilles véritables que des divisions d'un organe appendiculaire réfléchissant dans ses parties la forme du tout, et là, dans les impari-pennées, on a dû reconnaître qu'une foliole peut devenir terminale; mais, quant à la théorie de l'axe, l'objection tombe, puisque évidemment, la désarticulation le prouve, tout l'appareil nommé feuille composée, ne peut faire partie de l'axe; il y est appendu, il est latéral, il est anuexe, voilà tout: donc la foliole terminale ne prouve rien dans l'ordre d'idées qui nous occupe.

Ce serait une anomalie contraire à toutes les lois de la nature qu'un axe terminé par une feuille, et ici nous entendons cette terminaison par un épanouissement des, fibres de la tige elle-même et non par une feuille à l'éta، d'appendice. Et en effet, ce cas anormal doit être trèsrare, car nous en avons vainement cherché un seul exemple dans les ouvrages de tératologie végétale que nous possédons. M. Moquin-Tendon, entre autres, n'en dit pas un mot.

Cependant, depuis deux ans que nous cultivons dans nos serres particulières le Gesneria Geroltiana (Kth. et Bouché), il nous est déjà arrivé deux fois de constater un cas de tératologie que nous nommons Coryphyllie (de

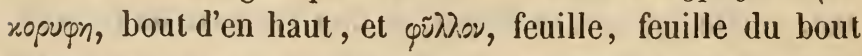
d'en haut), parce que, dans cette structure, il y a en effet, pour les yeux, une feuille réellement terminale de l'axe, tandis que l'intelligence trouve ailleurs sa place, son insertion et sa nature.

Laissons-nous d'abord décrire le fait dont la planche est destinée à donner une idée. Une tige centrale porte deux feuilles opposées, de l'aisselle desquelles s'échappent deux rameaux ordinaires, rameaux qui, à leur tour, ont des 
feuilles opposées et se terminent par des inflorescences cimeuses en thyrses. Nais la tige centrale, grosse du double des rameaux, continue son chemin et va se terminer par une énorme lame de feuille ayant quatre fois la longueur et la largeur des feuilles ordinaires. Ainsi les feuilles ordinaires mesuraient 7 centimètres de longueur sur $61 / 2$ de largeur, et la feuille terminale en avait $\mathbf{2 9}$ de longueur et 27 de largeur. Cette feuille énorme se marbrait de pourpre, de rose et de brun tout le long des nervures, ce que font aussi, mais moins, quelques feuilles ordinaires de cette espèce.

On le conçoit facilement, cette coryphyllie devait trouver son explication; la nature ne pouvait forfaire à ses lois, et l'entente des ouvres de la création ne devait pas faillir devant une gesnérie. Or, en regardant attentivement, on observait sur la longueur de l'axe central une ligne horizontale, à partir de laquelle les fibres devenaient plus visibles et la surface plus linéolée. Cette ligne offrait, d'un côté, un point d'atrophic. Cela semblait un nœud, et c'était, aussi bien au moral qu'au physique, tout le nœud du monstre.

En effet, il nous semble évident que l'axe a continué d'exister comme axe seulement jusqu'à cette ligne, mais là une feuille latérale, celle de gauche, s'est seule développée, en prenant à elle et à son profit exclusif, la substance organique et de la feuille de droite et du bourgeon terminal, done du thyrse floral qui devait, dans la structure normale, couronner cette tige. De là, cette soudure par mixtion. De cette assimilation intime de la substance d'autrui au profit exclusif de son propre développement, est venue l'hypertrophie extraordinaire de cette feuille terminale; de là est venu l'aspect étrange de celte monstruo- 


\section{(110)}

sité qui ne trouve pas d'analogue dans les exemples d'hypertrophie connus.

Évidemment la feuille terminale s'est colorée, comme nous l'avons dit, parce que, malgré l'intime mixtion de tissus vivants dans ses diachymes, la nature des cell, qui eussent formé les fleurs, n’a pas tout à fait chr ces couleurs redisent à l'esprit les teintes de la ruculte 


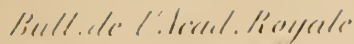

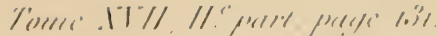

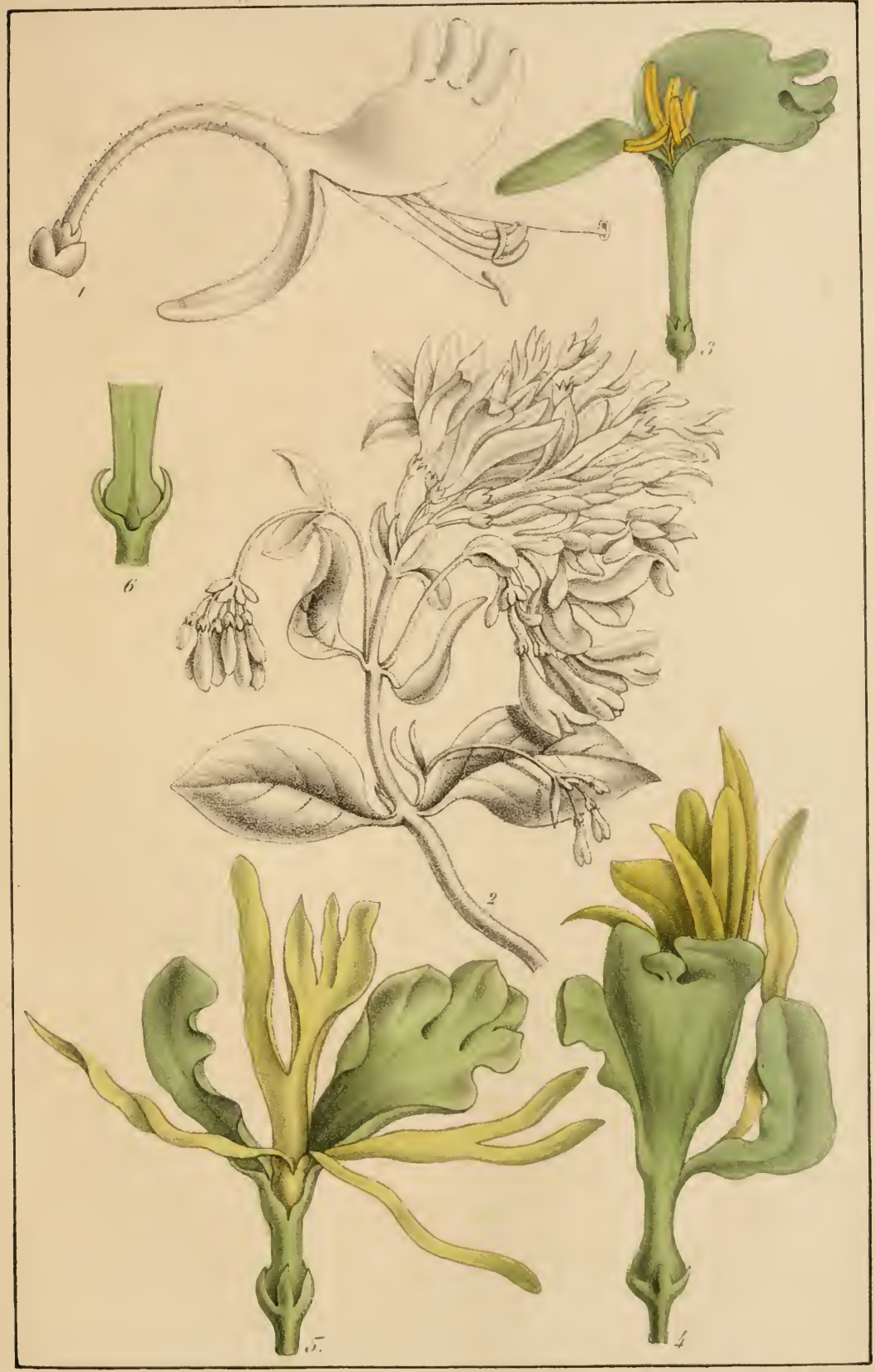

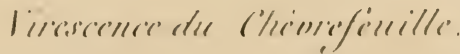





\section{IN OTE}

SUl UN PROCÉdé QUi faIT PROdUIRE a CERTAINES RACES dis POMMES DE TERRE QUATRE RÉCOLTES DANS L'ANNÉE;

par

ㄴl. Ch. Altorren,

Membre de l'Académie royale de Belgique.

Dans tout état de cause, que la maladie des pommes de terre sévisse en ce moment ou que ses dégâts soient peu importants, toujours croyons-nous utile de faire connaître à l'Académie un moyen que nous estimons entièrement neuf, pour augmenter les ressources, déjà si fécondes, de la précieuse solanée du Pérou.

Jusqu'ici on avait cru généralement qu'un tubercule appartenant soit aux variétés hâtives, soit aux variétés tardives, ne pouvait donner qu'une seule progéniture immédiate. En d'autres termes, on était d'avis qu'une plantation ne pouvait produire qu'une récolte par une seule semence (tubercule) déposée en terre.

En 1849 , et cette année, M. Leclerc, cultivateur à Grivegnée près de liége, dont les utiles travaux ont été plu- 


\section{(104)}

sieurs fois récompensés par des médailles d'or et par de premières distinctions à nos grandes expositions agricoles, a fail voir qu’à l'égard de ce fail, on était dans l'erreur. La pomme de terre est en quelque sorte inépuisable dans sa bonté pour l'homme.

Voici le fait reconnu par M. Leclerc dans toute sa simplicité, mais aussi dans toute son importance.

Des pommes de terre de variétés très-hâtives, comme les sept semaines, les neuf semaines et sans doute aussi les circassiennes, plantées entières dès les premiers beaux jours de février, donnent, malgré les gelées du printemps, une récolte dans le mois de mai. Celle année, 1850 , de semblables races, plantées le 9 février, ont fourni une abondante récolte le 11 mai. Nous avons dégusté ces produits; ils étaient en touts points aussi farineux, aussi pleins, aussi savoureux que les meilleurs tubercules des premières récoltes à l'usage desquels nous sommes accoutumés.

Ici vient l'observation importante de M. Leclerc. II replante immédiatement la mère dans la même fosse d'où l'on vient d'extraire sa première progéniture. Dans la dernière semaine de juin, cette mère produit une seconde récolte, même plus abondante que la première, et les tubercules sont plus gros, de la même consistance et de la même saveur que les produits d'une récolte première qui serait faite à la même époque et cela d'une race principale.

Cette même mère, loin d'être flasque, ridée et surannée, est encore très-propre à donner une troisième progéniture. M. Leclerc la met de nouveau en terre, et la troisième semaine d'août, il fouille la fosse et en retire une troisième progéniture semblable aux deux autres.

Enfin, il la replante une quatrième fois, et vers la mi ou 


\section{(100े)}

fin octobre, selon les circonstances atmosphériques, il fait la quatrième récolte de ces variétés, naguère réputées exclusivement hâtives, mais en réalité devenues tardives par le fait même de ces mêmes retransplantations.

Voila le fait pratique dont chacun peut prendre connaissance dans les cultures de M. Leclerc et qu'il se fait un plaisir de montrer à tous les agronomes.

Pour quiconque a étudié la physiologie des pommes de terre, ce résultat, quoiqu'inaltendu parce qu'on y a pas songé, n'a rien de surprenant. En eflet, on sait que le tubercule a, selon sa variété ou sa race, comme génératrices, une, deux ou trois spirales d'yeux courant parallèlement de la base du tubercule au sommet. A la base, les yeux de ces spirales sont distants, au sommet ils sont rapprochés. A la base, ces yeux sont dormants; au sommet, ils sont poussants; à partir de la date futale où le mouvement de la séve devient ascensionnel, e'est-à-dire du 27 janvier, les yeux poussants du sommet donnent les premiers jets qui produisent les premiers rameaux souterrains, dont les renflements sont les premières pommes de terre, celles de la première récolte. Puis viennent les yeux des tours de spires moyens antérieurs, moins poussants et à moitié dormants. Ils s'éveillent à la seconde plantation et donnent naissance à de nouveaux jets, qui encore une fois produisent des rameaux souterrains dont les amas de lécule, accumulés dans des renflements spéciaux, constituent les pommes de terre de la seconde récolte. De même à la troisième plantation poussent les yeux dormant naguère, mais éveillés actuellement par le temps plus long où ils ont vécu, et ces yeux moyens postérieur's donnent naissance aux produits tuberculiformes de la troisième récolte. Enfin, à la quatrième récolte, les veux de la base, dormant au prin- 
temps, poussant vers la fin de l'été, ont jeté leurs rameaux souterrains et formé une nouvelle série de tubercules.

On dit: les pommes de terre une fois plantées et ayant donné une progéniture ou une récolte, sont flasques, ridées, molles, sans fécule et pourries. Nous disons : qu'on y voie et l'on se convaincra que ce fait, assuré plus par labitude que par inspection, est loin d'être général pour toutes les races. Dans les races décidément hâtives, bien constituées, saines el résistantes, le fait contraire s'observe : il y a des mères qui, après avoir enfanté plusieurs fois, sont encore d'une apparence virginale, tandis que d'autres, après leur première parturition, sont flétries et condamnées à la stérilité. Cette vérité est surtout palpable, visible, vérifiable dans la nature à l'égard des pommes de terre, et il n'y a pas d'observaleur exact qui n'ait eu l'occasion de la constater. Tout le procédé de M. Leclerc est le résultat d'une observation de ce genre; mais si le fait a été vu et revu plusieurs fois, nous pensons que ce cultivateur a été le premier à en tirer une application si hautement utile que celle qui vient de faire le sujet de celte notice. Nous ne voyons rien dans ce que nous venons d'annoncer qui ne soit parfaitement conforme aux principes de la philosophie des pommes de terre, telle que l'illustre agronome Knight a cherché à l'établir dès le commencement de ce siècle, philosophie très-profonde et très-élégante qu'on ne perd que trop souvent de vue dans tout ce qu'on écrit de nos jours, à tort ou à raison, sur l'intéressant tubercule dont le mérite est non-seulement de faire rire quelques gens, mais de les nourrir tous. 


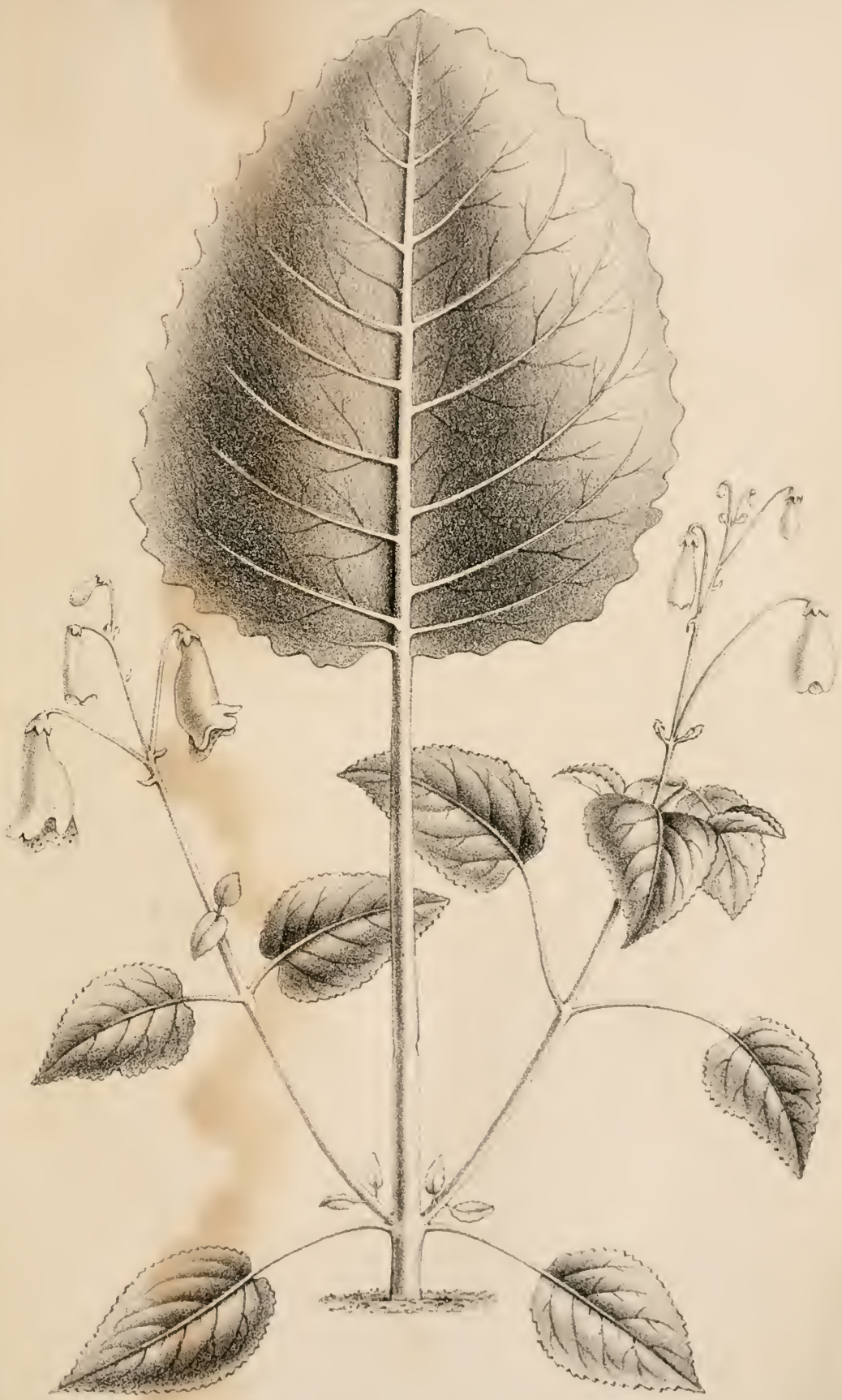

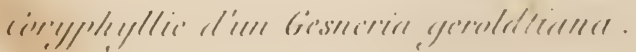




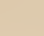


ICADRME ROYALE DE BELGIQUE.

Extrait du tonie XVIII, $n^{n} 1$, des Bulletins.)

\section{TÉRATOLOGIE VÉGÉTALE.}

\section{NOTICE}

SUR LE SPIRALISUE tÉRATOLOGIQUe DFS TIGES;

par

At. Cl). Atlorren,

Membre de l'Académic rovale de Belgique.

Les tératologistes savent quïl y a une tendance singulière, même de la part des organes les plus droits, à se contourner en spirale, cette courhe qui résume en elle toute la végétation et qu'on retrouve depuis la simple cellule, depuis l'élément le plus ténu de la constitution des plantes, la fibre, jusqu'aux organes et appareils compliqués, comme la tige, la feuille, l'appareil reproducteur, et enfin jusqu’à l'embryon, qui n'est, en dernier résultat, que l'être entier el pourvil de toute sa force de développement. 
Philippo Ré, en classant les cas tératologiques dans sa Pathologie végétale si incomplète d'ailleurs, n'a pas envisagé ce phénomène.

Meyen, dans sa Pflanzen Pathologie, ne regarde pas non plus ce fait curieux comme le résultat d'une disposition morbide. On sait que cet auteur se proposait de publier une tératologie végétale, et il est probable qu'il eût alors traité de cet organisme comme d'une déviation de l'organisation habituelle. M. Moquin-Tandon regarde ce genre de faits comme des monstruosités de forme, et les classant dans les déformations des organes axiles, il appelle ce genre les torsions. Nous avouons que le mot n'exprime pas trèsbien la nature du cas tératologique. Le mol de torsion implique une idée d'irrégularité; on peut être tordu autrement qu'en spirale, et cependant ce qui frappe tous les observateurs, c'est cetle courbe régulière en hélice le long de laquelle les fibres semblent courir, et qui est tellement symétrique que des naturalistes comparent les plantes qui en sont affectées à des mollusques, à des coquilles! Il nous semble donc que la dénomination de spiralisme exprimerait mieux l'idée, d'autant plus que ces spirales tératologiques s'observent sur une infinité d'appareils et qu'on peut désigner en y ajoutant simplement le nom de l'organe: ainsi il y a le spiralisme des racines, le spiralisme des tiges, le spiralisme des columelles, le spiralisme des embryons, comme spiralismes axiles, et puis viennent les séries des spiralismes de tous les organes appendiculaires, comme pétioles, pétiolules, feuilles, pédoncules, bractées, sépales, pétales, étamines, nectaires, pistils, etc. C'est sous ce point de vue que nous continuerons d'envisager le phénomène.

M. Simon Kros, dans son élégante dissertation De spira in plantis conspicua (Croningue, 1840), a été le premier au- 


\section{(115)}

teur qui ait rattaché ce spiralisme tératologique à la constitution spiraloide générale et normale de tout l'organisme végétal. Il a eu le bon esprit de faire dépendre ces cas de la phyllotaxic, sans toutefois saisir une loi générale mathématique très-élégante qui gît au fond du phénomène et dont nous parlerons plus loin. M. Simon Kros (Op. laud., 73 et 93) démontra comment le verticille, sur une tige droite, peut tératologiquement se modifier en une foliation spirale donnant lieu à une position rentrant dans un cas normal d'une autre plante. Ainsi, dans l'exemple cité par lui, le Lilium martagon observé par M. Nicolas Mulder, convertissait son verticille $=o$, à la position fractionnelle $\frac{2}{5}$, qui est un des cas de la série connue.

Jusqu'ici et sauf ce seul exemple, on s'est borné à inscrire les cas, mais on ne s'est guère inquiété de mettre en rapport les formules phyllotaxiques de l'espèce normale avec les formules phyllotaxiques des monstruosités. On comprend dis lors combien ces simples enregistrements perdent de leur intérêt. Cet intérêt équivaut à celui d'une description d'espèce sans sa physiologie : c'est le cadavre et non la vie.

Cépendant ces enregistrements, malgré toute leur sécheresse, ont quelque chose d'intéressant. C'est qu'à mesure que la science marche, la répétition de ces spiralismes anormaux sur les mêmes espèces aide le naturaliste dans ses recherches, et il ne demande plus au hasard de son coup d'œil ce qu'il devra désormais à l'acquit de son esprit. On le voit, à quelque chose malheur est bon. Nous prouvons ce fait par des exemples.

Vaucher (i) a découvert le spiralisme tératologique dans

(1) Monographie des Prël's, Genève, 1822, p. 56, pl. 11. - Institut, 18.11. 


\section{(114)}

la Prêle fluviatile (Equisetum fluviatile). L'axe, normalement rectiligne, s'y contourne régulièrement de la base au sommet. M. Adrien De Jussieu retrouve à Meudon le même cas tératologique sur la même espèce (1). Le professeur M. Van Hall, de Groningue, revoit le même monstre à Vreesdyck en 1552, et M. Kros déclare enfin qu'il est trèscommun en Hollande (2). Voilà donc une plante sur laquelle les tératologistes pourront étudier, avec plus de chances d'un exemple certain, la loi de ce spiralisme accidentel. Puis, remarquons qu'il doit y avoir évidemment dans cette espèce une prédisposition à ce spiralisme. Quelle est la cause de cette prédisposition? Il est singulier que dans un être dont l'ovule est entouré de spirales (élatères), la formation commence par une extension en lignes droites des filets confervoïdes, résultats de la germination de l'ovule, et puis par une soudure de ces filets. Est-ce que dans les Prêles spiralisées, ces filets confervö̈des ne l'étaient pas déjà eux-mêmes? Est-ce la constitution de l'ovule qui se poursuit? Toutes ces réflexions doivent maintenant occuper les esprits. Jusqu'ici, on s'est borné à constater l'existence du monstre, désormais, il faudra le voir venir et assister à sa formation. Cette recherche est possible actuellement : l'embryogénie de la tératologie est à nos portes.

M. Van Hall a constaté le spiralisme dans l'Equisetum limosum (3).

M. Adrien De Jussieu possède dans sa collection de monstruosités végétales un chaume de Scirpus lacustris

(1) Moquin-Tandon, Térat., p. 181.

(2) Kros, De spira, p. 75.

(3) $J b .$, p. 74 . 
assez régulièrement tordu par lui-mème, dit M. MoguinTandon (1).

M. Kros cite un cas dans les graminées : c'est le Phleum pratense. Il est remarquable que, dans le nombre immense de céréales semées, on n’ait jamais signalé un seul spiralisme. Pour nous, nous n'en avons jamais vu dans nos guérets.

M. Kíros a trouvé dans l'île d'Ameland un Epipactis palustris dont la tige était spiralisée inférieurement.

Près de Leeuwarden, en Frise, pays bas et humide, M. Kros trouva au lieu dit Achter de Hoven, un Sagitlaria sagitlifolia, dont le pẻdoncule était spiralisé.

Ainsi voilà sur six cas de monocotylédones et d'acotylédones supérieures cinq espèces des marais qui offrent le spiralisme monstrueux. Ajoutons que le spiralisme normal des tiges existe au plus haut point possible dans les Spiranthes, orchidées de pelouses sèches. Voilà un antagonisme curieux.

Cependant, MM. Schlechtendal, Vrolik et Nicolas Mulder ont respectivement constaté l'existence du spiralisme anormal dans trois autres espèces de monocotylédones, sans qu'on sache précisément si elles croissaient en des lieux plus humides qu'elles n'auraient dû occuper.

Le premier exemple est pris sur un Triticum repens, mais le spiralisme n'avait lieu que sur la feuille supérieure qui forme la gaine de la fleur, et encore la partie inférieure de cette gaine était droite (2).

Le second a été vu par M. G. V'rolik sur le Lilium can-

(1) Teratol., p. 181.

(2) lint. Zitit, 21 jul. 18 份, p. 4!). 
didum (1), et enfin le troisième affectait les verticilles du Lilium martagon. Le fait a été observé par M. N. Mulder et analysé par M. Kros (2).

Ces trois exemples, où l'on n'a pas tenu compte de la station des individus tératologiques, ne montrent finalement que des spiralismes restreints d'organes appendiculaires.

Passons aux dicotylédones.

Gilibert signala une Valériane monstrueuse : la tige en était courte, concave, striée : il la compara à une coquille connue sous le nom de Tonne (5). Évidemment, le spiralisme de la Valériane officinale, que mon fils Édouard découvrit dans une prairie (très-humide) de Tilft-sur-l'Ourthe (province de Liége), et que j’ai dessinée, fig. 1, est le monstre de Gilibert ressuscité. On ne pouvait rien voir de plus conchyologique. Nous reviendrons sur cette monstruosité.

M. Lapierre de Roane trouva dans des forêts de chênes des départements de l'Allier et de la Loire des Valérianes officinales spiralisées. L'une d'elles avait une tige de 29 centimètres de hauteur, 27 millimètres de diamètre debase et portant feuilles et fleurs (4). La partie spiralisée du sommet offrait 81 millimètres de diamètre, circonstance qui s'est reproduite sur la monstruosité découverte par Édouard Morren.

$M$. Viviani a vu au jardin botanique de Pavie une $V a$ leriana dioica spiralisée avec rejet des feuilles et des fleurs sur le còté en série linéaire verticale; fait curieux qui se

(1) Over eene rankvormige ontwikkeling a an witte Leliebloemen. Nouv. Mém. de l'Institut d'Amsterdam, t. I, p. 29:

(2) De spira, p. 75 .

(3) Moquin-Tandon, Térat., p. 181.

(4) Mém. Soc. Linn.; Paris, t. III, p. 39 
trouve de nouveau sur la Valériane officinale monstrueuse que j’ai figurée fig. 1 (1).

Voilà donc des cas nombreux de spiralisme signalés chez les Valérianes par plusieurs auteurs et dans des localités diverses. Les Valérianes sont encore une fois des plantes qui ne se trouvent que dans les parties humides des bois et des prairies, le long des eaux.

M. De Candolle signale et a fait dessiner par Heyland un très-beau cas de spiralisme dans le Mentha aquatica (2). La lige se tord en spirale, elle porte des stries alternes d'un vert pâle et foncé; toutes les feuilles sont rejetées sur un côté. Il eût été excessivement intéressant de posséder la formule phyllotaxique de la spiralisation comparée à la normale. N'oublions pas de remarquer que voici de nouveau une plante aquatique qui offre ce phénomène.

Le professeur Van Hall retrouva à peu près la mème monstruosité en 1859, dans le jardin économique de Groningue, mais cette fois sur un Mentha viridis. La tige spiralisée est tétragone au-dessous, puis hexagone au-dessus, les feuilles sont ternées sur la première partie et sur la partie spiralisée subsécondes (5).

Dans les rubiacées, il y a d'autres cas. George Franc (4) cite un Galium à tige renflée et fusiforme, terminée par un bouquet de feuilles. Tous les rameaux sortent d'une ligne latérale, comme les feuilles dans la menthe de De Candolle.

(1) Moquin-Tandon, p. 182.

(2) Cirganogr., t. 1, p. 155; t. 11, p. 278, p!. 56.

(3) Het Instituut, 1841. - Kros, De spira, 75.

(4) Ephèm. nut. cur., déc. 2, ann. 1, p. (i8, fig. 14.--Moquin-Tandon, Térat., p. 182. 
De mème, M. Nicolas Mulder possède, dans son herbier, une garance, Rubia tinctorum, spiralisée, à feuilles rejetées sur le côté (sans doute les stipules et les feuilles vraies). On cultiva la plante au Jardin botanique de Groningue; mais II. Kros ne dit pas ce qu'il en advint. Il affirme qu'en Zélande, daus les cultures de garance, cette monstruosité se retrouve souvent (1).

M. Nicolas Mulder possède aussi un Fraxinus communis à rameaux spiralisés sur une longueur d'un pied et demi. Il est comprimé(sans doute fascié avec spiralisation, comme le Zinnia de M. Decaisne) et puis contourné, dit M. Kros, comme une corne de bélier. M. Van Hall conserve une branche de 4 pieds et $1 / 2$ de la même espèce sujette aux mêmes monstruosités.

M. Moquin-Tandon signale en effet un Zinnia où le spiralisme se joignait à la fasciation. Il y avait une seule spirale de la base au sommet de la plante.

Le même auteur rappelle les spiralisations des rameaus sur les Robinia pseudo-acacia, dont le tronc est d'ailleurs droit et les spiralisations en tire-bouchon des raves tortillées et des raiforts, lesquelles se transmettent aux races cultivées. Ce dernier phénomène est différent du spiralisme dont nous parlons ici; nous reviendrons sur sa nature, qui est analogue à celle des tiges volubiles. C'est un cas d'enroulement.

Turpin dit que, dans les environs d'Alençon, où l'on cultive beaucoup de pommiers pour la fabrication du cidre, presque tous les trones sont spiralisés dans le même sens. Il aftirme le même fait pour les grenadiers (Punica gra-

(1) Zeenusche Volks-1lmumaeh, 184.5, p. 106. 
natum), et le professeur Van Hall a observé le même fait sur tous les grenadiers de Groningue (1).

M. le docteur Jaeger a observé un fait physiologique des plus curieux et qui se rattache, comme le docteur Kros l'a fait remarquer, au spiralisme (2). Ce phénomène a lieu sur le Pyrus torminalis.

M. Jaeger a remarqué que beaucoup de troncs de celle espèce étaient contournés en spirale, de sorte que les rameaux suivent une même direction. Un de ces pieds offrait les rameaux, quoique régulièrement placés, tous tournés vers le même point de l'horizon. Sept mois après, une torsion de $90^{\circ}$ eut lieu et à droite. L'arbre était déjà tourné quatre fois sur son axe de la même manière, quoiqu'il présentât, à trois pieds au-dessous du sol, une circonférence de sept pieds et une hauteur de cinquante. Pour tout le reste, il était fort sain.

A ces cas connus de spiralisme, nous venons en ajouter trois nouveaux. Un premier, constaté dans le Valeriana officinalis par mon fils, Édouard Morren, sur un pied venu dans les prairies humides de Tilft, aux bords de l'Ourthe, fig. 1. Cette spiralisation est accompagnée de boursouflure et de torsion également en spirale et imite la coquille univalve dont parle Gilibert. Il y a quatre gros tours de spire terminant une tige, et ces spires sont recouvertes d'un nombre considérable de petits traits d'un vert foncé et d'un vert pâle, alternativement, courant en spirale; le tout occupe 7 centimètres d'étendue. Une fenille existe à la base : elle est anormale de forme, elle porte

(1) Froriep's neue Notizen, t. VIII, p. 147.

(2) Allgem. Gart Zeit. Otto, n 47. - Bot. Zeit., 2mm anne, 1844, p. ․59. - Kros, De Spira, p. 75. 
deux folioles terminales; un raphé formé d'une quantité considérable de feuilles court sur le côté et en une ligne tout le long de la boursouflure tordue et se termine en haut par des inflorescences rabougries entremêlés de feuilles. Nous ne pouvons reconnaître aucune position claire dans ces feuilles. Le sens du spiralisme est.de gauche à droite.

Le second cas est celui que nous a offert un Scabiosa arvensis trouvé par nous dans les prairies de Droixhe près de Liége, dans un endroit fort humide. La spiralisation occupait plus d'un pied en longueur, mais on n'y voyait aucune feuille. Les taches brunes indiquent les spires aussi bien que les sillons, car cette tige fistuleuse avait l'air d'être formée par un ruban contourné dont les bords se seraient soudés. La spire allait de gauche à droite. Elle cessait à la trifurcation de la tige. Voyez la fig. 2.

Mais le cas le plus curieux est celui que nous avons constaté sur un Dracocephalum speciosum, cultivé chez M. Haquin, horticulteur à Liége. La tige normale, fig. つั, offre quatre raies noirâtres et quatre angles brunâtres; les feuilles sont rectisériées et décussées.

Sur la plante spiralisée, la tige était à la fois soumise à la spiralisation des fibres et à la torsion en même sens. Ce double état est exprimé dans la fig. 5. Les feuilles bien développées naissaient le long d'une ligne, laquelle se tournait en spirale sur la tige. La fig 4 indique que l'intervalle brun de la tige spiralisée correspondait entre les feuilles et à la nervure médiane d'une feuille. Donc, il y avait quatre lignes brunes aboutissant chacune à un ordre de feuilles ou deux conjugués.

Il est évident que le système phyllotaxique des feuilles, dans ce Dracocephalum normal, était un système rectisérié et que, dans le Dracocephalum tératologique, le système 
était an contraire curvisérié. Or, nons nous sommes démandé de suite si une formule phyllotaxique exprimerait avec régularité la nouvelle disposition, ct celte formule a été trouvée de $\frac{5}{15}$. Ainsi la 15 e feuille recouvrait la première, et le nombre de tour's de spire entre 1 et 15 feuilles était de 5 .

Or, si nous suivons pour un moment la notation ordinaire pour les feuilles décussées comme pour les feuilles alternes, nous aurons, la première feuille recouverte par la cinquième et deux tours de spire, puisque les feuilles décussées résultent, dans ce cas-ci, de deux lignes conjuguées; soit donc $\frac{2}{5}$ comme expression.

Ceci admis, la formule $\frac{5}{15}$, dans ses rapports avec $\frac{2}{5}$. montre d'abord que, malgré l'organisation tératologiqui', elle rentre dans les formules existantes:

$$
\frac{1}{2}, \frac{1}{5}, \frac{2}{5}, \frac{5}{8}, \frac{5}{15}, \frac{8}{91} \text {, etc. . . . . } \frac{n}{13} .
$$

De plus, il est remarquable que la fraction de la phyllotaxie tératologique, ne déviant pas de la loi des phyllotaxies normales, est précisément celle qui résulte de l'addition des numérateurs d'une part et de l'autre des dénominateurs des deux fractions qui précèdent dans la série naturelle phyllotaxique.

Cette coïncidence a lieu de surprendre. Nous voudrions qu'on retrouvât maintenant assez de spiralismes pour pouvoir examiner si la même loi se découvrira ailleurs. C'est pourquoi nous avons indiqué les genres des plantes où il y a chance de trouver ces curieuses monstruosités.

Dans tous les cas, nous croyons pouroir lixer l'attention des tératologistes sur ces points, comme déductions du présent travail :

$1^{\circ}$ La spiralisation on le spiralisme est différent de la torsion : celui-ci est un contournement de l'ase ou des parties 
appendiculaires, tandis que celui-là est un phénomène qui tient aux fibres de la plante; ces faisceaux de fibres sont dans le spiralisme contournés en spirale.

2 Ce phénomène retrouvable dans les trois grandes divisions dı règne végétal, semble sé lier avec la station humide, comme si l'eau, qui déjà se meut en spirale dans une cellule isolée, tendait à suivre, dans le végétal entier, le cours de la courbe générale à tous les organismes végétaux.

$5^{\circ}$ Quand le spiralisme est axile, les feuilles détournées de leur position phyllotaxique normale, retombent dans une position phyllotaxique nouvelle, mais analogue à celle qui existe dans l'ordre des positions connues, absolument comme si les lois de la phyllotaxie étaient antérieures et supérieures à toutes les déviations tératologiques possibles.

\section{EXPLICATION DE LA PLANCHE.}

Fig. 1. Spiralisme boursouflé et tordu en coquille du Valeriana officinalis.

2. Scabiosa arvensis spiralisé dans la tige.

5. Dracocephalum speciosum spiralisé réduit à un tiers de la grandeur.

4. Morceau de tigerle ce Dracocephalum, vu au double de sa grandeur.

5. Position normale des feuilles sur cette espèce, grandeur naturelle. 


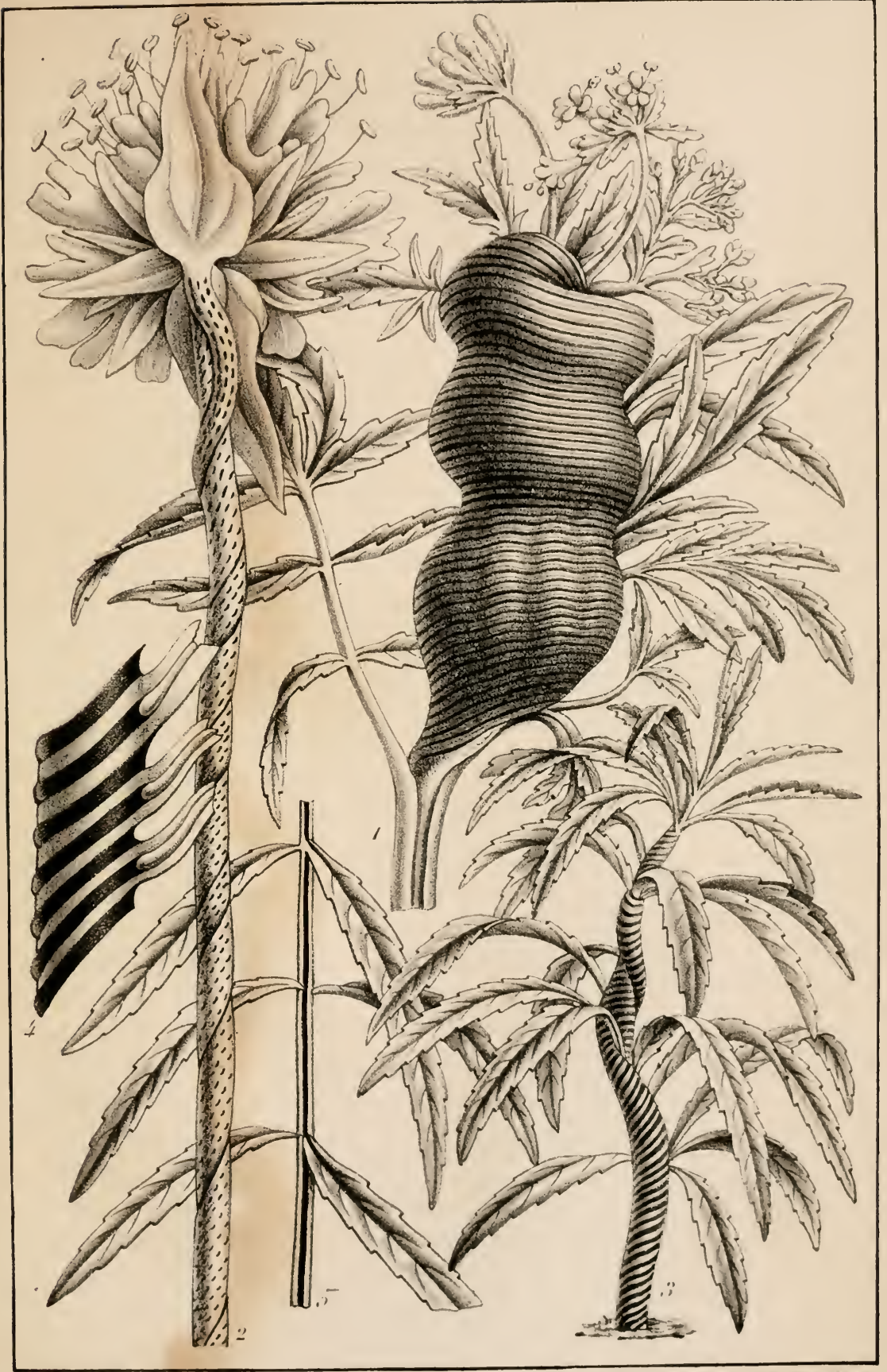

- Sipiralisurese 



\section{ACADÉMIE ROYALE DE BELGIQUN.}

(Extrail dn tome XVII, $n^{\circ}$, des Bulletins.)

\section{TÉRATOLOGIE VÉGÉTALE.}

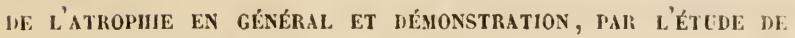
l'ORGANiSATION MÊME, DE CE FAIT QUE LES FOLLENS DE CERTAIXS MONSTRES SONT IMPUISSANTS;

M. Charles morren, Menlbre de l'Académic royale de Belgique.

La tératologie actuelle classe les atrophies végétales en deux grands groupes: les atrophies de l'axe el les atrophies des parties appendiculaires. Nous n'avons pas l'intention de nous occuper actuellement des premières, mais seulcment d'une partie de l'histoire des secondes. Ces atrophies ont été examinées dans les feuilles, mais d'une manière si incomplète que nous aurons bientôt l'occasion de démontrer comment ce phénomène est beaucoup plus riche en faits physiologiques et en conséquences philosophiques, 
qu'on ne le pense actuellement. Puis, on a cité quelques cas d'atrophies du calice, de la corolle, de l'androcée et du gynécée, et c'est à ce peu de documents que se bornent nos connaissances sur l'une des parties les plus intéressantes de la science des monstruosités.

Il est à remarquer d'abord que l'on ne possède guère d'études approfondies de ce qui se passe dans les appareils vivants, alors qu'une cause inconnue les frappe d'atrophie. On part toujours de l'idée que l'état d'atrophie est l'état permanent d'une formation qui n'aurait dù être que passagère, ce qui, au fond, au lieu d'être un axiome, est un fait à démontrer. L'atrophie peut avoir en soi bien des causes déterminantes et bien des natures diverses: on arrive à cette conséquence après avoir vu avec soin ces phénomènes qu'on est convenu d'appeler de ce nom :

L'atrophie est-elle le résultat inévitable d'une non-existence?

L'atrophie est-elle un arrêt de développement, ce qui suppose qu'alors l'organe ou l'appareil existerait?

L'atrophie est-elle une déviation de ce développement avec réduction de volume?

L'atrophie est-elle un avortement ou un retard dans le développement?

Toutes ces questions d'origine restent à examiner, et pour peu qu'on cherche à les résoudre dans les réalités du monde physique, on demeure convaincu que le fait connu sous le nom d'atrophie est souvent accompagné de phénomènes qui en compliquent singulièrement et la nature et la signification.

L'exposition de quelques faits de ce genre suffira pour laire comprendre la validité de cette assertion. Visitant, l'année dernière, les serres de M. le chevalier John De Knyff de 
Waelhem, nous y vimes un Ilymenocallis en fleur sous le nom d'Hymenocallis americana, espèce d'Amaryllidée encore incertaine quant à sa détermination. Découvrant entre les fleurs de cette superbe plante des appareils floraux avortés, puisque c'est là le nom vulgaire et même scientifique dont on se sert pour désigner ces organismes tératologiques, il nous prit fantaisie de les examiner, et MI. De Kinyff mit généreusement ì notre disposition des pieds qui produisaient ces simulacres de fleurs, le désespoir des horticulteurs et la joie de ces heureux botanistes qui trourent les êtres contrefaits et mal bâtis bien plus intéressants que les plus beaux modèles du genre, fussent même des Vénus ou des Apollon. C'est donc l'analyse et la dissection de ces Hymenocallis atrophiés que nous nous proposons de faire connaître aujourd'hui.

A la sertule de ces plantes, on trouve régulièrement cinq grandes et belles fleurs formées comme nous le dessinons fig. 1. Le périgone est supère, corollin, marcescent, persistant, le tube allongé, droit, trigone, la gorge à peine renflée ou non, le limbe à six divisions presque égales, linéaires, lâches et ouvertes.

La couronne fauciale tantôt sinuée à six dents, les dents staminifères (étamines), les sinus bidentés ou rarement privés de dents, tantôt à six lobes et alors staminifère entre les lobes entiers ou bifides.

Les étamines, au nombre de six, ouvertes, presque égales entre elles. Les filets filiformes décurrents. Les anthères linéaires, fixées au-dessous de leur milieu, incombantes.

L'ovaire infère, oblong, trigone, triloculaire, les ovules anatropes.

La colonne styline (style) filiforme, trigone, droite et déclinée, selon Herherl, ee qui dépend de l'henre oì on 
l'observe. Le stigmate capitellé est, au sommet, obscurément trilobé.

Une fleur normale de ce genre mesure moyennement quinze centimètres de l'extrémité du stigmate à la base de l'ovaire, et la même longueur se remarque d'un bout du périgone ouvert à l'autre horizontalement.

Or, à plusieurs sertules, on trouvait de misérables fleurs, hautes de sept centimètres et larges de quinze millimètres, et tandis que les hyménocalles, régulièrement formées, répandaient, pendant le jour, une délicieuse odeur de tubéreuse susceptible d'aromatiser de grands appartements, les fleurs tératologiques, privées de tout parfum, ne pouvaient charmer que l'intelligence d'un penseur.

A ces fleurs les bractées ou spathes se développent normalement (voy. fig.2). Donc elles ont été protégées comme les fleurs normales, et ce ne sont pas les premières culottes (bractée-culottes) qui leur ont manqué. Ceci est un premier avis à ceux qui font toujours intervenir les causes extérieures, le monde ambiant, les conditions externes comme provocatrices de tout phénomène tératologique, alors qu’il est évident que celui-ci procède le plus souvent d'une cause interne, d'une force qui affecte l'organisme, même dans ce qu'il a d'intime el d'intérieur.

Puis venait le périgone réduit à son verticille externe, donc calicinal, ce qui ne fait que corroborer ce que nous venons de dire. Ce verticille doit nous occuper un instant. A voir la fleur entière (fig. 2), on n'apercevait d'abord que deux divisions à ce calice, mais avec quelque soin, on lécouvrait que deux d'entre elles étaient seulement soudées en bas et en haut. La figure 5 montre comment cette soudure avait lieu par le moven d'une bride cellulaire, dont 


\section{$(127)$}

la division libre portait l'analogue au sonmet. Chaque division calicinale est cana!iculaire.

Ainsi, le périgone de la fleur atrophiée, réduit à la moitié de ses éléments, avait subi ici : I" une atrophie complète du verticille corollin; $2^{\circ}$ une diminution de volume, mais avec déviation de développement par soudure du verticille calicinal. lci, il y avait déjà, quant au verticille extérieur, atrophie par arrêt de développement, mais qui peut dire si le verticille intérieur n’était pas atrophié jar non-existence primitive? Pour résoudre cette question, il faudrait disséquer la fleur qui devrait s'avorter, rechercher, avant qu'elle ne s'avorte, l'état des mamelons primordiaux corollins dans la génèse de la fleur, et nous n'en sommes pas encore à ce progyrès dans la tératologie rationnelle. Dans tous les cas, il est nécessaire de diriger les recherches de ce côté, puisque là seulement peut se trouver le moyen de répondre à l'une des questions d'origine.

Comme corollaire, nous ferons observer encore, que si les bractées existaient normalement, l'organe protecteur le plus externe des appareils sexuels se retrouvait encore dans la fleur. Ainsi, il est toujours de plus en plus probable que les profondes modifications subies par ces appareils importants, viennent du dedans et non du deliors.

Nous passons à l'androcée. Évidemment la couronne fauciale des IIymenocallis représente le torus commun des deux rangs (verticilles) de l'androcée. La vraie corolle, les trois divisions internes du périgone, étant devenue dans sa forme, calicinale, alors que ses fonctions, partagées par le vrai calice, sont restées corollines (couleur, respiration, odeur, etc.), elle devenait moins importante quant à cette forme. Celle-ci s'est transportée à la base de l'androcée. c'est-ì-dire le torus, dont la rraie cornlle est la manifestation 
externe. Ainsi, par la philosophie botanique, on s'explique très-bien pourquoi cette couronne fauciale devient corolline. C'est par cette raison que la phytographie est en partie exacte cette fois, bien qu'elle ait tort de dire que les dents de cette couronne sont staminifères. C'est la couronne elle-même qui est staminale; et en étudiant, chez. l'Hymenocallis l'insertion des fibres qui correspondent à chaque étamine, fibres dont trois sont opposées aux divisions calicinales et trois aux divisions corollines, il est aisé de se rendre compte de la nature de ces prétendues dents de la couronne fauciale, qu'on ferait mieux de nommer directement et simplement des filets. Aussi longtemps que la phytographie et le glossologie ne reposeront pas sur les axiomes de la philosophie botanique, ce seront des sciences conventionnelles où les mots iront en s'augmentant, à mesure que les idées que ces mots sont destinés à exprimer, iront en se simplifiant : étrange et déplorable antagonisme entre l'esprit et le verbe!

Dans la fleur anormale, il y avait, pour les yeux, cinq étamines, chacune, proportionnellement avec les étamines normales, pourvue d'une grosse anthère et d'un petit filet; puis on remarquait absence complète de couronne fauciale.

Cinq éléments androcéens au lieu de six, voilà un phénomène complexe de l'atrophie, qui demande qu'on aille plus avant dans l'analyse.

Et d'abord, une étamine (voy. fig. 4) paraissait avoir ef avait effectivement une anthère beaucoup plus petite que les autres; puis, à côté d'elle, l'étamine du milieu (en étendant l'androcée) se retrouvait beaucoup plus grosse que ses voisines. Au bas, pas la plus petite trace de couronne ni de menbrane, mais chaqque filet était mince, hormis celui de la grosse étamine. 
Ce n'est pas tont. Quatre étamines de la fleur anormale avaient leur's anthères respectives insérées sur l'extrémité du filet, un peu plus bas que le milieu de l'anthère. Donc, dans l'anthèse, l'anthère devient oscillante, à équilibre instable, et le zépliyr l'agite. Cette insertion anthérienne normale se retrouvait dans la fleur anormale chez quatre étamines̀ sur cinq. Mais la cinquième étamine avait l'anthère dressée, soudée par les deux lobes inféricurs de l'anthère à un filet fort et large, ce qu'exprime la $f g .6, \mathrm{et}$, en suivant le filet jusqu'au bas, on pouvait ouvrir ce filet sans déchirer les tissus, en deux bords, comme le montre encore la fig. 6. Pour l'insertion de l'anthère, comparez l'anthère $f g .5$, vue sur le còté, avec l'anthère fig. 6 , et la différence sautera aux yeux.

Ainsi ces faits nous révèlent deux ordres d'idées. En premier lieu, il y a encore un souvenir de couronne fauciale au bas du filet de la grosse étamine; en second lieu, ce gros mâle en représente deux. L'hypertrophie de son anthère compliquée d'un changement d'insertion et le gros volume de son soutien, plus l'élargissement de la base de son filet, prouvent surabondamment que cet élément de l'androcée a fait soi la substance organique d'un de ses semblables. L'œil n'aperçoit ici aucune pièce séparée, soudée, annexée, qui rappelle cette double origine élémentaire, mais l'esprit aperçoit facilement que cette attraction, cette absorption, cette assimilation d'un élément organique au profit d'un autre ont eu lieu. Ici encore la genèse des fleurs anormales bien étudiéc rendrait service.

Mais il ne résulte pas moins de ces combinaisons que voila l'atrophie d'une fleur, comportant l'atrophie de son androcée, poussée si loin qu’il y a absence apparente d'un élément du verticille, compliquée d’une hypertrophic qui, 
seule, peut expliquer et cette absence et la diminution de volume de l'organisme entier. Qu'on dise qu'une atrophie résulte d'une hypertrophie, et l'on criera au paradoxe! Et cependant tout cela fait bien l'effet de se passer ainsi.

L'étude des anthères va donner à notre monstre d'Hyménocalle un nouvel intérêt. Plusieurs fleurs étaient anormalisées (qu'on me pardonne le mot, les savants sont depuis longtemps brouillés avec l'Académie du Dictionnaire!) sur le même plan. Aucune, ni jeune, ni adulte, ni vieille, ne montrait des anthères déhiscentes. 0 n peut donc croire que les organes mâles du monstre n'étaient jamais destinés à fournir du pollen, et encore moins, en conséquence, à entrer en copulation avec quelque femelle normale ou non. On a dit depuis longtemps, dans la tératologie animale, que les vrais monstres ou ne sont pas viables ou sont frappés de stérilité. La nature plus placide du végétal comporte-t-elle aussi cet anathème? et si la malédiction a frappé l'être anormal, comment la punition providentielle s'accomplit-elle?

Nous ne croyons pas qu'on ait abordé jusqu’à présent en tératologie ni cette question, ni l'anatomie du pollen d'un monstre autre qu'un double.

En examinant avec soin toutes les fleurs normales des Hyménocalles que nous avions devant nous, nous avons fini par trouver une étamine dont l'anthère, réduite en un petit sac sphérique et latéral, n'était pas destinée à s'ouvrir, et cela d'une manière évidente. La fig. 7 donne la représentation de cette anthère atrophiée, et condamnée elle aussi, dans une fleur normale, à la stérilité. Ce nouveau monstre devait, dans cette occurrence, nous plaire infiniment : aussi nous le regardâmes comme un envoyé du ciel.

Ces anthères stériles, d'où jamais le pollen ne devait 


\section{( 151$)$}

s'éjaculer, avaient-elles du pollen? première question, et, dans l'affirmative, ce pollen était-il normal ou anormal? deuxième question, et dans le cas de l'anormalité, comment était-il frappé d'impuissance, troisième question et, pensons-nous, la plus curieuse et la plus neuve de toutes? Nous allons répondre à chacun de ces points dinterrogation.

L'anthère en sphère fermée de la fleur normale, de même que les anthères de forme normale, mais non déhiscibles des fleurs atrophiées, renfermaient toutes du pollen. Ainsi l'organisme mâle s'est développé jusqu’à son essence, quoique, nous allons le voir, cetle essence fût pervertie, déviée dans son organisation.

Pour savoir comment ce pollen diffère d'un pollen génuin, il nous faudra d'abord voir celui-ci.

M. Hugo Mohl(1) avait déjà reconnu que, dans les Amaryllidées, le pollen est ellipsoïde, avec un ou deux sillons longitudinaux et la membrane externe variable. Comme dans le Pancratium maritimum, l'eximinine (membrane externe du pollen) est ici dans cet Hymenocallis une membrane celluleuse. Le tissu cellulaire est du genre que nous avons nommé, depuis plus de quinze ans, colpenchyme, c'est-à-dire formé par des cellules sinueuses. Celte eximinine est forte, résistante; elle sécrète beaucoup d'huile jaune qui se ramasse en globe et tournoie sur elle-même dans l'eau. On en voit les amas représentés, figures 8,9 , 10,11 et 12.

Sur l'eximinine du pollen normal, on voit bien le sillon longitudinal. Ce pollen est ellipsoïle, et toujours les grains

(1) Ann. des scienc. nat., nouselle sérir, 185i, Bot., 1. III, 1. j08. 
sont fermés aussi longtemps qu'ils sont sur l'anthère. La fig. 8 représente ce pollen normal.

Nous examinâmes le pollen de l'anthère déformée et close de la fleur normale (fig. 7). Tous les grains, vus à see, c'est-à-dire sans eau, sur le porte-objet, étaient ouverts et uniformément du genre des figures 11 et 12 . Les eximinines arrondies, sphériques, mais toutes ouvertes par une calotte de sphère qui en semblait tombée ou par une ouverture circulaire. De là sortait l'endiminine (membrane interne du pollen destinée à devenir boyau pollinique dans la copulation), toujours repliée en demi-lune, tantôt en simple cœcum, tantôt portant un mamelon terminal. La fovilla était contenue dans l'endiminine comme un mucilage dense, montrant de petits points grouillants, mais pas de cellules ni de cystoblastes visibles.

Dans les anthères fermées et bouffies des fleurs atteintes d'atrophie, un état analogue se rencontrait, quoique différent. Les eximinines étaient aussi toutes ouvertes, tantôt sur l'un des bouts de l'ellipsoïde (fig. 9), et l'endiminine faisait hernie, tantôt, et e'était le cas le plus constant, le long du sillon longitudinal, de sorte que l'endiminine prenait la forme d'un fuseau au milieu duquel pendait l'eximinine, comme si c'eût été une moule à petites écailles et à gros animal.

Ainsi, le fait général qui distingue le pollen sain du pollen des monstres, c'est que le premier est clos, destiné a s'ouvrir, selon ses lois, sur le stigmate, tandis que le second est crevé, d'une manière ou d'une autre; et, quoique les endiminines fussent entières, nous observions que bientôt, soit à l'air, soit dans un mucilage de gomme, soit dans du sirop, les membranes se rompaient et la fovilla sortait. Or, comme l'air atteindrait infailliblement le pollen 


\section{( 153$)$}

des monstres, si leur's anthères s'ouvraient par ce fait mème, les membranes internes rompues perdraicut le contenu, et la métamorphose du boyau pollinique en embryon, ou la production de celui-ci par celui-là, ne pourraient plus avoir lieu. Donc, l'impuissance des pollens des monstres est un résultat inévitable et fatal de leur organisation : ils crèvent avant d'agir et de plus, ils ne voient pas le jour.

Enfin, il ne nous reste plus qu'à dire quelques mots au sujet de l'appareil gynécéen. La colonne styline dans la fleur' anormale est l'organe le moins modifié (voy. fig. 2). Le stigmate ne diffère pas de celui d'une fleur régulière; le style est plus court de trois quarts, mais il conserve sa longueur relative vis-à-vis des étamines de la lleur anormale.

L'ovaire est plus petit, mais entièrement vide d'ovules remplacés seulement par un axe de tissu cellulaire trèsdense. Ainsi l'organe femelle est, dans l'espèce, aussi stérile que l'appareil mâle est impuissant.

Nous croyons pouvoir résumer, comme nous allons le faire, les principales conséquences des observations précédentes dans les propositions suivantes :

10 Quand l'atrophie atteint l'appareil floral, ce phénomène devient complexe, et ne suit pas les mêmes manifestations dans toutes les parties et dans tous les verticilles le cet apparcil.

¿. L'atrophie de l'appareil floral exprimée par une diminution de volume du tout, peut comporter l'existence normale des organes protecteurs, de manière à faire admettre que la cause déterminante du phénomène de latrophie mème ne provient pas du monde ambiant externe, mais d'une cause interne inliérente à l'organisme même.

5̄ Laltération atrophinge croit du dehors an dedans, 
de manière que les appareils les plus protégés sont les plus profondément atteints.

$4^{\circ}$ L'atrophie du calice peut se compliquer de soudure.

$\check{3}^{\circ}$ L'atrophie de l'appareil floral peut se compliquer de l'absence complète de l'élément corollin, sans doute par non-existence de cet élément, au lieu d'admettre toujours l'arrêt dans un développement qui présuppose la présence de l'organe.

$6^{\circ}$ L'atrophie de l'androcée peut se compliquer de l'absorption complète des éléments qui eussent normalement formé un organe au profit d'un organe similaire, de sorte que l'hypertrophie de celui-ci sera la suite de l'atrophie de celui-là. La force hypertrophique viendra donc compliquer encore le phénomène de l'atrophie.

$7^{\circ}$ Dans l'atrophie de l'appareil staminal, les anthères pourront ne pas être susceptibles de déhiscence, comme une anthère d'une fleur normale pourra être frappée du même vice d'organisation; par conséquent, si ces anthères sont pollinifères, ce pollen n'est pas destiné à voir le jour.

8० Et dans ces deux cas, ce pollen est impuissant, parce que sa membrane externe, au lieu de rester close pour conserver, à travers l'air, l'intégrité de la membrane interne qui doit, en s'allongeant, donner naissance au boyau pollinique, s'ouvre et donne passage à la membrane interne qui fait hernie.

$9^{\circ}$ Sans que la membrane interne du pollen s'ouvre à son tour et que la fovilla se perde, cependant, dans les anthères atrophiées ou dans les anthères des fleurs atteintes d'atrophie générale, le pollen est frappéd'impuissance, puisque l'intérieur, qui doit être préservé contre les influences de l'air atmosphérique, est alors mis à nu. Par conséquent, 


\section{5}

l'impuissance du pollen d'un mâle atrophié est une conséquence de l'organisation viciée de ce dernier.

\section{EXPLICATION DES FIGURES.}

Fig. 1. Fleur en grandeur naturelle de l'Hymenocallis americana. Kunth.

2. Fleur anormale atrophiée, grandeur naturelle.

5. Verticille ealycinale de la même fleur.

4. Étamines, grandeur naturelle, vues devant le calice.

5. Étamine avec l'insertion dorsale de l'anthère (2 diamètres).

6. Étamine hypertrophiée avec l'insertion basilairc.

7. Anthère atrophiée d'une fleur, autrement normalc.

8. Grain de pollen normal très-ģrossi.

9 et 10. Grains de pollen d'une anthère de fleur atrophiée.

11 et 12. Grains de pollen d'une anthère atrophiée de fleur, autrement normale.

Les fig. 8, 9, 10, 11, 12 sont fortement grossies au microscope. 

liull de l: Icradt. Kiony.

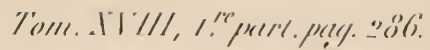

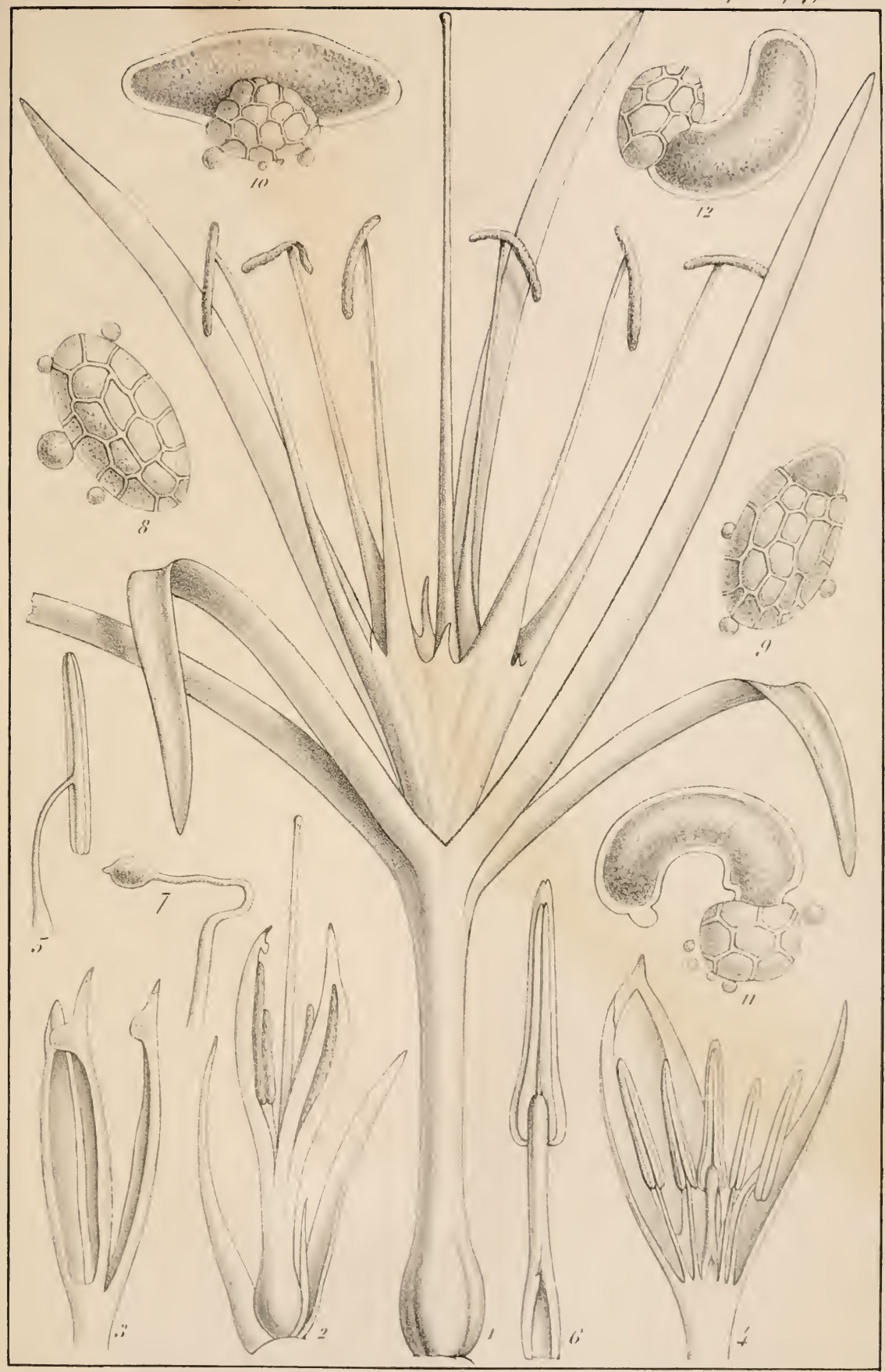






\section{ACADEMIE ROYALE DE BELGIQUE.}

(Extrail du tome XVIII, $n^{0} 6$, des Bulletins.)

\section{TERATOLOGIE VEGETALE.}

D'une pélorisation sigmoüde des Calcéolaires, nouveau genre de monstruosité, d'une synanthie bicalcéifère el cndostaminale, et enfin d'une synanthie unicalcéifère et exostaminale de ces mémes plantes;

In. (ㄴ). Aloren,

Membre de l'Acarlemie rovale de Belginue.

J’ai traité précédemment (1) de la pélorisation lagéniforme des calcéolaires, en citant les cas connus de cette régularisation d'un type irrégulier. Les tératologistes anglais ont bien voulu traduire mes pages à cet égard (2), et quoique habitant le pays le plus horticole de l'Europe, ils n'ont pas cependant cité des exemples nouseaux de

(1) Bulletins te l'Académie, 1. XV, n 7. - Finchsia, p. 89.

(2) Thomas Moore, Mayazyn of Botamy, 1851, part. XYI, 1. 127. 
celte singulière structure. M. l'abbé Van Oyen, professeur de sciences physiques et naturelles au petit séminaire de $S^{\prime}$-Trond, de l'obligeance duquel je tenais les pélorisations décrites, a eu la complaisance de m’en envoyer cette anuée quatre cas nouveaux, confirmant tous, sans exception, les détails précédemment observés. Le calice régulièrement formé, la corolle, en longue bouteille, terminée par un col aplati et s'ouvrant par une bouche linéaire, cette corolle colorée en dedans, vers le bas, et en dehors, vers le col, de teintes plus vives, pas d'étamines et un pistil normal. Ces caractères de la monstruosité se sont tous retrouvés sur ces quatre fleurs nouvelles. On peut donc admeltre que celte pélorisation se présente toujours avec une uniformité de structure qui manifeste aussi la fixité des lois sous l'empire desquelles elle se forme. A mesure que la tératologie avance, les idées sur la production des monstres par l'effet des causes extérieures se modifient, el cette théorie perd tous les jours de plus en plus de sa valeur. L'hypothèse d'une force interne, opposée, quant à la symétrisation, à la force formatrice spécifique (nisus formations specificus) acquiert, au contraire, de plus en plus de vraisemblance, et, de la même manière que les êtres normaux sont tous de la forme de l'espèce, les êtres anormaux sont tous aussi de la forme donnée de la monstruosité spécialisée. Pas plus là qu'ailleurs, le vague n'existe et l'indéterminé n'est pas dans la nature.

Parmi les monstruosités remarquables que M. Van Oyen a bien voulu m'envoyer récemment, je distingue une pélorisation d'un groupe qui, je crois, n'a pas encore été signalée dans les cadres tératologiques. Quand je la nomme pélorisation, je me sers d'un nom impropre, mais la langue est si pauvre devant la richesse de la nature, qu'il faut bien 
ne pas donner à l'expression un sens trop absolu. Lat prilorie est, comıne on le sait, la monstruosité régulière d’une fleur irrégulière dans sa structure ordinaire. l.es calcéolaires sont des scrophulariacées très-irrégulières; leur pélorie est, an contraire, parfaitement régulière. La pélorie lagéniforme est droite et ne rapjelle plus du tout lat ligure calcéiforme dı type grénérique.

Or, qu'on veuille bien jeter les regards sur la fig. $1^{\text {re }}$. On y voit une monstruosité qui tient le milieu entre la forme spécifique et la pélorie régulière lagéniforme. Le ealice n'a rien de distinct. La corolle offre d'abord le bas du tube droit et régulier comme dans la pélorie connue, puis, l'organe se détourne de sa direction; il se renfle cu deux bosses en avant, lesquelles bosses rappellent évidemment les boursouflures de la lèvre inférieure des corolles calcéiformes normales. Au-dessus de ces renflements, la corolle se rétrécit; elle se courbe en cou de cyouc et poussant en avant deux dents creuses; elle relève une forme de bec où se trouve l'ouverture linéiire de la corolle. Quant. au coloris, il suit l’interversion de la pélorie lagéniforme. Au bas, les couleurs foncées sont en dedans, et an bout elles sont en dehors.

Au foud, et à moins de domner à la pélorie un sens trop̣ restreint, ce cas de téralologie ne peut rentrer que dans la classe des pélorisations. Seulement il nécessitcra désormais une section qu’il sera peut-être convenable de nommer semi-pélorisations, car, évidemment, c'est une pélorie arrivée à mi-chemin de la régularisation : ello rappelle encore en tont point la corolle convolutée du tyje générique normal. Si l'on vent la laisser dans la classe des pélories, je proposerai de la distinguer de la pélorir lagéniforme, forme quielle n’a décidément pas, par le nom 
de pélorie sigmoïde, forme qui est bien la sienne. C'est un cou de cygne ou un S majuscule.

Cette pélorisation sigmoïdale n'est pas sans une certaine éloquence dans l'interprétation des lois de la métamorphose. Toute corolle est ouverte, les sexes devant être mis en rapport avec l'atmosphère et les êtres qui y vivent (oiseaux, insectes, hommes, etc.), ou les météores qui le modifient (vent, chaleur, humidité, sécheresse, etc.). La pélorie lagéniforme présente son ouverture au bout, mais on ne voit pas de suite si cette ouverture représente bien celle du bas de la corolle du type générique des calcéolaires. La pélorie sigmoïde le démontre à l'instant. Le col rétréci semble vouloir reporter cette ouverture à la base de l'organe, et cette indication donne la clef de l'interversion des coloris, observée précédemment entre les calcéolaires normales et les calcéolaires pélorisées. En effet, sur une calcéolaire normale, la teinte la plus foncée est en dedans, vis-à-vis de l'ouverture du soulier que représente la corolle; puis, sur l'empeigne de cette pantoufle, la haute couleur se distribue de nouveau. Comparons cet état normal à l'anormal. Il est clair que, dans les deux pélories lagéniforme et sigmoïde, la coloration foncée du dedans représente celle du bas, et la coloration foncée du dehors celle de l'empeigne. 0 n peut donc se figurer la corolle calcéiforme génuine se déroulant pour former la corolle lagéniforme ou la corolle sigmoïde, en prolongeant l'empeigne primitive en bas et la changeant en col droit ou courbe. On lit maintenant mieux qu'on ne le faisait naguère, alors que les monstres de Chamisso, de Guillemin et de Van Oyen venaient d'être connus dans leur régularité, les passages entre l'état complétement génuin ę l'état complétcment pélorisé. 


\section{(14)}

Ce n'est pas cependant que ces deux pélories ne viennent intirmer la théorie physiologique de feu Dutrochet, sur la distribution des couleurs dans la fleur. En prétendant que les couleurs les plus foncées sont toujours extérienres et en rapport avec la surface éclairée le plus, il reste à démontrer pourquoi, iei, dans une corolle bien fermée, bien close, en long tube droit ou courbé, la couleur la plus haute est en dedans et la plus faible en dehors. Sur la corolle calcéilorme génuine, la théorie de Dutrochet a la ressource de la gorge ouverte par où la lumière entre, mais cetle raison n'en est plus une pour la corolle lagéniforme et pour la corolle sigmoïe. Là, les gorges sont fermées ou à peu près.

A mes yeux, ce fait prouve que la cause qui détermine les métamorphoses des formes normales en formes, je ne. dis pas anormales, mais tératologiques, est plus puissante dans l'organisme que les forces physiologiques, et qu'elle tient plus à l'essence même de la formation de l'être que la puissance fonctionnelle. Et si l'on descenil de ces hauteurs, peut-être un peu métaphysiques, alors que la science actuelle a assez l'habitude de marcher terre à terre, on ne peut s'empêcher de faire cette réflexion, à savoir que si, dans la physiologie de Dutrochet, les couleur's étaient les suites, les effets d'un éclairement plus ou moins actif, ici. sous une lumière diffuse, dans un tube clos et coloré, les teintes s'avivent sous un éclairement bien moindre que celui auquel est soumise la surface du dehors. Ce fait, certes, ne rend pas plus claire cette théorie du pouvoir del'éclairement.

J'abandonne ici le monstre sigmoïde pour passer à l'étude d'un autre ordre de faits, dont M. Van Oyen m'arait fourni également un premier et m’a donné actuellement un second exemplaire. 
de veux parler des fleurs synanthiques. J'ai déjà eu l'occasion plusieurs fois de montrer combien peu les lois de la synanthie sont connues. Dans une classification générale, il est si vite établi que des fleurs peuvent se réunir, le nom de synanthie cache si promptement tout ce que ce phénomène a d'intéressant, qu'il arrive de ce nom ce qui advient de l'histoire naturetle en général. Quand on a trouvé le nom d'une espèce, on tirait que l'esprit n'a plus rien à faire, et ce n'est cependant que lorsque ce nom est rrouvé, que le véritable naturalisie commence à réfléchir, sil réfléchit. La connaissance de la nature ne se eirconscrit pas dans un dictionnaire de noms. Cependant telle est encore l'influence d'une tératologie commençante. Quand on a dit que tel monstre est une synanthie, on croit avoir expliqué une merveille, et la merveille est tout entière dans le silence qui suit la classification.

Dans ma publication antérieure sur une synanthie de calcéolaire (1), je disais que, dans le cas jusqu'alors non signalé, il y avait des phénomènes compliqués, tels que la résorption de la lèvre supérieure, le non-développement d'un calice double, une résorption de la quatrième étamine, et j'ajoutais: «Cette forme tératologique permettra peut-être de mieux saisir un jour la cause intime des synanthies. D Ce passage et le monstre lui-même ont eu l'honneur d'être traduit et reproduit par la presse anglaise et par une plume des plus savantes des Iles Britanniques. C'est en partie ce qui m'a engagé à consigner ici les détails d'une seconde synanthie bicalcéifère de calcéolaire, qui présente des complications curieuses et prouve que la sou-

(1) Fuchsia, 1. 95. 
diare de deux hleurs irrégulières peut ètre accompagnée de phénomènes de genres divers.

J'ai représenté la fleur synanthisée, fig. $\mathcal{2}$, en avant et, fig. $\bar{j}$, en arrière. D’abord le calice, quoique formé sur un rang unique, présente en arrière (fig. 5) huit divisions, le double du nombre normal, tandis que, dans la fleur synanthisée précédemment décrite, il y avait un ealice à quatre divisions et ayant l'aspect d'un organe normal. Ici, les deux divisions inférieures étaient atteintes d'une légère atrophie, mais aussi, par compensation, une neuvième livision calicinale s'était développée du còté opposé et en avant, de manière à se pencher directement sur les deux lìvres supérieures et soudées de la corolle (fig.2, b). Ce fait montre comment, dans les synanthies, malgré la fusion de deux organismes, il y a tendance au dédoublement, quaud, par le balancement organique, il y a atrophie de quelques organes foliaires.

La corolle, de la forme générique, était bien double, avec fusion plus grande du côté supérieur et division et individualisme plus prononcés des lèvres inférieures, parties uormalement hypertrophices. Les deux corolles offraient la grandeur et la coloration ordinaires à la variété qui avait produit le monstre.

Dans la synanthie décrite dans ma Fuchsia, il y avait trois étamines : l'une était née ver's le haut et sans hypertrophie, de manière à faire admettre une torsion latérale du verticille androcéen et la résorption de la quatrième ctamine. Ici, rien de semblable. Il y avait deux étamines seulement (fig. 2, c), l'une à droite et l'autre à gauche. comme dans une fleur génuine; mais elles étaient soudées l'une à l'autre par un fort frein mitoyen, indiquant par sa masse et sa position opposée aux filets développés, que 
c'était bien ce frein qui représentait à lui seul les deux étamines non déreloppées. De ce côté donc, pour chaque lleur sunanthisée, il y avait réduction à la monandrie, et pour les deux fleurs réunies, diandrie tératologique imitant la diandrie naturelle.

De même, on y voyait deux pistils, mais ceux-ci complets u frappés d'un caractère très-prononcé de divarication, chaque ovaire regardant la droite et la gauche obliquement, les styles dirigés augulairement et côtoyantl'anthère de son côté respectif $(f i g .2, d)$. Cette direction, cette obliquité, ce développement de l'appareil pistillaire rendaient cette synanthie très-remarquable.

Ainsi voilà dans un même type de fleur irrégulière et așrmétrique au moins deux sỵstèmes déjà connus de synanthies très-différentes. D'une part, normalité de calice unique, dualité de corolles soullées, irrégularité dans l'androcée, fusion de deux pistils à ovaires distincts avec soudure complète de deux styles et de deux stigmates. D'une autre, dualité de calice et tendance à son dédoublement, dualité de corolles soudées comme dans le cas précédent, mais réduction à l'unité de l'androcée normale déjà réduite à deux étamines normalement, fusion et métamorphose en organe stérile des deux étamines restantes, enfin normalité des deux organes pistillaires. Ainsi, le type naturel s'était conservé dans l'un des cas au profit de l'appareil calicinal, dans l'autre au profit de l'appareil pistillaire, les deux pôles de la fleur qui ont entre eux et dans leur nature la plus grande et la plus profonde analogie. Dans les deux cas aussi, dissimilitude radicale dans les modes de finsion qui ont affecté les productions du torus, l'androcée et la corolle, les deux appareils les moins stahes de la fleur. Je pense donc avoir dit arec raison que 


\section{( 145 )}

l'étude des synanthies nous conduirait un jour à apprécier plus profondément la cause intime de ces sortes de phénomènes. On voit ici clairement que l'organographie philosophique peut prévoir jusqu’a un certain point les variations que la force tératologique doit apporter dans le développement des organismes anormaux, et jentends par là ceux qui s'éloignent du type habituel.

Ce n'est pas tout. M. Jules de Fisse m'envoya de même de $S^{t}$-Trond une nouvelle synanthie qui offre un troisième système de soudure. J'ai figuré le monstre, fig. 4 , en avant

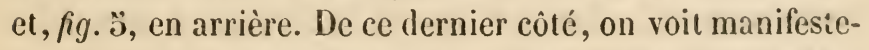
ment que sur un seul pédoncule nait un calice double, formé de huit divisions, dont les deux latérales sont de grandeur normale et plus développées que les autres. Puis vient la corolle dont la lìvre supérieure offre, comme dans les deux cas précédents, une soudure complète des deux lèvres primitives; mais ici la lèvre inférieure présente de même une fusion totale, de sorte que la synanthie est unicalcéifère. C'est ce que montre la figure 4. Mais le plus intéressant appartient à l'androcée. Nous venons de roir que, dans la synanthie bicalcéifëre précédente, les deux étamines déreloppées partent de la ligne médiane du monstre. Ici, c'est l'inverse, les deux seules étamines entièrement développées d'après le type de l'espèce sont externes. Dans la ligne médiane, il n'y a pas de trace d'organes mâles, mais on trouve deux pistils soudés entièrement et offrant avec une atrophie des deux styles, deux stigmates un peu divariqués. Il est évident, en comparant ce système au précédent, que la différence réside surtout dans ce développement des deux étamines représentant, par une insertion incontestable, l'étamine externe latérale de chaque fleur, nommant étamines internes les deux organes de cette na- 


\section{(146)}

ture qui dans une simple conjonction de deux fleurs sans soudure et fusion, se toucheraient l'un l'autre. C'est, sans aucun doute, celte fusion avec atrophic de ces organes absorbés au profit de l'être tératologique tout entier, qui a amené la soudure complète aussi des deux lèvres inférieures en pantoufle en une seule plus large, mais de cette mêıne forme. Il est prudent de désigner ce mode de synanthie d'une façon particulière, puisque ce mode est différent. Nous le nommons synantlie unicalcéifère exostaminale, tandis que la précédente est une synanthic bicalcéifère endostaminale, exprimant par là les structures tératologiques à la fois de la corolle et des étamines.

M. Moquin-Tandon, dans son remarquable Traité de tératologie (p. 264 et suiv.), a déjà discuté en partie les lois des synanthies; mais ces exemples-ci avec ces singulières combinaisons lui étaient inconnus. Cependant la loi de la soudure des parties homologues s'y vérifie complétement et la confirment : cela saute aux yeux pour le calice, la corolle et le pistil. Seulement nulle part nous ne voyous ici la loi des homologues produire une fusion des étamines; mais, au contraire, une annihilation de ces éléments staminaux et, dans le premier cas, la synanthie tristaminale, le déplacement par torsion d'une étamine de l'une des fleur's qui a fondu l'autre dans la greffe des deux fleurs. Un autre fait non moins remarquable, qui résulte de la comparaison de ces trois synanthies de calcćolaires, est celui du premier cas où le calice était normal avec une soudure de deux corolles, de deux androcées et deux pistils, qui a amené une fusion complète entre les appareils pistillaires et la moitié de la corolle ou les deux lèvres supéricures. II. Moquin-Tandon, qui a compulsé un grand nombre d'écrits sur la science des monstruosités, a raison de dire 


\section{$(147)$}

que ce cas d'unité d'un organe normal avec la dualité ou la pluralité des autres, est une des combinaisons les plus rares qu'effectue la nature, de même que les synanthies de verticilles floraux, qui n’augmentent le nombre des éléments que d'un seul d'entre eux, ont pu se voir quelquefois, mais doivent être classées aussi parmi les observations les plus rares. L’intérèt qui s’attache, par conséquent, an premier cas que nous avons fait connaître, ne fait que s'augmenter vis-à-vis des judicieuses déductions publićes par le savant professeur de Toulouse.

\section{EXPLICATION DE LA PLANCIE.}

r.jy. I. Flenr pélorisée ou pélorie sıgmoïde d'une calcéolaire, frrandeur naturelle.

๖. Fleurs synanthisćes bicalcéifères et endostaminales, vues en avant.
(1. Calice.
b. Division surnuméraire calicinale.
c. Étamines.
d. Pistils.

j. Les mêmes fleurs vues en arrière pour montrer le calice.

4. Fleurs synanthisées unicalcéifères et exostaminales, vues devant.

5. Mêmes fleurs, rues en arricre pour montrer le calice. 



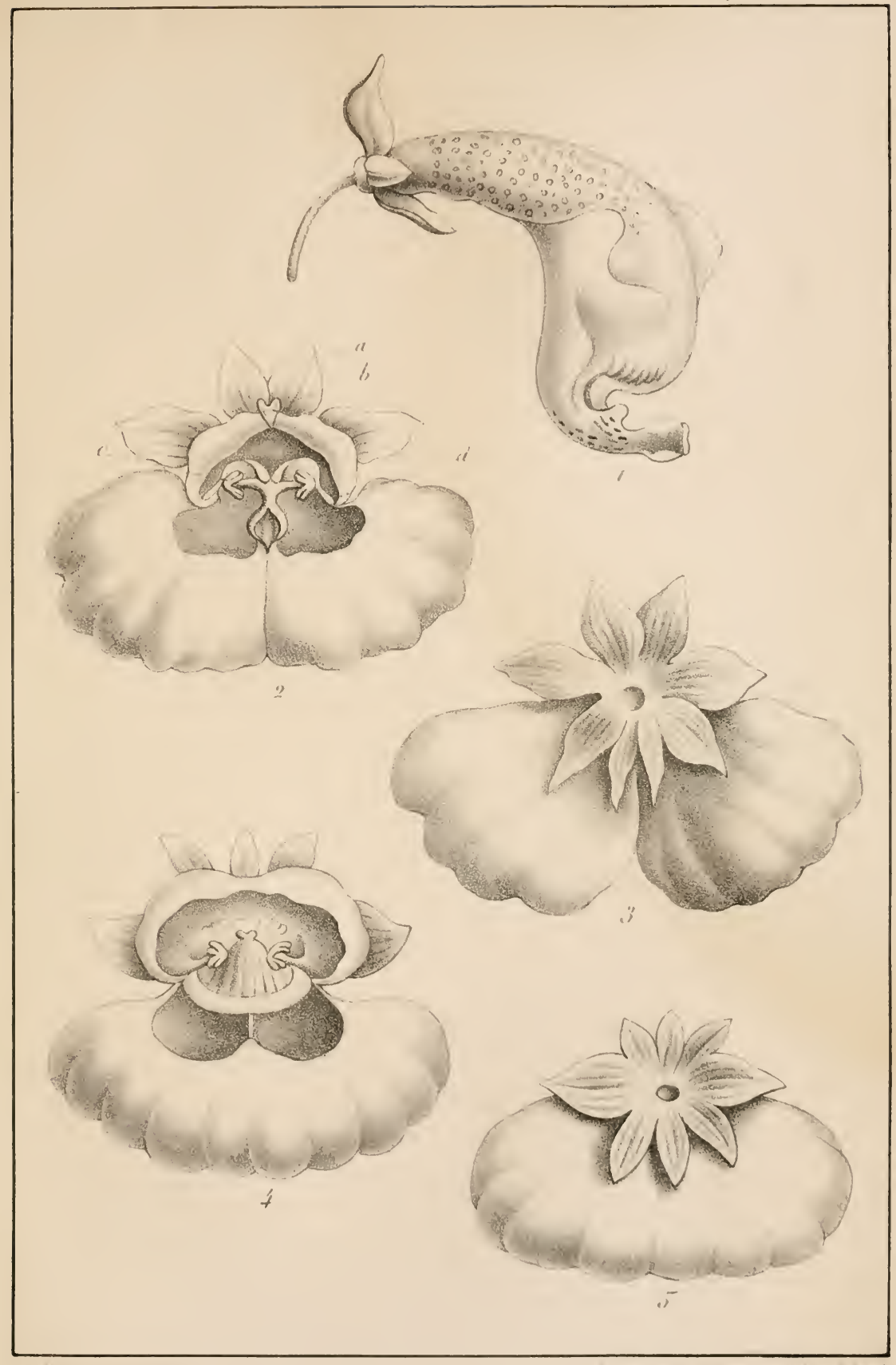

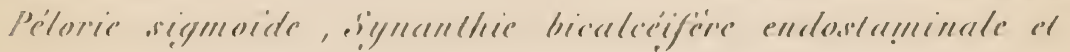

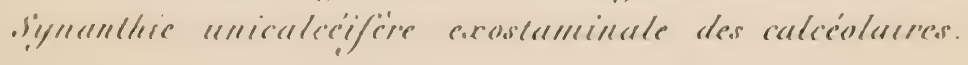



ACADEMIE MOYALE DE IBLGIQUE.

(Extrait da tome Xvill, $n^{\circ} 8$, des Bulletins.)

\title{
TÉRATOLOGIE VÉGÉTALE.
}

\begin{abstract}
SOLENAIDIE OU MÉTAMORPHOSE DES ORGANES SEXUELS EN TUBES CREUX ET STÉRILES;
\end{abstract}

par

Al. (C). Alorrer,

Yenbre de l'Académie royale de Belgique.

II existe parmi les prétendues variétés de l'Antirrinum majus, qu'on cultive dans des jardins de la Belgique, ce yue les horticulteurs appelle le mupe de veau blanc double, plante tout à fait stérile et qu'on ne multiplie que par éclat de racine. Elle se distingue dans les parterres des muftes. de veau par une taille constamment plus petite, des épis nombreus, une blancheur sans mélange dans les fleurs 
et une persistance à fleurir beaucoup plus longtemps.

Quand on analyse cette fleur, on reconnaît bientôt que ce n'est pas une variété, mais bien une monstruosité. C'est une fleur double, en ce sens que les étamines et le pistil y sont devenus complétement stériles, mais à peine peut-on dire que ces organes se sont pétalifiés, et, dans tous les cas, si, dans cette signification, il est permis de la qualifier de fleur double, ce n'est pas une fleur dédoublée, car le nombre de parties y reste le même, et dans la classification des fleurs doubles, ce serait une double simple, idée qui est loin d'être un paradoxe.

A l'extérieur (voy. fig. 1), on ne remarque qu'une chose, c'est une irrégularité apparente au mufle de la corolle; la lèvre inférieure surtout semble mal faite, et entre les lèvres, dans le rictus oris, on voit poindre les lames blanches recoquillées. Pour se rendre compte de la cause de celte structure, il faut ouvrir la fleur.

Remarquons d'abord que rien n'est changé au calice et que le tube de la corolle porte sa bosse accoutumée. (Voy. fig. 1.) En ouvrant la fleur, tout change. On y retrouve une lèvre supérieure portant deux lobes en arrière, comme dans une fleur normale. (Voy. fig. $2 A$, et fig. 6.) Seulement le bord est plus entier et moins ondulé. La lèvre inférieure présente aussi à peu près la forme génuine, les deux séries de poils sur deux élévations longitudinales, mais les lobes sont aussi plus irréguliers que ceux d'une corolle normale. (Comparez B fig. 2 et fig. 8).

La modification est plus importante quant aux étamines. La disproportion entre les deux grandes et les deux petites se conserve encore, mais l'ordre est interverti. Sur une fleur normale, les deux étamines les plus courtes ( $f g .6$ et 7 ) restent attachées à la lèvre supérieure. Ce sont 


\section{(151)}

les slamina postica des descripteurs, et les deux étamines les plus longues (stamina antica), appartiennent à la lèvre inférieure. (Fig. 8 et 9.) Ces dénominations d'anlica et poslica viennent de ce qu'on suppose la fleur relevée et parallèle à l'axe de l'épi : alors en effet la lèvre inférieure est l'antérieure. Or, sur la monstruosité en question, ce sont les deux grandes étamines qui côtoient la lèvre supéricure, et ces deux étamines sont tout autrement formées que celles des fleur's normales. Celles-ci $(f i g .6$ et 7 ) ont, en dessous du filet, une petite bosse légèrement vélue, puis le filet, aplati en forme de lame fort étroite, porte au sommet une anthère s'ouvrant en deux loges, chacune aplatie et lamelliforme. Dans le monstre, les filets sont devenus des tubes sans bosses, et ces tubes blancs, creux, longs, allant à peine en s'élargissant, se terminent chacun par une lame cuculliforme ou spatuliforme tantôt droite (fig. $2 \mathrm{D}$ ), tantòt réliéchic $(f i g .2 E)$.

Parlois, dans quelques fleurs de cette monstruosité, on trouve entre les deux étamines tubulifiées (fig. $5 A$ et $B$ ), la cinquième étamine des scrophulariacées sous la forme d'un filet simple et blanc ( $f g .5 C$ ) correspondant au lobe supérieur du calice, ce qui est son insertion régulière.

Les deux étamines correspondant aux stamina antica des descriptions, les plus grandes normalement et les plus petites dans le monstre, sont, à leur tour, non plus en lame (figures 8 et 9 ) élargie vers son quart superieur, mais en tube conique $(f g .2 E F)$, et au lieu d'une anthère biloculaire et à loges en coquille, ces étamines se terminent par une lame aplatie et en forme d'oreille d'âne.

Mais ici se présente une particularité bien plus digne d'intérêt. La seule loi qui, dans toute l'organographie, la morphologie et la tératologie, reste à l'abri de toute in- 


\section{( 152$)$}

fraction, est la loi des insertions. Or, l'insertion de l'androcée est normalement entre la corolle et l'ovaire ou, si l'on veut considérer l'androcée et la corolle comme des modifications de formes et de fonctions d'un seul tout naissant du torus, on dira que l'insertion est normalement entre le calice et l'ovaire. Mais si l'on jette un coup d'œil sur les dessins, figures $\mathbf{2}, \mathbf{4}$ et $\mathfrak{5}$, on voit clairement ce que l'observation nous montre dans la dissection de cette monstruosité, un organe vert, formé de deux feuilles, placé entre les lobes du calice et occupant le centre de la fleur. On ne douterait pas, en le voyant, que ce ne fùt l'ovaire, et puisque les scrophulariacées sont, morphologiquement parlant, des solanées irrégularisées, il est évident que les baies biloculaires des solanées sont représentées par les capsules biloculaires des scrophulariacées : donc le fruit est le résultat de deux feuilles carpellaires. Quoi donc représenterait mieux ces deux feuilles carpellaires que ces deux folioles vertes du centre de la fleur monstrueuse, d'autant plus que l'on en voit sortir un pistil réduit, comme les étamines tubulifiées, en un cylindre creux terminé par deux lames opposées béantes comme un stigmate de Mimulus? (Voy. fig. 2 G.)

Cependant, hors de ce prétendu ovaire ouvert et réduit à ses lames ou feuilles carpellaires, que voit-on sortir sur un grand nombre de fleurs métamorphosées? Deux étamines et quelquefois ces étamines sont seules ( $/ \mathrm{g}$. 4); quelquefois elles sont accompagnées au centre d'un pistil ici tubulé, là réduit en un simple fil extrêmement mince (fig. 5).

Des étamines, même métamorphosées, naissant dans un ovaire seraient une irrégularité d'insertion tellement extraordinaire qu'avant de l'admettre comme explication du 
fait que nous venons de faire connaître, il faudrait $y$ regarder à deux fois.

C'est ce que nous avons fait. En examinant avec une scrupuleuse attention le dedans du calice d'une fleur d'Antirrhinum majus normale (voy. fig. 10), et en écartant les lobes de ce calice, on découvre, au-dessous de l'ovaire et de chaque côté, un léger rebord saillant et vert. Supposons que ce corps soit un peu plus volumineux, on le saluera du nom de disque et on en fera un disque hypogyne, un nectaire, si on l'aime mieux. Aujourd'hui, dans la description du genre Antirrhinum, il n'est pas question de disque, parce qu'il est trop petit, mais quand on regarde attentivement le dessous de l'ovaire, on le découvre. (Voy. $f g .10$, $A$ et $B$.

Nous disons qu'il y a deux de ces rebords, un de chaque côté, à droite et à gauche. Quand on examine les deux lames ou folioles vertes du prétendu ovaire de la fleur métamorphosée, on reconnaît de suite que e'est là aussi la position de ces deux lames, c'est-à-dire qu'elles sont latérales; et si l'on prend, au contraire, le diagramme horizontal des scrophulariacées, on voit, comme dans la figure ci-dessous,

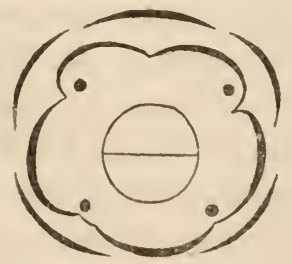

que les deux carpelles du fruit sont placées dans un sens opposé à ces lames, ou, en d'autres termes, que la nervure médiane de la vraie feuille carpellaire du côté des 


\section{( 154 )}

étamines postérieures (stamina, postica) est opposée au lobe supérieur du calice.

Cette position ne permet donc nullement de considérer les lames de la fleur tératologique, simulant si parfaitement l'ovaire, comme appartenant à cet organe, et les lois de l'alternance, comme l'axiome des insertions, ne laissent tout au plus d'explication possible au phénomène, que de regarder ces lames comme les deux éléments hypertrophiés et foliaires du disque.

Alors on comprend pourquoi les deux étamines postérieures sont renfermées en dedans de ces lames, puisque ce disque est un organe extérieur à l'ovaire, et l'on se rend compte en même temps de la raison qui permet bien plus simplement encore l'existence entre ces étamines, et, au centre de tout l'appareil, d'un pistil plus ou moins développé.

Avec cette singulière structure, il y a absence complète d'ovaire, et le style seul se reconnaît à sa position et à la dualité de ses lames stigmatiques pétalifiées, puisqu'on sait que le stigmate est, dans les Antirrhinum, brièvement bilobé. (Voy. fig. 10.)

Nous n'avons trouvé aucune mention de cette structure tératologique dans les ouvrages que nous possédons sur cette science. Il nous semble évident que le caractère le plus frappant de cette anomalie est la conversion des organes génitaux en tubes creux et stériles. C'est pourquoi nous proposons de nommer ce genre de monstruosités

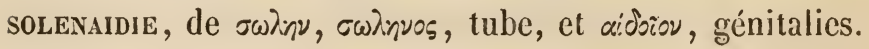
C'est la conversion des étamines et des pistils en corps tubulaires fistuleux, sans fonctions sexuelles possibles par conversion de l'anthère et du stigmate en lames inactives, et par atrophic complète d'ovaire. 
La solenaidie ne doit pas se confondre avee une autre tubulification qui s'observe dans les Bellis, les Tageles, les Pyrethrum, etc., c'est-à-dire dans les composées, sortes de structure bien connues des horticulteurs. Dans ce cas, c'est le fleuron ou mieux la corolle qui devient tube, et c'est assez dans les habitudes de cet organe d'affecter cette forme, légitimée d'avance par la protection qu'ildoit offrir à des appareils sexuels généralement inclus. Cette monstruosité des composées, qui ḍonne naissance à tant de belles variétés, est une Salpiganthie ( $\sigma \alpha \lambda \imath_{\imath} \gamma \xi$, trompette, $\alpha \nu 0 \circ$, fleur) d'une tout autre nature. Nous en avons étudié récemment la structure, à propos des Tagetes (1).

Comme conséquences du présent travail, nous concluons aux propositions suivantes :

$1^{\circ}$ Les organes des appareils sexuels mâle et femelle des plantes sont susceptibles de subir une métamorphose tératologique, appelée solenaidie, qui convertit chacun de ces organes en un tube creux;

2" Ces organes sont frappés en même temps de stérilité par la métamorphose des deux loges de l'anthère en une seule lame dépourvue de tout pollen et acquérant la consistance des pétales, et par la métamorphose du stigmate en deux lèvres pétaloïdes hypertrophiées;

$5^{\circ}$ Deux des étamines soumises à la solenaidie, dans les scrophulariacées naissant soit seules, soit avec le pistil, avec deux folioles vertes, qui ne peuvent représenter qu'un disque hypogyne à peine visible dans le type original des Antirhimum.

(1) Voy. In Belgique horticole, 1. I, p. 3ิเn. 


\section{( 1506$)$}

\section{EXPLICATION DES FIGURES.}

Fig. 1. Fleur de l'Antirrhinum majus, frappée de solenaidie, vue de cóté, grandeur naturelle, comme toutes les autres figures.

2. Fleur ouverte par la séparation des lèvres.

A. Lèvre supérieure.

$B$. Lèvre inférieure.

C. Étamine tubulifiée, lame anthẻrienne réfléchie.

D. Étamine tubulifiée, lame anthérienne droite.

$E$. Étamine antérieure tubulifiée libre.

$F$. Étamine antérieure tubulifiée soudée.

$G$. Pistil de cette fleur et les deux écailles dle sa base.

3. Lèvre supérieure d'une autre fleur, où les étamines tubulifiées sont en $A$ et $B$, et la cinquième en $C$.

4 et 5 . Les deux étamines postérieures partant d'entre deux folioles vertes. La figure 4 est sans et la figure 5 avec pistil.

6. Lèvre supérieure d'un Antirrhinum normal.

7. Étamine postérieure, vue isolée, d'une fleur normale.

8. Lèvre inférieure d'un Antirrhinum normal avec les deux étamines qui lui appartiennent.

9. Une de ces étamines à filet élargi et aplati.

10. Pistil et calice.

$A$ et $B$ traces de disque hypogyne. 


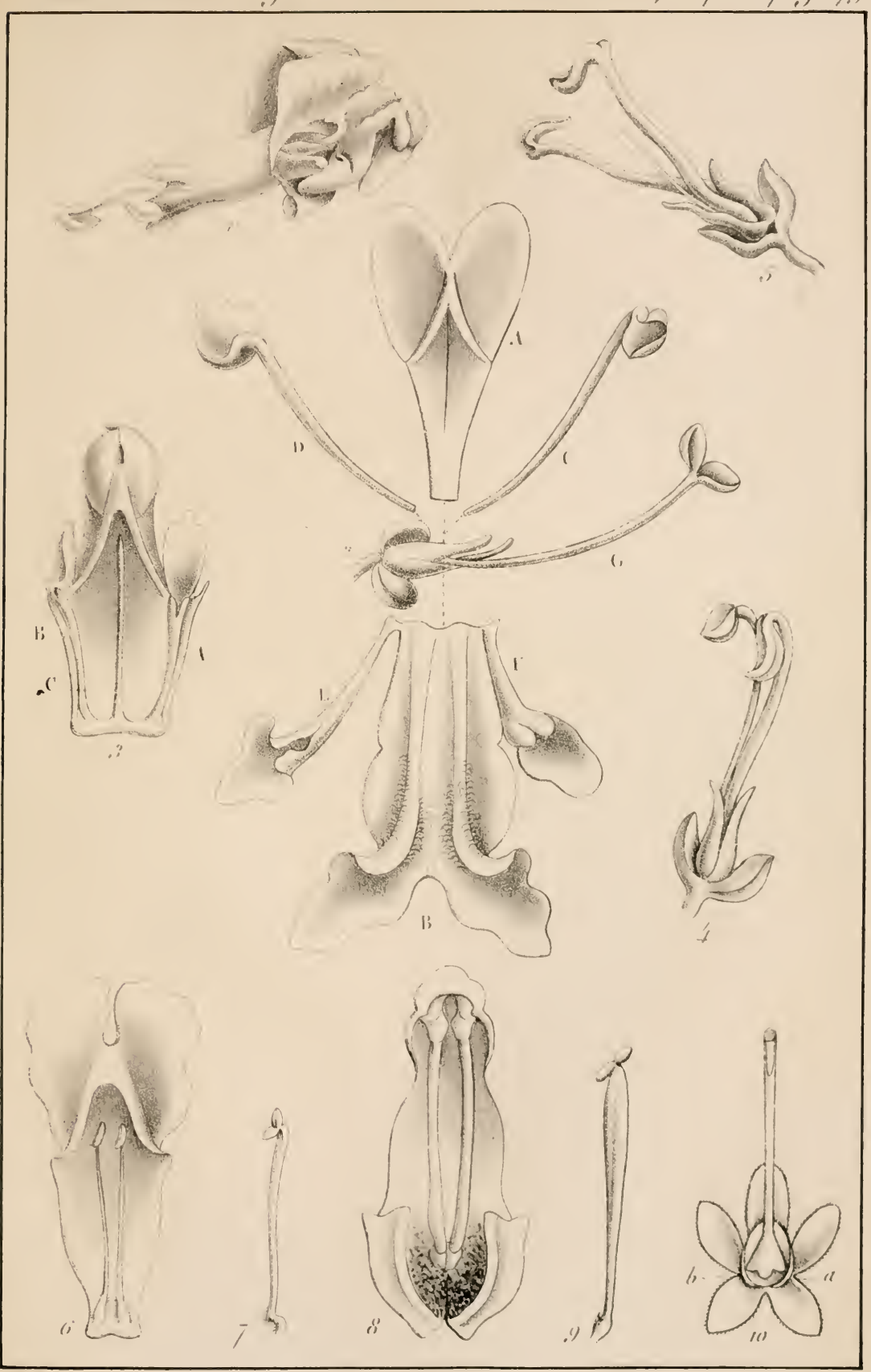

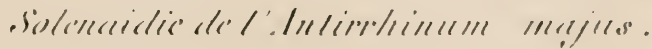



I) L'INFIUENCE

DE

L'ÉCLIPSE IDE SOLEIL DU 28 JUILLET 1831

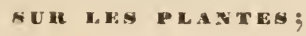

PAR

II. CHI, MORREN,

Membre de l'Académie royale de Belgique.

J'avais étudié, en 1856, les effets de l'éclipse de soleil sur les fonctions de la vie des plantes, éclipse qui cut lieu, cette année, le 150 mai. Ces effets furent de deux genres, le premier, la cessation complète de la respiration active des parties vertes des plantes, mais avec des gradations d'une diminution successive, selon les espèces des végétaux, et le second, une somnolence, analogue au vrai sommeil, produite chez les espèces susceptibles de montrer ce phénomène. On m’objecta, à l'Académie de Bruxelles, que j'aurais dù comparer les résultats observés avec ceux qui se produiraient au moyen d'une obscurité artificielle au même degré que celle résultant de l'éclipse, et que si l'éclipse n'avait occasionné qu'une somnolence et non un sommeil, on devait s'y attendre, puisque ce dernier phé- 
nomène, périodique tous les soirs, ne se déplace qu'insensiblement et non brusquement.

Je ne répondis pas alor's à ces objections, puisqu'il fallait attendre une seconde éclipse de soleil et qu'il ne dépendait pas de la bonne volonté de mes adversaires de la faire naître. Aujourd'hui, qu'une éclipse de ce genre s'est présentée pour le lieu que nous habitons, dans des conditions très-favorables à l'observation de certains phénomènes, je me suis empressé de refaire mes anciennes expériences et de vérifier de nouveau mes observations précédentes. Je pourrai ainsi répondre aux réflexions qu'on a émises sur ce sujet.

Je parlerai d'abord de ce qui concerne la respiration des plantes. En 1856, je mis en expérience le peuplier-tremble, le Delphinium consolida, le Populus fastigiata (peuplier d'Italie) et une algue, le Zygnema quininum. L'éclipse commença à 2 heures 46 minutes (temps moyen de Bruxelles). Quand le disque de la lune eut occulté le soleil à peu près jusque dans son milieu, l'émission de l'oxygène était arrêtée sur toutes les plantes, mais les bulles avaient continué le plus longtemps à s'échapper du peuplier-tremble.

Cette année, le temps était très-convenable pour observer à Liége l'éclipse du 28 juillet $\mathbf{1 8 3 1}$. De petits nuages ne vinrent se placer devant les astres que vers la fin du phénomène, et pendant toute la journée, le soleil avait été assez vif et assez permanent pour produire une respiration normale chez les végétaux. Nême les cinq jours précédents, l'atmosphère ayant été couverte, pluvieuse et agitée par des vents assez forts, les plantes devaient se trouver d'autant plus disposées à respirer activement que durant cet intervalle de temps, elles n'avaient eu qu'une respiration passive, exercée à la lumière diffuse. 
Dès le matin, 10 heures, je mis donc en expérience les plantes suivantes :

$1^{\circ}$ Populus fastigiata (peuplier l'Italic), un sommet de branche portant cinq feuilles jeunes et fraîches.

$2^{0}$ Vitis vinifera (vigne), un sommet de branche portant trois feuilles et deux vrilles.

$5^{\circ}$ Thuya occidentalis (Thuya d'Occident), un sommet de rameau long de 8 centimètres et présentant 20 extrémités de ramuscules vertes, le tout vert et sain.

$4^{\circ}$ Ampelopsis quinquefolia (vigne vierge), une jeune feuille armée de toutes ses folioles.

$\Im^{\circ}$ Nerium oleander (laurier-rose), une feuille moyenne, adulte, mais fraîche.

$6^{\circ}$ Heliotropium peruvianum (héliotrope), l'extrémité d'un rameau vert portant huit feuilles saines et vigoureuses.

$7^{\circ}$ Weigela rosea (weigelie), sommet d'un jeune rameau formé de deux feuilles.

So Mercurialis annua (mercuriale), sommet de tige mâle portant fleurs et feuilles.

$y^{\circ}$ Cobcea scandens (cobée), une feuille terminée par une vrille déjà contournée.

$10^{\circ}$ Sedum Sieboldtii (sedum de Sieboldt), jeune tige entière, formée de trois mérithalles et de neuf belles feuilles.

Toutes ces plantes étaient attachées à des fils de soie passés autour de pierres assez lourdes, pour tenir les tiges ou les feuilles droites dans une eau fraîche, abondante en acide carbonique.

A 11 heures, toutes ces plantes respiraient à pleine gorgée au soleil; elles étaient placées, chacune dans son vase cylindrique, sur un meuble noir et recevant le soleil lans la direction du midi. A ce moment (midi), la respiration était dans son plein, et les bulles d’oxygène montaient 
avec une régularité de volume et une précipitation telles qu'il était impossible de ne pas admettre l'exercice normal d'une fonction dont les résultats s'observaient par preuve et contre-épreuve. Le peuplier d'Italie était le plus actif et le sedum le moins; ce dernier respirait lentement, et les bulles ne se dégageaient que peu à peu; le Nerium, le Weigela, l'héliotrope et la vigne montraient de même une ardente respiration, tandis que la mercuriale, l'Ampelopsis, le Cobca et surtout le Thuya manifestaient moins de force dans l'émission de l'oxygène.

Quand l'éclipse commença, toutes les plantes respiraient. A mesure que la lumière s'affaiblit, les bulles devinrent de plus en plus rares, et quand le disque du soleil fut occulté dans sa moitié environ, toute respiration avait cessé; le peuplier d'Italie seul laissait encore échapper des traînées de bulles, mais plus lentement et de bien moindre volume que lorsque le soleil éclairait complétement les plantes. Ce résultat était obtenu vers 5 heures et un quart.

Or, le lendemain, les appareils se trouvaient encore dans le même état, et quoique ce fussent des plantes coupées de la veille, et que, par conséquent, il faille bien admettre que des fonctions, comme la respiration, pouvaient déjà souffrir de cette position, la respiration s'y manifestait, à midi, avec une grande force; alors je glissai peu à peu un écran de carton devant elles, de manière à les placer dans une lumière diffuse dont l'éclairement me semblait bien inférieur en intensité aux rayons blafards produits la veille par l'éclipse. Cette ablation de la lumière fut loin de produire sur les plantes à l'état d'expiration une cessation dans le développement des bulles d'oxygène comparable à celle qui avait été observée pendant l'éclipse, et il ne peut rester de doute pour moi que ce phénomène n'excrce une 
action prompte, complète et très-active sur la respiration diurne des parties vertes des végétaux.

D'ailleurs, depuis 1856 , la question a bien changé de face : alors le daguerréotype n'existait pas; on ne savait pas que la couleur verte des plantes ne se transmet pas dans les images fixées par la chambre obscure, et l'on ne soupçonnait pas que la réduction de l'acide carbonique, dans la respiration des plantes, füt due, non à l'effet de la lumière considérée comme agent de la clarté, mais à l'effet des propriétés chimiques le celte lumière, ou ce que l'on a nommé les rayons chimiques. On a donc dit que la respiration active des végétaux ne s'exécutait que sous l'influence de la lumière directe et qu'elle devenait passive, c'est-à-dire très-faible sous la Iumière diffuse. De là il faut admettre que, dans les conditions naturelles de la végétation sur le globe, la lumière est ou entièrement directe, comme dans un ciel serein, ou plus ou moins diffuse, comme dans un ciel nuageux, ou alternativement direcle et diffuse, celte dernière à degrés variables, comme dans un ciel à éclaircies. Mais dans aucun cas, lorsque la lumière est directe, elle ne l'est pas plus ou moins. $0 \mathrm{r}$, dans une éclipse de soleil, cette lumière, en restant directe, diminue en quantité, et l'on a vu cependant comment elle ne permet plus à la respiration végétale de s'exercer, absolument comme une lumière fortement dimninuée en intensité par des réfractions ou des réllexions. Il fauilrait donc admettre que, pour que la respiration végétale active pùt avoir lieu, il est nécessaire d'agir au moyen d'une certaine quantité de lumière directe. Quelle est cette quantité? elle ne peut être absolue, puisqu'on a vu que le peuplier respirait encore quand le soleil avait les dix-douzièmes de son disque occultés, tandis que d'autres plantes ne respiraient 


\section{( 162$)$}

plus. a Si l'on réfléchit, dit De Humboldt (Cosmos, כु, p. 114), aux actions complexes qui ont déterminé, dans le monde primitif, la séparation des éléments solides, liquides et gazeux et qui ont constitué finalement l'écorce terrestre avec ses enveloppes actuelles, il sera impossible de se soustraire à l'idée que l'humanité a couru le danger de vivre dans une atmosphère opaque, favorable encore, il est vrai, à plusieurs espèces végétales, mais qui aurait voilé à nos regards les merveilles du firmament. La structure des cieux aurait échappé à l'esprit d'analyse; hors la terre, rien n'existerait pour nous dans la création, si ce n'est peut-être le soleil et la lune; l'espace semblerait uniquement fait pour ces trois corps. \ Ainsi, d'après les idées de l'immortel philosophe de Berlin, la vie végétale de quelques espèces serait encore possib!e dans une atmosphère opaque analogue à l'état de l'air pendant $i l$ tiempo de la garua du Pérou. Ces végétations ne pourraient être, dans ce cas, qu'analogues à celles qui vivent presque éternellement par l'influence d'une lumière diffuse, comme quelques algnes, les mousses, des hépatiques, des jungermannes et peu de fougères. Nais il sera sans doute permis de supposer que les végétations exigeant pour leur respiration normale, c'est-à-dire active, une lumière directe, il leur faudra la nécessité absolue de recevoir celte lumière directement du seul astre photogène de notre système planétaire, le soleil, et non d'un satellite quelconque, comme la lune qui, on le sait depuis longtemps, n'agit en rien sur la respiration des plantes, sa lumière réfléchie ne possédant pas le pouvoir de réduire l'acide carbonique. En admettant donc que les planètes, éloignées du soleil comme Jupiter, Saturne, Uranus ou même Neptune, eussent une végétation à leur surface, supposi- 
tion qui n’est point sans présenter quelque intérêt dans la recherche des idées exactes sur l'univers, il serait permis de croire, d'après la résistance plus ou moins grande qu'ofire la respiration de ce peu d'espèces observées pendant l'éclipse du 28 juillet 1831 , que des organisations plutòt semblables à celles des peupliers, par exemple, qu’à tout autre organisme, ptissent exister ainsi sur ces planètes éloignées, tandis que des plantes grasses, conıme les sedum, n'y pourraient vivre. Je conçois combien ces réflexions sur la détermination probable des formes de la végétation dais un autre monde que le nôtre, peuvent paraître aux esprits sévères gratuites el même de pure fantaisie, mais il n'en est pas moins vrai que ce sont des raisonnements de ce genre qu'on a souvent invoqués dans ce que Humboldt appelle, avec son originalité connue, a les conquête's de l'esprit humain à la possession du cosmos. D

On me dira que dans une chambre obscure on peut soumettre les plantes à l'action d'une lumière directe plus ou moins limitée, en faisant passer sur le disque du soleil un écran, et simuler ainsi une éclipse. Je le sais, mais je demande précisément qu'on veuille bien soumettre à des expériences de ce genre une série de végétaux, et je ne doute pas qu'on y observe une très-grande dissimilitude sous le point de vue des quantités de lumière directe qu’il faut à chayue espèce pour l'amener à respirer. Ces recherches seraient extraordinairement utiles, non-seulement pour la physiologie purement spéculative, mais aussi pour l'horticulture pratique: elles intéresseraient même ceux qui embrassent l'univers entier dans le champ de leurs recherches, et pourraient conduire à des idées d'un ordre sur lequel nous ne possédons, je ne dirai pas rien de fondé, mais même rien qui s'approche d'une simple probabilité. 


\section{(164)}

Je passe maintenant à une autre série d'observations faites pendant l'éclipse dı 28 juillet $18 \check{1}$, c'est-à-dire à l'étude du sommeil et de la somnolence instantanée produites par l'occulation du soleil et en plein jour, aux heures où les plantes ne dorment pas.

Dans l'éclipse du 10 mai $\mathbf{1 8 5 6}$, quand la lumière blafarde ne présentait plus de pénombre, le Cassia sulfurea, le Tamarindus indica, l'Acacia speciosa, la sensitive (Mimosa sensitiva), le Mimosa pudica et le Mimosa arborea, avaient tous éprouvé une somnolence, c'est-à-dire un demisommeil. Ainsi que je l'ai dit plus haut, on m'objecta, à l'Académie de Bruxelles, qu'on devait s'attendre à ce phénomène, parce que, disait-on, De Candolle avait constaté que les heures de sommeil et de veille des plantes ne se changeaient pas instantanément, mais seulement au bout d'un temps plus ou moins long (Bulletins, p. 500 , t. III). Je n'ai jamais bien compris cette objection, car il me semble évident que c'est le raisonnement contraire qu'on aurait dû tenir. Les expériences de De Candolle ont prouvé (Physiol., t. II, p. 860), d'abord, que les sensitives soumises, pendant le jour à une obscurité artificielle, résistent à cette obscurité et se ferment sans règle fixe; ensuite, que l'accélération de l'arrivée de leur sommeil a été environ d'une heure et demie ou de deux heures par jour; que lorsque l'obscurité est continue, elles offrent des alternatives de sommeil et de réveil très-irrégulières. Voilà un point sur lequel j'insiste. En voici un second : De Candolle affirme qu'il n'a jamais pu modifier le sommeil de l'Oxalis incarnata, de l'Oxalis stricta, ni par l'obscurité, ni par la lumière, ni en les éclairant à des heures différentes de celles qui leur sont naturelles. "Je pense, ajoutait ce profond botaniste, qu'on peut conclure de ces faits que 
les mouvements du sommeil et du réveil sont liés à une disposition de mouvement périodique inhérente au végétal, mais qui est essentiellement mise en activité par l'action stimulante de la lumière, laquelle agit avec une intensité différente sur différents végétaux, de telle sorte que la même dose de lumière produit des résultats divers sur diverses espèces. "

Il résulte clairement de cette citation exacte des faits qu'on ne devait pas s'attendre à voir les plantes dormir pendant l'éclipse, puisqu'elles n'avaient pas l'habitude de prendre leurs allures du repos nocturne à 2 heures 27 minutes de l'après-midi, la veille et les jours suivants. Voilà la déduction la plus logique à tirer des expériences de De Candolle, qui a eu besoin de près de sept jours pour amener un résultat régulier. Ensuite, je dirai, dans un instant, comment ce que De Candolle n'a pu produire sur les oxalis, si susceptibles d'insomnie avec les obscurités artificielles, l'éclipse l'a fait en peu d'instants en leur versant en ample dose les pavots de Morphée.

Je ne m'arrêterai donc pas davantage aux objections de 1856; elles sont réfutées par De Candolle lui-même, qu’on avait négligé de consulter avant d'écrire.

Pendant l'éclipse du 28 juillet $\mathbf{1 8 3 1}$, six jeunes botanistes, habitués à observer les plantes, m'aidèrent dans mes recherches, et chaque observation était vérifiée par nous tous. Ces botanistes étaient : MNI. Dechamps, Deggeller, Desbataille, Franck, Delheid et Edouard Morren. Quand l'éclipse fut à peu près dans son plein, nous nous transportâmes devant le parterre des oxalidées. Là, tous nous l'avons vu, les Oxalis stricta, corniculata, carnosa et Deppii dormaient complétement. Ce fait n’a pas l'ombre d'un doute dans nos esprits. La perte de la lumière du so- 
leil par l'éclipse a donc fait ce que l'obscurité continue n’a pu produire, de l'aveu même de la principale autorité scientifique qu'on invoque en ces matières.

Le Journal de Cologne avait annoncé, quelques jours avant l'éclipse, dans un article évidemment rédigé par un homme instruit dans les sciences naturelles, qu'on verrait les Impatiens noli tangere rabattre leurs feuilles protectrices (folia munientia). Nous n'avons pu observer l'Impatiens noli tangere, mais nous avions devant nous un grand parterre d'Impatiens parviflora. Pas une feuille n'était rabăttue, pas une fleur qui fût recouverte, et toutes les plantes veillaient en sentinelles infatigables malgré l'éclipse.

Les Colutea avaient leurs feuilles dressées comme dans la nuit. Le Psoralea palestina montrait toutes ses folioles pliées; il dormait d'un profond sommeil.

Toutes les feuilles de I'Isostoma axillaris étaient fermées, et ses fleurs se tenaient parfaitement ouvertes.

Les Acacias présentaient leurs feuilles dans une somnolence ou demi-sommeil, et tel était le caractère général du plus grand nombre de plantes dormeuses. Nous citerons quelques exemples :

Dans la serre, les Mimosa pudica offraient leurs folioles relevées angulairement et leurs feuilles à moitié pendantes.

Il en était de même du Gleditzia microphylla.

Les Biophyıum avaient abaissé leurs folioles de 45 degrés.

Les frênes laissaient pendre leurs feuilles, et les Lilas relevaient le bord des leurs.

Le Fontanesia phyllaroïdes, le Salvia pubescens, le Selago corymbosa présentaient un état analogue.

Le Cassia hyemalis ne dormait que du bout de ses 
feuilles, et l'Acacia lophanta offrait l'aspect qu'il présente à l'entrée de la nuit.

Nous devions être naturellement intéressés à observer quelques fleurs équinoxiales (qui s'ouvrent et se ferment régulièrement plusieurs jours de suite), et des fleurs éphémeres (qui ne s'ouvrent qu'une fois pour se faner ensuite). Le Journal de Cologne avait annoncé quue, pendant l'éclipse, les fleurs des Oenothera, notamment celles du biennis, qui auraient dù s'ouvrir le 28 juillet, vers 8 heures du soir, célébreraient leurs noces vers $\overline{5}$ heures pendant l'éclipse. Je dois déclarer que cette prévision s'est parfaitement vérifiée, comme si l'auteur de l'article eût reçu le mot d'ordre du grand prêtre de la nature, qui avait arrêté, l'heure de ce mariage. A trois heures et demie nous avions devant nous un grand nombre de fleurs d'Oenothera ouvertes, alors que toute la journée du 28 , journée trèsclaire à Liége, aucune ne l'était.

Une des lleurs dont mon fils, Édouard Morren, a constaté souvent l'excessive susceptibilité, au point même, assure-t-il, qu'un simple nuage passant devant le soleil, en ferme soudain la corolle en la relevant et en la tordant, est l'Elscholtzia californica. Nous devions donc nous attendre à voir, dès le commencement de l'éclipse, ses fleurs se fermer. Cependant elles se fermèrent successivement, et à $\tilde{5}$ heures $1 / 2$, plus une n'avait résisté.

Les Nymphaea blancs, dont les fleurs étaient parfaitement écloses à la surface d'un étang à eau tiède du Jardin botanique de Liége, fermèrent à moitié leurs corolles et sommeillèrent pendant la durée du phénomène.

Quand l'éclipse fut finie, tout s'éveilla : la nature végétale avait repris son libre cours.

Ainsi, de l'ensemble de ce peu d'observations, il résulte 


\section{( 168 )}

avec autant d'évidence que l'éclipse a été elle-même évidente, que ce phénomène a une action sur le monde végétal que ne produisent pas nos obscurités artificielles; que telles plantes qui ne dorment jamais sous l'influence de ces obscurités et s'éveillent encore moins sous l'empire de nos lumières artificielles (les oxalidées), sont soumises à un sommeil complet quand la lumière du soleil disparaît au milieu du jour, non par les nuages, mais par une véritable occultation. Aujourd'hui aussi, on sait que le sommeil est un phénomène non de repos et précédant la veillée, comme temps de fatigue, mais une phase de la respiration; on sait que l'oxygène circule avant d'être expiré, et que les vaisseaux et les cellules qui jouent, dans le sommeil et le réveil, une action mécanique, ne le font qu'à la suite d'une oxygénation des sucs. Le sommeil est donc une expression de la respiration modifiée. Il est ainsi moins étonnant que, dans une éclipse, les rayons chimiques de la lumière, étant diminués de beaucoup, la respiration, et par suite le sommeil, soit produite comme par une nuit naturelle, hors de son temps normal et sans qu'une lumière diffuse puisse déterminer un fait analogue.

Il y a donc telles plantes qui ne dorment pas pendant les obscurités factices et qui subissent le sommeil pendant l'éclipse; telles autres plantes dont le sommeil est complet, et enfin telles autres qui n'éprouvent qu'une somnolence.

Enfin les fleurs éphémères nocturnes s'ouvrent comme dans la nuit, malgré la périodicité du phénomène naturel, et des fleurs équinoxiales sommeillent (Nymphea), tandis que d'autres dorment profondément (Elscholtzia). 


\section{TÉRATOLOGIE VÉGÉTALE.}

Recherches sur un nouveau genre de monstruosités végétales, modifianl l'axe de certaines feurs et appelé Gruvaxoxis ou dénudation de cet organe;

PAR

vi. CH. NTOER REN,

Membre de l'Académie royale de Belgique.

Lés tératologistes sont d'accord sur ce fait, qui tient à l'un Łles principes fondamentaux de l'organisation végétale, à savoir, que les structures anormales de l'axe sont infiniment plus rares que les structures anormales des parties appendiculaires. La variabilité est la caractéristique de ces derniers organes; l'uniformité, l'essence du premier. Il s'ensuit que les chances d'apporter dans cette variabilité même des combinaisons qui ne liennent pas à la forme ordinaire de l'être, croissent dans la même proportion : c'est une raison pour laquelle il doit y avoir beaucoup plus de monstres dans les organismes périphériques que dans les centraux. Il y a une seconde raison : l'axe est un, car tige et racine ne diffèrent essentiellement que dans leur direction, ce qui est une propriéte physiologique, non une 
qualité de structure; l'axe thoral ou la columelle dans le fruit ne sont, après tout, qu'une extrémité de tige. De ce principe il découle que l'axe étant un et ses parties appendiculaires mulciples, il doit y aroir nécessairement el fatalement très-peu de monstruosités pour l'axe et beaucoup pour les organes qui en naissent.

La théorie tératologique des causes roule encore sur deux illées opposées, qui sont actucllement en présence à pen près avec des forces égales: l'anormal daus l'organisme est-il le résultat de l'action des facteurs du monde ambiant ou provient-il d'une force formatrice, pervertie en ellemème? La structure tératologique est-elle autochthone, sans que les influences du dehors la provoquent ou la produisent, ou, au contraire, est-elle un résultat des facteurs du dehors? Les parties appendiculaires vivent essentiellement sous l'action de ces facteurs. On a done dit que la lumière, la chaleur, l'humidité, la sécheresse, le sol, la pression, les insectes, les parasites végétaux, pouvaient et devaient, en variant leurs influences, produire des formes inaccoutumées, des soudures, des avortements, des hypertrophies, des variations dans les organes. Or, l'axe est plus à l'abri de ces agents. Sa formation première est protégée dans la graine et le bourgeon, ses deux siéges d'enfance, par des parties appendiculaires préexistantes. Quand il se fait jour au dehors, c'est-à-dire qu'il se soumet aux actions des facteurs du monde ambiant, il ue fait plus que se développer, que grandir, que s'étendre; il ne se forme plus, il est tout formé. La structure déviée, l'organisation tératologique prend naissance, surtout à la première origine des corps, quand les organes qui en sont atteints, se forment cux-mêmes. Donc, on s'est dit que les axes étant rarement et très-rarement hétérodromes, c'est-à-dire autrement constitués qu'ils doivent l'être dans la forme de l'espèce, 
ce fait provient de re que les axes échappent aux influenres pervertrices du monde ambiant; raisomement qui implique de toute nécessité que c'est dans les facteurs extérieurs que gît la force de la déviation, la cause occasionnelle de l'anormal.

Cette théorie est au fond, croyons-nous, plus spécicuse que réclle et exacte. Quand il s’agit de spécilier les faits, on ne lui trouve plus une seule assertion qui ne soil hasardée. Quand on fait varier, de propos prémédité el d'une manière certaine, les actions des lacteurs, quand on combine autour de l'organisme, en voic de formation, un autre monde que celui de la nature, on ne produit pas de monstres, on arrête on on excite l'organisme, mais les formes restent ce qu'elles sont. On a dit cependant: semez des pavots à l'ombre, et vous convertirez les étamines en pistils; mais l'expérience a répondu et des pavots semés au soleil et développés sous une lumière pleine et entière, autant que le ciel peut en donner, ont produit tout autant qu'un semis à l'ombre, sur un nombre donné, des lleurs où les mâles étaient devenus des femelles. On n'ira pas sans doute se contenter de raisons à priori et qui, pour élayer nue hypothèse, s'appuient elles-mêmes sur une autre, au lieu de s'asseoir sur le positif et la certitude. Ainsi, quand on pose en fait que le mâle doit essentiellement être en relation avec la lumière, parce qu’à lui appartient l'action initiative de la perpétuité de l'espèce et que la femelle est un être passif, par suite qu'elle peut se former et croître à l'ombre, et qu'ainsi, ce facteur ambiant, l'ombre, peut, sur certains organismes, qui y sont forcément soumis, métamorphoser le mâle en femelle; quand on raisonne, disons-nous, sur ces bases, il faut avant tout dépouiller les prémisses du syllogisme de tout ce qu'elles ont d'incertain et d'arbitraire. Or, il serait facile de prouver qu'il y a tout antant de femelles 
qui aiment et recherchent la lumière, se forment et vivent sous son influence, qu'il y en a pour lesquelles l'ombre est une condition d'existence et que, réciproquement, il y a autant de mâles se formant et se développant à l'ombre que des femelles, sans pour cela changer de sexe.

Chaque fois que, dans la théorie des facteurs ambiants, on analyse un fait avancé, on lui trouve, comme dans le cas que nous venons de citer, l'une on l'autre base de raisonnement en défaut, et par suite de ces sophismes accumulés, on doit, en conscience, avoir sa conviction fortement ébranlée à l'endroit d'une théorie que le matérialisme semblait rendre si claire et si incontestable.

On nous dira que la théorie de l'autochthonie des forces organisatrices perverties repose à son tour sur un principe qu'il s'agit précisément de démontrer, au lien de l'admettre comme fait premier propre à expliquer ensuite les cas particuliers. Nous ne le nions pas; mais nous répondons qu'ici du moins, les faits ne nous contredisent pas, que nous n'avançons jamais rien dans celte doctrine, que nous ne puissions prouver, et qu'en dernier résultat, admettre que l'organisation puisse dévier de sa marche en vertu d'une force intrinsèque, inhérente à son essence, n'est, après tout, pas plus difficile à concevoir que cette autre qualité de l'organisation, qui est de perpéluer son type normal et spécifique. C'est la vie, dit-on, qui, en raison de mouvement communiqué, imprime le cachet des formes dans la matière des êtres. Soit, nous pouvons donc tout aussi bien prétendre que cette même vie a le pouvoir de faire varier ce cachet entre certaines limites de variabilité au delà desquelles elle ne peut se manifester. Cețe hypothèse permet du moins d'expliguer tous les grands problèmes tératologiques, comme la formation des monstres à l’origine de leur génèse, leur classement limité, 
léternité ou la permanence des mêmes types anormaux qui reviennent constamment les mèmes, l'indépendance des organismes déviés de l'action des facteurs du monde ambiant, le résultat négatif de toutes les expériences faites pour faire varier l'organisme en faisant varier les agents extérieurs, et enfin les monstruosités, tont aussi possibles des parties internes excentriques que des parties externes et périphériques. Toutes les bases de la tératologie sont là.

Nous avons dit plus haut la véritable cause, selon nous, pourquoi les monstruosités de l'axe sont moins fiéquentes que celles des parties appendiculaires, à savoir que l'axe est un de sa nature, qu'il n'est guère multiple dans ses expressions organiques comme les appendices de cet axe. Satrophier, s'hypertrophier, se diviser, se souder, se spiraliser, se boursoufler et se fascier, voilà quelles sont à très-peu prè̀s les seules modifications qu'on a observées dans l'axe. Nous nous permettrons toutefois d'ajouter à ces cas connus et discutés de la tératologie des axes végétaux, une nouvelle forme anormale dont nous n'avons pas trouvé, daus l's ouvrages et les écrits sur la matière, de citation antérieure. Nous sommes ici sur un champ tout neuf.

Dans le Cuphea miniata, le Cuphea silenoïdes et sur le Lobelia erinus, nous avons observé, depuis quelques années, un cas de structure anormale très-singulier. Nous prions le lecteur de jeter un coup d'œil sur notre planche avant de nous lire.

Dans le Cuphea miniala, la fleur est horizontale (fig. 1); elle ressemble à un fléau de balance dont les bras sont incégaux en longueur. D'un còté, on a un éperon avec une glande nectarienne en dedans (fig. 2), de l'autre, la corolle et au centre les étamincs at le pistil; celui-ci offre un ovaire de la forme d'une gousse de pois. II suil de 
là que l'axe de la fleur arrivé au sommet du pédonenle, devient forcément horizontal, qu'il fait un angle droit avec le soutien de lappareil floral, et qu'il se prolonge an centre de l'ovaire dans la fleur, de la capsule dans le fruit sous la forme d'un placentaire filiforme et central, auquel sont appendus les ovules ou les graines lenticulaires. Voilà la structure normale.

Sur de grands pieds de Cuphéas, nous voyons souvent des fleurs isolées, en rien différentes des autres fleurs, chez lesquelles, pendant l'anthèse même et alors que la fleur est loin d'ètre fanée, la corolle et l'ovaire éclatés et sortant droit d'entre eux, dans la prolongation du pédoncule, un gros placentaire central, enflé et charnu, auquel appendent des graines. En disséquant une fleur semblable, on voit l'ovaire réduit déjà à l'état de mince pellicule, comme sera l'enveloppe capsulaire elle-même. Les figures 5 et 4 sont destinées à représenter cet état tératologique et l'ovaire ouvert.

Si l'on coupe ce placentaire longitudinalement, on n'y voit qu'un parenchyme ordinaire et des fibres se rendant aux funicules des graines. Nous avons constaté par des expériences réitérées, que des graines prises sur des lieurs semblables étaient fécondes et devenaient mûres. Elles germent et produisent des plantes en tout conformes à l'essence de l'espèce.

Nous avions cru pendant quelque temps que cet état du Cuphea représentait sa déhiscence naturelle et normale du fruit; mais il est facile de s'assurer, tant chez le Cuphea miniata que chez le Silenoïdes, quand la rupture normale du fruit s'opère, que l'axe reste horizontal, sans forte enflure et les funicules allongés et recourbés.

Nous avons nommé ce genre de monstruusité Gyin- 
naxonie (de zupvos, nu, et d'ähs)y-ovos, axe), parce quien cflet, ce yu’il y a de singulier lans cette structure, c'est la dénulation, le redressement, l'hypertrophie de l'axe central de la fleur, destiné, dans le cas normal, à rester couvert, incliné et contenu dans les enveloppes pistillaires.

Les graines sont des parties appendiculaires, en ceri distinctes des autres: qu'elles renferment en elles le germe et le principe d'un axe indépendant. Or, dans le gymnaxonie, il est évident que la perversion tératologique n’atteint pas la partie appendiculaire, qui est même féconde et susceptible de reproduire l'espèce, cl celte même perversion se fixe daus le centre de l'organisme pour le modifier complétement dans sa direction, son volume, ses formes et ses relations. Aurions-nous done tort de croire que réellement les forces tératologiques sont inhérentes à l’ètre, qu'ella's procèdent de sa vie, qu'elles se confondent avec elle et que le monde ambiant est pour très-peu de chose, si tant est qu’il y est, dans les modifications qu'on peut récllement appeler tératologiques.

Un second cas de gymnaxonie s'est présenté à nous dans les fleurs du Lobelia erinus (voy. fig. 6, 7 et 8). La fleur normale est représentée pl. fig. 6 . On y roit poindre le stigmate hors du tube anthérien, tous denx horizontaux comme la fleur elle-mêne.

Mais arrive un développement gymnaxonique, la corolle se fend, la colonne se lève perpendiculairement; l'ovaire reste ce quil est el où il est, mais le style se courbe, se dénude du tube staminal et forme un conde (fig. S), de sorte que les génitalies sont dressées, au lieu d’ètre inclusc's dans la corolle. Ces lleurs de Lobelia se fécondent comme les autres et dounent des graines mûres qui ne reproduisent pas plus la inonstrunsité que d'autres. 
Il y a bien une différence dans la gymnaxonie de ce $L o$ belia d'avec celle du Cuphea, en ce que la dénudation et la déviation de l'axe, compliquées d'hypertrophie, d'un côté sculement, frappe dans l'une espèce l'axe réel de la fleur ou le placenta, et dans l'autre le style, lequel est évidemment l'organe moteur ici, lequel en traîne avec lui le tube staminal dont la partie anthérienne est trop tenace pour céder. Mais comme au fond les placentaires peuvent être regardés tout aussi bien comme la conjonction des bords des feuilles carpellaires, que comme des prolongements effectifs de l'axe tigellaire et que tout style se compose bien certainement d'une partie de ces mêmes feuilles carpellaires représentant la prolongation de la nervure médiane, il n'y a aucune raison pour ne pas prendre les deux cas tératologiques comme rentrant dans un genre identique, c'est-à-dire deux vraies gymnaxonies.

Toutes deux peuvent être comptées comme des arguments de plus en faveur de l'autochthonie et de l'indépendance des forces perverties de l'organisme dans la formalion des structures tératologiques.

\section{EXPLICATION DES FIGURES.}

Fig. 1. Fleur du Cuphea miniata agrandie quatre fois.

2. La même ouverte pour montrer l'ovaire.

5. Une fleur gymnaxonique de la même espèce avec le placentaire hypertrophié, dressé et dénudé.

4. Le même placentaire avec les g̛̣aines et l'ovaire déchiré et membraneux.

5. Une ğraine mûre aģrandie huit fois.

6. Fleur normale du Lobelia erinus, agrandie trois fois.

7. Mème fleur g.j mnoxanique.

8. Colonne gymnaxonique avec le tube staminal fendu et le pistil coudé et dénudé. 


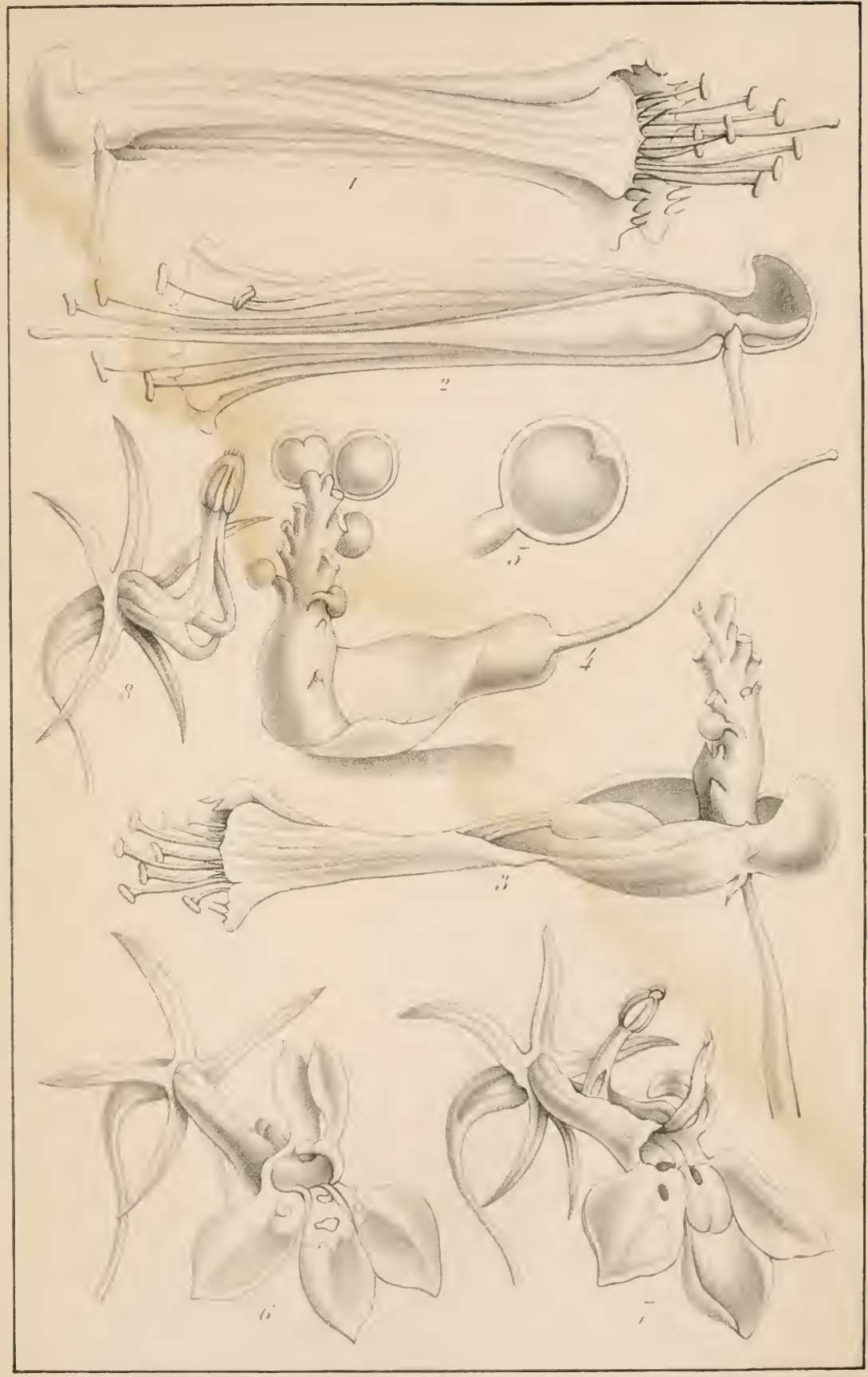

li,jel11111.1 11/11's) 

ACADEMIE hOYALE DE BELGiQUe.

(Extr. du t. XVI!I, n"s 11 et 12, des Bulletins.)

\section{NOPICE}

SUR LES

\section{ANOMALIES DE DÉPLACEMENT}

ET

ANALSE HE MONSTRES MOUVEAT COMPLIQUES IE METIRHIME, DE DEDOULLENEXT ET DE DISSONCTIOX;

PAR

At. Ch. ERtorren,

ML NERE DE LACADIMIE RUSALE DE BELGIQUE.

(Lue dans la seance du 6 decembre 1831.)

Un organe est plutòt anéanti que déplacé, disait arce beauroup de justesse Cieofiroy de S'-Hilaire. Ce principe, qui maintient dans toute sa valeur la théorie de linser- 
tion, telle que M. Auguste de $\mathrm{S}^{t}$-Hilaire l'expose aujourd'hui, est passée à l'état de vérité dans la hotanique tératologique. M. Moquin-Tandon a déjà fait entrevoir une des véritables causes pour lesquelles les ectopies ne se représentent pas dans le règne végétal; car, en lisant attentivement tous les cas rapportés par le savant tératologue de Toulouse, on est convaincu qu'aucun n'est une ectopie véritable, c'est-à-dire un déplacement d'un organe quelconque de l'endroit où il aurait dù naître dans un endroit où il aurait dû ne naître pas. Cette véritable cause, à laquelle les observateurs des anomalies végétales ne font pas une attention assez grande, est évidemment la métamorphose, propriété si fondamentale de l'organisme des plantes et si inhérente à leur nature, qu'aucun individu n'y échappe. Ainsi, quand, sur une hampe de tulipe, on voit se développer en dehors de la ileur un organe qui possède toute l'apparence et toutes les couleurs d'une division du périanthe, il est évident que ce n'est point ni un sépale ni un pétale qui a pris son insertion en dehors de la fleur au milieu de la tige, mais la métamorphose d'une feuille en organe similaire à l'élément calicinal ou corollin. Ainsi, encore, si, dans le trèfle rampant, il est si commun de trouver au lieu du carpelle léguminiforme du pistil une feuille, ce n'est point cet organe qui a franchi l'espace du dessous de la fleur à son milieu ou au-dessus d'elle sur son axe, mais une simple conversion de la gousse en limbe foliaire. Ces faits et bien d'autres ne font plus conteste aujourd'hui.

Lorsqu'on observe une feuille décurrente et qu'on aperçoit la libération de la lame bien an-dessus du point d’insertion du pétiole, il n'est plus personne actuellement qui attribuerait ce fait à un déplacement, puisque la soudure 


\section{( 179$)$}

l'explique tout aussi bien que, se trouvant expliquées par les mêmes raisons, l'intlorescence épibractéenne du tilleul ou les lleurs épiphylles des Ruscus.

Quand donc on est en présence d'un cas de métaphérie ( $\mu \varepsilon \tau \alpha-p \dot{s} \rho_{0}$, transporter) non encore expliqué, et vis-à-vis de la déclaration formelle des tératologues, que les ectopies ou déplacements (et non transport, remarquons-le bien) d'organes n'existent que dans le règne animal, ou doit prendre toutes les précautions pour ne pas tomber dans une fausse interurétation des phénomènes, et user de tous les dons de la seconle vue, que possède si bien l'intelligence humaine, capable d'apprécier les faits avec l'esprit, autrement que ne le font nos yeux avec leur fonction.

Ces réflexions sont commandées par la description d'un ordre de monstruosités végétales et florales du plus haut intérêt, dont aucun auteur de tératologie ne s'est encore occupé, à notre connaissance. Des collaborateurs au Gardener's Chronicle ont bien signalé et figuré diflérentes anomalies des Fuchsia; mais aucune d'entre elles n'était du genre de celles dont nous allons nous occuper ici. Le petit séminaire de $\mathrm{S}^{\mathrm{t}}$-Trond est devenu pour nous une pépinière de fort jolis monstres, la plupart très-instructifs et très-éloquents, et c'est encore de cette source fécondeque nous sont venus les cas fort remarquables de métaphéries qui forment l'objet de cette notice. Nous en rendons grâce à II. le professeur Van Oyen et à l'un de ses élèves les plus perspicaces, M. Jules de Fize.

Rappelons-nous d'abord la structure normale et spécifique des fleurs de Fuchsia : un ovaire infëre et un long tube calicinal terminé par quatre divisions. Alternativement entre elles, quatre pétales naissant (ou mieux se libérant) au sommet du tube calicinal et plus courts, quoique 


\section{$(180)$}

plus larges que les divisions du calice; puis, huit étamines exsertes, que le taxonomiste (Endlicher, par exemple) fait naître à l'insertion des pétales, et cette insertion il la place au sommet du tube du calice; les filets filiformes, simples, contenus et terminés par des anthères introrses, biloculaires, incombantes et longitudinalement déhiscentes. Le style est filiforme, libre dans le tube calicinal, à partir de l'ovaire et exsert; il se termine par un stigmate capité, en clou ou quadrifide.

On sait combien les horticulteurs ont semé de Fuchsia pour en obtenir des centaines de variétés. L'une d'elles, appelée Scaramouche par cette singulière espèce de botanistes, si toutefois un horticulteur botanophile seulement et rien de plus, peut prétendre au grade de botaniste, présente une vraie structure anomale des plus originales. Nous ne pensons pas qu'il y ait dans la végétation des monstres un second exemple de cette organisation où les yeux de la tête n'hésitent pas de voir un véritable déplacement d'organes. Ce Scaramouche se reproduit par bouture; il est plein d'enseignement et vaut beaucoup mieux que son nom, trop indigne, il faut le reconnaitre, d'ètre jamais celui d'une plante respectable. On ne trouve ce nom de Scaramouche que dans les comédics de Molière et dans les catalognes horticoles. Nous regrettons done de devoir l'employer, et nous ne le rappelons ici que pour fournir aux botanistes tératologistes l'agrément d'acheter un monstre curieux et unique dans l'histoire des belles horreurs de la nature.

La figure $1^{\text {re }}$ de notre planche représente une fleur de ce Scaramouche. L'ovaire est normal, le calice aussi ; mais immédiatement att-dessus commence l'anomalie. On voit sortir de l'endroit où cesse le tube calicinal et où com- 


\section{(181)}

mencent ses quatre divisions, les filets des étamines, cette fois non enveloppés dans les quatre pétales. On dirait que ceux-ci manquent, du moins à leur place naturelle. Niais on est tout étonné de trouver ces quatre pétales sous la forme de quatre grands capuchons corollins et d'un pourpre carminé éclatant, au sommet des étamines et enveloppant les anthères. Le pistil passe intact et n'a rien d'anomal. Le calice en rose, les filets des étamines incarnats, et les capuchons seuls sont d'une couleur éclatante.

Nous avons représenté la fleur vue en dedans (fig. 2). On y voit le pistil au centre parfaitement libre, très-long et normal; puis on découvre quatre filets, couleur de chair, longs et étroits, correspondant chacun, quant à sa libération, c'est-à-dire quant à son insertion selon la description du taxonome, à la nervure médiane de chaque division calicinale. Chacun de ces filets porte sur le dos, extérieurement à l'axe de la fleur, un cornet ou pétale cuculliforme, en capuchon dilaté et très-grand. Le filet de gauche continue son filet sous la forme d'une seule étamine avec une anthère fertile qui se replie dans le capuchon; les deux filets d'au-dessus et de droite ont chacun deux étamines à anthères fertiles, devenant distinctes l'une de l'autre, un peu au-dessus de la naissance du cornet. Enfin, le filet de dessous, outre un capuchon fort bien formé, offre trois étamines distinctes au-dessus du capuchon et chacune ayant une anthère fertile.

Voilà ce que l'on voit.

Évidemment, si l'ectopie n'existe pas de la végétation, c'est-à-dire une monstruosité par déplacement, il doit y avoir certainement transport d'organes, car les pétales, au lieu de naitre entre et à la base des divisions du calice, autdessus de son tulse, naissent et deviennent visibles, 


\section{(182)}

amples ct colorés, au haut des étamines, au-dessous des anthères. Il y a donc ce que nous appelons métaphérie ou monstruosité par transport. Ce transport est une glissade organique; nous le verrons tout à l'heure.

Cette métaphérie donne lieu à plusieur's inductions intéressantes.

Au fond, il est évident qu'en remontant à son origine première, on la trouve dans une soulure de l'élément corollin avec l'élément androcéen. Les filets des étamines ont absorbé les pétales, ils les ont avalés, si nous pouvons le dire, ils ont fait soi les pétales, et puis, plus hant que leur libération ordinaire, près des anthères, ces fibres pétaloïdes se sont fait jour, et l'organe a repris sa forme, sa texture, ses couleurs, avec quelque váriation, il est vrai, mais au total avec, la plupart des caractères essentiels et sa nature normale.

A l'œil, on dirait l'insertion variée, transportée, déplacée; car nous ne voyons nulle part des étamines produire et porter des pétales, mais nous voyons souvent des pétales porter des étamines (stamina catapelala). Mais on a bientôt, par l'esprit, redressé l'erreur commise par l'inspection et ramené à sa véritable cause la soudure d'une anomalie si extraordinaire.

Un second fait est non moins clair. C'est la dissimulation complète de la corolle dans les filets de l'androcée, pendant tout le trajet où le capuchon n'existe pas. Si la sondure existe, et elle ne saurait se nier, on doit dire qu'elle est telle que son existence ne se traduit nullement au dehor's. On dirait d'une fusion complète et d'une réduction totale de matières organisées.

Il est vrai que, dans une fleur de Fuchsia normale, la soudure intime avec fusion des matières organiques des 


\section{$(185)$}

appareils confondus, se fait entre la corolle et le calice, de manière à libérer le premier de ces deux verticilles senlement là où le second perd sa forme de tube. Dans la métaphérie signalée, la fusion et la soudure des organes corollius se continue du calice aux lilets de l'androcée; mais ce fait même n’en est que d'autant plus intéressant.

Le type spéciliłue de la fleur du Fuchsia est basé sur le nombre quatre et ses multiples. Il s'ensuit qu’il y a pour les lunit élamines denx verticilles de quatre étamines chacun. Les lois de l'alternance prouvent donc que, dans la mélaphérie en question, ce sont les étamines du verticille inférieur (ou le plus externe, ou le premier) yui ont forcé les antres à se souder avec elles. En cffet, ces étamines du premier verticille doivent se trouver opposées avec les sépales, alterner arec les pétales, el la dissection prouve évidemment que ces étamines ont conservé leur rang, leur insertion, tandis que les autres ont perdu leur place pour venir se joindre aux premières tantôt deux à deux, tantôt trois à trois, tantôt mème (fig. 7) quatre à quatre.

Cette observation mène nalurellement à une autre question plus difficile à résoudre et dout le résultat est plus entaché d'incertitude. Celte question la voici :

Il est évident que, dans une fleur normale de Fuchsin, les pétales occupent liutervalle entre les divisions calicinales. Cependant, dans la mélaphérie, chaque rornet pétalö̈de est placé vis-à-vis des divisions du calice. Y a-t-il en déplarement? Y a-t-il eu torsion de 仿 degrés du verticille corollin dans la somdure androcéenne? Aucun indice d'un tel monvement circulaire ne sobserve dans la dirertion des fibres: toutes celles du calice et des filets sont rectilignes. Il serail done plus prudent d'almeltre que chaque cornet staminal dans la métaphérie provient de deux 
moitiés respectivement voisines de deux pétales alternes avec les sépales, à peu près comme on s'explique l'organisation de l'androcée dans les Fumariacées et les Asclépiadées. Mais nous n'hésitons jas à déclarer qu’à l'égard de cette génèse des cornets, nous conserrons quelques doutes, bien que nous soyons légilimement en droit de la concevoir de cette façon, vis-à-vis des lois de l'alternance, plus fixes que les disjonctions à soudures.

Nous ferons remarquer qu'il est impossible, dans celte métaphérie, d'almettre que les cornets pétaloïles et rouges qui accompagnent les étamines soient des modifications des connectifs comme dans les Atjuiléges. Celle impossibilité saute aux yeux, vis-i-vis des figures 4 et $\bar{\tau}$, qui représentent, l'une (4) un de ces cornets portant à son bord et à l'extrémité du filet une anthère parfaitement normale, sans modification aucune du connectif; l'autre (7), un double cornet évidemment formé de deux parties soudécs, mais provenant d'un filet rentorcé de quatre éléments staminaux. Aussi y a-t-il là quatre anthères complètes, dont trois terminent des extrémités de filets séparés, et une anthère soudée, la quatrième, porte même une loge supplémentaire transversale, qui ferait croire à uue soudure avec demi-résorption de deux anthères en une. Il ne peut donc être question ici de modification du connectif en pétales. Nous verrons cependant conment le passage entre ces deux sortes de cornets s'établit dans les Fuchsia Scaramouches mêmes.

Examinons la fleur représentée fig. 5. Elle est certes un monstre des plus intéressants. L'ovaire intëre est netlement distinct du calice; mais au bas du tube de celui-ci se présente une feuille dont la coloration, d'un vert jaunâtre, ferait soupconner la nature des bractées, et à 


\section{(185)}

l'aisselle de cette feuille une élamine isolée, avec anthère fertile, placée donc entièrement hors de la fleur. Ici, on dirait d'une ectopie véritable.

Puis vient le tube du calice, divisé, en haut, en sept lanières, et l'une de ces lanières oflre une teinte rose sur une moitié et une teinte rouge pourpre sur l'autre. Deux pélales de forme ordinaire se développent immédiatement sur la gorge de ce calice évidemment dédoublé, et de là naissent aussi sept élamines, lesquelles offrent les particularités suivantes :

Deux de ces organes présentent leur structure ordinaire;

Trois se trouvent soudés par leur filet en un corps unique, mais vers la moitié de l'organe, les filets respectils de ces étamines s'isolent;

Une étamine laisse voir, sur la moitié de la longueur de son filet, un lambeau denté d'un pétale, rouge comme celui-ci;

Une septième étamine présente, avec une torsion spiralö̈de de son filet, une conversion de son anthère en cornet pélalö̈le;

Enfin, le pistil est normal.

Sur deux autres lleurs de Fuchsia appartenant à d'autres variétés que le Scaramouche, nous avons retrouvé un état analogue, et ce sont les analyses fiates de ces anthìres modifiées que nous avons représentées figures $\ddot{3}$ et 6 . Sur l'étamine $\ddot{3}$, il est évident que le cornet est dủ à un prolongement du connectif, avec séparation et distraction des loges de l'anthère rendues stériles. Ces loges sont réduites ¿ deux callosités divergentes.

L'étamine fig. 6 montre le passage du cornet corollin de la fig. 4 au cornet commerdival de la fig. (i, puisque: l'organe rouge el de consistance pétalö̈de nait a la base 


\section{( 186 )}

de l'anthère et au-dessous, pour se prolonger au-dessus et comprendre dans son plan les deux loges de l'anthère réduites également à un état caronculaire.

Donc, nous avions raison, pensons-nous, de nous servir de cette métaphore dans notre langage de plus haut, à savoir que le pétale glissait sur l'étamine pour se souder avec elle el se détacher ici à moitié chemin (étamine de la figure $\overline{\text { s) }}$, là au-dessous de l'anthère (étamine) des figures 1 et 2 , figures 4 et 7 ), et enfin dans et audessus de l'anthère mème, modifiant ainsi son connectif, prolongement du tilet sur lequel le pétale a glissé ( $f \mathrm{~g}$. et 6). Ce glissement organique est un transport sans déplacement, une métaphérie sans ectopie; car l'insertion (placement) de l'élément corollin n'a pas changé, mais seulement sa libération, son exsertion, comme l'eût dit De Candolle, a eu lieu plus haut, vers le sommet de la fleur, que dans l'état normal. Nous pensons que c'est là l'explication naturelle qu'il faut donner de ces phénomènes d'un ordre anomal.

Il nous reste maintenant à discuter un des faits les plus intéressants signalés dans la fleur métaphérique figurée au numéro 5 . Nous voulons parler de cette étamine isolée, extra-calicinale, naissant, dirait-on à l'aisselle d'une bractée. En décrivant la fleur, nous disions : on dirait d'une ectopie véritable. En effet, qu'y aurait-il de plus simple pour se rendre compte de cette inscrtion si extraordinaire que d'admeltre le déplacement d'une étamine, élément organique interne dans la fleur, unité du verticille androcéen, le troisième en rang dans la fleur normale, dans un endroil externe, en dehors et ant-dessous dı calice? Quand on a nié, ajouterait-on, dans les traités de tératologie végétale, l'existence des ectopies, 


\section{( 187 )}

telles qu'il en existe dans le règne animal, c'est qu'un cas comme celui-ci ne s'était pas présenté. Mais ici, l'étamine ne naît pas à sa place; elle est insérée à l'aiselle d'une bractée et en dehors et au-dessous du calice. Donc s'il y eût une ectopie au monde, e'est bien la structure de ce Fuchsia monstrueux.

Mais telle est notre foi dans les lois immuables de l'organisation typique, qu'un fait si extraordinaire, comme le scrait un vrai déplacement contraire aux règles de l’insertion, ne peut pas à nos yeux exister réellement. II faut dégager l'apprarence de tout ce qu'elle offre de capticux, et arriver à la vérité en écartanı les causes nombrenses d'erreurs échelonnées sur la voie au bout de laquelle la nature restera saine et sauve, toujours semblable à ellemême. Analysons donc cette fleur ussentiellement instructive avec toute la perspicacité possible de la seconde vue que donne l'étude si attrayante d'une tératologie philosophique.

L'organe bractéimorphe à l'aisselle duquel cette étamine prend naissance, est-ce bien une bractée? La conleur verte la ramène seule à cet ordre d'organes. Son insertion est au-dessus de l'ovaire, non au-dessons, et dans les Fuchsia l'ovaire est infëre. Cette dernière raison suffirait pour rejeter l'opinion que ce pût être une bractée sondée à l'ovaire et se faisant jour au-dessus. Il y en a une seconde. Dans cette fleur métaphérique, le calice esı dédonblé : on voit visiblement sept divisions au sommel du tube. Où esı le huilième? Il en faut luit. puisque le nombre normal des divisions calicinales est quatre. Évidemment, cette huitième division, ou, si l'on vent, ce huitième sépale est la bractée prétendue; seulement l’organe, la fenille calicinale, an lien de poursuivre sa soudure au-dessus de 


\section{( 188 )}

l'ovaire avec le tube de son verticille, s'est libéré plus bas que de coutume, et cela sans doute à la suite du dédoublement organique de son verticille, du transport de deux pétales sur quatre et de la force d'anomalie qui déjà s'était emparée des organes staminaux. Une anomalie aussi profonde qu'une métaphérie, la seule qui se rapproche autant d'une ectopie impossible, peut bien, ce nous semble, agir sur l'organisme en voie de développement, au point de déjeter vers le dehors des fibres et des éléments tissulaires qui normalement auraient dû rester soudés. C'est même un petit effet pour une altération si grande.

Reste maintenant à expliquer, d'après les lois ordinaires de la disjonction, la présence de l'étamine qui semblait une ectopie. Rien de plus simple. Il y a sept étamines en place dans la fleur : c'est donc la huitième seule qui serait déplacée et serait pourvue d'une insertion contraire à toutes les lois les plus immuables. Nais, remarquons que dans les fleurs de Fuchsia, les étamines sont normalement catapétales ou souciées en bas à la corolle, et celle-ci est supère, done soudée avec le calice. Or, quoi de plus naturel que si un sépale, au lieu de se souder avec ses homologues en tube, reste libre, qu'il entraine avec lui le filet de l'étamine du premier verticille de l'androcée correspondant à sa nervure médiane? C'est donc une simple disjonction, un rejet au dehors, une exsertion anticipée, que celte étamine si singulièrement située, mais ce n'est pas un déplacement organique, ce n'est point une ectopie. Telle est, suivant nous, la véritable signification tératologique qu'il faut donner à ce gentre de monstruosité extraordinaire, il est vrai, par sa rareté, curieux par les réflexions qu'elle fait naitre et liautement intéressante par l'appui donné aux vérités fondamentales d'une science si 


\section{( 189$)$}

intimement rattachée aux vues les plus philosophiques et les plus élégantes.

\section{EXPLICATION DES FIGURES.}

Fig. 1. Fleur de Fuchsia, variété dité Scaramouche; grandeur naturelle.

2. Il. vue en dedans et d'en haut.

5. Id. frappée de métaphérie c(rolline, de dédoublement calicinal et de disjonction staminale.

4. Cornet métaphérié d'une étamine, agrandi à la loupe.

5. Anthère à connectif pétalifié, agrandi à la loupe.

6. Anthère à connectif pétalifié soudé à un cornet métaphérié, agrrandic à la loupe.

7. Double cornet métaphérié appartenant à quatre étamines, agrandi à la loupe. 

linell.de l: lecrel. lines.

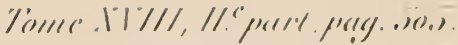

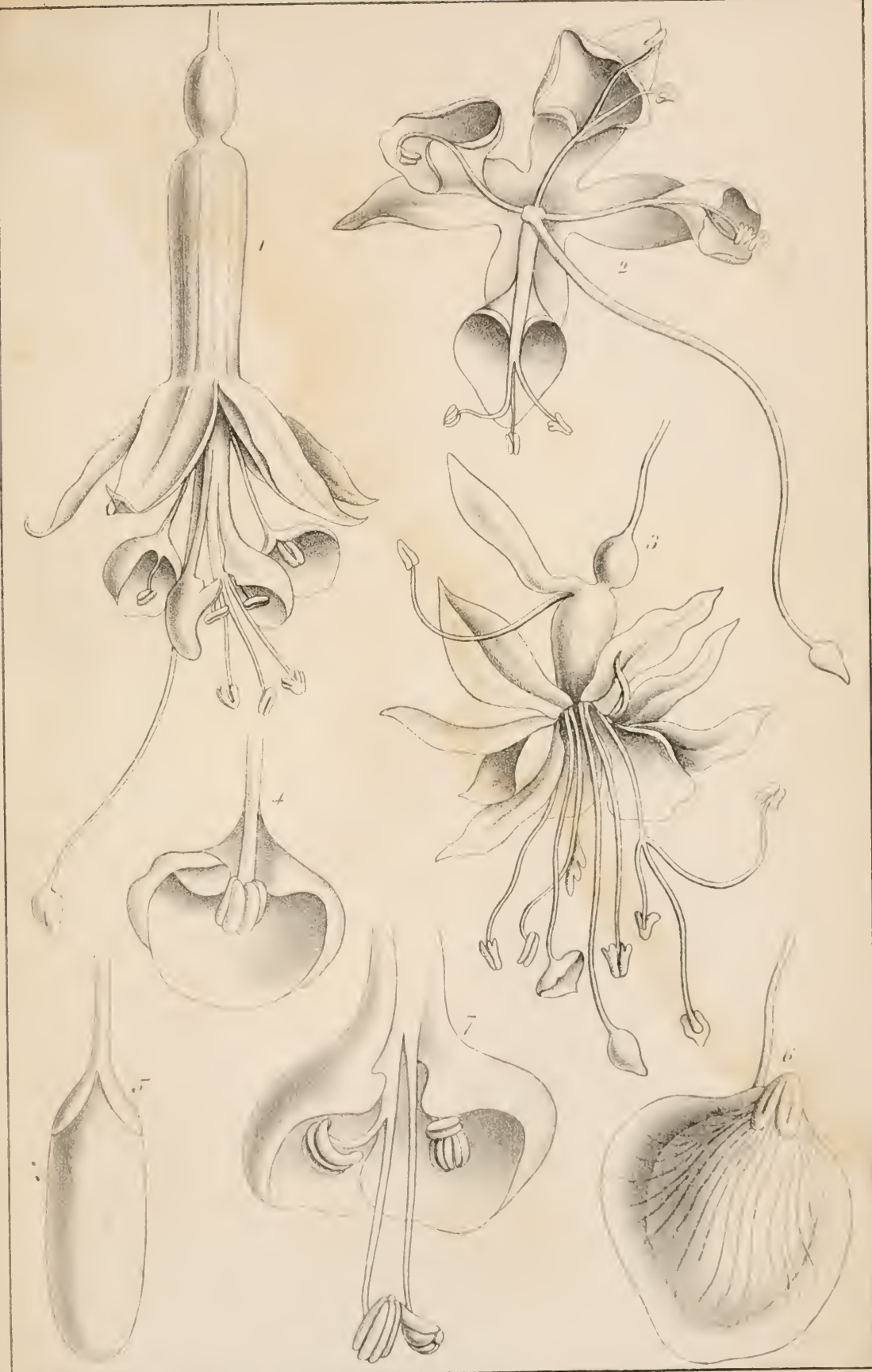

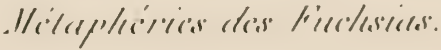



(Extr. du t. XVIII, nos 11 et 12, des Bulletins.)

\section{RAPPOR'T}

Sur un mémoire ayant pour épigraphe PRO PATRIA, présenté à l'Académie royale des sciences, des lettres et des beauxarts de Belgique, en $18 \mathrm{1} 1$, en réponse à la question suivante :

"Faire connaitre la nature, la formation et la topographic aetuelle " des polders de la rive gauche de l'Escaut et du littoral belge; " donner un coup d'œil sur les différentes périodes de leur formation " et de leurs accroissements, en s'anpuyant sur des documents histo"riques; en décrire la mise en culture, les endiguements et les tra" vaux d'art, et exposer le système d'économie rurale qui y est ac"tuellement en usage, les constructions, les instruments aratoires, "les races d'animaux domestiques, les causes de la fertilité; enfin, " étudier les différents moyens d'augmenter les ressourees agricoles " de cette contrée."

par i. Cif. Morren.

L'Académie, a de tout temps, regardé comme l'une de ses plus nobles prérogatives, et nous disons même comme un de ses droits les plus imprescriptibles, de ne pas enserrer la science dans les liens étroits de la politique. Que celleci limite les frontières de la Belgique, bien en deçà des rives de l'Escaut, la nature, sans s'incliner devant les po- 
teaux de la douane ni limiter ses provinces par le bariolage des uniformes, emploie, pour circonscrire ses régions par des barrières ineffacables, des fleuves, des mers, des montagnes, l'ossature même du globe terrestre. L'Académie, en vertu de son éternelle mission, a donc cru devoir suivre en cette circonstance les prescriptions d'une géo. graphie vraiment naturelle, et sans s'inquiéter de la police des passe-ports, elle a étendu, cette fois, les bienfaits d'un concours national au delà des frontières du pays; elle a pensé que puisque la Flandre et la Zélande ont des côtes communes, on pouvait les regarder comme fatalement inséparables. C'est cette idée qui a fait comprendre dans une question du concours de 18̈̊1, et en vue d'une étude complète, le littoral belge et la rive gauche de l'Escaut occidental.

La Belgique, livrée depuis vingt et un ans, l'âge des majorités, aux libertés d'une émancipation, virile de bonne heure, a compté et compte encore des peintres habiles qui ont esquissé à grands traits le caractère fortement accentué de plusieurs de nos régions. Les Ardennes ont été sillonnées par des touristes doués de l'art difficile de bien décrire. Les bords de la Meuse, célébrés en vers et en prose, ont éveillé de chaleureux souvenirs; les légendes , les récits historiques charment les veillées autant que la description de leurs richesses industrielles. La Campine elle-même, avec ses vastes horizons et ses bruyères uniformes, si riches d'avenir, s'est vue scrutée dans son sein comme à sa surface, dans son histoire comme dans ses ressources, et la Belgique tout entière s'est intéressée à son sort. Les plaines fécondes de la Flandre, les collines variées du Brabant, le Hainaut si puissant par son génie et ses trésors manufacturiers, le pays de Liége si émouvant par le caractère pittoresque de ses paysages et par les péripéties incessantes 
de son histoire, toutes ces régions sont incessamment parcourues, peintes et décrites par me foule empressée, heureuse de constater la puissance agricole, industrielle, artistique, littéraire et scientifique de ces anciennes provinces. C'est ainsi que la Belgique augmentera l'estime qu'elle se doit à elle-même en apprenant à se connaitre.

Mais, afin qu’aucun membre de ce corps, la patrie, qu'il s'agit d'observer minutieusement, n'échappe à l'investigation de cenx qui le fécondent en l'étudiant, l'Académie, qui n’a jamais cessé d'éclairer l'opinion publique dans le cercle de ses attributions, s'est empressée de lui signaler une partie du pays, rarement visitée par les hommes désireux de s'instruire et de s'émouvoir, oubliée, pour ainsi dire, sur nos côtes sans marine et ì peine connue de quelques-uns de ces savants fort rares, qui, dans l'intérêt de la géologie et pour connaître quelques terres, dans l'intérêt de la botanique et pour retrouver quelques chétives plantes, dans l'intérêt de l'agriculture, la science des paysans et des propriétaires campagnards, ne se font pas faute d'aller en pleine Europe à la découverte de certains mondes ignorés. Cette partie du pays est celle généralement désignée sous le nom de région des polders, limitée du côté des eaux par l'Escaut occidental et la mer du Nord. et du côté des terres par une ligne prartant de Burcht, près d'Anvers, longeant à peu près nos f'rontières limitrophes de la Zélande pour entrer dans la filandre occidentale, laisser Bruges en dehors de sa direction, descendre enfin près de Dixmude, célèbre par ses gras pâturages, et aboutir à Bulscamp, entre Furnes et Dunkerque. Celte limite est une lisière en forme de croissant, de 150 kilomètres de longuenr et de 1:5 kilomètres de largeur; elle comprend une zone des plus curieuses, des plus instructives, des plus riches, et disons-le, quoiquion le conteste, une des 
plus heureuses de nos contrées européennes. Elle abonde en phénomènes de tout genre, elle est pleine d'enseignements dont d'autres pays, s'ils le veulent et s'ils comprennent leurs intérêts, sauront tirer un fructueux parti. Voilà quelques-unes des raisons pour lesquelles l'Académie avait pensé à celte partie du pays, et remarquons-le, comme l'auteur du mémoire envoyé à son examen a eu la délicatesse de le rappeler lui-même, le premier corps savant de la Belgique a manifesté plus d'une fois ses sympathies en faveur de cette zone intéressante. En 1775, il mettait au concours la relation de l'ancien état de la Flandre maritime; en 1827, il demandait qu'on étudiât les changements que la côte avait subis d'Anvers à Boulogne, depuis César jusqu'à nos jours, et chaque fois l'Académie eut à couronner des travaux qui avaient répondu à son appel avec un incontestable talent. Cette fois, en 1850 , le concours sur l'exploration de cette région exigeait beaucoup plus de variété dans le savoir des auteurs : ce n'était plus une spécialité restreinte, mais la question embrassait la géologie, la topographie, les changements subis par le territoire dans la suite des siècles, les documents historiques, toute l'agriculture et l'économie rurale, les constructions, les endiguements, les travaux d'art, les hommes, les êtres animés et vivants; et pour couronner fructueusement cet ensemble, le concours, ne se bornant pas à l'état actuel des choses, exigeait de tracer pour l'avenir des conseils utiles et des améliorations réalisables. On eût pu croire que, devant tant d'exigences, un zèle même éclairé, et précisément parce qu'il avait cette qualité, eût pu fléchir; mais le rapporteur a hâte de le dire, il s'est trouvé parmi les fils mêmes de cette région des polders un homme instruit, qui a répondu presque avec un succès complet à l'attente de l'Académie; ce rapport aura plus d'une fois 
l'oceasion de faire valoir le mérite de son remarquable travail.

Nous quittons Bruselles, plongée dans les distractions fastucuses des capitales, nous saluons devant Laeken le palais de nos souverains, nous volons à travers les prairies de Vilvorde, où l'ail de l'agronome roit subsister avec chagrin de nombreux inonticules, suite d'une déplorable négligence; bientôt nous arrivons aux sables de iralines, que l'engrais a fécondés, nous tournons vers les Flandres; le petit Brabant, région aggricole toute spéciale, apparaît à nos yeux, ceint de ses milliers de haies et de ses innombrables clotures; insensiblement les champs prennent l'aspect blond et coquet que leur donne l'agriculture flamande; l'odorat nons avertit que nous sommes en pleine Flandre, et l'on se demande pourquoi la chimie, en possession de procédés très-simples, n’a pas assez d'empire sur ces populations si actives pour rendre à l'atmosphère de cette province une propreté digne de celle de ses terres: nous sommes à Gand, à qui incombe cette mission.

De la seconde ville du royaume à la région des polders, aucun embranchement d'un chemin de fer quelconque ne conduit les populations sur les ailes de la vitesse. Le premier contact qui met en relation l'étranger avec l'habitant de ces lieux, se fait par l'antique char à banc, ample et largement taillé, décoré dans le pays du nom radieux de phueiton. L'œil attentif s'est aperçu déjà d'un changement dans les proportions des objets, et quelyues regards jetés sur le cocher et les chevaux, ont bientôt justifié ces remarques. L'encolure, le poitrail, la croupe, les membres vigoureux et dilatés de ces carrossiers, donnent à l'observateur une idée anticipée, mais vraie, de la fécondité du pays. A peine, gràce i leurs pas retentissants, a-t-on franchi les fauboures de la ville, qu'on sent à je ne sais quelle 


\section{$(196)$}

moiteur dans l'air et à quelle odeur salée, répandue autour de soi, qu'on se trouve dans une contrée très-basse et qu'on marche vers le littoral. Les fossés rectilignes, carrés et nombreux, la disparition complète des prairies, leur remplacement par des bordures vertes ceignant de petits champs, des haies doubles et parallèles, des arbres qui ne naissent pas de la surface de la terre, mais dont les trones sortent d'à demi-côte des fossés, des essences molles taillées pour en faire du bois à sabot, des chemins proprets et précautionneux, des routes pour les chevaux, des accotements pour les hommes et des arbres partout, tout cet ensemble caractérise la vraie Flandre agricole.

Peu à peu les arbres deviennent plus nombreux et plus grands, des bois, des forêts même viennent ajouter leur fraîcheur à la brise naturelle et constante de l'air, une viridité dont les autres provinces ne pourraient fournir un second exemple, vous entoure de toute part, le ciel a peine à se chercher entre les branches pressées et touffues; la terre toujours humectée est moussue et veloutée, et l'on comprend devant cette végétation arborescente pourquoi, dans les descriptions de cette partie de notre pays, on signale ce hout-land (pays de bois) particulièrement; ce hout-land, quoique cultivé en parcelles très-petites et distinctes, par des fermes exiguës, n'en contient pas moins plus d'arbres, à étendues de terrain égales, que nos provinces les plus boisées. On croirait en effet voyager sous une voûte sans fin, de bosquets et de parcs seigneuriaux.

Tout à coup et sans transition aucune, mais brusquement et subitement, tous les arbres sont laissés derrière vous, et un dernier regard, jeté sur le hout-land que vous quittez, vous montre sur toute l'étendue d'un horizon dont aucun accident de terrain ne vient interrompre l'uniformité, une longue lisière en rideau, espèce de serpent im- 


\section{( 197 )}

mense, dont chaque écaille est un tronc vigoureux et de laute taille. Au delà et devant vous, plus une cime, plus un trone, mais de rares arbustes, rabougris et tortueux, et au lieu d'un dôme de verdure, l'azur pâle ou le voile gris de la voùte céleste. Les fossés, les haies, les clôtures ont disparu, mais des champs féconds, couverts d'une luxueuse et grasse végétation, admirablement labourés, remués et sillonnés malgré leur étendue, d'une propreté sans rivale, peignés et sans tache comme une statue antique, se parquent à vos côtés et à perte de vue. Ces champs se limitent par des lignes toujours droites, des angles Iroits et des digues élevées, toutes liées entre clles. De distance en distance et au milieu de ces plaines endiguées se détachent des fermes isolées. Une population dont le caractère grave et digne, dont les gestes mesurés quoique: sans lenteur, dont le maintien, la physionomie et surtout le regard, expriment la droiture de la raison et le calme de l'àme, cette population, ce ciel et cette terre frappent de nous ne savons quel sentiment de méditation et de prudence, l'homme impressionmable qui visite les polders, car nous y étions dès que les cimes du hout-land nous avaient abandonnés.

Nous avions raison de le dire, la zone des polders ne ressemble à aucume autre contrée de notre pays; ciel et terre, eaux et champs, plantes et animaux, demeures et hommes, langue et pensées, tout y diflère d'ailleurs. " L'habitant des polders, dit l'auteur du mémoire qui a été soumis au jugrement de l'Académie, vit an milieu d'inmuences énervantes; il a besoin de plus de bien-être, de plus propreté, de plus de chaleur, de plus de stimulants et de plus de nourriture. Tout cela le rend moins apte pent-être aux travaux et aux soins incessants de la vie des rampagnards d'antres pays. II lérlaigne le travail des 
mains, il aime la conversation et même la lecture. Le soin réclamé par l'élève des animaux domestiques est peu de ses goûts; il préfère la culture des céréales dont la défaite est plus facile et plus assurée. Réduit à cette seule ressource, sa fortune, son avenir dépendent des chances du marché : quelques années de bas prix le ruinent, quelques bonnes années l'enrichissent et le mettent à même de se reposer de ses affaires. Tandis que le cultivateur retiré est, dans les Flandres, un homme vraiment à plaindre, dans les polders, il est considéré et en devient fier, le rusten landman vit dans le confort et se donne largement les agréments d'une double vie, la matérielle et l'intellectuelle. »

A tous ceux, en effet, qui sont fatigués des agitations de ce monde, nous dirions d'aller vivre dans les polders; ni villes, ni palais ne viennent vous rappeler les préoccupations et les soucis inquiets des peuples, et que mes. sieurs les publicistes, si chatouilleux sur l'immense empire exercé par la presse, nous le pardonnent, car nous ne saurions qu'y faire, mais leurs carrés de papier, s'ils y arrivent, s'y oublient dans une indifférence complète. Le silence d'une quiétude générale pénètre l'atmosphère; les eaux, dont la vue ne saisit pas les limites, sont veuves de voiles, et des phoques nombreux, mais sans voix, soufllent avec crainte pour ne pas interrompre cette pause que la nature s'y donne; des nuées d'oiseaux du littoral y pêchent sans trouble une proie abondante, et dans quelques rares marais de la contrée, les hérons, appuyés gravement sur une patte, attendent dans une sécurité pressentant son succès que le reptile se présentera de lui-même pour lui servir de pâture. Il y a partout dans cette région, dans tout ce qui vit, sent ou respire, un maintien d'assurance et de confiance en soi, tellement prononcé que l'ombre d'une inquiétude ne peut jeter la moindre perturbation 
dans des jours qui s'y écoulent éternellement les mèmes. Quand les horizons politiques se rembrunissent, que les orages couvent, grondent ou éclatent, le cultivateur des polders trace paisiblement son sillon et se repose en Dieu et dans son grain, dont il sait bien que les hommes ne sauront jamais se passer. Cette assurance est le secret de sa vie tranquille.

Conquises sur le domaine de l'Océan, les terres poldériennes n'ont pu être utilisées par l'homme qu'à la suite de grands et solides travaux d'art. La géologie donne exactement la limite de ces terres de dépôt. L'auteur du mémoire reçu, décrit, dans la première partie de son travail, la topographie de cette localité; mais, prévenant le lecteur et ses juges, il déclare habiter ces lieux dans une privation complète de bibliothèque et de commerce scientifique. On ne saurait méconnaître, en effet, que la partie géologique est faible en comparaison de ses excellents chapitres sur l'économie rurale et l'agriculture. L'auteur lait de la géologie poétique; il parle volontiers de cataclysmes et de soulèvements, comme si la géologie n'avait pas depuis longtemps abandonné en grande partie ses rêves de révolution et fait entrer aussi le calme dans la formation du globe. Cataclysmes et soulèvements dans un endroit où les sédiments et les dépôts se forment paisiblement ne viennent guère à propos. II est même à regretter que, M. Dumont ayant publié, dans le $5^{\mathrm{e}}$ volume du Bulletin de l'scadémie, et ce en 1858, une carte géologique des terrains poldériens avec des détails très-préris sur leur nature, l'auteur du mémoire n’ait pas pris connaissance de ce travail indicateur.

Il le devait, selon nous, pour plus d'un motif. La question de l'Académie demandait de déterminer la nature des terrains des polders, et ectle demande était faite entiere- 


\section{( 200 )}

ment en faveur des concurrents : elle leur laissait l'occasion de publier, pour la première fois, l'analyse de terres les plus extraordinaires du monde, sous le rapport de leur fécondité. Il y avait lieu, à cette occasion, d'entrer dans les entrailles d'une agriculture raisonnée et exacte. Les minéralogistes et les géologues ont des idées très-vagues sur ce qu'il faut entendre par argile : ce spnt pour eux des terres plutôt caractérisées par leurs propriétés physiques que par leur composition chimique. Les analyses de MM. Berthier et de Salvetat prouvent que, chez les argiles à poteries, la silice l'emporte sur l'alumine; le reste est, dans ces terres, de l'oxyde de fer, de la chaux, de la magnésie et de l'eau (1). Au contraire, les analyses de Thäer et d'Einhoff, confirmées par MM. Boussingault, Pelouse et Fremy (2), faites sur les terrains argileux, réputés les meilleurs pour la production du froment, donnent un excédant en faveur des éléments argileux au détriment de la silice ou du sable siliceux, et cela dans des rapports de nombre proportionnellement inverses. Le rapporteur de votre commission a étudié par lui-même les polrlers, il a analysé leurs terres au microscope et démontré l'excédant chez elles du sable; il possède des analyses chimiques multipliées de différentes terres de ces contrées, faites par M. Kuppferschlaeger, professeur de chimie à l'Université de Liége, et ces recherches prouvent qu’à la fertilité la plus riche en fait de production de froment, les terres poldériennes joignent la composition des argiles à poteries : contradiction flagrante avec tous les principes admis en agriculture. De plus, il y avait à examiner à ce sujet com-

(1) Voyez Dufresnoy, Minéralogie, 1. III, p. $2: 59$.

(2) Toyez Pelouse of Fremy, Chimie (1850), t. III, p. 847. 


\section{(201)}

ment le sel, dont la quantité dans les polders, nouvellement endigués, ne permet pas la culture de nos plantes alimentaires, disparaissait du sol ultéricurement et faisait place à une fécondité continue et remarquable. Le rapporteur pense que, dans cel ordre de faits, la physiologie des plantes spontanées est appelée à jeter des lumières du plus haut intérêt. Dans son esprit, en proposant la question à l'Académie, il avait en vue de laisser parcourir aux concurrents ce champ si heureux en découvertes utiles. Le concurrent ne s'y est pas avancé.

La partie historique nous paraît beaucoup mieux traitée. L'auteur joint à son travail des cartes de 960 , de 1500 , de 1610 , de 1775 et de 1811 . L'un de nous regrette de ne pas voir l'analyse, parmi ces travaux, des études de l'ingénieur M. Kummer, et tout au moins la réduction des cartes publiées par ce savant. C'est, du reste, une omission facile à réparer. L'auteur discute, ce nous semble, en pleine connaissance de cause, les changements de nos côtes avec une sage critique, et il émet à cette occasion, sur la fosse Othonienne, des idées qui, sans doute, seront appréciées avec intérêt par nos collègues si érudits de la classe des lettres.

La seconde partie de son mémoire s'étend sur les travaux d'art. Elle est conforme aux vrais principes en cette matière, elle reproduit avec fidélité et dans une grande simplicité de langage, l'état des choses actuel, et sous ce point de vue, la publication de ce mémoire rendra des services aux contrées où des travaux analognes sont réclamés. Notre honorable collègue, M. De Vaux, chargé d’examincr avec nous ce travail, a consigné, daus son rapport spécial, des vues à cet égard entièrement conformes à notre propre jugement.

I a troisième parlie comprend l'économic rurale of l'aggri- 


\section{( 202 )}

culture. Ici, nous nous croyons le droit d'être sévère, quoique juste, parce qu'évidemment, nous avons devant nous un homme qui possède le tact de ces affaires, riche de son expérience ou de celle d'autrui, éclairé de ses observations ou de celles des autres, et, après une étude si remarquable des polders, il est certes très-licite de lui demander d'être exact et utile jusque dans les dernières limites. Le rapporteur se met donc à l'aise; il croit devoir, dans l'intérêt même du concurrent, attirer son attention sur plusieurs lacunes qu'on peut signaler dans un mémoire où, se plaisant à rappeler le correctif d'un regret, les bonnes qualités l'emportent de beaucoup sur les défectuosités.

Après s'être attaché à l'étude du Thomas-Polder, près de Biervliet, l'auteur parle de l'enfouissement des herbes maritimes. Il était là sur une pente pleine d'intérêt. Son mémoire ne discute pas la question de savoir à quels ordres de faits il faut faire remonter cette prodigieuse fécondité des terres poldériennes qui se couvrent de riches récoltes pendant vingt ans sans recevoir jamais d'engrais. Quand il expose la formation des schorres et la construction des premiers endiguements, il ne parle pas du singulier phénomène de la végétation initiale et spontanée de ces terres, toujours la même, se succédant toujours dans les mêmes variations. Il ignore, à ce qu'il paraît, le mécanisme providentiel qu'emploie la nature pour ôter de ces terres le sel en excès au moyen de la bienfaisante salicorne. Ces recherches si belles et les seules qui puissent ici satisfaire à la curiosité de l'esprit et à l'exigence de la raison, ne paraissent pas être du domaine de l'auteur, et nous nous l'expliquons, car dans plus d'un passage de son mémoire, il laisse percer cet éloignement que professent certains propriétaires-cultivateurs et non agronomes pour les savants, les livres et la vérité. Cependant, la science, et 
mème seulement la science complète et approfundie, pent, dans tout ce qui appartient à l'intelligence lımaine (et depuis quand l'agriculture ne serait-elle plus de son domaine?) donner le dernier mot des problèmes. Cette tendance, dans l'esprit de certains aveugles, peut momentanément être déplorable, mais c'est une simple question de temps, le grand niveleur des opinions au profit du vrai.

En parlant des améliorations, l'auteur signale le drainage. Le rapporteur n'a pas vu, sans un pénible étonnement, que, dans un mémoire approfondi, exact surtout dans la description des méthodes de culture, le drainage dont on a tant parlé dans ces dernières années, était mécomnu dans son origine et dans son invention. En effet, le drainage par tuyaux en terre cuite et souterrains est pratiqué depuis des siècles dans les polders; les baux en font foi, et ces tuyaux y ont été appelés de tout temps droog-buysen, tuyaux de desséchement. Cette importante amélioration agricole doit être réclamée par nous comme une invention nationale, que les Anglais sont renus copier chez nous et contrefaire chez cux. Les polders étaient lettre morte dans les annales de l'agriculture. Il était facile de leur ravir, sans se donner l'apparence même d'un plagiat, une si féconde idée; mais nous, qui avons vu dans les polders de l'arrondissement de Philippine, le drainage établi selon toutes les règles, nous à qui des cultivateurs répondaient que leurs aïeux les plus reculés faisaient la même opération, comme on pouvait s'en assurer par les baux et par les fardes processales, nous ne pouvons conserver aucun doute sur la haute antiquité de ce travail dans les régions les mieux faites pour le recevoir et en recucillir les bienfaits.

Quand l'auteur décrit et figure la grande charrue, dite wallonne dans la région des polders, il en attribue la propagation à des conscrits français réfugiés en Zélande. Le 
rapporteur ne rend pas cet honneur à un conscrit français, mais à un conquérant d'une taille presque antédiluvienne, ni plus ni moins qu’à Charlemagne. Allen Ransome cile un manuscrit saxon, publié en Angleterre, où l'on voit figurer la charrue que Charlemagne faisail introduire par les Saxons vaincus dans les pays de son empire. C'est en tout point la charrue des polders, charrue qui jamais ne s'est vue dans nos provinces wallonnes depuis des temps connus. L'auteur ne parle pas non plus à ce sujet du coutre circulaire et à mouvement continu, coutre qu'on voit appliquer à cet instrument. Nous en avons trouvé le même modèle dans le Northumberland et le comté de Durham, où cette charrue servait à découper les tourbes. Ce coutre est aussi une très-ancienne invention.

Le rapporteur signalera, de même, à l'auteur du mémoire Pro patria, quelques lacunes moins importantes qu'il serait utile de combler dans l'intérêt de l'agriculture générale de notre royaume. Il voudrait voir publier le dessin de la charrette à trois roues, de l'araire ordinaire des polders, ainsi que les représentations du cheval, du taureau, de la génisse, du pore, du mouton de ces contrées. Le rapporteur s'étonne, et il le confesse sans détour, de ne pas trouver dans ce travail sur l'économie rurale de notre littoral, un chapitre tout entier en faveur des ânes. On vante à tout propos les ânes de Nalte. Il se fait en ce moment une exportation considérable de ces intéressants quadrupèdes en Amérique, qui demande à la vieille Europe tout ce qu'elle a de perfectionné, de bon et d'utile. Un bel étalon d'âne se vend même dix mille francs; le rapporteur en citerait, au besoin, les acquéreurs. Or, tous ceux qui connaissent notre littoral savent quels ânes magnifiques abondent aux environs de Nieuport. Le pinceau de notre célèbre confrère Verboeckhove peut seul rendre 
l'ampleur élégante du corps, l'esprit, la finesse épigrammatique et le regard calculateur de ces înes modèles. Nous prions l'auteur du mémoire de prendre lâne en mûre considération et de rendre justice à l'animal sobre, patient, docile et toujours calomnié.

Un village est isolé au milieu des dunes, Adinkerke, c'est une oasis complète. La vache y paît l'herbe des dunes; elle devient petite, délicate, et lactifère comme une vache des Ardennes. Ainsi, tandis que tous les animaux atteignent, dans les polders et le long du littoral, à des dimensions au-dessus des moyennes, la vache d'Adinkerke se miniaturise. Quelle est la cause de ce phénomène? Est-ce l'influence de la nourriture qui l'emporte sur celle du climat? L'auteur ferait chose utile de joindre à ce qu'il dit une bonne figure de cette race.

En parlant de Dixmude, il cite, à bon droit, ses excellents pâturages; mais il conviendrait d'être explicite, même en étant savant et seulement à la condition de l'être. Quelle est la flore de ces prairies? M. Lecoq, de Clermont-Ferrand, a publié un ouvrage classique sur cet ordre de faits, et il serait certes très-profitable à l'agriculture de la Belgique de voir de pareilles études appliquées à nos provinces.

Enfin et pour terminer les observations que nous soumettons à l'Acadénie, nous regrettons quelques passages à l'endroit des améliorations à introduire. L'auteur attribue aux engrais artificiels une importance trop grande. Quand ces matières sont falsifiées et de mauvaise nature, la méfiance habituelle de nos cultivateurs les met vite ì l'ombre et dans l'oubli. Une commission de surveillance établie par autorité du gouvernement, deviendrait inutile. Ses idées sur l'instruction agricole, qu'elle soil française ou flamande, sont un peu étroites, car après tout, ces termes 


\section{( 206 )}

scientifiques contre lesquels on s'insurge avec complaisance, existent en quantité dans tout langage parlé, même à la campagne. Enfin, il y a maints instruments aratoires, autres que ceux indiqués et prônćs par l'auteur, qui penvent très-certainement s'introduire avec profit dans les polders et le littoral. Le rapporteur changerait la nature de son travail d'appréciation, s'il entrait dans les discussions à cet égard, mais il croit son opinion fondée sur l'état actuel de l'agriculture dans les pays les plus avancés.

Nos observations paraîtront peut-être à quelques personnes plus importantes que nous ne les avons dans notre volonté et dans notre désir. Nous les indiquons afin de rendre le mémoire aussi utile que possible, et tout noire vœu, le seul que nous formulions, est que l'auteur, du consentement de l'Acarlémie, veuille bien y avoir égard. Nous regretterions sincèrement, dans l'intérêt de notre puissante industrie agricole, qu'un travail de cette valeur ne fùt pas publié, mème s'il restait forcément tel qu'il esı; car il y dans ce mémoire des chapitres parfaitement étıdiés. Tout ce qui tient aux modes de cultu e, aux exploitations, aux détails pratiques, y est fort bien conçu, clairement traité et élégamment décrit. Quelques instruments sont aussi bien détaillés que finement dessinés; l'utilité de cette publication nous paraît donc incontestable, et puisque l'auteur est sans concurrent, l'Académie ne fera tort à personne en signalant les lacunes qu'elle désire voir combler par l'auteur lui-nıême. Elle l'en croit très-capable.

Cependant le mémoire, nous pensons avoir motivé notre jugement, laisse à désirer. Nous proposons donc à la classe des sciences de décerner à l'auteur du mémoire Pro patria la médaille de vermeil et les honneurs de l’impression. ๖

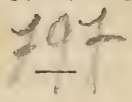





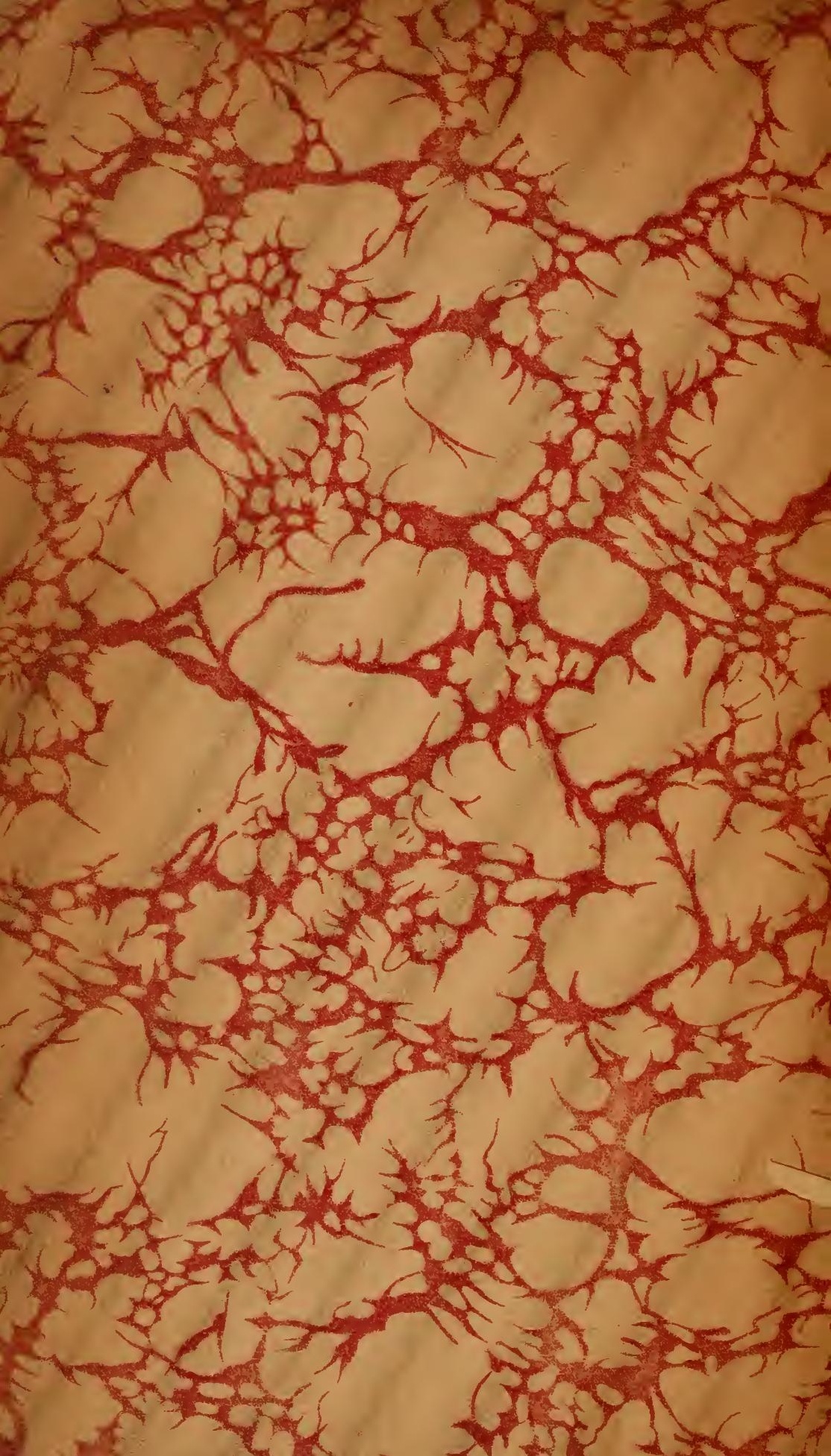




\section{0 ose \\ ta \\ 290}

$20+3 x+2$

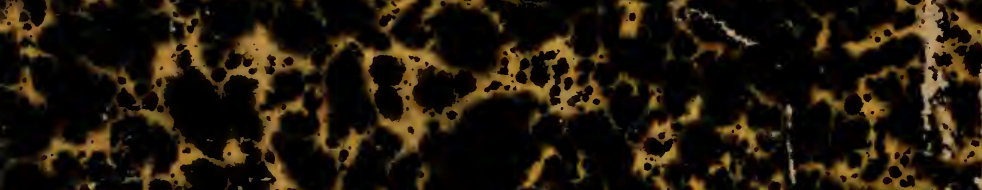

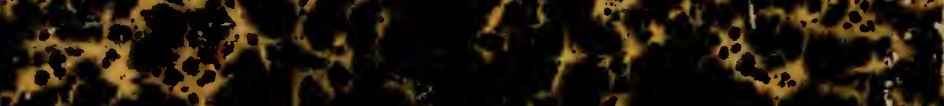

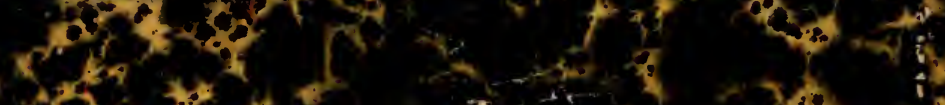

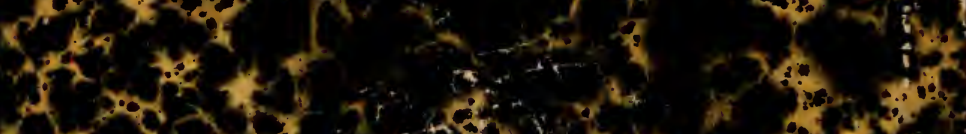

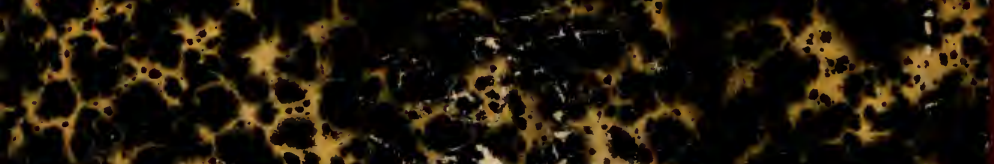

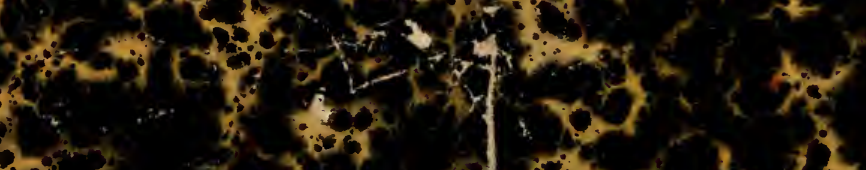

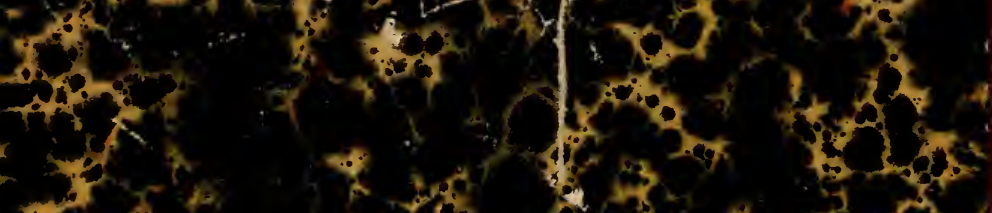

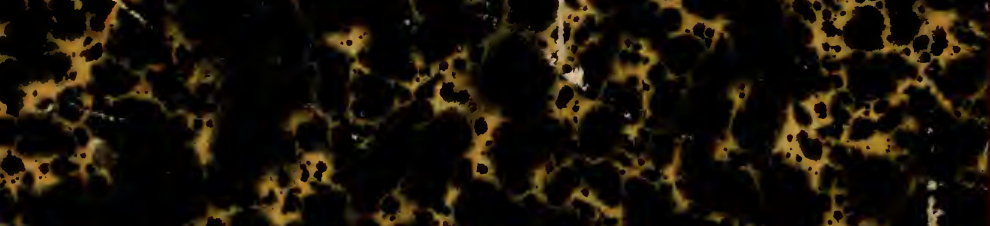

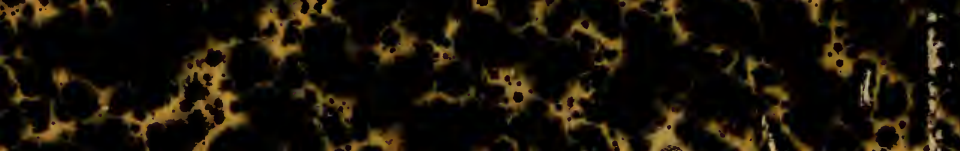
m $x$

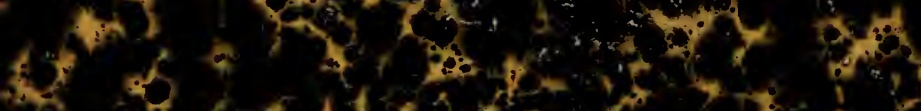

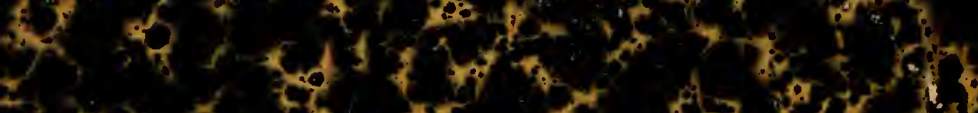
a

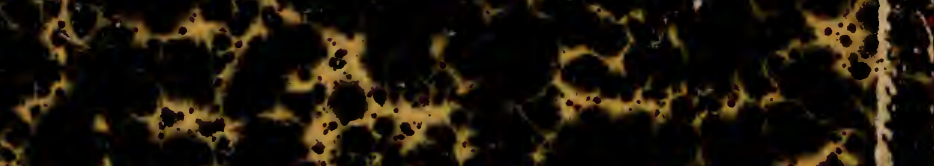
(4) $1+x^{2} x^{2}+x^{2}+x$ a d W. 